UNIVERSIDADE DE SÃO PAULO

FFCLRP - DEPARTAMENTO DE BIOLOGIA

PROGRAMA DE PÓS-GRADUAÇÃO EM BIOLOGIA COMPARADA

Histórico de introdução do siri invasor Charybdis hellerii (A, Milne-Edwards, 1867) (Decapoda, Portunidae) na costa americana: ferramentas moleculares e morfologia comparativa

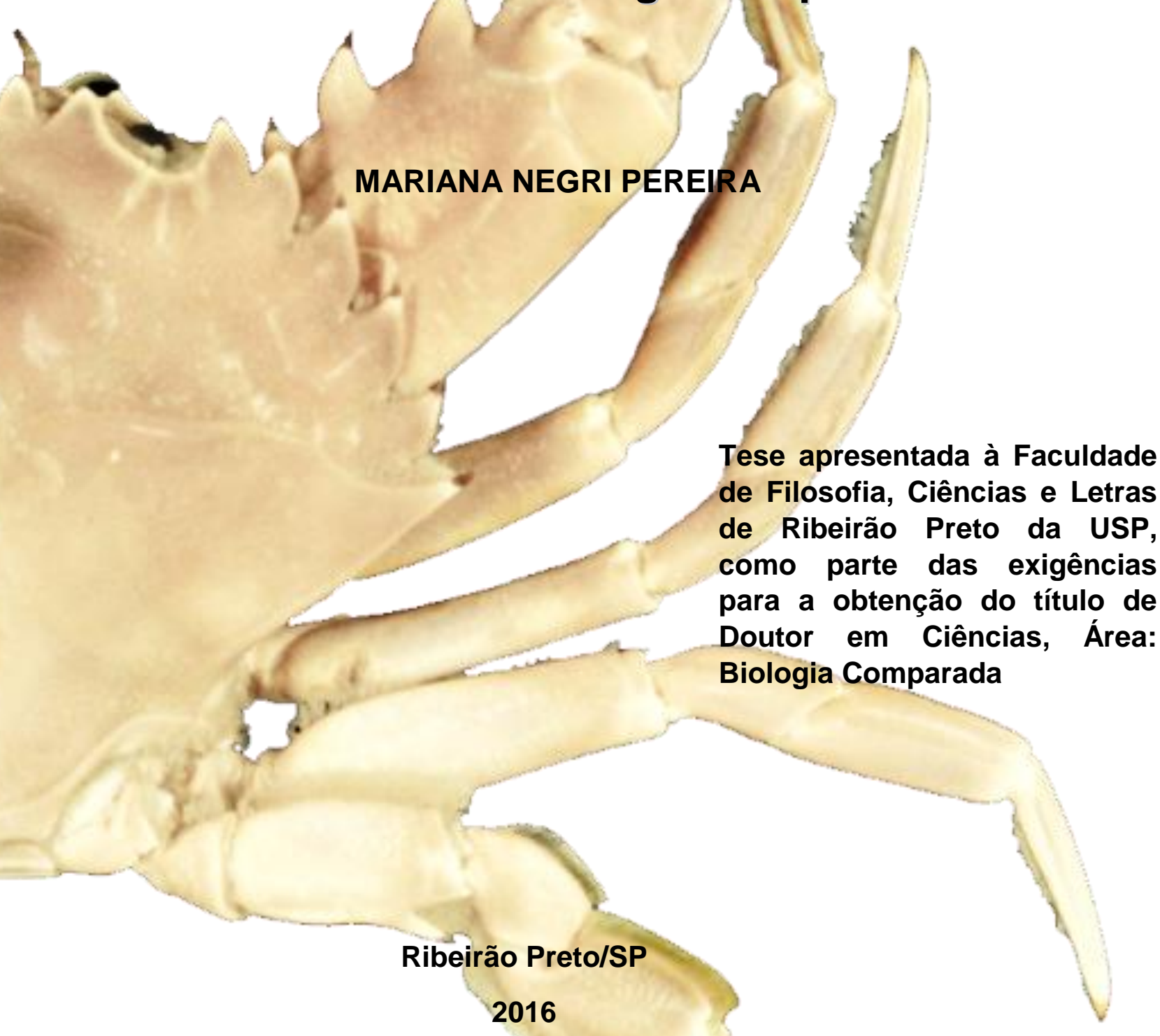




\author{
UNIVERSIDADE DE SÃO PAULO \\ FFCLRP - DEPARTAMENTO DE BIOLOGIA \\ PROGRAMA DE PÓS-GRADUAÇÃO EM BIOLOGIA COMPARADA
}

\title{
Histórico de introdução do siri invasor Charybdis hellerii (A. Milne-Edwards, 1867) (Decapoda, Portunidae) na costa americana: ferramentas moleculares e morfologia comparativa
}

\author{
MARIANA NEGRI PEREIRA
}

Tese apresentada à Faculdade de Filosofia, Ciências e Letras de Ribeirão Preto da USP, como parte das exigências para a obtenção do título de Doutor em Ciências, Área: Biologia Comparada.

Orientador: Prof. Dr. Fernando Luis Medina Mantelatto

Versão corrigida

Ribeirão Preto/SP 
Autorizo a reprodução e divulgação total ou parcial deste trabalho, por qualquer meio convencional ou eletrônico, para fins de estudo e pesquisa, desde que citada a fonte.

\section{Pereira, Mariana Negri}

Histórico de introdução do siri invasor Charybdis hellerii (A. Milne-Edwards, 1867) (Decapoda, Portunidae) na costa americana: ferramentas moleculares e morfologia comparativa

Ribeirão Preto, 2016

viii $+164 \mathrm{p}$.

Tese apresentada à Faculdade de Filosofia, Ciências e Letras de Ribeirão

Preto/USP. Departamento de Biologia. Área: Biologia Comparada

Orientador: Fernando Luis Medina Mantelatto

$\begin{array}{lll}\text { 1. Rotas de introdução } & 2 \text {. Estrutura genética } & 3 \text {. Marcadores mitocondriais }\end{array}$

4. morfometria 5. Thalamitinae 
"So there we were, with Scylla on the one hand and dread Charybdis on the other. We could see the sea seething as in a cauldron, and the black ooze at the bottom with a wall of whirling waters careering round it."

The Odyssey, Book XII

Homer 
Aos meus maiores incentivadores de todos os dias, minha mãe, Cristina, meu irmão, Nicolas e meu amor, Tchores 


\section{Agradecimentos}

Agradeço, primeiramente, ao Prof. Dr. Fernando Luis Medina Mantelatto não apenas por me fornecer a oportunidade de integrar o LBSC (Laboratório de Bioecologia e Sistemática de Crustáceos) e desenvolver o presente projeto sob sua orientação, mas por orientar toda minha carreira científica desde o segundo ano da graduação de forma paciente e engajada. Por todas as outras oportunidades de trabalho e cooperações a mim concedidas, visando meu enriquecimento profissional, por todos os ensinamentos, dedicação e confiança. Ainda, pelo constante empenho na obtenção de recursos e exemplares para a execução do projeto. Finalmente, por todo o crescimento pessoal advindo de todas estas oportunidades e a ele pelo oferecimento da ideia precursora deste projeto e de todas as facilidades e condições para o seu pleno desenvolvimento e execução.

Agradeço à Universidade de São Paulo, em especial ao Departamento de Biologia e ao Programa de Pós-Graduação em Biologia Comparada (FFCLRP), por toda infra-estrutura, manutenção da limpeza das salas e consertos. Ainda, à secretária do programa, Vera Cássia Cicilini de Lucca, e ao pessoal da secretaria de pósgraduação por todo auxílio em questões burocráticas de forma sempre muito eficiente.

Agradeço à Fundação de Amparo à Pesquisa do Estado de São Paulo (FAPESP) pelo apoio financeiro ao projeto de Doutorado Direto (Processo DD 2012/06300-3) e durante o período de estágio no exterior pela Bolsa de Estágio e Pesquisa no Exterior (BEPE Processo 2014/14245-8). Agradeço também à Coordenação de Aperfeiçoamento de Nível Superior (CAPES) pela bolsa de doutorado concedida no primeiro mês de desenvolvimento desse projeto. Este estudo também contou com os suportes logístico e financeiro de outros projetos, todos coordenados pelo Prof. Dr. Fernando L. Mantelatto: Conselho Nacional de Desenvolvimento Científico e Tecnológico - CNPq (PQ 302748/2010-5; 473050/2007-2; 471011/2011- 
8), da Fundação de Amparo a Pesquisa do Estado de São Paulo (FAPESP): Procs. 2010/50188-8 (Projeto Temático Biota), 2009/54931-0 (Projeto Coleções Científicas) e da Coordenação de Aperfeiçoamento de Nível Superior (CAPES - Ciências do Mar II) (2005/2014 - Proc. 23038.004308/2014-14). Esses auxílios foram imprescindíveis para a obtenção de espécimes e dados para o presente projeto, bem como para a infraestrutura, aquisição de equipamentos e reagentes, participação em eventos e realização de coletas de campo.

Agradeço à Pró-Reitoria de Pós-Graduação (Processo 2013.1.574.59.1) pelo custeio da viagem aos EUA para obtenção de exemplares fundamentais para o desenvolvimento do presente projeto durante visitas ao National Museum of Natural History, Smithsonian Institution, Washington D.C. e Florida Museum of Natural History, University of Florida, Gainesville, Florida.

Agradeço à Universidade de Regensburg (Alemanha) por permitir que eu utilizasse seus recursos durante o período de estágio no exterior e ao Prof. Dr. C.D. Schubart pela supervisão durante esse período, estendendo-me uma mão quando achei que o estágio não seria mais possível. Agradeço também por todas suas sugestões e discussões prósperas. Esse mesmo período não teria sido tão positivo se não tivesse contado com a ajuda de duas companheiras, Renata de Oliveira e Ivana Miranda.

Agradeço ao Prof. Dr. Fernando Zara e ao Laboratório de Microscopia Eletrônica da Faculdade de Ciências Agrárias e Veterinárias, Universidade estadual Paulista "Júlio de Mesquita Filho, campus de Jaboticabal por toda infra-estrutura e recursos para o desenvolvimento das análises de microscopia eletrônica de varredura.

Este projeto, inquestionavelmente, tornou-se possível graças à ajuda de muitos que auxiliaram na obtenção de espécimes e no suporte durante as visitas às instituições carcinológicas. Assim, agradeço à Alessandra Batista Bentes (UFPA), 
Alexandre Almeida (MZUESC), Carlos Lira (Universidad del Oriente), Charles Fransen (NBC), Christopher Tudge (AU), Darryl Felder (ULLZ), Gary C. B. Poore (Museum Victoria), Gustav Paulay (FMNH), Irene Cardoso (MNRJ), Jesser F. de Souza Filho (UFPE), Karen Reed (USNM), Karen van Dorp (NBC), Laure Corbari (MNHN), Luis Ernesto Bezerra (UFERSA), Marcos Tavares (MZUSP), Mauro Cardoso Junior (MZUSP), Michael Türkay (SMF), Miranda Lowe (NHM), Nathaniel Evans (FMNH), Paul Clark (NHM), Rafael Lemaitre (USNM), Shane T. Ahyong (AM), Stephen Keable (AM), Tereza Calado (UFAL). São inúmeras também as pessoas que participaram ativamente na coleta dos animais. Embora não enumerados, todos foram imprescindíveis para a execução deste projeto e sou imensamente grata.

Agradeço à técnica Agda Facincani do Departamento de Tecnologia da Faculdade de Ciências Agrárias e Veterinárias de Jaboticabal, Universidade Estadual Paulista pela execução da etapa do sequenciamento. Agradeço também ao N.T. Son (National University of Singapore) pelas imagens de $C$. hellerii gentilmente cedidas.

Agradeço à cada membro do LBSC pela ajuda em diferentes aspectos e convívio muito agradável. Em especial às minhas amigas do coração, Raquel e Mari, por toda amizade, suporte em questões profissionais e pessoais, companhias em viagens, pelos inúmeros momentos felizes e leves regados a muitas calorias. Sem dúvida tudo teria sido menos divertido e bonito sem vocês. À outra amiga querida, Natália Rossi, principalmente, por me fazer manter os pensamentos positivos e sensatos. Admiro muito sua força! À mais uma amiga querida, Tatiana Magalhães, por sua delicadeza e simplicidade, que certamente tornam o dia de qualquer um melhor. À querida amiga Ana Francisca Tamburus, sempre pronta a ajudar e de coração enorme, além de garantir muitas risadas. Ao meu querido do coração, Rafael Robles, agradeço todos os ensinamentos, conhecimentos compartilhados e animais obtidos. Obrigada também por nos deixar contagiar por seu bom humor, alegria e forma de ver a vida. Agradeço ao Caio de Oliveira por me ensinar algumas metodologias da 
genética de populações e à técnica do LBSC, Mayara Jundurian, por manter o laboratório de molecular sempre impecável para que possamos desempenhar nossos trabalhos.

Agradeço também a todos os demais membros do LBSC (atuais e egressos), que certamente contribuíram para uma convivência muito alegre e para o bom funcionamento do laboratório, além do auxílio para obtenção de animais e discussões importantes, Álvaro Costa, Ana Luiza Silva, Bárbara Prado, Carla Kuhl, Camila Silveira, Edvanda Carvalho, Elis Pereira, Fabrício Carvalho, Isabela Leone, Jéferson Pedrosa, Juliana Paixão, Keity Nishikawa, Kimberly Mazagão, Leonardo Pileggi, Mateus Lopes, Nicole Olguin, Sabrina Simões, Sílvia Mandai e Suzana Rodriguez

Finalmente, agradeço às pessoas que são essenciais em minha vida. À minha mãe, Maria Cristina, e ao meu irmão, Nicolas, agradeço imensamente por me acompanharem nessa jornada, sempre apoiando minhas decisões e dando preciosos conselhos. Em especial à minha mãe, por toda sua força delicada, por toda sua dedicação, por cada marmita cuidadosamente preparada, por todo carinho e amor infinito. Em especial ao meu irmão, por representar meu exemplo de integridade e senso de humanidade. Ao meu noivo incrível, Tchores, por compartilhar comigo a vida e me mostrar a parte mais bonita e simples de tudo, por escutar pacientemente meus longos e desesperados desabafos, por toda compreensão e por me fazer sorrir sempre! Amo vocês infinitamente.

Enfim, a todos que direta ou indiretamente contribuíram para este trabalho, meu muito obrigada! 


\section{Sumário}

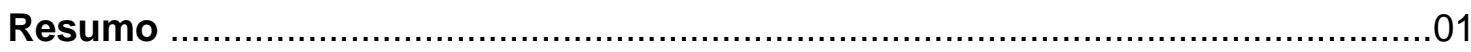

Abstract

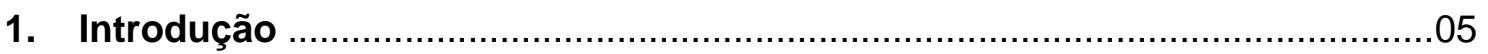

1.1 Invasões biológicas: definições, causas e consequências .............................05

1.2 Estudos genéticos das invasões biológicas ............................................07

1.2.1 Identificação das populações de origem e de introduções múltiplas ...........07

1.2.2 Gargalo genético associado ao processo de introdução ...........................10

1.30 caso do siri invasor Charybdis hellerii ................................................13

1.4 Charybdis variegata: mais um caso de introdução na costa

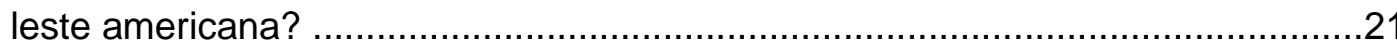

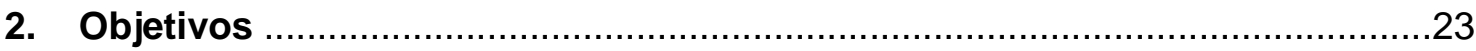

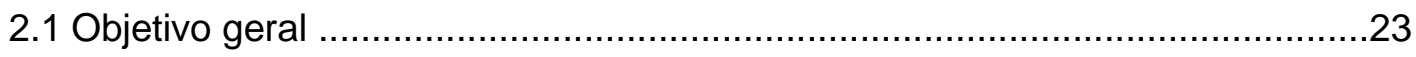

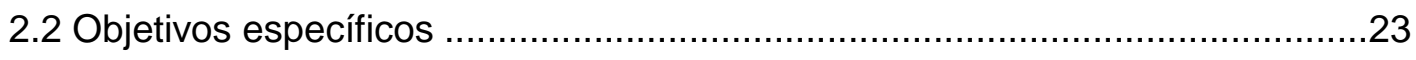

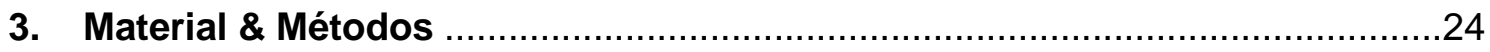

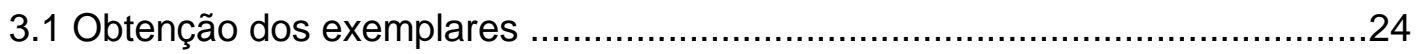

3.2 Escolha dos marcadores moleculares ...................................................25

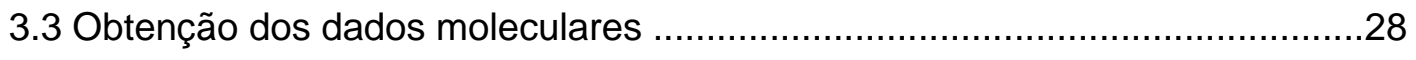

3.3.1 Extração do DNA ............................................................... 43

3.3.2 Amplificação dos genes .......................................................44

3.3.3 Purificação e amplificação dos produtos da PCR ..............................46

3.3.4 Precipitação e sequenciamento do DNA ...........................................47

3.3.5 Edição das sequências de DNA ….................................................48

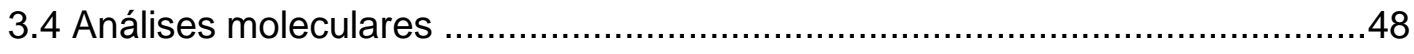


3.4.1 Análises de distância genética ......................................................49

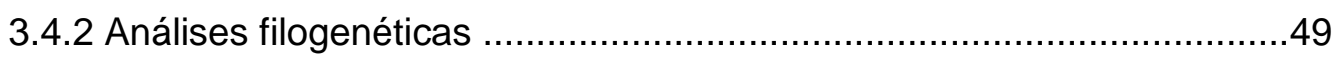

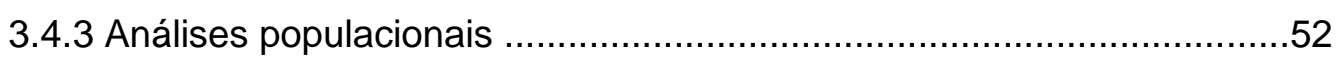

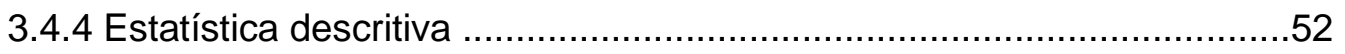

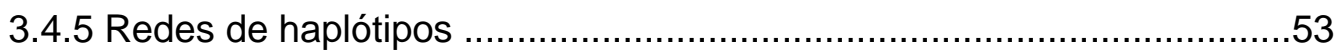

3.4.6 Análise de estrutura populacional: Bayesian Analysis of Population

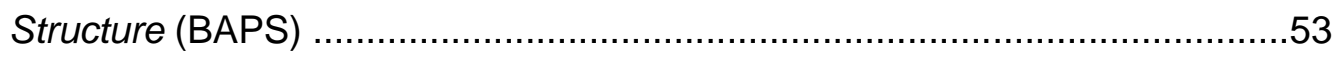

3.4.7 Análise de estrutura populacional: Análise de Variância Molecular

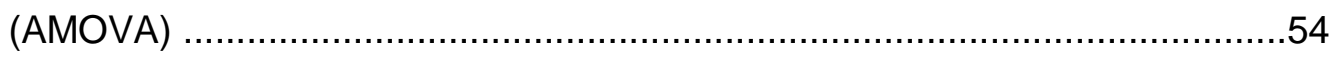

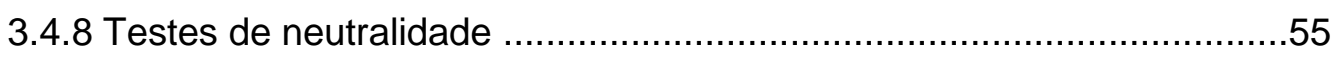

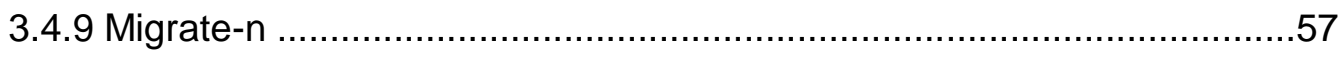

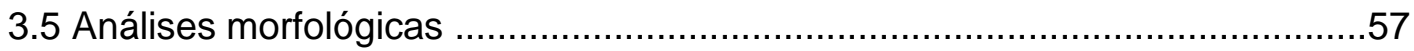

3.5.1 Obtenção dos dados e análises morfológicas comparativas .................58

3.5.2 Microscopia eletrônica de varredura do gonópodo 1 ..........................66

3.5.3 Análise morfológica comparativa do espécime utilizado para o registro de Charybdis variegata na América ..................................................67

3.5.4 Obtenção e análises dos dados morfométricos ................................68

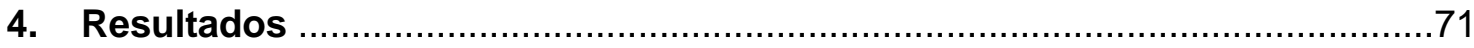

4.1 Distância genética intra e interespecífica ............................................... 71

4.2 Análise filogenética ........................................................................ 72

4.3 Análises populacionais - localidades nativas e do mar

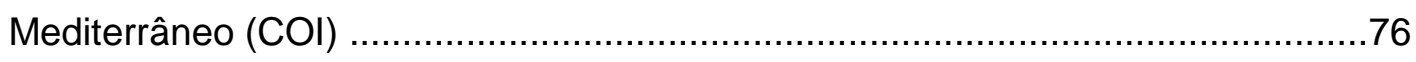

4.3.1 Estatística descritiva ............................................................... 76

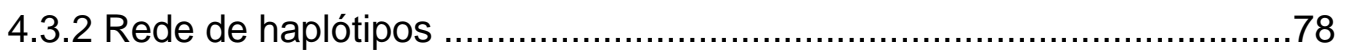

4.3.3 Bayesian Analysis of Population Structure (BAPS) ............................79

4.3.4 Análise de Variância Molecular (AMOVA) ..........................................81

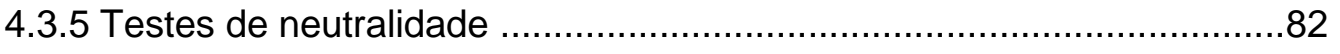


4.3.6 Estimativas do sentido de movimento da migração - Migrate-n

4.4 Análises populacionais - localidades nativas e do mar Mediterrâneo (16S

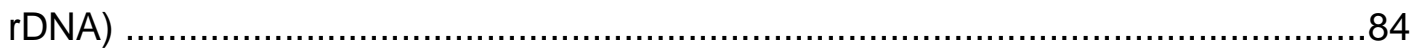

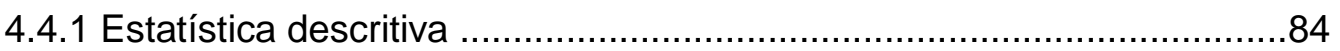

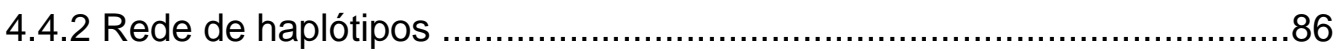

4.4.3 Bayesian Analysis of Population Structure (BAPS) ............................87

4.4.5 Análise de Variância Molecular (AMOVA) ...........................................89

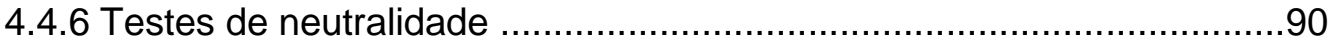

4.5 Análises populacionais - localidades nativas, do mar Mediterrâneo e da

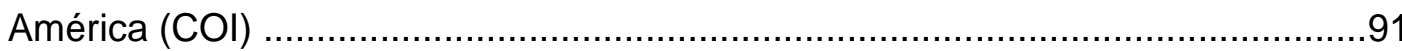

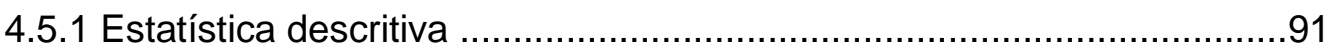

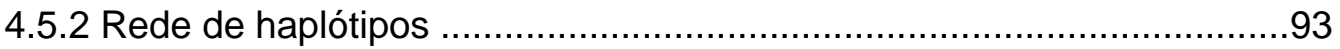

4.5.3 Bayesian Analysis of Population Structure (BAPS) ....................97

4.6. Análises populacionais - localidades nativas, do mar Mediterrâneo e da

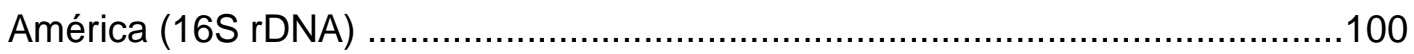

4.6.1 Estatística descritiva ................................................................... 100

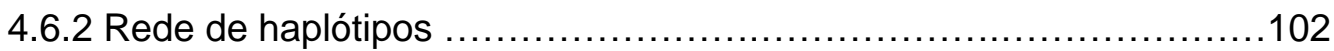

4.6.3 Bayesian Analysis of Population Structure (BAPS) ....................103

4.7 Bayesian Analysis of Population Structure (BAPS) - COI e 16S rDNA

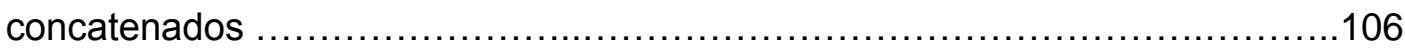

4.8 Análise morfológica comparativa de Charybdis hellerii ..............................109

4.9 Análise morfológica comparativa do indivíduo utilizado para o registro de Charybdis variegata na América

5. Discussão

5.1 Status taxonômico de Charybdis hellerii (A. Milne-Edwards, 1867) e comparações interespecíficas 
5.2 Diversidade e estruturação genética de Charybdis hellerii em suas localidades nativas e mar Mediterrâneo

5.3 Aspectos genéticos e histórico da introdução de Charybdis hellerii na costa americana

5.4 Registro de Charybdis variegata (Fabricius, 1798) na costa

americana

6. Conclusão

7. Referências 


\section{Resumo}

Charybdis hellerii (A. Milne-Edwards, 1867), espécie de siri nativa do IndoOeste Pacífico, dispersou-se para o mar Mediterrâneo com a abertura do canal de Suez. Em 1987, foi registrada pela primeira vez no Atlântico Ocidental, onde populações estabelecidas são reconhecidas dos EUA ao sul do Brasil. Acredita-se que sua introdução no continente americano teria ocorrido por meio de água de lastro de navios provenientes do mar Mediterrâneo. Por meio de análises moleculares utilizando-se três marcadores genéticos (um nuclear, $\mathrm{H} 3$, e dois mitocondriais, $\mathrm{COI}$ e 16S rDNA), de forma integrada à morfologia comparativa, realizou-se uma investigação do status taxonômico de $C$. hellerii e dos aspectos relacionados ao seu histórico de introdução. Para este último fim, objetivou-se: (1) o reconhecimento de regiões de origem e rotas de introdução; (2) a detecção ou não de gargalo genético e (3) de introduções múltiplas. A validade de $C$. hellerii como uma única entidade foi corroborada por alguns resultados: $100 \%$ de similaridade no marcador nuclear; monofilia de $C$. hellerii nos filogramas construídos com diversas espécies de Thalamitinae; divergência genética intraespecífica (COI - 0 a 4,2\% e $16 \mathrm{~S}$ rDNA - 0 a $0,9 \%$ ) inferior à interespecífica esperada (COI - 6,2 a 21,5\% e 16S rDNA - 3,9 a $15,2 \%$ e total similaridade genética entre indivíduos com características morfológicas distintas. Estruturação genética e morfométrica foi detectada nas localidades nativas (+ mar Mediterrâneo), evidenciando dois grupos: Índico oeste + mar Mediterrâneo e Índico leste + Pacífico. A AMOVA para COI mostrou que $38,739 \%$ da diversidade encontrada está entre esses dois grupos $(\phi c t=0,38, p=0,00)$. A diferenciação genética entre o Índico e o Pacifico é recorrentemente associada a baixas do nível no mar na conexão entre estes oceanos no Pleistoceno. Essa estruturação nas áreas de origem foi fundamental para a detecção de introduções múltiplas na costa americana. A maior parte dos indivíduos da América se agrupou com o Índico oeste + mar Mediterrâneo, suportando o mar Mediterrâneo como a principal origem das populações americanas. No entanto, o agrupamento de espécimes do sul do Brasil com o grupo Índico leste + Pacífico também revelou introduções provenientes dessa região. Um grupo geneticamente distinto detectado na costa americana e geneticamente mais próximo do Índico leste + Pacífico sugere introdução proveniente de uma localidade não amostrada nas áreas de origem. Para ambos os marcadores mitocondriais, os valores de diversidade haplotípica nas áreas exóticas foram comparáveis aos das de origem e a diversidade nucleotídica foi predominantemente superior nas primeiras em relação às segundas. Estes resultados estão possivelmente relacionados à ocorrência de introduções múltiplas de áreas geneticamente distintas. Dos haplótipos de COI 
detectados no agrupamento Índico oeste + mar Mediterrâneo, apenas dois não foram encontrados nas populações americanas, sugerindo a não ocorrência de um gargalo genético expressivo. Para a introdução proveniente do Índico oeste + Pacífico, gargalo genético significativo possivelmente ocorreu, uma vez que dos 22 haplótipos encontrados nos 40 espécimes do agrupamento Índico leste + Pacífico, apenas três foram encontrados em quatro dos 87 indivíduos amostrados na América. Por fim, análises moleculares e morfológicas demonstraram que Charybdis variegata, espécies congênere recentemente registrada como uma nova espécie exótica na América, consiste na realidade em mais um exemplar de $C$. hellerii. 


\section{Abstract}

Charybdis hellerii (A. Milne-Edwards, 1867), an invasive swimming crab species native to the Indo-West Pacific, dispersed to the Mediterranean Sea via Suez Canal. In 1987, it was first reported to the western Atlantic, where self-maintaining populations are currently found from the USA to southern Brazil. It is suggested that animals were transported to America in their larval stages through ballast water from ships probably loaded at Mediterranean ports. An integrative approach of morphological and molecular analyses using three molecular markers (one nuclear, $\mathrm{H} 3$ and two mitochondrial, COI and $16 \mathrm{~S}$ rDNA) was performed in order to check the taxonomic status of $C$. hellerii and investigate its introduction history. For the latter purpose, this study aimed: (1) to track potential sources and routes of introduction, (2) assess the occurrence or not of multiple introductions and (3) of genetic bottlenecks. C. hellerii was confirmed as a single entity according to the following results: $100 \%$ of similarity for the nuclear marker; monophyly of $C$. hellerii clade in the phylograms including several species of the subfamily Thalamitinae; intraspecific genetic diversity (COI - 0 to $4.2 \%$ and $16 \mathrm{~S}$ rDNA - 0 to $0.9 \%$ ) inferior to interspecific value expected for the studied loci (COI - 6.2 to $21.5 \%$ and $16 \mathrm{~S}$ rDNA - 3.9 a $15.2 \%$ ) and total genetic similarity of individuals with different morphological traits. Genetic and morphometric structure was detected in $C$. hellerii native range (and the Mediterranean Sea), showing two groups: Western Indian Ocean + Mediterranean Sea and Eastern Indian + Pacific Oceans. The AMOVA results for $\mathrm{COI}$ revealed that $38.739 \%$ of variation was between both groups $(\phi c t=0.38, p=$ 0.00). This genetic break between the Pacific and Indian Oceans is constantly associated with sea level fluctuations in the connection between both Oceans during the Pleistocene glaciation events. This genetic structure allowed the detection of independent introduction events along the American coast. As most animals from this exotic range were clustered with the Western Indian Ocean + Mediterranean Sea group, the Mediterranean populations were supported as the main source of the American ones. However, the cluster of animals from the southern Brazil with the Eastern Indian + Pacific Oceans group indicated that introductions from these native regions might also have occurred. A third group found solely in the American range and genetically related to Eastern Indian + Pacific also suggested introductions from an unsampled locality of native range. The haplotype diversities of American localities were comparable to those of source ones, whereas the nucleotide diversities were predominantly higher in the non-native localities. These diversity indexes results might be related to the occurrence of multiple introductions from genetic distinct areas. 
Among all haplotypes of the Indian Ocean + Mediterranean Sea cluster, only two were not found in America, what suggests no expressive bottleneck in the introduction from this source. However, a genetic bottleneck might explain the low number of equal haplotypes between the Eastern Indian + Pacific Ocean cluster and the Atlantic range. Only three haplotypes were detected in four specimens out of 87 collected in American localities in comparison to 22 found in the native group. In addition, the molecular and morphological analyses confirmed that a congeneric species, Charybdis variegata, recently recorded on the American coast, is actually another $C$. hellerii specimen. 
1. INTRODUÇÃO 


\subsection{Invasões biológicas: definições, causas e consequências}

Uma espécie é considerada introduzida quando passa a ocupar um ambiente distinto do seu limite natural historicamente reportado e definido por seus mecanismos naturais de dispersão, em decorrência da ação humana intencional ou não e normalmente transpondo grandes barreiras geográficas (Richardson et al., 2000; 2011). O emprego de outras terminologias, principalmente o de espécie invasora, normalmente recai em ambiguidades e diferentes interpretações (Colautti \& Maclsaac, 2004). Segundo alguns autores, uma espécie introduzida passa a ser considerada invasora quando ocasiona efeitos adversos no ambiente invadido, como alterações na composição, estrutura e/ou função do ecossistema nativo e impactos nas atividades econômicas humanas (e.g. Davis \& Thompson, 2000; Mack et al., 2000; Grapputo et al., 2005). Esta definição é a mais popular entre as organizações internacionais, como a Organização Internacional para a Conservação da Natureza (IUCN, 2000).

No entanto, outros empregam o termo espécie invasora independentemente dos efeitos provocados por ela (Richardson et al., 2000; 2011; Colautti \& Maclsaac, 2004). Estes últimos autores propuseram um sistema de terminologias baseado no estágio em que uma população ocupa no processo de invasão a fim de evitar interpretações errôneas e em busca de uma padronização (Colautti \& Maclsaac, 2004). Segundo eles, uma espécie invasora é considerada aquela que já está estabelecida no novo ambiente, ou seja, com uma população autossustentável fora de sua distribuição nativa (Kolar \& Lodge, 2001), podendo ser: localmente dominante, mas não disseminada em uma vasta área de ocorrência; ocupar uma vasta área, mas não ser dominante em nenhuma delas; ou apresentar a combinação de ambos os fatores (Colautti \& Maclsaac, 2004). Adianto aqui que esta definição é a adotada ao longo do presente estudo e vale ressaltar que a designação de uma espécie como invasora, na verdade, refere-se a populações invasoras de uma espécie, uma vez que a mesma 'espécie' é invasora em uma região, porém nativa em outra (Colautti \& Maclsaac, 
2004). O uso destes adjetivos dependem da escala de observação. Como exemplo, uma espécie pode ser invasora para um país, porém nativa para o continente (Richardson et al., 2011).

Outros termos comumente empregados são os de espécie exótica e não nativa (Colautti \& Maclsaac, 2004). Estes são mais abrangentes e podem designar tanto populações estabelecidas ou não. Assim, um indivíduos encontrado fora de sua distribuição historicamente reportada será considerado exótico nesse local, porém não necessariamente invasor (Colautti \& Maclsaac, 2004).

Somando-se ou até sobrepondo-se às vias dispersivas naturais, atividades antrópicas recentes tem ocasionado uma ampla redistribuição e alteração da composição das espécies em diversos ambientes (Carlton, 1989). A introdução de espécies fora de sua ocorrência natural é facilitada por meio de várias atividades, como navegação e aquicultura (Carlton \& Geller, 1993; Naylor et al., 2001). Uma vez estabelecidas, as espécies introduzidas podem afetar de várias maneiras a dinâmica das comunidades nativas, por meio da competição por alimento, espaço ou predação sobre outros membros dessa comunidade (Carlton \& Ruiz, 2005a). Podem, consequentemente, causar a destruição de habitats, perda da biodiversidade, bem como levar a extinções (Elton, 1958; Pimental et al., 2000). As comunidades invadidas podem ser alteradas de tal forma que também acometem impactos sociais e econômicos (Elton, 1958). Por essas razões, o combate às bioinvasões tem sido visto como uma prioridade por autoridades em todo o mundo (Hewitt et al., 2009) e um dos maiores desafios dos biólogos da conservação nas próximas décadas (Allendorf \& Lundquist, 2003).

Visando o manejo dessas espécies não nativas e a previsão de seu potencial de expansão, é essencial identificar e confirmar as localidades de origem, rotas e vetores de transporte (Grosholz, 2002; Carlton \& Ruiz, 2005b), bem como os fatores contribuindo para o sucesso da invasão (Lallias et al., 2015). A fim de obter tais 
informações, ferramentas moleculares tem sido amplamente utilizadas para determinar a estruturação das populações, a origem da invasão, número de introduções independentes e o potencial de expansão de espécies não nativas, auxiliando de modo geral na compreensão de sua história de introdução (Holland, 2000; Sakai et al., 2001; Lee, 2002; Grapputo et al., 2005; Geller et al., 2010; Cristescu, 2015). Todo o conhecimento gerado fornece subsídio para o desenvolvimento de estratégias de controle e manejo eficientes e de políticas em níveis regionais, nacionais e internacionais, fortemente encorajadas quando espécies introduzidas se estabelecem e dispersam nessa nova área afetando as comunidades locais (Sakai et al., 2001; Geller et al., 2010).

\subsection{Estudos genéticos das invasões biológicas}

\subsubsection{Identificação das populações de origem e de introduções múltiplas}

Microssatélites (e.g. Astanei et al., 2005; Dupont et al., 2007; Rius et al., 2012) e marcadores mitocondriais (e.g. Audzijonyte et al., 2008; Kajita et al., 2012) têm sido amplamente utilizados em estudos genéticos das invasões, os quais, uma vez em associação, podem ajudar na predição de futuras invasões, no reconhecimento de padrões e processos das bioinvasões (Holland, 2000; Sakai et al., 2001; Lee, 2002; Geller et al., 2010) e facilitar na sua compreensão em um contexto evolutivo (May et al., 2006). As ferramentas moleculares também permitem que a validade taxonômica de espécies invasoras sejam testadas e muitas vezes que estas sejam corretamente identificadas (Bucciarelli et al., 2002; Geller et al., 2010). A correta atribuição taxonômica de uma espécie invasora é crucial para a compreensão e manejo das bioinvasões (Bucciarelli et al., 2002).

A ocorrência de invasões crípticas tanto em nível inter como intraespecífico pode ser detectada por meio de estudos genéticos (Geller et al., 2010). A primeira se refere 
à qualquer evento de invasão que permanece não reconhecido por motivos diversos, como a dificuldade de distinção morfológica da espécie exótica em relação a alguma espécie nativa, ou a introdução de espécies crípticas inicialmente reportadas como uma única espécie não nativa (Carlton, 2009; Geller et al., 2010). A segunda se refere ao não reconhecimento da introdução por linhagens evolutivas distintas de uma mesma espécie (Geller et al., 2010). Este último caso pode estar associado à ocorrência de introduções múltiplas, que consiste em duas ou mais introduções independentes de uma mesma espécie, normalmente detectáveis somente por análises moleculares ou observação direta (Geller et al., 2010). A não identificação de invasões crípticas pode levar a inferências erradas sobre o número de introduções, bem como o não reconhecimento de todas as rotas prováveis e vetores de introdução (Geller et al., 2010).

Introduções múltiplas provenientes de localidades de origem caracterizadas por uma estrutura filogeográfica considerável podem significar o ingresso de animais com relevantes diferenças ecofisiológicas e é justamente a existência de tal estruturação genética nas áreas nativas que facilita a detecção da ocorrência de mais de uma introdução (e.g. Mclvor et al., 2001; Meusnier et al., 2002; Lejeusne et al., 2014). Reconstruções filogeográficas utilizando sequências de DNA de indivíduos de populações nativas e não nativas, tanto através da construção de árvores filogenéticas ou redes de haplótipos, podem revelar a existência de duas ou mais linhagens evolutivas. Este resultado, em combinação com a distribuição geográfica da diversidade genética tanto nas áreas introduzidas, como nas nativas, pode evidenciar a ocorrência de introduções múltiplas (Geller et al., 2010). Dessa forma, a presença de certos haplótipos em uma população introduzida que não apresentam distribuição sobreposta nas áreas de origem pode sugerir introduções múltiplas e independentes proveniente de regiões geneticamente distintas, possibilitando, assim, a inferência das populações de origem mais prováveis (Darling et al., 2008; Geller et al., 2010). 
Por outro lado, quando as populações nativas são geneticamente homogêneas devido à falta de variação no marcador escolhido ou ao intenso fluxo gênico entre elas, a identificação da origem torna-se uma tarefa impossível (Geller et al., 2010). Contudo, a diferenciação genética extrema entre as populações nativas também dificulta o rastreamento da população de origem de uma introdução. Isso ocorre em decorrência dos limites de amostragem das populações nativas, de modo que as chances de amostragem da população de origem tornam-se muito reduzidas (Geller et al., 2010). Portanto, estruturação genética moderada permite a inferência mais bem sucedida das áreas de origem (Geller et al., 2010).

Em termos práticos, a identificação correta de uma população de origem suporta o desenvolvimento de políticas de controle biológico mais efetivas, a predição de futuras introduções, bem como possibilita inferências acuradas sobre as mudanças evolutivas após a invasão (Roderick \& Navajas, 2003; Darling et al., 2008). No entanto, tendo em vista que a invasão é um processo dinâmico, é necessário tomar em conta a possibilidade de variações temporais tanto nas populações nativas como nas não nativas. Fatores como gargalo genético, deriva genética e seleção podem levar a uma grande divergência entre elas, de modo que inferências sobre possíveis origens podem ser dificultadas (Selkoe et al., 2008; Geller et al., 2010).

Em alguns casos, a definição da variação genética detectada como inter ou intraespecífica pode requerer uma análise mais ampla. Quando isso ocorre, recomenda-se uma abordagem integrativa da taxonomia, por exemplo, por meio da inclusão de comparações morfológicas ou ecológicas, bem como análises moleculares em um contexto taxonômico mais amplo, permitindo, por exemplo, uma estimativa da variação interespecífica esperada para um determinado locus (Geller et al., 2010). Se por um lado designada como interespecífica, a variação genética indicaria a existência de invasões crípticas ao nível de espécie. Por outro lado, caso designada como 
intraespecífica, sugere fortemente a ocorrência de introduções múltiplas provenientes de origens geneticamente distintas (Geller et al., 2010).

\subsubsection{Gargalo genético associado ao processo de introdução}

Eventos de introdução são normalmente associados à redução da diversidade genética como decorrência dos processos estocásticos do efeito fundador (Nei et al., 1975; Holland, 2000; Hassan et al., 2003; Roman \& Darling, 2007; Dlugosch \& Parker, 2008; Clark \& Hartl, 2010). Pressupõe-se que em populações fundadoras pequenas (entende-se pequeno tamanho populacional efetivo), a diversidade alélica pode ser perdida em poucas gerações pela fixação ou perda dos alelos fundadores, culminando em uma composição alélica distinta da população de origem (Holland, 2000). O oposto, ou seja, em casos de introdução de populações maiores e geneticamente diversas (maior tamanho populacional efetivo), espera-se pouca ou nenhuma redução da diversidade alélica em relação à população de origem (Holland, 2000).

Estimativas e comparações da diversidade genética em populações exóticas e de origem podem fornecer uma indicação da diversidade genética perdida durante o efeito do fundador associado à introdução (Sakai et al., 2001). Os processos de invasão podem apresentar efeitos tanto na diversidade de marcadores neutros ou em genes com importância adaptativa, isto é, aqueles que permitem a reorganização de características adaptativas (Hassan et al., 2003). A comparação da diversidade em marcadores neutros, que são comumente empregados em estudos genéticos de espécies introduzidas, pode indicar a redução da diversidade genética no processo de introdução e, segundo autores como Sakai et al. (2001) e Allendorf \& Lundquist (2003), esta redução refletiria na perda de oportunidades para a evolução de mudanças adaptativas. Com base nisso e de forma equivocada, surgiu a ideia de que as populações introduzidas deveriam enfrentar um "paradoxo genético da invasão" (Allendorf \& Lundquist, 2003). Se, por um lado, como consequência do gargalo 
demográfico associado aos eventos de introdução, as populações introduzidas tenderiam a ter uma variabilidade genética mais baixa que as nativas (Barrett \& Kohn, 1991; Sakai et al., 2001; Allendorf \& Lundquist, 2003; Grapputo et al., 2005). Por outro lado, supõe-se que quanto maior a variabilidade genética dos espécimes introduzidos, maiores suas chances de estabelecer populações em ambientes diferentes (Lee, 2002). Assim, a ocorrência de introduções múltiplas e, consequentemente, a elevação da diversidade genética dela advinda, foi apontada como a solução para este paradoxo (Sakai et al., 2001; Allendorf \& Lundquist, 2003; Kolbe et al. 2004; Frankham 2005; Roman \& Darling 2007; Hufbauer 2008).

Vários aspectos suportam a natureza equivocada dessa proposição. Estudos mais recentes têm demonstrado que, embora comparações das variâncias genéticas aditivas sejam raras, o efeito do fundador pode não conduzir a extremas reduções em traços quantitativos e a maioria dos traços relacionados ao fitness possuem natureza quantitativa (Dlugosch \& Parker, 2008; Dlugosch et al., 2015). Além da não observação, em alguns exemplos, de uma redução na divergência fenotípica (Koskinen et al., 2002). Desse modo, a redução da diversidade genética indicada por marcadores neutros não necessariamente refletiria em uma redução no potencial adaptativo e não seria um limitante para o sucesso da invasão pelo menos a curto prazo (Dlugosch \& Parker, 2008). Pesquisadores, por isso, afirmam que a importância da natureza da variação se sobrepõe à quantidade desta em uma população introduzida (Dlugosch et al., 2015).

Argumenta-se que mesmo com a diversidade diminuída, as populações invasoras apresentam elevado potencial para a evolução adaptativa em traços quantitativos, de modo que todas as desvantagens associadas à redução da diversidade genética sejam amenizadas (Dlugosch \& Parker, 2008). Demonstrou-se, por exemplo, que populações de uma determinada espécie de planta em que o gargalo genético foi constatado responderam mais rapidamente à seleção artificial do 
que populações estáveis (Briggs \& Goldman, 2006). Especula-se, assim, que a relevância da seleção natural sobre populações fundadoras em um novo ambiente seria superior aos efeitos estocásticos do evento de introdução na trajetória evolutiva de uma população (Wares et al., 2005) e aparentemente há uma desconexão entre a variação genética total e a variação adaptativa (e.g. McKay \& Latta, 2002; Leinonen et al., 2008) de modo que a primeira não serviria como uma medida da segunda.

A não detecção ou a pouca redução da diversidade genética em populações invasoras é constantemente associada à ocorrência de introduções múltiplas provenientes de regiões geneticamente distintas (Dlugosch \& Parker, 2008). Esse fator é fortemente apontado como o responsável pelo sucesso de determinadas invasões (Allendorf \& Lundquist, 2003; Kolbe et al., 2004; Frankham, 2005; Wares et al., 2005). As hipóteses prévias atribuíam esse sucesso principalmente ao aumento da diversidade genética propiciado pelas introduções independentes, de modo que a diversidade entre populações nas áreas nativas seria convertida em diversidade dentro da mesma população nas área introduzidas (Allendorf \& Lundquist, 2003), e à alta pressão de propágulo devido ao alto número de indivíduos introduzidos em uma certa localidade (Lockwood et al., 2005; Blackburn et al., 2015; Cristescu, 2015).

Contudo, introduções múltiplas parecem ter um efeito modesto na quantidade total de variação genética medida pelos marcadores comumente empregados, pelo menos a curto prazo (Dlugosch et al., 2015). Acredita-se, porém, que a ocorrência de introduções múltiplas pode influenciar na variação genética adaptativa por meio da ocorrência de novas combinações genéticas associadas à diversificação fenotípica, podendo aumentar o potencial adaptativo da espécie introduzida a longo prazo (Dlugosch \& Parker, 2008; Rius \& Darling, 2014). Assim, a diversidade genética adicional por meio de introduções múltiplas seria importante para a manutenção da mudança adaptativa em populações fundadoras, mas não necessariamente crucial para o início do processo de invasão, pois, a princípio, introduções provenientes de 
localidades distintas poderiam permanecer por um tempo como "mosaicos de más adaptações" (Dlugosch \& Parker, 2008).

De modo geral, alguns trabalhos tem mostrado que traços adaptativos evoluíram em populações introduzidas (e.g. Stockwell et al., 1996; Hendry \& Quinn, 1997; Koskinen et al., 2002), fornecendo subsidio para a importância da evolução no sucesso das invasões como já sugerido (Mayr, 1965). No entanto, não se deve negligenciar totalmente os efeitos da deriva genética no processo de invasão. A ação isolada da deriva genética também pode promover invasões bem sucedidas (Tsutsui et al., 2000) e o estudo de marcadores neutros é imprescindível para a compreensão dos processos demográficos relacionados aos eventos de introdução de espécies invasoras.

\subsection{0 caso do siri invasor Charybdis hellerii}

$\mathrm{Na}$ mais recente classificação de Brachyura, infraordem composta por todos os siris e caranguejos ( $\mathrm{Ng}$ et al., 2008), a superfamília Portunoidea Rafinesque, 1815 é constituída por duas famílias: Geryonidae Colosi, 1923 e Portunidae Rafinesque, 1815. Os siris da família Portunidae são crustáceos que habitam áreas infra-litorâneas, estuários e offshore em todo o mundo (Stephenson, 1972). De acordo com a análise feita por Melo (1996), 20 espécies possuem registro para a costa brasileira. Sete subfamílias são reconhecidas para a família Portunidae, dentre as quais a subfamília Thalamitinae Paulson, 1875. Esta é composta por três gêneros, sendo um deles Charybdis de Haan, 1833 ( $\mathrm{Ng}$ et al., 2008), o segundo mais diverso dentro da subfamília, com cerca de 60 espécies ( $\mathrm{Ng}$ et al., 2008).

O siri invasor Charybdis hellerii (A. Milne-Edwards, 1867) (Figura 1), membro deste gênero, tem habitat variável. Nas áreas nativas, indivíduos podem ser coletados em regiões intermareais, sob rochas ou em corais (Stephenson et al., 1957). Nas áreas não nativas podem ser encontrados tanto em águas intermareais como 
submareais, em sedimentos consolidados, como rochas e corais, ou em sedimentos não consolidados, como lama e fundos de areia (Gómez \& Martínez-Iglesias, 1990; Mantelatto \& Souza-Carey, 1998; Ahmed \& Abbas, 1999; Özcan et al., 2005; Almeida et al., 2003). Juvenis já foram reportados em colônias de briozoários (Schizoporella errata) (Mantelatto \& Souza-Carey, 1998) e algas (Sargassum spp) (Mantelatto \& Corrêa, 1996). Há ainda registros de espécimes associados a raízes de árvores de manguezais (Rizophora mangle) (Campos \& Türkay, 1989; Dineen et al., 2001).

Segundo Stephenson (1976), C. hellerii é uma das espécies mais facilmente reconhecidas do gênero Charybdis, sendo que a presença de um espinho na margem posterior do carpo do quinto pereiópodo (Figura 20) consiste em sua principal característica diagnóstica (Stephenson, 1976). Duas outras espécies, Charybdis vannamei Ward, 1941 e Charybdis spinifera (Miers, 1884), também apresentam esta característica (Padate et al., 2010). No entanto, o sexto dente ântero-lateral menor que os demais em $C$. vannamei e a margem posterior do própodo da pata natatória lisa em C. spinifera, bem como a presença de dentes frontais submedianos arredondados nesta espécie, consistem em características que as diferem de C. hellerii (Padate et al., 2010). O sexto dente ântero-lateral de $C$. hellerii é alongado, projetando-se além dos demais, seus dentes frontais submedianos são triangulares e a margem posterior do própodo da pata natatória é denticulada (Padate et al., 2010).

A distribuição nativa de C. hellerii abrange: mar Vermelho, Djibuti, Somália, África do Sul, Madagascar, Golfo Pérsico, Ceilão, Índia, China, Japão, Singapura, Indonésia, Filipinas, Nova Caledônia, Austrália e Havaí. Após eventos de introdução e dispersão, sua ocorrência se estendeu para: Egito, Israel, Síria, Chipre, Turquia e Líbano no Mediterrâneo oriental e Flórida, Cuba, Belize, Panamá, Colômbia, Venezuela, Guiana Francesa, Antilhas e Brasil (do Pará a Santa Catarina) na costa leste América (Stephenson et al., 1957; Calado, 1996; Mantelatto \& Dias, 1999; Dineen et al., 2001; Tavares \& Amouroux, 2003; Felder et al., 2009). 


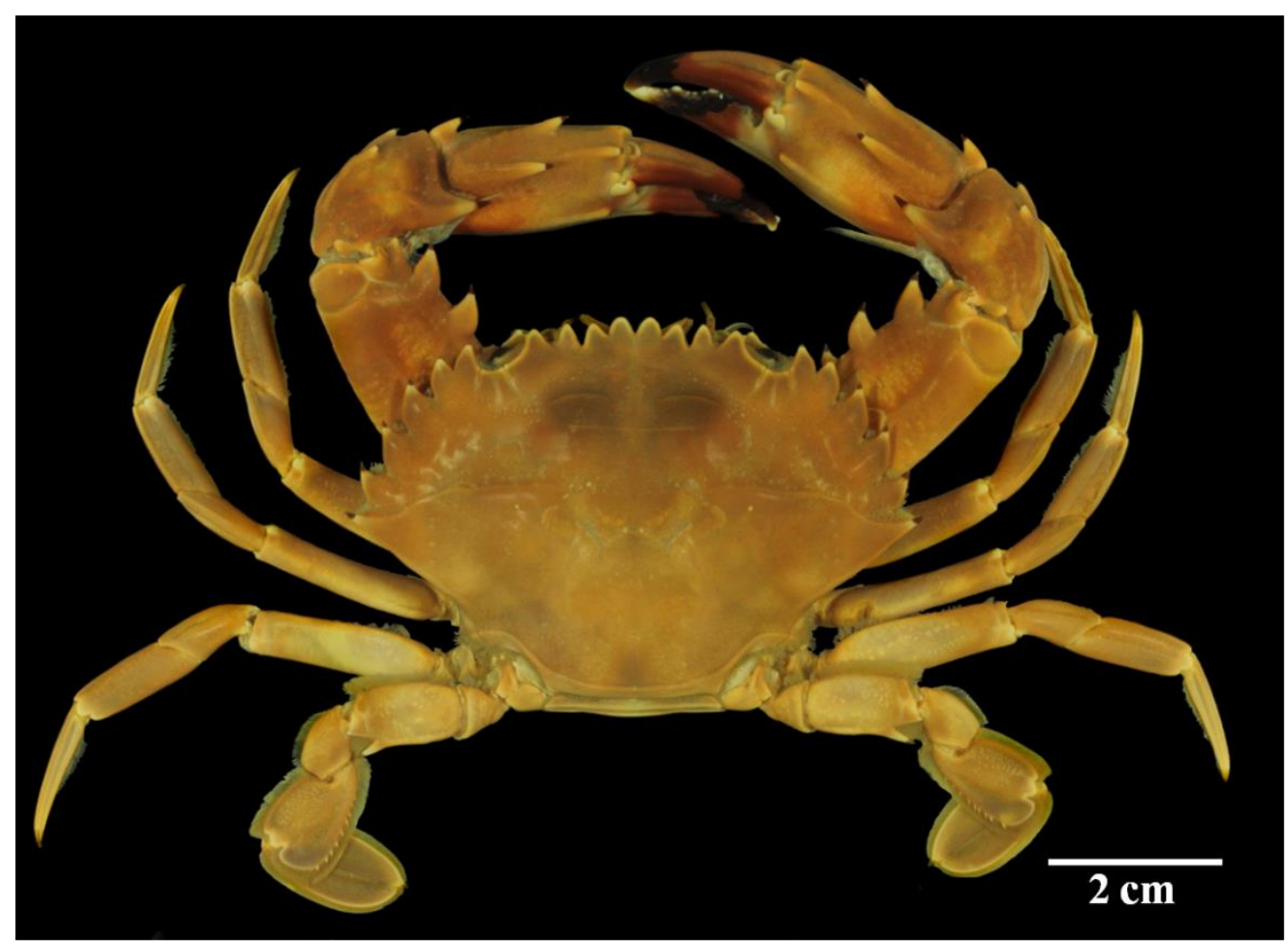

Figura 1. Charybdis hellerii (A. Milne-Edwards, 1867), exemplar de um macho adulto (CCDB 1942). Foto: Buranelli, R.C. \& L.G. Pileggi.

Esta espécie apresenta um longo histórico de introduções e dispersões: originária do Indo-Oeste Pacífico, em 1924-1925 foi encontrada pela primeira vez no mar Mediterrâneo, mais precisamente na costa israelense (Steinitz, 1929), sendo que, a partir de então, teria se dispersado para o Líbano, Síria, Turquia, Chipre e Egito (Galil, 2000). A chegada de C. hellerii no mar Mediterrâneo teria sido proveniente do mar Vermelho e ocorrido através do Canal de Suez (Por, 1978). A abertura deste canal em 1869 promoveu a quebra da barreira geográfica entre esses dois mares e, consequentemente, originou uma via de invasão entre eles (Por, 1978).

Em 1987, C. hellerii foi registrado pela primeira vez na costa leste americana, mais especificamente em Cuba (Gómez \& Martínez-Iglesias, 1990), e posteriormente esse registro se estendeu para a Venezuela (Hernandez \& Bolaños, 1995) e Colômbia 
(Campos \& Türkay, 1989), ambos também com coleta em 1987. Em 1995, foram coletados na Flórida, EUA (Lemaitre, 1995) e no Brasil (Calado, 1996; Carqueija \& Gouvêa, 1996; Negreiros-Fransozo, 1996; Tavares \& Mendonça Jr., 1996); em 2001, na Guiana Francesa (Tavares \& Amouroux, 2003); em 2002, em Belize (Felder et al., 2009); em 2004, no Golfo do México, mais precisamente na costa oeste da Flórida (McMillen-Jackson, 2008) e para o presente estudo também foram obtidos espécimes do Panamá em 2011, localidade já considerada como parte da distribuição na América por Brockerhoff \& McLay (2011). Um animal, porém, capturado em 1986 na costa do estado da Carolina do Sul (EUA) foi apenas identificado em 2001 como mais um exemplar de C. hellerii (McMillen-Jackson, 2008).

No litoral brasileiro C. hellerii foi encontrado em 1995 nos estados de Alagoas (Calado, 1996), Bahia (Carqueija \& Gouvêa, 1996), São Paulo (Negreiros-Fransozo, 1996) e Rio de Janeiro (Tavares \& Mendonça Jr., 1996); em 1997 foi coletado pela primeira vez no Rio Grande do Norte (Ferreira et al., 2001); em 1998, em Santa Catarina (Mantelatto \& Dias, 1999); em 2000, em Pernambuco (Coelho \& Santos, 2003); em 2004, no Ceará (Bezerra \& Almeida, 2005) e no Espírito Santo (MusielloFernandes et al., 2011); em 2005, no Maranhão (Feres et al., 2007); em 2007, no Piauí (Lima-Júnior et al., 2008; Loebmann et al., 2010); em 2011, no Pará (Bentes et al., 2013) e, finalmente, em 2013, em Sergipe (Rosa, 2014). O registro de C. hellerii no Paraná foi feito por Frigotto \& Serafim-Junior (2007), mas estes autores não mencionam precisamente o ano de coleta dos exemplares.

Acredita-se que o transporte das formas larvais em tanques de lastro teria seria o vetor mais provável de introdução dessa espécie na costa americana (Lemaitre, 1995; Mantelatto \& Dias, 1999). Segundo Campos \& Türkay (1989), a introdução dessa espécie no hemisfério ocidental coincidiu com o aumento da navegação entre o Mediterrâneo oriental e locais distantes na década de 80. Do mesmo modo, Mantelatto \& Dias (1999) afirmaram que os registros dessa espécie nas costas dos estados de 
São Paulo e Santa Catarina aparentam correlação com o aumento do tráfego de navios vindos de outras regiões para estas (Mantelatto \& Dias, 1999). A teoria sobre o transporte de $C$. hellerii na forma larval encontra suporte nos estudos de Dineen et al. (2001), segundo o qual a fase larval dessa espécie (com duração de 44 dias em condições laboratoriais) é duas vezes mais longa do que as três semanas necessárias por um navio para o percurso entre o Mediterrâneo e águas costeiras do Atlântico ocidental.

A água de lastro é carregada por grandes navios comerciais transoceânicos, os quais normalmente requerem grandes quantidades de peso adicional para alcançar estabilidade (Holland, 2000) e representa uma das principais ameaças à biodiversidade marinha (Norse, 1993). Isto ocorre, pois esse volume de água do mar carrega e transfere os organismos nela contido entre regiões do mundo todo, propiciando eventos de introdução (Holland, 2000).

Apesar das hipóteses sobre o vetor de chegada dessa espécie na América serem de amplo consenso, as explicações para sua ocorrência ao longo de quase toda a extensão da costa do oceano Atlântico Ocidental são confusas e divergentes. Gómez \& Martínez-Iglesias (1990), Campos \& Türkay (1989), Lemaitre (1995) e Tavares \& Mendonça Jr. (1996) sugerem que uma ou múltiplas introduções podem ter ocorrido na costa caribenha, possivelmente provenientes do Mediterrâneo, com subsequente dispersão de formas larvais desse portunídeo em outras regiões caribenhas e na Flórida por meio das correntes oceânicas (Lemaitre, 1995). Assim, os indivíduos da América seriam provenientes de uma população também não nativa (mar Mediterrâneo). Tavares \& Mendonça Jr. (1996) propuseram ainda que a dispersão dos estágios larvais seria responsável pela ocorrência dessa espécie no Atlântico sul, conjecturando a possibilidade de que as populações do Brasil sejam provenientes do Caribe. Nesse caso, C. hellerii teria sido introduzido no Caribe e se dispersado na forma larval por meio da corrente brasileira (com direção norte-sul) e, 
subsequentemente, colonizado áreas da costa do Brasil (Tavares \& Mendonça Jr., 1996). A dispersão dessa espécie na costa americana pode também ter sido facilitada pelo movimento de navios ao longo da costa (Tavares \& Amouroux, 2003) ou até pela migração de adultos (McMillen-Jackson, 2008).

No entanto, Ferreira et al. (2001) propuseram que $C$. hellerii tenha sido introduzido também no nordeste brasileiro, a partir de onde teria se dispersado para o sul por meio da corrente oceânica brasileira. Mantelatto \& Dias (1999) questionaram se o modo de chegada dessa espécie no litoral de Santa Catarina e de São Paulo teria ocorrido como consequência de uma extensão das populações existentes por meio das correntes ou como novas introduções. Não apontam especificamente, porém, quais seriam as prováveis origens dessas novas introduções, ou seja, se estas seriam provenientes de populações introduzidas da América, mar Mediterrâneo ou até mesmo de regiões do Indo-Pacífico. A possibilidade de introduções provenientes do IndoPacífico baseia-se no fato de que o registro de $C$. hellerii no sul e sudeste do Brasil coincide com o aumento do tráfego de navios para essa região, em particular no porto de Itajaí com o fluxo de navios japoneses (F.L. Mantelatto, comunicação pessoal). Com isso, é possível questionar a hipótese de que a invasão da costa brasileira tenha ocorrido como consequência da dispersão de larvas provenientes do Caribe, podendo ser levantada a possibilidade de que processos independentes e de múltipla entrada possam ter ocorrido entre o Atlântico sul e o Caribe.

De maneira geral, os crustáceos decápodes são bem adaptados para migrações a longas distâncias e ocupação de novas localidades (Rodríguez \& Suárez, 2001). No caso específico de C. hellerii, além da fase larval prolongada (Dineen et al., 2001), essa espécie possui outros atributos biológicos que favorecem sua dispersão, estabelecimento e manutenção em novas áreas: (1) seu crescimento e maturação são rápidos, sendo completados em menos de um ano, o que contribui para a ocorrência de gerações mais curtas e promove rápido crescimento populacional; (2) seus 
espécimes podem estocar esperma e produzir desovas múltiplas; (3) sua dieta é generalista, o que permite uma exploração oportunista dos recursos alimentares; (4) possuem capacidade de explorar e adaptar-se a habitats diversos, aumentando a chance de colonização, e (5) atingem a maturidade sexual com tamanho inferior ao ocorrido na localidade de origem (Dineen et al., 2001; Sant'Anna et al., 2012a). Mantelatto \& Garcia (2001) demonstraram que fêmeas de C. hellerii no litoral paulista alcançam a maturidade sexual com apenas $35 \mathrm{~mm}$ de largura da carapaça, tamanho este muito inferior ao observado para espécimes do Indo-Pacífico.

Tais fatores contribuem para que, assim como no Mediterrâneo (Galil et al., 2002) e no Caribe (Lemaitre, 1995; Bolaños et al., 2012), esta espécie já esteja também bem estabelecida no litoral brasileiro (Mantelatto \& Garcia, 2001), podendo ser considerada um dos exemplos de introdução bem sucedida de uma espécie exótica marinha no oceano Atlântico (Tavares \& Amouroux, 2003). O estudo populacional desenvolvido por Mantelatto \& Garcia (2001) na Baia de Ubatuba demonstrou que esta população apresenta altas densidades de adultos, jovens e fêmeas ovígeras, confirmando essa hipótese. Além disso, C. hellerii também mostrouse estabelecido em São Vicente, onde, ao contrário de Ubatuba, altas frequências de fêmeas ovígeras não foram detectadas, mas indicaram um padrão reprodutivo contínuo, embora heterogêneo (Sant'Anna et al., 2012a).

Conforme apontado na seção anterior, a realização de estudos comparativos e de caracterização, por meio de dados moleculares, das populações nativas e não nativas de espécies invasoras tem auxiliado com surpreendente precisão investigações sobre seus históricos de introdução (Handley et al., 2011). A abordagem molecular tem possibilitado a obtenção de respostas a questões de extrema relevância para o entendimento dos processos de invasão, como a identidade taxonômica de espécies invasoras, o reconhecimento das áreas de origem e dos vetores de introdução e a detecção de gargalo genético e da ocorrência ou não de introduções 
múltiplas (Sakai et al. 2001; Geller et al., 2010). A aplicação dessas ferramentas para estudos da espécie $C$. hellerii, integrada a investigações morfológicas comparativas, possibilitou, assim, que diversas hipóteses anteriormente delineadas fossem testadas na presente tese: (1) todos os indivíduos introduzidos representam uma única entidade taxonômica; (2) há estruturação genética entre suas populações; (3) as populações da América possuem como principal origem o Mediterrâneo; (4) ocorreram múltiplas introduções ao longo da costa americana; (5) houve uma diminuição da diversidade genética em decorrência do gargalo demográfico associado à introdução.

A elucidação destas questões é fundamental para a elaboração de estratégias de manejo (Geller et al., 2010). Embora o conhecimento sobre os impactos da introdução de C. hellerii seja limitado (Felder et al., 2009), há evidências de que esta seja potencialmente capaz de competir por alimento e espaço com espécies nativas de portunídeos (Mantelatto \& Dias, 1999; Coelho \& Santos, 2003; Almeida et al., 2003; Sant'Anna et al., 2012a). Além disso, potenciais impactos predatórios e competitivos foram reportados por Felder et al. (2009), pela observação de espécimes se alimentando de crustáceos nativos, um do gênero Callinectes e outro Panulirus.

O comportamento altamente agressivo dessa espécie invasora também foi verificado, principalmente contra o portunídeo nativo Cronius ruber (Lamarck, 1818) (Sant'Anna et al., 2012a), de forma que, hipóteses têm sido levantadas de que as populações desta espécie nativa têm estado em declínio desde a introdução de $C$. hellerii (Sant'Anna et al., 2012a). Ainda, altas taxas de animais com apêndices mutilados ou em regeneração foi verificada em uma população americana estudada (Sant'Anna et al., 2012a). Diferentemente do que ocorre no sudeste da Ásia (Moosa, 1981), essa espécie não possui importância econômica na América (Lemaitre, 1995), mas consiste em um potencial risco de impacto negativo sobre as pescas locais de siris e camarões (Coelho \& Santos, 2003). Os organismos invasores podem, indiretamente, afetar as espécies nativas pela introdução de doenças (Rodríguez \& 
Suárez, 2001). C. hellerii é um potencial hospedeiro do Vírus da Síndrome da Mancha Branca (em inglês White Spot Sindrome Virus - WSSV), que naturalmente infecta várias espécies do gênero Charybdis, bem como outros Decapoda. Isso representa um risco para a aquicultura, pois há inúmeras formas de um vírus migrar do ambiente natural para culturas (Chang et al., 2001; Chakraborty et al., 2002; Tavares, 2011).

\subsection{Charybdis variegata: mais um caso de introdução na costa leste americana?}

Para que todos esses esforços voltados à compreensão do processo de introdução tenham significado, é de extrema importância que a identificação acurada das espécies não nativas seja feita (Bucciarelli et al., 2002). Isto se torna evidente quando uma nova espécie introduzida é identificada (Geller et al., 2010). Além disso, espécies não nativas que parecem muito bem conhecidas taxonomicamente, muitas vezes são dissolvidas em complexos de espécies quando examinadas com maior perícia (Geller et al., 2010). Contudo, a falta de taxonomistas especializados em táxons particulares tem propiciado erros de identificação e em um conhecimento incompleto da biodiversidade marinha, incluindo aquele acerca das espécies exóticas (Geller et al., 2010).

Recentemente, outra espécie do gênero, Charybdis variegata (Fabricius, 1798), foi registrada como sendo mais uma espécie introduzida na costa leste da América. Esse registro foi feito com base em um único exemplar de uma fêmea juvenil coletada em Ponta da Praia, Santos, São Paulo, Brasil (Sant'Anna et al., 2012b) e incitou questionamentos sobre a sua identificação. A identificação do exemplar foi feita com base em alguns caracteres apontados por Padate et al. (2010): 1) presença de cristas na superfície dorsal da carapaça posteriores ao sexto dente anterolateral; 2) região mesobranquial da carapaça com dois pares de cristas transversais nos espécimes de pequeno tamanho; 3) sulco transversal na região cardíaca não interrompido; 4) segundo dente anterolateral tão largo quanto o primeiro; 5) sexto dente anterolateral 
como sendo o mais largo, espiniforme e projetado lateralmente; 6) todos os dentes frontais acuminados na extremidade.

A fim de confirmar a identificação do espécime e a veracidade desse novo registro, análises morfológicas e moleculares do espécime utilizado foram realizadas. Sequências dos genes mitocondriais, inclusive da região definida pela técnica de $D N A$ Barcoding (Hebert et al., 2003), foram obtidas a partir dele, as quais foram inseridas nas análises moleculares conduzidas no presente trabalho. A técnica de DNA Barcoding se baseia em observações de que as variações genéticas inter e intraespecíficas não se sobrepõem possibilitando a atribuição inequívoca de indivíduos a nível de espécies em vários taxa (Hebert et al., 2003). 


\section{OBJETIVOS}




\subsection{Objetivo geral}

O presente trabalho teve como objetivo principal investigar a história de introdução de Charybdis hellerii na costa americana por meio de dados moleculares e morfologia comparativa.

\subsection{Objetivos específicos}

Para o alcance do objetivo principal, os objetivos específicos foram:

1) Verificar a identidade taxonômica de $C$. hellerii por meio de dados moleculares e morfológicos, detectando o grau de variabilidade dos caracteres morfológicos analisados e de diferenciação genética no contexto do gênero Charybdis;

2) Descrever a distribuição da diversidade genética e sua estruturação nas áreas nativas e do mar Mediterrâneo a fim de testar a hipótese de estruturação genética nas possíveis áreas de origem das introduções na América, bem como checar a possibilidade de estruturação morfométrica;

3) Descrever e comparar a composição genética das áreas introduzidas na costa americana entre si e com as áreas nativas e do mar Mediterrâneo a fim de testar as hipóteses de origem mediterrânea das populações americanas e de ocorrência de introduções múltiplas ao longo de sua costa;

4) Descrever e comparar a variabilidade genética entre áreas nativas e não nativas a fim de testar a hipótese de gargalo genético associado ao evento de introdução;

5) Checar por meio de dados morfológicos e moleculares (DNA Barcoding) o registro da espécie Charybdis variegata para a costa americana. 
3. MATERIAL \&

MÉTODOS 


\subsection{Obtenção dos exemplares}

Os espécimes ou amostras de tecido de $C$. hellerii e de outras espécies do gênero Charybdis utilizados neste estudo foram obtidos de diferentes formas:

* Grande parte dos espécimes analisados estava depositada na Coleção de Crustáceos do Departamento de Biologia (CCDB) do Laboratório de Bioecologia e Sistemática de Crustáceos (LBSC), Faculdade de Filosofia, Ciências e Letras de Ribeirão Preto da Universidade de São Paulo (FFCLRP/USP);

* Outros exemplares foram adquiridos por meio de coletas realizadas por membros do LBSC em Ubatuba e Cananéia (São Paulo, Brasil) e Vitória (Espírito Santo, Brasil). Esses animais foram obtidos por meio de coletas manuais utilizando-se puçá, foram então armazenados em álcool etílico 80\%, e, posteriormente, depositados na CCDB/FFCLRP/USP;

* Empréstimos de coleções científicas: Museu de Zoologia da Universidade de São Paulo, São Paulo (MZUSP); Museu Nacional do Rio de Janeiro, Rio de Janeiro (MNRJ); Museu de Zoologia da Universidade Estadual de Santa Cruz, Ilhéus, Bahia (MZUESC); Coleção Carcinológica do Museu de Oceanografia da Universidade de Pernambuco, Recife (MOUFPE); Coleção de Carcinologia do Instituto de Ciências do Mar - B (LABOMAR - B), Universidade Federal do Ceará, Fortaleza (UFC); National Museum of Natural History, Smithsonian Institution, Washington D.C., Estados Unidos da América (USNM) e Florida Museum of Natural History, University of Florida, Gainesville, Florida, Estados Unidos da América (UF).

* Doações de tecidos e exemplares de instituições científicas: Florida Museum of Natural History, University of Florida, Gainesville, Florida, Estados Unidos da América (UF); Zoological Collection of the University of Louisiana, Lafayette, Estados Unidos da América (ULLZ); Marine Invertebrates Collection of Museum Victoria, Melborne, Austrália (MV); Laboratorio de Zoología, Universidad de Oriente, Núcleo de Nueva 
Esparta, Escuela de Ciencias Aplicadas del Mar; Science Faculty, Department of Biology, University of Istanbul, Istanbul, Turquia; Natural History Museum, Londres, Inglaterra (NHM); Rijksmuseum van Natuurlijke Historie, Naturalis Biodiversity Center, Leiden, Holanda (RMNH); Museum National d'Histoire Naturelle, Paris, França (MNHN); Senckenberg Museum, Frankfurt, Alemanha (SMF); Australian Museum, Sydney, Austrália (AM); Western Australian Museum, Perth, Austrália (WAM) Os exemplares recebidos como doação foram depositados na CCDB/FFCLRP/USP.

Todos os espécimes analisados tiveram sua identificação confirmada com base nas características morfológicas diagnósticas, nas descrições da espécie e chaves de identificação do gênero Charybdis (Stephenson et al., 1957; Wee \& Ng, 1995; Apel \& Spirodonov, 1998; Padate et al., 2010).

\subsection{Escolha dos marcadores moleculares}

Dois marcadores mitocondriais, citocromo oxidase I (COI) e 16S rDNA, e um nuclear, histona $\mathrm{H} 3$, foram empregados no presente estudo. O genoma mitocondrial é considerado mais informativo em níveis taxonômicos mais baixos (espécies e gêneros) e estudos filogeográficos (Avise, 2009), pois geralmente possui taxas de mutação mais rápidas que o nuclear (Brown et al., 1979) e uma presumida neutralidade (Hickerson et al., 2010). O genoma mitocondrial é também haploide, recombinações são raras e é altamente compacto, ou seja, não possui introns ou longos trechos intergênicos de sequências espaçadoras não codificantes que caracterizam o genoma nuclear (Hajibabaei et al., 2007; Avise, 2009). Os marcadores mitocondriais codificam genes estritamente ortólogos (Qian et al., 2011) e são fáceis de serem amplificados em virtude da disponibilidade de vários primers universais (Simon et al., 1994) e grande quantidade de suas cópias nas células (Schubart et al., 2000). Além disso, devido à herança maternal, possuem tamanho populacional efetivo baixo e, dessa forma, menor tempo de coalescência (Hickerson et al., 2010) e divergências genéticas maiores 
detectáveis entre populações devido somente à deriva. Essas características os tornam mais sensitivos para detectar estruturação genética entre populações.

Os marcadores mitocondriais, principalmente o gene codificante COI, são comumente utilizados em trabalhos populacionais e de espécies invasoras (e.g. Darling et al., 2008; You et al., 2008; Fratini et al., 2010; Lejeusne et al., 2014). Estes fornecem informações a respeito da estruturação populacional dificilmente acessados por marcadores nucleares (Gopurenko, 2002). A frequência de haplótipos obtida ao longo da distribuição de uma espécie pode, inclusive, ser utilizada para inferir níveis de fluxo gênico entre as populações (Gopurenko, 2002).

O resultado da tradução do transcrito do gene COI corresponde a uma proteína localizada na membrana interna das mitocôndrias que participa da sequência final da cadeia respiratória (Schubart et al., 2000; Nelson \& Cox, 2006). Embora seja um gene codificante e, assim, se esperar que seja mais conservado, o cOl geralmente apresenta taxas de divergências genéticas maiores que as de 16S rDNA (não codificante) (e.g. Harrison, 2004; Francisco \& Galetti Junior, 2005; Liu et al., 2007; Pileggi \& Mantelatto, 2010) e de genes nucleares (Avise, 2009; Zink \& Barrowclough, 2008; Hickerson et al., 2010). Por suas características, uma determinada região desse gene foi designada como o código de barras para a identificação das espécies (Hebert et al., 2003). A sua escolha se baseou na observação de que há um gap entre a variação inter e intraespecífica, possibilitando a atribuição de indivíduos a espécies (Hebert et al., 2003). Estudos baseados na região barcode tem se mostrado, portanto, muito úteis para descrever invasões crípticas (Geller et al., 2010).

O outro gene mitocondrial, o $16 \mathrm{~S}$ rDNA, consiste em um gene estrutural bastante utilizado para a determinação das relações evolutivas entre os animais, tanto aquelas mais antigas quanto os eventos mais recentes, o que, provavelmente, deve-se ao fato de o mesmo ser constituído por uma combinação de regiões variáveis e conservadas, característica comum ao DNA ribossomal (Kim \& Abele, 1990; Schubart 
et al., 2000). Seu transcrito, em associação com outras proteínas, forma uma estrutura conservada secundária que corresponde à subunidade maior dos ribossomos mitocondriais (Schubart et al., 2000). Em estudos sobre decápodes, o uso desse gene é muito frequente em virtude de sua porção conservada mostrar-se um importante marcador interespecífico (e.g. Mantelatto et al., 2007; Rossi \& Mantelatto, 2013; Negri et al., 2012) e de haver uma quantidade grande de primers disponíveis para as análises moleculares em invertebrados (Schubart et al., 2000).

O emprego de marcadores moleculares mitocondriais é preponderante nos estudos populacionais em relação aos genes nucleares, posicionando-se apenas ao lado dos microssatélites (Zhang \& Hewitt, 2003). Os genes nucleares podem ser informativos de espécies a ordens, embora são muito usuais em trabalhos sobre as relações entre níveis taxonômicos mais elevados (e.g. Chu et al., 2009; Robles et al., 2009). No entanto, a inclusão de genes nucleares pode fornecer um quadro complementar sobre a história evolutiva das populações, uma vez que alguns problemas podem ser decorrentes do uso de marcadores mitocondriais (Zhang \& Hewitt, 2003). Por exemplo, a existência de pseudogenes mitocondriais no genoma nuclear, bem como o fato de esses marcadores refletirem apenas a história evolutiva materna, dado que a herança mitocondrial é materna, podendo incorrer em alguns problemas durante as análises de reconstrução da história evolutiva das populações (Zhang \& Hewitt, 2003). Assim, tem sido constantemente reforçado o benefício do uso aliado de marcadores mitocondriais e nucleares tanto em análises populacionais quanto em níveis taxonômicos superiores (Timm \& Bracken-Grissom, 2015).

O gene H3 está contido na região promotora do gene que codifica a histona H3 e, como gene nuclear e codificante, possui taxa evolutiva menor. Isso lhe confere propriedades para o uso em inferências de relações genealógicas entre as sequências (Neigel, 1997). Em estudos populacionais, caso haja a detecção de divergências entre sequências de marcadores nucleares, há um forte indício de variação interespecífica. 


\subsection{Obtenção dos dados moleculares}

Para o gene mais variável, citocromo oxidase I (COI), buscou-se obter, sempre que possível, sequências de pelo menos cinco indivíduos de $C$. hellerii por localidade. Para os demais genes, 16S rDNA e H3, que são mais conservados, não se estipulou um número mínimo de sequências a serem obtidas. Para as outras espécies congêneres foram obtidas apenas sequências dos marcadores mitocondriais de pelo menos um indivíduo de cada espécie. Os dados moleculares foram obtidos seguindo protocolos de Schubart et al. (2000), Mantelatto et al. (2006, 2007, 2009) e Pileggi \& Mantelatto (2010), com as modificações necessárias.

Além de sequências de COI, 16S rDNA e H3 de C. hellerii (Tabela 1) provenientes de diversas localidades ao longo de sua distribuição mundial (Figura 2), foram obtidas sequências dos marcadores mitocondriais de 27 espécies congêneres (Tabela 2) a fim de comparar as variações de $C$. hellerii às interespecíficas ao nível do gênero Charybdis. 
Tabela 1. Continua. Relação de espécimes de Charybdis hellerii utilizados nas análises moleculares. AM: Australian Museum, Sydney, Austrália; CCDB: Coleção de Crustáceos do Departamento de biologia da Faculdade de Filosofia, Ciências e Letras, Universidade de São Paulo, Ribeirão Preto; Brasil; CUHK: The Chinese University of Hong Kong, LABOMAR - B: Coleção de Carcinologia do Instituto de Ciências do Mar - B, Universidade Federal do Ceará, Fortaleza, Brasil; MNHN: Museum National d'Histoire Naturelle, Paris, França; MNRJ: Museu Nacional do Rio de Janeiro, Rio de Janeiro, Brasil; MOUFPE: Museu de Oceanografia da Universidade Federal de Pernambuco, Recife, Brasil; MV: Marine Invertebrates Collection of Museum Victoria, Melborne, Austrália; MZUESC: Museu de Zoologia da Universidade Estadual de Santa Cruz, Ilhéus, Bahia, Brasil; MZUSP: Museu de Zoologia da Universidade de São Paulo, São Paulo, Brasil; NHM: National History Museum, Londres, Inglaterra; RMNH CRUST: Crustáceos do Rijksmuseum van Natuurlijke Historie, Naturalis Biodiversity Center, Leiden, Holanda; SMF: Senckenberg Museum, Frankfurt, Alemanha; UF: University of Florida, Gainesville, Florida, Estados Unidos da América; ULLZ: Zoological Collection of the University of Louisiana, Lafayette, Estados Unidos da América; USNM: National Museum of Natural History, Smithsonian Institution, Washington D.C., Estados Unidos da América; WAM: Western Australian Museum, Perth, Austrália. Símbolos: -, Sequências ou medidas não obtidas; M, macho; F, fêmea.

\begin{tabular}{|c|c|c|c|c|c|}
\hline \multirow[t]{2}{*}{ Localidade e data de coleta } & \multirow{2}{*}{ Coleção } & \multicolumn{3}{|c|}{ GenBank } & \multirow{2}{*}{$\begin{array}{l}\text { Análises } \\
\text { Morfométricas }\end{array}$} \\
\hline & & COl & $16 S$ & H3 & \\
\hline Praia de Iskenderun, Província de Hatay, Turquia, 27/12/1990 & $\begin{array}{l}\text { RMNH. CRUST. D. } \\
\quad 38576\end{array}$ & $\begin{array}{l}\text { KX060313 } \\
\text { KX060314 }\end{array}$ & $\begin{array}{l}\text { KX060498 } \\
\text { KX060499 }\end{array}$ & - & $1 \mathrm{M}$ \\
\hline Turquia, 15/07/2014 & CCDB 5460 & $\begin{array}{l}\text { KX060339 } \\
\text { KX060340 }\end{array}$ & $\begin{array}{l}\text { KX060528 } \\
\text { KX060529 }\end{array}$ & - & $1 \mathrm{M}$ \\
\hline Egito, data de coleta não informada & Em2012-C2 & KF793329 & - & - & - \\
\hline Próximo a Tantura, sul de Haifa, Israel, 03/05/1962 & $\begin{array}{c}\text { RMNH. CRUST. D. } \\
17717\end{array}$ & KX060357 & - & - & - \\
\hline Saint George Bay, Beirute, Líbano, data de coleta não informada & RMNH. CRUST. 29162 & - & - & - & $\begin{array}{l}1 \mathrm{M} \\
1 \mathrm{~F}\end{array}$ \\
\hline & & KX060329 & KX060518 & - & $\begin{array}{l}1 \mathrm{M} \\
1 \mathrm{M}\end{array}$ \\
\hline Fujairah, Emirados Árabes Unidos, 02/07/1995 & SMF 24352 & $\begin{array}{l}- \\
- \\
-\end{array}$ & $\begin{array}{l}- \\
- \\
-\end{array}$ & $\begin{array}{l}- \\
- \\
-\end{array}$ & $\begin{array}{l}1 \mathrm{M} \\
1 \mathrm{M} \\
1 \mathrm{~F}\end{array}$ \\
\hline $\begin{array}{l}\text { Porto Bandar-Abbas, Província de Hormozgan, Golfo Pérsico, Irã, } \\
\text { 06/1/2008 }\end{array}$ & SMF 40796 & KX060330 & KX060519 & - & $1 \mathrm{M}$ \\
\hline Ilha Qeshm, Golfo Pérsico, Irã, 10/01/2008 & SMF 40797 & $\begin{array}{l}\text { KX060331 } \\
\text { KX060332 }\end{array}$ & $\begin{array}{l}\text { KX060520 } \\
\text { KX060521 }\end{array}$ & - & $\begin{array}{l}1 \mathrm{~F} \\
1 \mathrm{~F}\end{array}$ \\
\hline Ilha Qeshm, Golfo Pérsico, Irã, 08/01/2008 & SMF 40794 & KX060338 & KX060527 & - & $1 \mathrm{M}$ \\
\hline
\end{tabular}


Tabela 1. Continuação.

\begin{tabular}{|c|c|c|c|c|c|}
\hline Localidade e data de coleta & Coleção & COI & $\begin{array}{l}\text { GenBank } \\
16 S\end{array}$ & H3 & $\begin{array}{c}\text { Análises } \\
\text { Morfométricas }\end{array}$ \\
\hline Ilha Qeshm, Golfo Pérsico, Irã, 07/05/2008 & SMF 40791 & $\begin{array}{l}- \\
- \\
- \\
- \\
-\end{array}$ & $\begin{array}{l}- \\
- \\
- \\
- \\
-\end{array}$ & $\begin{array}{l}- \\
- \\
- \\
- \\
-\end{array}$ & $\begin{array}{l}1 \mathrm{M} \\
1 \mathrm{M} \\
1 \mathrm{M} \\
1 \mathrm{M} \\
1 \mathrm{~F}\end{array}$ \\
\hline Ilha Qeshm, Golfo Pérsico, Irã, 07/05/2008 & SMF 40795 & - & - & - & $1 \mathrm{M}$ \\
\hline $\begin{array}{l}\text { Bandar-Abbas, cidade de Elich, Hormozgan, Golfo Pérsico, Irã, } \\
\text { 06/01/2008 }\end{array}$ & SFM 40796 & - & - & - & $1 \mathrm{M}$ \\
\hline Irã, 10/04/2013 & CHIpC1 & KF870477 & - & - & - \\
\hline Ras Al Jlay'ah, Kuwait, 12/10/1979 & NHM 1998. 2593-2594 & $\begin{array}{l}- \\
- \\
-\end{array}$ & $\begin{array}{c}\text { KX060530 } \\
- \\
-\end{array}$ & $\begin{array}{l}- \\
- \\
-\end{array}$ & $\begin{array}{c}- \\
1 \mathrm{M} \\
1 \mathrm{M}\end{array}$ \\
\hline Índia, 12/01/2014 & - & KP292977 & - & - & - \\
\hline \multirow{2}{*}{ Índia, 23/10/2012 } & VITCIFE-KON-CH1 & - & KF220507 & - & - \\
\hline & VITCIFE-KON-CH2 & - & KF220508 & - & - \\
\hline \multirow{2}{*}{ Índia, 12/08/2012 } & VITCIFE-KON-053 & KF574086 & - & - & - \\
\hline & VITCIFE-KON-052 & KF574085 & - & - & - \\
\hline Baía de Baguala, Província de Molucas, Indonésia, 5/12/1990 & $\begin{array}{l}\text { RMNH. CRUST. D. } \\
\quad 42963\end{array}$ & $\begin{array}{l}\text { KX060315 } \\
\text { KX060316 } \\
\text { KX060317 } \\
\text { KX060318 }\end{array}$ & $\begin{array}{l}\text { KX060500 } \\
\text { KX060501 } \\
\text { KX060502 } \\
\text { KX060503 }\end{array}$ & $\begin{array}{l}- \\
- \\
- \\
-\end{array}$ & $\begin{array}{c}1 \mathrm{M} \\
- \\
1 \mathrm{M} \\
-\end{array}$ \\
\hline Bengkulu, Sumatra, Indonésia, 11/1925 & USNM 1188774 & KX060293 & - & - & $1 \mathrm{M}$ \\
\hline Okinawa, Japão, 25/07/2004 & UF 7113 & KX060299 & KX060484 & - & $1 \mathrm{M}$ \\
\hline Singapura, 05/2013 & CCDB 4882 & $\begin{array}{l}\text { KX060304 } \\
\text { KX060305 } \\
\text { KX060306 } \\
\text { KX060307 }\end{array}$ & $\begin{array}{l}\text { KX060490 } \\
\text { KX060491 } \\
\text { KX060492 } \\
\text { KX060493 }\end{array}$ & $\begin{array}{l}- \\
- \\
- \\
-\end{array}$ & $\begin{array}{l}1 \mathrm{~F} \\
1 \mathrm{~F} \\
1 \mathrm{~F} \\
1 \mathrm{~F}\end{array}$ \\
\hline
\end{tabular}


Tabela 1. Continuação.

\begin{tabular}{|c|c|c|c|c|c|}
\hline Localidade e data de coleta & Coleção & COI & $\begin{array}{c}\text { GenBank } \\
16 S\end{array}$ & H3 & $\begin{array}{c}\text { Análises } \\
\text { Morfométricas }\end{array}$ \\
\hline \multirow[t]{3}{*}{ Rio Loboc, Bohol, Filipinas, 02/05/2005 } & UF 11430 & $\begin{array}{l}\text { KX060296 } \\
\text { KX060297 }\end{array}$ & $\begin{array}{l}\text { KX060481 } \\
\text { KX060482 }\end{array}$ & $\begin{array}{c}\mathrm{KX060389} \\
-\end{array}$ & $\begin{array}{l}1 \mathrm{M} \\
1 \mathrm{M}\end{array}$ \\
\hline & MNHN-B31559 & KX060326 & KX060514 & - & $1 \mathrm{~F}$ \\
\hline & MNHN-B31560 & - & KX060513 & - & $1 \mathrm{~F}$ \\
\hline \multirow{2}{*}{ Filipinas, 17/03/1976 } & MNHN-B31561 & KX060327 & KX060515 & - & $1 \mathrm{M}$ \\
\hline & MNHN-B7338 & - & KX060516 & - & $1 \mathrm{M}$ \\
\hline Pialba, Queensland, Austrália, 21/7/1990 & MV J20584 & KX060266 & - & - & - \\
\hline Burrum Heads, Queensland, Austrália, 06/1971 & MV J8998 & KX060260 & $\begin{array}{l}\text { KX060462 } \\
\text { KX060463 }\end{array}$ & $\begin{array}{l}\text { KX060376 } \\
\text { KX060377 }\end{array}$ & - \\
\hline Pialba, Queensland, Austrália, 07/1971 & MV J8999 & $\begin{array}{l}\text { KX060255 } \\
\text { KX060265 }\end{array}$ & $\begin{array}{l}- \\
-\end{array}$ & $\begin{array}{c}\mathrm{KX060385} \\
-\end{array}$ & $\begin{array}{l}- \\
-\end{array}$ \\
\hline Pialba, Queensland, Austrália, 20/07/1991 & MV J20579 & KX060259 & KX060461 & KX060375 & - \\
\hline Scarness, Baia Harvey, Queensland, Austrália, 09/1970 & MV J9256 & - & - & KX060378 & - \\
\hline Baía de Rowes, Rio Townsville, Queensland, Austrália, 27/03/1964 & AM P16580 & $\begin{array}{l}\text { KX060350 } \\
\text { KX060351 }\end{array}$ & $\begin{array}{l}\text { KX060541 } \\
\text { KX060542 }\end{array}$ & - & - \\
\hline Yule Point, Queesland, Austrália, 08/06/1999 & SMF 38899 & - & - & - & $1 \mathrm{~F}$ \\
\hline Fannie Beach, Darwin, Austrália, 05/07/2012 & UF 35870 & $\begin{array}{l}\text { KX060308 } \\
\text { KX060309 }\end{array}$ & $\begin{array}{l}\text { KX060494 } \\
\text { KX060495 }\end{array}$ & - & $\begin{array}{l}- \\
-\end{array}$ \\
\hline Port Jackson, New South Wales, Austrália, 07/05/1974 & AM P20150 & $\begin{array}{l}\text { KX060352 } \\
\text { KX060353 }\end{array}$ & $\begin{array}{l}\text { KX060543 } \\
\text { KX060544 }\end{array}$ & - & $\begin{array}{c}1 \mathrm{M} \\
-\end{array}$ \\
\hline Kimberley, Western Australia, 22/06/2008 & WAM C42913 & KX060354 & KX060545 & - & - \\
\hline Quandong - Coulomb Points, Kimberley, Western Australia, 16/06/2008 & WAM C42912 & KX060356 & KX060547 & - & - \\
\hline
\end{tabular}


Tabela 1. Continuação.

\begin{tabular}{|c|c|c|c|c|c|}
\hline \multirow{2}{*}{ Localidade e data de coleta } & \multirow{2}{*}{ Coleção } & \multicolumn{3}{|c|}{ GenBank } & \multirow{2}{*}{$\begin{array}{c}\text { Análises } \\
\text { Morfométricas }\end{array}$} \\
\hline & & COl & $16 S$ & H3 & \\
\hline South West Creek, Port Hedland, Western Australia, 07/07/2013 & WAM C55532 & KX060355 & KX060546 & - & - \\
\hline Apra Harbor, Baia de Sasa, Ilhas Mariana, Guam, 04/08/1998 & UF 2489 & KX060295 & KX060480 & - & $1 \mathrm{M}$ \\
\hline Apra Harbor, Baia de Sasa, Ilhas Mariana, Guam, 20/01/2000 & UF 217 & - & KX060489 & - & - \\
\hline Hong Kong, China, data de coleta não informada & CUHK & $\begin{array}{l}\text { KX060311 } \\
\text { KX060312 } \\
\text { KX060310 }\end{array}$ & $\begin{array}{l}\text { KX060496 } \\
\text { KX060497 }\end{array}$ & $\begin{array}{l}- \\
- \\
-\end{array}$ & $\begin{array}{l}- \\
- \\
-\end{array}$ \\
\hline Porto de To Lo, Hong Kong, China, 23/09/1986 & NHM 1986.851 & KX060342 & KX060532 & - & - \\
\hline Hong Kong, China, 15/04/2009 & $\begin{array}{l}\text { Coleção pessoal C.D. } \\
\text { Schubart }\end{array}$ & $\begin{array}{l}\text { KX060343 } \\
\text { KX060344 } \\
\text { KX060345 } \\
\text { KX060346 }\end{array}$ & $\begin{array}{l}\text { KX060533 } \\
\text { KX060534 } \\
\text { KX060535 } \\
\text { KX060536 }\end{array}$ & $\begin{array}{l}- \\
- \\
-\end{array}$ & $\begin{array}{l}- \\
- \\
-\end{array}$ \\
\hline & MNHN-B31557 & KX060322 & KX060508 & - & $1 \mathrm{M}$ \\
\hline Nova Caledônia, 29/04/1988 & MNHN-B31558 & KX060323 & KX060509 & - & $1 \mathrm{~F}$ \\
\hline & MNHN-IU-2014-10225 & $\begin{array}{c}\mathrm{KX} 060325 \\
- \\
-\end{array}$ & $\begin{array}{l}\text { KX060511 } \\
\text { KX060540 } \\
\text { KX060512 }\end{array}$ & $\begin{array}{l}- \\
- \\
-\end{array}$ & $\begin{array}{l}1 F \\
- \\
-\end{array}$ \\
\hline Nova Caledônia, 27/04/1988 & MNHN-IU-2014-10224 & KX060324 & KX060510 & - & $1 \mathrm{~F}$ \\
\hline Nova Caledônia, 22/06/2005 & MNHN IU 2014-10273 & KX060328 & KX060517 & - & - \\
\hline $\begin{array}{l}\text { Nova Caledônia, data de coleta não informada, lectótipo designado por } \\
\text { Apel \& Spirodonov (1998) }\end{array}$ & MNHN 732 & - & - & - & $1 \mathrm{M}$ \\
\hline Georgetown, Carolina do Sul, EUA, 07/06/2000 & USNM 251489 & KX060292 & - & - & $1 \mathrm{~F}$ \\
\hline
\end{tabular}


Tabela 1. Continuação.

\begin{tabular}{|c|c|c|c|c|c|}
\hline Localidade e data de coleta & Coleção & COI & $\begin{array}{c}\text { GenBank } \\
16 S\end{array}$ & H3 & $\begin{array}{c}\text { Análises } \\
\text { Morfométricas }\end{array}$ \\
\hline \multirow{2}{*}{ Monroe, Florida Keys, Long Keys, Flórida, EUA, 02/05 } & UF 26362 & KX060303 & KX060487 & - & $1 \mathrm{~F}$ \\
\hline & UF 26363 & KX060302 & KX060488 & KX060390 & $1 \mathrm{M}$ \\
\hline Flórida, EUA, 31/07/2006 & ULLZ 6920 & KX060254 & KX060457 & KX060374 & - \\
\hline \multirow[t]{2}{*}{ Palm Beach County, Flórida, 03/02/2013 } & UF 35646 & $\begin{array}{l}\text { KX060300 } \\
\text { KX060301 }\end{array}$ & $\begin{array}{l}\text { KX060485 } \\
\text { KX060486 }\end{array}$ & - & $1 \mathrm{M}$ \\
\hline & FTP 0219 & KP255147 & - & - & - \\
\hline \multirow[t]{2}{*}{ Indian River Lagoon, Flórida, USA, 19/05/2013 } & FTP 0220 & KP254538 & - & - & - \\
\hline & FTP 0071 & KP254353 & - & - & - \\
\hline Twin Cays, Belize, 20/02/2009 & ULLZ 11108 & $\begin{array}{l}\text { KX060347 } \\
\text { KX060348 }\end{array}$ & $\begin{array}{l}\text { KX060537 } \\
\text { KX060538 }\end{array}$ & - & - \\
\hline Twin Cays, Belize, 07/10/2002 & ULLZ 6455 & KX060349 & KX060539 & - & - \\
\hline Harbor Marine, Bocas del Toro, Panamá, 10/08/2011 & CCDB 3551 & $\begin{array}{l}\text { KX060257 } \\
\text { KX060256 } \\
\text { KX060258 }\end{array}$ & $\begin{array}{l}\text { KX060459 } \\
\text { KX060458 } \\
\text { KX060460 }\end{array}$ & $\begin{array}{c}- \\
\text { KX060384 } \\
-\end{array}$ & $\begin{array}{l}1 \mathrm{M} \\
1 \mathrm{~F} \\
-\end{array}$ \\
\hline \multirow[t]{2}{*}{ Saint Martin, Antilhas Francesas, 17/04/2012 } & UF 32327 & KX060294 & KX060479 & - & $1 \mathrm{M}$ \\
\hline & MNHN-IU-2013-6823 & - & KX060504 & - & $1 \mathrm{M}$ \\
\hline \multirow[t]{2}{*}{ Guadalupe, 02/05/2012 } & MNHN-IU-2013-6824 & KX060319 & KX060505 & - & $1 \mathrm{~F}$ \\
\hline & MNHN-IU-2014-10223 & KX060320 & KX060506 & - & $1 \mathrm{~F}$ \\
\hline Guadalupe, 28/05/2012 & MNHN-IU-2013-4917 & KX060321 & KX060507 & - & $1 \mathrm{~F}$ \\
\hline
\end{tabular}


Tabela 1. Continuação.

\begin{tabular}{|c|c|c|c|c|c|}
\hline Localidade e data de coleta & Coleção & COI & $\begin{array}{c}\text { GenBank } \\
16 S\end{array}$ & H3 & $\begin{array}{c}\text { Análises } \\
\text { Morfométricas }\end{array}$ \\
\hline Martinica, 09/01/2004 & SMF Não catalogado & $\begin{array}{l}\text { KX060333 } \\
\text { KX060334 } \\
\text { KX060337 }\end{array}$ & $\begin{array}{l}\text { KX060522 } \\
\text { KX060523 } \\
\text { KX060526 }\end{array}$ & $\begin{array}{l}- \\
- \\
-\end{array}$ & $\begin{array}{l}1 \mathrm{~F} \\
1 \mathrm{~F} \\
1 \mathrm{M}\end{array}$ \\
\hline Baía Canoe, Ilha Tobago, Trinidad \& Tobago, 03/02/2005 & UF 11258 & KX060298 & KX060483 & - & $1 \mathrm{M}$ \\
\hline \multirow[b]{2}{*}{ Venezuela } & ULLZ 4630 & - & DQ407665 & - & - \\
\hline & ULLZ 4631 & - & DQ407666 & - & - \\
\hline Isla de Cubagua, Nueva Esparta, Venezuela, 22/03/2012 & CCDB 4601 & KX060287 & KX060475 & - & $1 \mathrm{M}$ \\
\hline Isla Margarita, Venezuela, 31/08/2011 & CCDB 3859 & KX060252 & KX060455 & KX060373 & $1 \mathrm{M}$ \\
\hline Plage de Remiré, Guiana Francesa, 10/12/2001 & MZUSP 10271 & - & KX060478 & - & - \\
\hline Bragança, Pará, Brasil, 15/06/2011 & CCDB 3858 & KX060253 & KX060456 & - & $1 \mathrm{M}$ \\
\hline Praia do Farol do Trapiá, Camocim, Ceará, Brasil, 08/04/2012 & CCDB 4561 & KX060289 & KX060476 & - & $1 \mathrm{M}$ \\
\hline \multirow[t]{2}{*}{ Pontal do Maceió, Fortim, Ceará, Brasil, 27/09/2004 } & CCDB 4563 & KX060291 & - & - & $1 \mathrm{~F}$ \\
\hline & MOUFPE 150867 & KX060269 & KX060465 & KX060380 & - \\
\hline $\begin{array}{l}\text { Praia do Zumbi, Município de Rio do Fogo, Rio Grande do Norte, Brasil, } \\
\text { 24/11/2009 }\end{array}$ & MZUSP 22463 & $\begin{array}{l}\text { KX060283 } \\
\text { KX060284 } \\
\text { KX060285 } \\
\text { KX060286 }\end{array}$ & $\begin{array}{c}\text { KX060472 } \\
\text { KX060473 } \\
\text { KX060474 } \\
-\end{array}$ & $\begin{array}{c}\mathrm{KX} 060387 \\
- \\
\mathrm{KX} 060388 \\
-\end{array}$ & $\begin{array}{c}1 \mathrm{M} \\
1 \mathrm{M} \\
- \\
1 \mathrm{~F}\end{array}$ \\
\hline Rio Paripe, Itamaracá, Pernambuco, Brasil, 04/2009 & MOUFPE 14961 & KX060267 & KX060464 & KX060379 & - \\
\hline Ponta Verde, Maceió, Alagoas, Brasil, 09/08//2012 & CCDB 4562 & KX060290 & KX060477 & - & $1 \mathrm{M}$ \\
\hline
\end{tabular}


Tabela 1. Continuação.

\begin{tabular}{|c|c|c|c|c|c|}
\hline Localidade e data de coleta & Coleção & col & $\begin{array}{c}\text { GenBank } \\
16 S\end{array}$ & H3 & $\begin{array}{c}\text { Análises } \\
\text { Morfométricas }\end{array}$ \\
\hline Barra do Camaragibe, Alagoas, Brasil, 28/10/2011 & MZUSP 24839 & KX060281 & KX060470 & KX060386 & $1 \mathrm{M}$ \\
\hline Passo do Camaragibe, Alagoas, Brasil, 01/04/2010 & MZUSP 22351 & KX060282 & KX060471 & - & $1 \mathrm{M}$ \\
\hline Passo do Camaragibe, Alagoas, Brasil, 1998? & NHM 1998. 2678 & KX060341 & KX060531 & - & $1 \mathrm{~F}$ \\
\hline Caravelas, Bahia, Brasil, 28/08/2007 & MZUESC 961 & $\begin{array}{l}\text { KX060261 } \\
\text { KX060262 } \\
\text { KX060263 }\end{array}$ & $\begin{array}{c}\text { KX060452 } \\
- \\
-\end{array}$ & $\begin{array}{c}\mathrm{KX060370} \\
- \\
\mathrm{KX060371}\end{array}$ & $\begin{array}{l}- \\
- \\
-\end{array}$ \\
\hline & MZUESC 964 & $\begin{array}{l}\text { KX060250 } \\
\text { KX060251 }\end{array}$ & $\begin{array}{l}- \\
-\end{array}$ & - & - \\
\hline Bahia de Camamu, Bahia, Brasil, 25/03/2005 & MZUESC 687 & KX060264 & KX060453 & KX060372 & - \\
\hline Ilha do Frade, Vitória, Espírito Santo, Brasil, 21/06/2012 & CCDB 4040 & $\begin{array}{l}\text { KX060273 } \\
\text { KX060274 } \\
\text { KX060275 } \\
\text { KX060276 } \\
\text { KX060277 } \\
\text { KX060278 }\end{array}$ & $\begin{array}{c}\text { KX060466 } \\
\text { KX060467 } \\
- \\
- \\
- \\
\text { KX060468 }\end{array}$ & $\begin{array}{c}\text { KX060383 } \\
- \\
- \\
- \\
- \\
-\end{array}$ & $\begin{array}{c}1 \mathrm{M} \\
1 \mathrm{M} \\
1 \mathrm{M} \\
- \\
1 \mathrm{~F} \\
1 \mathrm{M}\end{array}$ \\
\hline Angra dos Reis, Rio de Janeiro, Brasil, 02/04/2011 & CCDB 473 & $\begin{array}{l}\text { KX060232 } \\
\text { KX060233 } \\
\text { KX060234 } \\
\text { KX060235 }\end{array}$ & $\begin{array}{c}\text { KX060442 } \\
\text { KX060443 } \\
- \\
\text { KX060444 }\end{array}$ & $\begin{array}{c}\mathrm{KX} 060363 \\
- \\
- \\
\mathrm{KX} 060364\end{array}$ & $\begin{array}{l}1 \mathrm{M} \\
1 \mathrm{M} \\
1 \mathrm{M} \\
1 \mathrm{~F}\end{array}$ \\
\hline Praia da Urca, Bahia de Guanabara, Rio de Janeiro, Brasil, 09/11/1995 & MNRJ 1586 & KX060271 & - & KX060382 & - \\
\hline Praia da Urca, Bahia de Guanabara, Rio de Janeiro, Brasil, 04/12/1995 & MNRJ 1587 & KX060270 & - & KX060381 & $1 \mathrm{~F}$ \\
\hline Bacia de Campos, Rio de Janeiro, Brasil, 14/12/2002 & MNRJ 18373 & KX060272 & - & - & $1 \mathrm{~F}$ \\
\hline São Paulo, Brasil, 1995 & CCDB 2038 & - & FJ152142 & - & - \\
\hline
\end{tabular}


Tabela 1. Continuação.

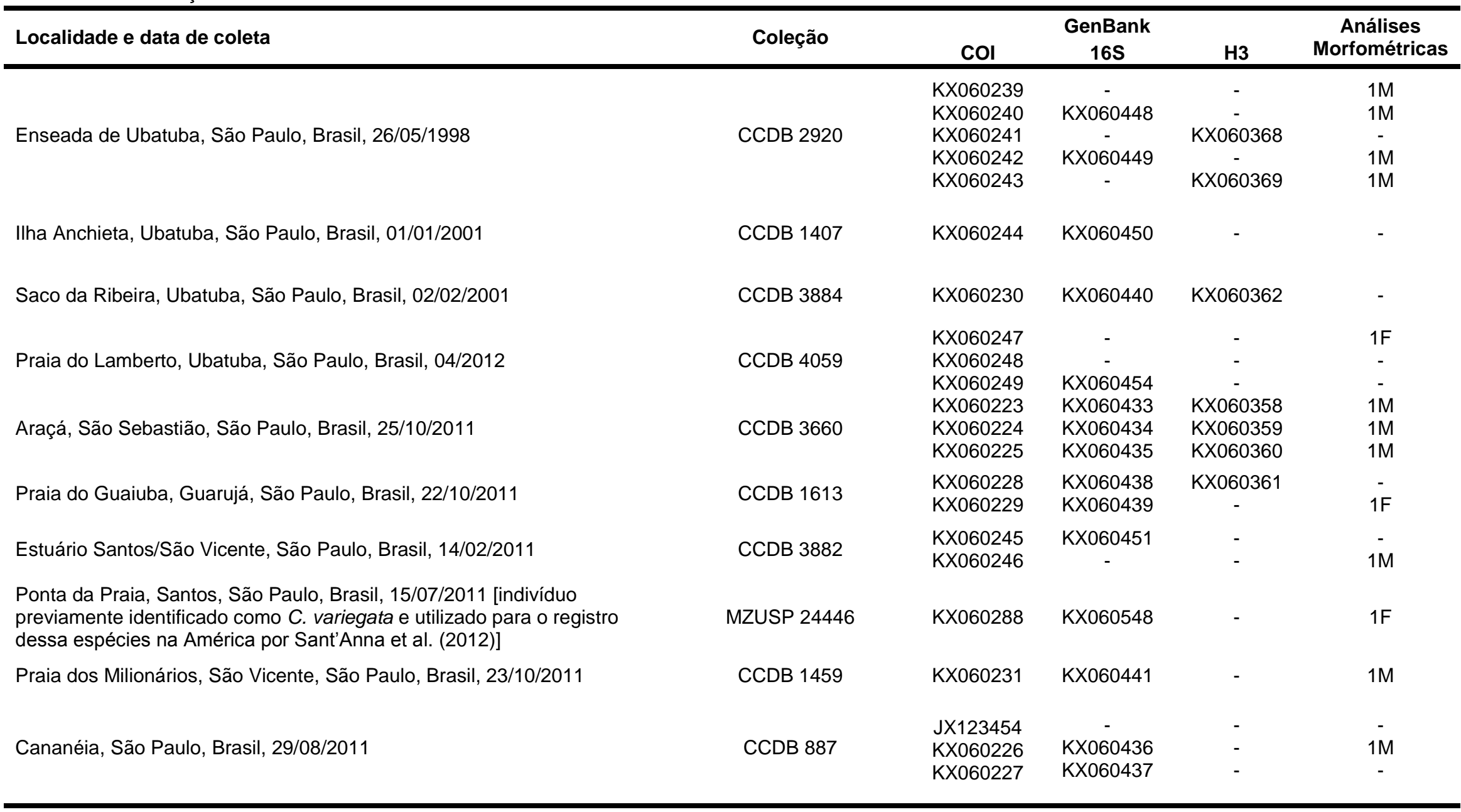


Tabela 1. Conclusão.

\begin{tabular}{|c|c|c|c|c|c|}
\hline \multirow{2}{*}{ Localidade e data de coleta } & \multirow{2}{*}{ Coleção } & \multicolumn{3}{|c|}{ GenBank } & \multirow{2}{*}{$\begin{array}{c}\text { Análises } \\
\text { Morfométricas }\end{array}$} \\
\hline & & Col & $16 S$ & H3 & \\
\hline Cabaraquara, Guaratuba, Paraná, Brasil, 29/09/2007 & MZUSP 20190 & $\begin{array}{l}\text { KX060279 } \\
\text { KX060280 }\end{array}$ & KX060469 & - & $1 \mathrm{M}$ \\
\hline Caieira da Barra, Florianópolis, Santa Catarina, Brasil, 01/04/1998 & CCDB 2909 & $\begin{array}{l}\text { KX060236 } \\
\text { KX060237 } \\
\text { KX060238 }\end{array}$ & $\begin{array}{l}\text { KX060445 } \\
\text { KX060446 } \\
\text { KX060447 }\end{array}$ & $\begin{array}{l}\text { KX060365 } \\
\text { KX060366 } \\
\text { KX060367 }\end{array}$ & $\begin{array}{c}1 \mathrm{M} \\
1 \mathrm{M} \\
-\end{array}$ \\
\hline Ribeirão da Ilha, Santa Catarina, Brasil, 15/07/2010 & SMF 40170 & $\begin{array}{l}\text { KX060335 } \\
\text { KX060336 }\end{array}$ & $\begin{array}{l}\text { KX060524 } \\
\text { KX060525 }\end{array}$ & - & $\begin{array}{l}1 \mathrm{~F} \\
1 \mathrm{M}\end{array}$ \\
\hline
\end{tabular}




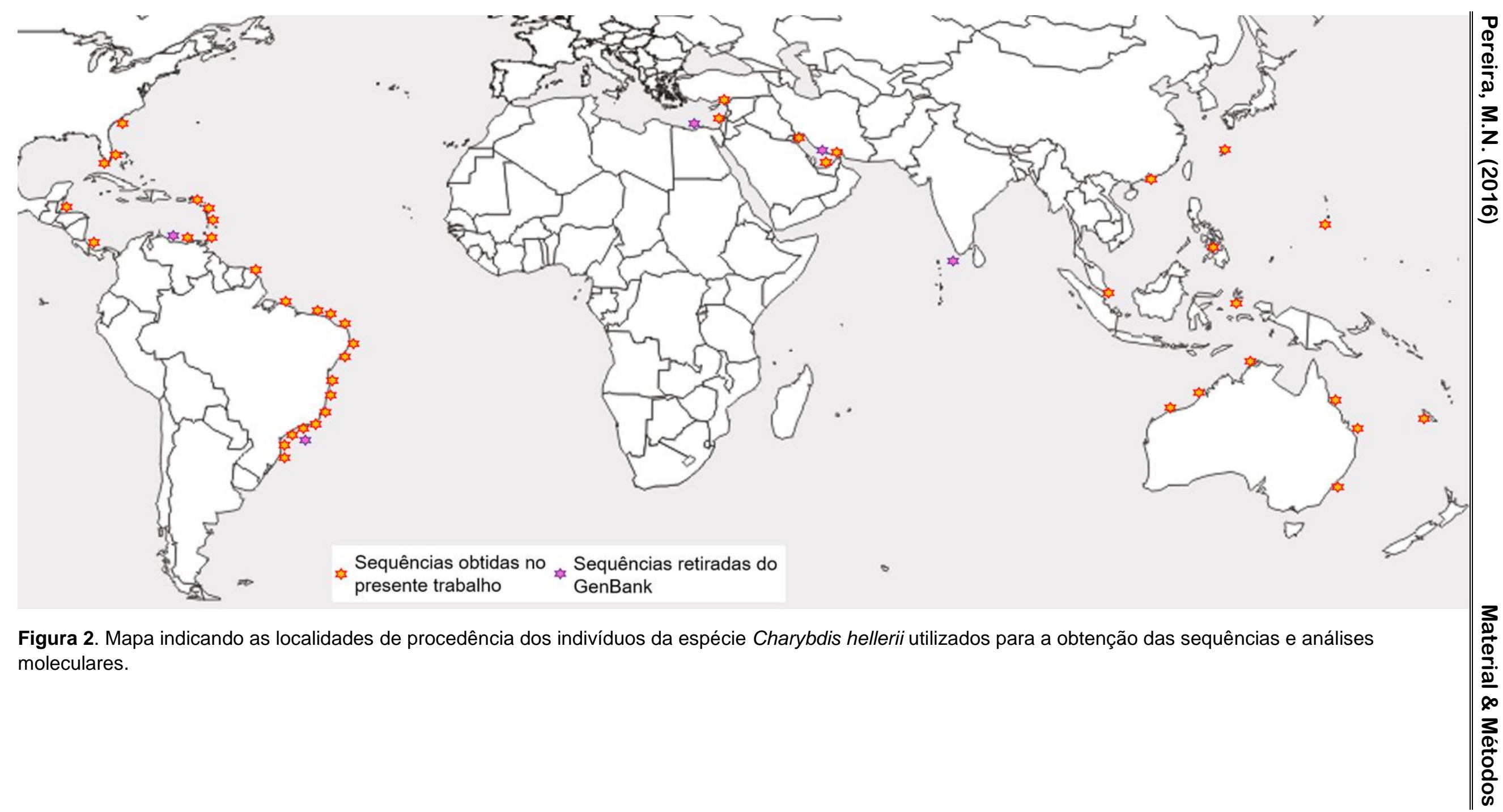


Tabela 2. Continua. Relação de espécimes do gênero Charybdis e Thalamita utilizados nas análises moleculares interespecíficas. AM: Australian Museum, Sydney, Austrália; MNHN: Museum National d'Histoire Naturelle, Paris, França; RMNH. CRUST.: Crustáceos do Rijksmuseum van Natuurlijke Historie, Naturalis Biodiversity Center, Leiden, Holanda; SMF: Senckenberg Museum, Frankfurt, Alemanha; UF: University of Florida, Gainesville, Florida, Estados Unidos da América; ULLZ: Zoological Collection of the University of Louisiana, Lafayette, Estados Unidos da América; ZMMU: Zoological Museum of Moscow University. Símbolos: -, Sequências não obtidas.

\begin{tabular}{|c|c|c|c|c|}
\hline \multirow{2}{*}{ Espécie } & \multirow{2}{*}{ Localidade e data de coleta } & \multirow{2}{*}{ Coleção } & \multicolumn{2}{|c|}{ GenBank } \\
\hline & & & COI & $16 S$ \\
\hline \multirow{3}{*}{ Charybdis sp. } & $\begin{array}{l}\text { Port Jackson, New South Wales, Austrália, } \\
24 / 02 / 2000\end{array}$ & AM P70244 & KX060197 & KX060412 \\
\hline & Localidade não informada, 25/10/1989 & MNHN-IU-2014-10236 & KX060413 & KX060198 \\
\hline & Localidade não informada, 25/10/1989 & MNHN-IU-2014-10236 & KX060414 & KX060199 \\
\hline Charybdis acuta (A. Milne-Edwards, 1869) & Ta-hsi Harbor, Taiwan, 11/03/2000 & UF 13466 & KX060203 & - \\
\hline \multirow{2}{*}{ Charybdis acutifrons (De Man, 1879) } & Naha harbor, Okinawa, Japão, 16/07/2010 & UF 27220 & KX060177 & - \\
\hline & Albatross Rock, Madagascar, 07/06/2010 & MNHN-IU-2014-10271 & KX060178 & KX060392 \\
\hline Charybdis amboinensis Leene, 1938 & Baía de Saint Vincent, Nova Caledônia, 18/10/1989 & MNHN-IU-2014-10234 & KX060208 & KX060427 \\
\hline \multirow{3}{*}{ Charybdis anisodon (De Haan, 1850) } & Naklua, Chonburi, Tailândia, 15-19/01/1993 & RMNH. CRUST. D. 42484 & KX060210 & KX060422 \\
\hline & Baía de Longoni, Mayotte, 08/11/2009 & MNHN-B32476 & KX060211 & - \\
\hline & Baía de Saint Vincent, Nova Caledônia, 25/04/1985 & MNHN-IU-2014-10274 & KX060209 & KX060423 \\
\hline \multirow{2}{*}{ Charybdis bimaculata (Miers, 1886) } & Porto Daxi Fish, Taiwan, 04/07/2011 & UF 29503 & KX060216 & KX060391 \\
\hline & Ta-hsi Harbor, Taiwan, 11/03/2000 & UF 13467 & KX060215 & - \\
\hline \multirow{2}{*}{ Charybdis annulata Fabricius, 1798} & Koh Larn, Chonburi, Tailândia, 12-24/01/1993 & RMNH. CRUST. D. 42498 & KX060206 & KX060415 \\
\hline & Ilhas Gloriosas, 08/12/2012 & MNHN-IU-2013-7313 & KX060207 & KX060416 \\
\hline \multirow{2}{*}{$\begin{array}{l}\text { Charybdis crosnieri cf. Spiridonov \& Türkay, } \\
2001\end{array}$} & Madagascar, 10/03/1968 & MNHN-IU-2014-10239 & KX060185 & KX060397 \\
\hline & Madagascar, 1990 & MNHN-B22406 & - & KX060398 \\
\hline \multirow[b]{2}{*}{ Charybdis erythrodactyla (Lamarck, 1818) } & Sem informações de localidade, 04/2008 & MNHN-IU-2014-10242 & KX060181 & KX060393 \\
\hline & $\begin{array}{l}\text { Atol Rangiroa, Aquipélogo Tuamotu, Polinésia } \\
\text { Francesa, 10/01/2001 }\end{array}$ & UF 1398 & KX060180 & - \\
\hline
\end{tabular}


Tabela 2. Continuação.

\begin{tabular}{|c|c|c|c|c|}
\hline \multirow{2}{*}{ Espécie } & \multirow{2}{*}{ Localidade e data de coleta } & \multirow{2}{*}{ Coleção } & \multicolumn{2}{|c|}{ GenBank } \\
\hline & & & col & $16 S$ \\
\hline \multirow{3}{*}{ Charybdis feriata (Linnaeus, 1758) } & Filipinas, 18/03/1976 & MNHN-IU-2014-10237 & - & KX060428 \\
\hline & Porto Daxi Fish, Taiwan, 04/07/2011 & UF 29464 & KX060192 & KX060430 \\
\hline & $\begin{array}{l}\text { Possivelmente de Taiwan ou proximidades da } \\
\text { China }\end{array}$ & UF 3739 & KX060193 & KX060429 \\
\hline Charybdis hongkongensis Shen, 1934 & $\begin{array}{l}\text { Ilha Koh Larn, Província Chonburi, Tailândia, } \\
\text { 30/01/1992 }\end{array}$ & RMNH. CRUST. D. 42072 & KX060217 & KX060408 \\
\hline \multirow{3}{*}{ Charybdis japonica (A. Milne-Edwards, 1861) } & Praia de Qingdao, China, 26/06/2010 & $\begin{array}{l}\text { Coleção pessoal C.D. } \\
\text { Schubart }\end{array}$ & KX060214 & - \\
\hline & Informações não fornecidas & não fornecida & EU586120 & EU586119 \\
\hline & Informações não fornecidas & não fornecida & HM237597 & HM237590 \\
\hline \multirow{3}{*}{ Charybdis longicollis Leene, 1938} & Palmachim, Israel, 03/06/2000 & RMNH. CRUST. D. 48620 & KX060194 & KX060410 \\
\hline & Sem informações & MNHN-IU-2014-10243 & KX060195 & KX060411 \\
\hline & Porto de Fort-Dauphin, Madagascar, 08/05/2010 & MNHN-IU-2010-6268 & KX060196 & KX060409 \\
\hline Charybdis lucifera (Fabricius, 1798) & Índia, 18/01/2013 & VITCIFE-KON-039 & KC928401 & - \\
\hline Charybdis meteor Spiridonov \& Türkay, 2001 & Mar Vermelho, Bab-el-Mandeb, 05/03/1987 & SMF 24064 & - & KX060426 \\
\hline \multirow{4}{*}{ Charybdis miles (De Haan, 1835) } & Papua Nova Guiné, 30/12/2012 & MNHN-IU-2013-633 & KX060183 & KX060394 \\
\hline & $\begin{array}{l}\text { Port Jackson, New South Wales, Austrália, } \\
24 / 02 / 2000\end{array}$ & AM P72216 & - & KX060396 \\
\hline & Filipinas, 26/03/1976 & MNHN-B7339 & KX060182 & KX060395 \\
\hline & Ta-hsi Harbor, Taiwan, 11/03/2000 & UF 3870 & KX060184 & - \\
\hline \multirow{3}{*}{ Charybdis natator (Herbest, 1794) } & Recife Ningaloo, Austrália, 14/05/2009 & UF 21403 & KX060204 & - \\
\hline & Tailândia, 08-09/1990 & RMNH. CRUST. D. 38723 & - & KX060424 \\
\hline & Ilha de Masirah, Omã, 11/1999 & MNHN-B27693 & KX060205 & KX060425 \\
\hline
\end{tabular}


Tabela 2. Continuação.

\begin{tabular}{|c|c|c|c|c|}
\hline \multirow{2}{*}{ Espécie } & \multirow{2}{*}{ Localidade e data de coleta } & \multirow{2}{*}{ Coleção } & \multicolumn{2}{|c|}{ GenBank } \\
\hline & & & $\mathrm{COI}$ & $16 S$ \\
\hline Charybdis obtusifrons Leene, 1937 & Ilha Moorea, Polinésia Francesa, 28/10/2008 & UF 16220 & KX060179 & - \\
\hline Charybdis orientalis Dana, 1852 & $\begin{array}{l}\text { Baía de Baguala, Ambon, Moluccas, Indonésia, } \\
\text { 05/12/1990 }\end{array}$ & RMNH. CRUST. D. 42960 & KX060212 & KX060420 \\
\hline \multirow[t]{2}{*}{ Charybdis rathbuni Leene, 1938} & Porto de Fort-Dauphin, Madagascar, 13/05/2010 & MNHN-IU-2010-3235 & KX060213 & KX060421 \\
\hline & Shikoku, Península Muroto, Japão, 27/03/1984 & RMNH. CRUST D. 50628 & KX060187 & KX060402 \\
\hline \multirow[t]{2}{*}{ Charybdis riversandersoni Alcock, 1899} & Filipinas, 25/11/1980 & MNHN-IU-2014-10238 & KX060189 & KX060401 \\
\hline & Ilha Paeowa, Papua Nova Guiné, 31/12/2012 & MNHN-IU-2013-15177 & KX060188 & KX060400 \\
\hline $\begin{array}{l}\text { Charybdis rufodactylus Stephenson \& Türkay, } \\
1968\end{array}$ & Nova Caledônia, 19/03/1994 & MNHN-B31576 & KX060186 & KX060399 \\
\hline Charybdis sagamiensis cf. Parisi, 1916 & Porto Daxi Fish, Taiwan, 04/07/2011 & UF 29482 & KX060190 & KX060403 \\
\hline Charybdis smithii MacLeay, 1838 & Ilha de Masirah, Omã, 11/1999 & MNHN-B27685 & KX060191 & KX060404 \\
\hline \multirow{2}{*}{ Charybdis truncata (Fabricius, 1798) } & Laem Chabang, Chomburi, Tailândia, 11/01/1991 & RMNH. CRUST. D. 38715 & KX060219 & KX060406 \\
\hline & Ilha Paeowa, Papua Nova Guiné, 21/11/2012 & MNHN-IU-2013-738 & KX060218 & KX060407 \\
\hline \multirow{2}{*}{ Charybdis vadorum Alcock, 1899} & Baía de Saint Vincent, Nova Caledônia, 25/4/1985 & MNHN-IU-2014-10274 & KX060220 & KX060405 \\
\hline & Informações não fornecidas & LRC03 & EU284141 & - \\
\hline \multirow{3}{*}{ Charybdis variegata (Fabricius, 1798) } & Madagascar, 25/05/2010 & MNH-IU-2010-7972 & KX060200 & KX060419 \\
\hline & Madagascar, 07/06/2010 & MNHN-IU-2010-3154 & KX060202 & KX060418 \\
\hline & Porto de Ehoala, Madagascar, 16/05/2010 & MNHN-IU-2014-10272 & KX060201 & KX060417 \\
\hline
\end{tabular}

$B$ 
Tabela 2. Conclusão

\begin{tabular}{|c|c|c|c|c|}
\hline \multirow{2}{*}{ Espécie } & \multirow{2}{*}{ Localidade e data de coleta } & \multirow{2}{*}{ Coleção } & \multicolumn{2}{|c|}{ GenBank } \\
\hline & & & COI & $16 S$ \\
\hline \multirow{2}{*}{ Thalamita admete (Herbst, 1803) } & Polinésia Francesa & 2Flb8f21 & JQ180244 & - \\
\hline & África do Sul, 2001 & ULLZ 4382 & - & FJ152163 \\
\hline \multirow{2}{*}{ Thalamita crenata Rüppell, 1830} & Informações não fornecidas & ZMMU:Ma 3343 & JX398104 & - \\
\hline & Oahu, Havaí, 2003 & ULLZ 8664 & - & FJ152164 \\
\hline Thalamita danae Stimpson, 1858 & Labrador, Canadá, 1999 & ULLZ:4760 & - & FJ152165 \\
\hline Thalamita prymna (Herbst, 1803) & Informações não fornecidas & ZMMU:Ma 3346 & JX398103 & - \\
\hline \multirow{2}{*}{ Thalamita sima H. Milne Edwards, 1834} & Informações não fornecidas & ZMMU:Ma 3373 & JX398105 & - \\
\hline & Austrália & ULLZ:4761 & - & FJ152166 \\
\hline
\end{tabular}




\subsubsection{Extração do DNA}

Foram eleitos de cada lote, sempre que possível, os espécimes de maior tamanho e adultos, para que não houvesse dúvidas quanto à identificação. Primeiramente, o DNA genômico foi extraído do tecido muscular dos quelípodos ou pereiópodos dos exemplares selecionados. Em seguida, dois métodos distintos para obtenção do material genômico foram empregados no LBSC, a extração salina ou extração utilizando Chelex ${ }^{\circledR} 100$ - Molecular Biology Grade Resin. O segundo foi utilizado para amostras cuja quantidade de tecido obtida foi bastante reduzida.

Para o primeiro tipo, o tecido retirado foi inicialmente incubado por $48 \mathrm{~h}$ em 600 $\mu \mathrm{l}$ de tampão de lise a $65^{\circ} \mathrm{C}$ adicionado de $200 \mu \mathrm{l}$ de proteinase $\mathrm{K}(500 \mu \mathrm{g} / \mathrm{ml})$. Em seguida, o tecido remanescente foi macerado quando necessário e as proteínas foram separadas e removidas pela adição de $200 \mu \mathrm{l}$ acetato de amônio (7,5 M) seguida por centrifugação $\left(14000 \mathrm{rpm}\right.$ a $\left.18^{\circ} \mathrm{C}\right)$ por $10 \mathrm{~min}$. Posteriormente, o DNA foi precipitado pela adição de $600 \mu \mathrm{l}$ isopropanol resfriado $\left(-20^{\circ} \mathrm{C}\right)$ seguido de centrifugação (14000 rpm a $\left.18^{\circ} \mathrm{C}\right)$ por 10 min e armazenado em baixa temperatura $\left(-20^{\circ} \mathrm{C}\right)$. Por fim, após no mínimo 24 h de descanso, o resíduo (pellet de DNA) resultante foi lavado com etanol $70 \%$, liofilizado e ressuspendido em $20 \mu$ tampão TE.

Para o segundo tipo, uma suspensão de $5 \%$ de Chelex $^{\circledR}$ foi adicionada ao tecido removido, assim como $10 \mu \mathrm{l}$ de proteinase $\mathrm{K}(20 \mathrm{mM})$. Em seguida, a extração foi incubada por $12 \mathrm{~h}$ a $55^{\circ} \mathrm{C}$. Terminado este período e a fim de cessar a atividade da proteinase $\mathrm{K}$, a temperatura foi elevada a $95^{\circ} \mathrm{C}$ por $3 \mathrm{~min}$. Posteriormente, depois de uma centrifugação por 3 min a 14.000 rpm, todo o sobrenadante contento o DNA foi transferido para outro tubo. Finalizados ambos os métodos de extração, a concentração e a qualidade do DNA extraído foram analisados por espectrofotometria no NanoDrop $1000^{\circledR}$. Esse procedimento permitiu adequar a concentração do DNA extraído à concentração necessária para a realização da amplificação dos genes de interesse pela técnica de PCR (Polymerase Chain Reaction) (Sambrook et al., 1989). 
Parte das sequências foram obtidas durante período de estágio (Doutorado Sanduiche) na Universidade de Regensburg (Alemanha), onde os procedimentos para extração de DNA foram feitos de acordo com o protocolo local. O DNA genômico total foi extraído de amostras de tecido por meio do Puregene (Qiagen) buffer system. Para isso, primeiramente, o tecido foi colocado em $200 \mu \mathrm{l}$ de solução de lise com $1 \mu \mathrm{l}$ de proteinase $\mathrm{K}$ e incubado overnight a $55^{\circ} \mathrm{C}$. Em seguida, o tecido remanescente foi macerado e incubado a $55^{\circ} \mathrm{C}$ por mais $2 \mathrm{~h}$. Para a separação e remoção das proteínas, $68 \mu \mathrm{l}$ de Protein Precipitation Solution ( 8M acetato de amônio) foram adicionados e seguidos por centrifugação a $14.000 \mathrm{rpm}$ por $10 \mathrm{~min}$. O sobrenadante foi, então, removido e colocado em novos tubos com $540 \mu \mathrm{l}$ de estanol 100\%. Estes tubos foram invertidos pelo menos vinte vezes, centrifugados a $14.000 \mathrm{rpm}$ por $10 \mathrm{~min}$ e novamente estocados overnight a $-70^{\circ} \mathrm{C}$ para a decantação do DNA. No próximo dia, depois uma centrifugação (14.000 rpm, $10 \mathrm{~min}$ ), o etanol 100\% foi cuidadosamente removido, o pellet de DNA foi lavado em $100 \mu \mathrm{l}$ de etanol $70 \%$, novamente centrifugado (14.000 rpm) por 5 min e, após a remoção do etanol 70\%, o pellet de DNA foi mantido na capela por $2 \mathrm{~h}$ para secagem. Finalmente, os pellets secos de DNA foram ressuspendidos em $20 \mu \mathrm{l}$ de TE buffer e uma quantidade de $2 \mu \mathrm{l}$ de cada extração foi analisada por eletroforese em gel de agarose $1 \%$ para visualmente estipular e adequar as concentrações de DNA para a amplificação.

\subsubsection{Amplificação dos genes}

A região de interesse do gene foi amplificada por meio da técnica de PCR (polimerase chain reaction) (Sambrook et al., 1989). No LBSC, esta foi realizada em um termociclador da Applied Biosystems modelo Veriti ${ }^{\circledR}$ 96-Well e na Universidade de Regensburg, em um termociclador Life ECO ${ }^{\mathrm{TM}}$ Gradient Thermal Cycler.

Os produtos da PCR foram obtidos em uma reação de volume total de $25 \mu \mathrm{l}$ tanto nos procedimentos realizados no LBSC como na Universidade de Regensburg. 
As reações conduzidas no LBSC contiveram: $2 \mu$ de albumina bovina 1\% (Sigma); $3 \mu \mathrm{l}$ de 10X Taq Buffer (Thermo Scientific); $3 \mu \mathrm{l}$ de $\mathrm{MgCl}_{2}(25 \mathrm{mM}) ; 5 \mu \mathrm{l}$ de betaina $(5 \mathrm{M})$ (Acrós Organics); $5 \mu \mathrm{l}$ de água destilada e deionizada; $4 \mu \mathrm{l}$ de DNTPs $(5 \mathrm{mM}) ; 1 \mu \mathrm{l}$ de cada primer (10 ou $20 \mu \mathrm{M})$; Thermus aquaticus polimerase (5 $\mathrm{U} / \mu \mathrm{l})$ (Thermo Scientific) e $1 \mu \mathrm{l}$ do DNA previamente extraído (50 - $100 \mathrm{ng} / \mathrm{ml})$. As reações conduzidas na Universidade de Regensburg continham: $0,3 \mu \mathrm{l}$ de cada primer $(20 \mu \mathrm{M}) ; 2 \mu \mathrm{l}$ de $\mathrm{MgCl}_{2}$ (25 mM); 2,4 $\mu \mathrm{l}$ de DNTPs $(1,25 \mathrm{mM}) ; 5 \mu \mathrm{l}$ de $2 \mathrm{X}$ Green GoTaq ${ }^{\circledR}$ Reaction Buffer (Promega); $1 \mu \mathrm{L}$ de Thermus aquaticus (Taq) GoTaq ${ }^{\circledR}$ Hot Start Polymerase $(0,5 \mu \mathrm{M})$ (Promega); $13 \mu$ l de água destilada e deionizada e $1 \mu$ l do DNA previamente extraído.

Os ciclos termais empregados foram os seguintes: COI e 16S rDNA desnaturação inicial por 4 min a $94^{\circ} \mathrm{C}$; anelamento por 40 ciclos ( $45 \mathrm{~s}$ a $94^{\circ} \mathrm{C}$; $60 \mathrm{~s}$ a $48-58^{\circ} \mathrm{C}$ e 90 s a $72^{\circ} \mathrm{C}$ ); extensão final por 5 min a $72^{\circ} \mathrm{C}$; H3 - desnaturação inicial por 4 min a $94^{\circ} \mathrm{C}$; anelamento por 40 ciclos ( $45 \mathrm{~s}$ a $94^{\circ} \mathrm{C}$; $45 \mathrm{~s}$ a $48^{\circ} \mathrm{C}$ e $60 \mathrm{~s}$ a $72^{\circ} \mathrm{C}$ ); extensão final por 5 min a $72^{\circ} \mathrm{C}$. As temperaturas de melting variaram de acordo com o par de primers utilizado (Tabela 2). Foram desenhados e sintetizados dois pares de primers específicos e inéditos para a amplificação do gene $\mathrm{COI}$ em $C$. hellerii, facilitando a amplificação e possibilitando a obtenção de sequências a partir de espécimes mais antigos. Estes foram denominados como: COILCH1/COIHCH1 e COILCH2/ COIHCH2.

Os resultados da PCR foram analisados por meio de eletroforese em gel de agarose $1-1,4 \%$ e fotografados em câmera digital C-7070 Olimpus $^{\circledR}$ em um transiluminador UV M20 UVP ${ }^{\circledR}$ (LBSC) utilizando os marcadores GelRed e Loading ou por meio do sistema de documentação de gel Alphalmager HP (Universidade de Regensburg). 
Tabela 3. Primers utilizados na amplificação dos genes de interesse por meio da técnica de PCR (Polymerase Chain Reaction).

\begin{tabular}{|c|c|c|c|}
\hline Gene & Primer & Sequência & Referência \\
\hline \multirow{4}{*}{ COI } & $\begin{array}{l}\text { LCO-1490 } \\
\text { HCO-2198 }\end{array}$ & $\begin{array}{l}\text { 5'-GGTCAACAAATCATAAAGATATTG-3' } \\
\text { 5'-TAAACTTCAGGGTGACCAAAAAATCA-3' }\end{array}$ & \multirow{2}{*}{$\begin{array}{l}\text { Folmer et al., } 1994 \\
\text { Reuschel and } \\
\text { Schubart, 2006 }\end{array}$} \\
\hline & $\mathrm{COH} 3$ & 5'-AATCARTGDGCAATWCCRSCRAAAAT-3' & \\
\hline & $\begin{array}{l}\mathrm{COILCH} 1 \\
\mathrm{COIHCH} 1\end{array}$ & $\begin{array}{l}\text { 5'-TCGAGCAGAATTAGGTCAACCAG-3' } \\
\text { 5'-GYTAAAGAACGGGGTCRCCTC-3' }\end{array}$ & Presente estudo \\
\hline & $\begin{array}{l}\text { COILCH2 } \\
\text { COIHCH2 }\end{array}$ & $\begin{array}{l}\text { 5'-CCAGACACTTTATTTTTTGGAGCTTG-3' } \\
\text { 5'-ATGTTGGTAGAGGACGGGGT-3' }\end{array}$ & Presente estudo \\
\hline \multirow{3}{*}{$\begin{array}{l}\text { 16S } \\
\text { rDNA }\end{array}$} & $\begin{array}{ll}16 \mathrm{H} 9 \\
16 \mathrm{~L} 9\end{array}$ & $\begin{array}{l}\text { 5'-CCGGTCTGAACTCAGATCAC-3' } \\
\text { 5'-CGCCTGTTTATCAAAAACAT-3' }\end{array}$ & $\begin{array}{l}\text { Schubart \& Huber, } \\
2006\end{array}$ \\
\hline & $16 \mathrm{HLeu}$ & $\begin{array}{l}\text { NADH1 para 16S; 5'-CATATTATCTG } \\
\text { CCAAAATAG-3' }\end{array}$ & \multirow{2}{*}{$\begin{array}{l}\text { Schubart, } 2009 \\
\text { Schubart et al., } 2001\end{array}$} \\
\hline & $16 \mathrm{~L} 2$ & $\begin{array}{l}\text { 16S para NADH1; 5'-YGCCTGTTTATCAA } \\
\text { AAACAT-3' }\end{array}$ & \\
\hline \multirow[b]{2}{*}{ H3 } & H3af & 5'-ATGGCTCGTACCAAGCAGACVGC-3' & \multirow[b]{2}{*}{ Colgan et al., 1998} \\
\hline & H3ar & 5'-ATATCCTTRGGCATRATRGTGAC-3' & \\
\hline
\end{tabular}

As reações positivas de PCR obtidas na Universidade de Regensburg foram enviadas para a Macrogen Europe para a condução dos procedimentos necessários para a obtenção das sequências, ou seja, para a realização das etapas de purificação, PCR de sequenciamento, precipitação e sequenciamento. Uma vez no LBSC, os resultados da PCR foram purificados e só então, enviados para os demais procedimentos de sequenciamento no Centro de Recursos Biológicos e Biologia Genômica do Departamento de Tecnologia da Faculdade de Ciências Agrárias e Veterinárias de Jaboticabal (FCAV) da Universidade Estadual Paulista "Júlio de Mesquita Filho".

\subsubsection{Purificação e amplificação dos produtos da PCR}

A purificação dos produtos da PCR foi efetuada utilizando-se o kit SureClean Plus $^{\circledR}$ (Bioline USA Inc.), seguindo o protocolo da empresa. Aos produtos da PCR foram inicialmente adicionados $20 \mu \mathrm{l}$ do kit de purificação SureClean ${ }^{\circledR}$, agitados no vórtex e incubados à temperatura ambiente por $20 \mathrm{~min}$. Foi feita uma etapa de 
centrifugação a 14.000 rpm por 30 min, remoção do sobrenadante e adição de $40 \mu \mathrm{l}$ de etanol 70\%. Em seguida foi feita mais uma etapa de centrifugação a 14.000 rpm por 30 min, remoção do sobrenadante e secagem no Concentrator 5301 Eppendorf $^{\circledR}$. Após secagem, os pellets foram ressuspendidos em $42 \mu$ de água ultrapura, mantidos no banho seco por $30 \mathrm{~min}$ e descansando overnight a temperatura ambiente. Finalmente, a concentração foi mensurada no Thermo NanoDrop $2000^{\circledR}$.

A purificação foi seguida por uma nova etapa de amplificação, utilizando 50 ng de produto de PCR purificado, $3 \mathrm{ml}$ de tampão de sequenciamento (Save money 2,5X), 1,0 ml de BigDye ${ }^{\circledR}$ Terminator Cycle Sequencing versão 3.1 (Applied Biosystems), $10 \mathrm{pM}$ de primer e quantidade de água bidestilada estéril que completasse $10 \mathrm{ml}$. O ciclo termal utilizado consistiu no seguinte: desnaturação inicial de $96^{\circ} \mathrm{C}$ por 1 min, seguida de 39 ciclos. Cada ciclo consistiu em: desnaturação a $96^{\circ} \mathrm{C}$ por $15 \mathrm{~s}$; anelamento dos primers com temperatura variável de 48 a $58^{\circ} \mathrm{C}$ de acordo com o primer utilizado por $15 \mathrm{~s}$ e polimerização a $60^{\circ} \mathrm{C}$ por $4 \mathrm{~min}$. Ao final, as amostras foram mantidas a $4^{\circ} \mathrm{C}$.

\subsubsection{Precipitação e sequenciamento do DNA}

A precipitação do produto dessa nova amplificação foi feita pela adição de $80 \mu \mathrm{l}$ de isopropanol $75 \%$ a cada reação, seguida de leve agitação no vórtex e incubação por 15 min a temperatura ambiente. Após centrifugação a $3040 \mathrm{~g}$ a $20^{\circ} \mathrm{C}$ em centrífuga de placas Rotanta 46R (Hettich) com rotor para microplacas, por $30 \mathrm{~min}$, o sobrenadante foi descartado e as amostras foram lavadas duas vezes com $200 \mathrm{ml}$ de etanol $70 \%$, seguido de centrifugação a $3040 \mathrm{~g}$ a $20^{\circ} \mathrm{C}$ por $10 \mathrm{~min}$, na mesma centrífuga. Por fim, as amostras foram secas a vácuo, ressuspendidas em $10 \mathrm{ml}$ de formamida, desnaturadas por $5 \min$ a $95^{\circ} \mathrm{C}$ e submetidas ao sequenciamento no sequenciador automático ABI 3730 XL DNA Analyzer (Applied Biosystems) conforme recomendações sugeridas pelo fabricante. 


\subsubsection{Edição das sequências de DNA}

As duas fitas complementares (senso e anti-senso) foram sequenciadas para todas as amostras e genes, aumentando, assim, a confiabilidade das sequências obtidas. A edição e a construção do consenso dessas sequências complementares foram realizadas por meio do programa computacional BioEdit v.7.0.5 (Hall, 2005). Em seguida, as sequências de DNA consenso foram submetidas ao alinhamento no BLAST ("Basic Local Alignment Search Tool”) para comparação com a assembleia do banco de dados NCBI (http://blast.ncbi.ncbi.nlm.nih.gov/blast.cgi) e confirmação de sua identidade. Adicionalmente, a inexistência de códons de terminação foi visualmente checada para cada sequência por meio da tradução realizada na plataforma online ExPASy: SIB Bioinformatics Resource Portal (http://www.expasy.org/). Este procedimento foi adotado a fim de verificar a possibilidade de que tenham sido obtidas sequências de pseudogenes.

Todos os testemunhos genéticos, a partir dos quais foram obtidos amostras de tecido e sequências para as análises, estão depositados na CCDB/LBSC/FFCLRP/USP ou na respectiva coleção de origem.

\subsection{Análises moleculares}

Após a edição das sequências nucleotídicas, elas foram alinhadas separadamente para cada gene no software MUSCLE (Multiple Sequence Comparison by Log- Expectation) (Edgar, 2004a; 2004b) por meio da plataforma online do EMBLEBI (European Molecular Biology Laboratory - The European Bioinformatics Institute) (Goujon et al., 2010; McWilliam et al., 2013; Li et al., 2015) utilizando os parâmetros padrões pré-definidos. 


\subsubsection{Análises de distância genética}

As distâncias genéticas foram calculadas no programa Mega 6.06 por meio do modelo de substituição Kimura 2-parâmetros. Todas as posições nucleotídicas foram comparadas diretamente para cada par de sequências separadamente para cada gene (Hall, 2008), utilizando tanto as sequências de $C$. hellerii (Tabela 1) como as obtidas a partir dos indivíduos das demais espécies do gênero (Tabela 2). Um total de 144 sequências de COI e 121 de $16 \mathrm{~S}$ rDNA de $C$. hellerii foram comparadas entre si e com sequências obtidas para cada uma das espécies congêneres (uma de cada espécie), as quais também foram comparadas entre si. Dessa forma, com base nesses marcadores, foi possível avaliar a variação intraespecífica de $C$. hellerii e interespecífica para o gênero Charybdis. Após o cálculo das distâncias genéticas par a par, histogramas representando as frequências de pares por intervalo de distância genética foram construídos no programa Microsoft Excel 2010. Para o gene nuclear H3, foram comparadas 33 sequências obtidas apenas a partir de exemplares de $C$. hellerii.

\subsubsection{Análises filogenéticas}

Primeiramente, para testar a validade taxonômica da espécie $C$. hellerii, esta foi analisada em um contexto taxonômico mais amplo e incluindo todas as sequências de COI e 16S rDNA obtidas a partir de exemplares de espécies congêneres (Tabela 2), bem como sequência retiradas do GenBank do gênero Thalamita (Tabela 2), o qual consiste em outro gênero da subfamília Thalamitinae. Para tanto, as sequências de H3 não foram utilizadas, pois foram obtidas apenas para espécimes de $C$. hellerii.

As sequências de COI e 16S rDNA foram concatenadas, sendo que a matriz final foi constituída de 1225 pares de base. Para os indivíduos de C. hellerii foram utilizadas uma única sequência de cada haplótipo identificado nas análises 
populacionais tanto para COI quanto para 16S rDNA (ver abaixo) e foram utilizadas todas as sequências obtidas para as demais espécies, independentemente se estas foram obtidas para ambos os genes ou não. Os filogramas foram construídos por inferência Bayesiana (Huelsenbeck \& Ronquist, 2001) e Máxima Verossimilhança (Felsenstein, 1973; 1981) utilizando as seguintes sequências como grupo externo: Achelous spinicarpus Stimpson, 1871 (acesso GenBank: COI - KX060221; 16S rDNA - KX060431), Arenaeus cribrarius (Lamarck, 1818) (acesso GenBank: COI JX123445; 16S rDNA - JX123469), Arenaeus mexicanus (Gerstaecker, 1856) (acesso GenBank: COI - JX123450; 16S rDNA - JX123449) e Callinectes exasperatus (Gerstaecker, 1856) (acesso GenBank: COI - KX060222; 16S rDNA - KX060432).

A inferência Bayesiana foi conduzida no programa MrBayes v3.2.2 (Ronquist et al., 2012), com cada gene como partição distinta, assim como cada posição do códon no gene codificante COI, totalizando quatro partições. Os modelos de substituição de nucleotídeos foram selecionados dentre os modelos disponíveis no jModelTest v.2.1.6 (Darriba et al., 2012) pelo Critério de Informação Bayesiano (BIC). Para o gene COI, foi utilizado o modelo $H K Y+I+G$ (frequência de $A=0,3947$; frequência de $C=0,844$; frequência de $G=0,1600$; frequência de $T=0,3609$; proporção de sítios invariáveis = 0,5870; distribuição gama $=0,6160)$. Para o gene $16 \mathrm{~S}$ rDNA, o mesmo modelo $(\mathrm{HKY}+\mathrm{I}+\mathrm{G}$ ) foi selecionado (frequência de $A=0,3845$; frequência de $C=0,0784$; frequência de $G=0,1428$; frequência de $T=0,3943$; proporção de sítios invariáveis = 0,4530; distribuição gama $=0,3960$ ). A análise foi feita com $2 \times 10^{8}$ gerações, frequência de amostragem igual a 500, quatro cadeias de aquecimento (três aquecidas e uma fria), a análise foi concluída se atingida a estacionaridade (desvio padrão médio entre as duas simulações menor que 0,01 ) após o número de gerações estipulado. Posteriormente, os dados obtidos foram coletados da fase estacionária da cadeia e os estados iniciais descartados (burnin $=10 \%$ ). Os níveis de suporte de 
ramos foram calculados pelo método de probabilidade a posteriori. A árvore gerada foi editada no programa FigTree v.1.3.1 (Rambaut, 2009).

A construção do filograma pelo método de Máxima Verossimilhança foi conduzida no programa RAxML v.7.0.4 ("Randomized Axelerated Maximum Likelihood") (Stamatakis, 2006) através da plataforma online CIPRES (“Cyberinfrastructure for Phylogenetic Research") (Stamatakis et al., 2008; Miller et al., 2010). Esse critério de otimização, com base em um modelo de evolução nucleotídica, busca pela árvore mais provável que reflete os dados analisados (Hall, 2008) e seguiu o modelo de evolução previamente detectado.

Para medir a consistência da topologia, a opção para determinar o número adequado de réplicas de bootstrap (Felsenstein, 1985) foi selecionada. Apenas os valores acima de $50 \%$ foram reportados. Como grupo externo foram utilizados os mesmos táxons da inferência bayesiana.

Essa análise foi conduzida para diferentes configurações: (1) apenas com sequências de COI em uma e três partições; (2) apenas com sequências de 16S; (3) sequências dos dois genes concatenadas em uma única partição; (4) sequências dos dois genes concatenadas em duas partições, uma para cada gene; (5) sequências dos dois genes concatenadas com quatro partições, onde cada posição dos códons COI foi tratada como uma posição. Além disso, embora saturação significativa não tenha sido constatada para ambos os genes por meio do teste de saturação de Xia et al. (2003) implementado no software DAMBE, o alinhamento concatenado foi submetido à análise no software Gblocks (Castresana, 2000; Talavera \& Castresana, 2007) implementado online pelo Castresana Lab, Animal Biodiversity and Evolution Program (http://molevol.cmima.csic.es/castresana/index.html) para a remoção de regiões muito variáveis.

Análises intraespecíficas pelo critério de Máxima Verossimilhança também foram conduzidas considerando apenas as sequências de $C$. hellerii obtidas. Isso foi 
feito separadamente para cada gene (16S rDNA e COI) de duas formas, uma incluindo apenas as sequências de sua área de ocorrência nativa + mar Mediterrâneo e outra considerando exemplares ao longo de toda sua distribuição. Sequências de três espécies congêneres compuseram o outgroup: Charybdis annulata (acesso GenBank: COI - KX060207; 16S rDNA - KX060416), Charybdis longicollis (acesso GenBank: COI - KX060196; 16S rDNA - KX060196) e Charybdis natator (acesso GenBank: COI - KX060205; 16S rDNA - KX060425).

\subsubsection{Análises populacionais}

Todas as análises intraespecíficas de C. hellerii, inclusive os filogramas construídos por Máxima Verossimilhança anteriormente descritos, foram feitas primariamente incluindo apenas as sequências de indivíduos provenientes de populações nativas e do mar Mediterrâneo, ou seja, as potenciais áreas de origem da população americana. Em seguida, incluindo os espécimes provenientes de toda a sua distribuição, ou seja, incluindo as localidades nativas, as do mar Mediterrâneo e as da América. Este procedimento em duas etapas visou que, inicialmente, fosse feita uma análise das áreas nativas, possibilitando a detecção de estruturação genética nessas regiões, para que, em seguida, com a inclusão dos espécimes da América, fosse possível analisar os aspectos relacionados ao processo de introdução propriamente ditos, como a identificação das potenciais populações que contribuíram para a introdução (Wares et al., 2005).

\subsubsection{Estatística descritiva}

O número de haplótipos (h), sítios polimórficos (S), diversidade haplotípica $(\mathrm{Hd})$, diversidade nucleotídica $(\pi)$ e número médio de diferenças nucleotídicas $(\mathrm{K})$ foram calculados no software DnaSP v.4.10.9 (Rozas \& Rozas, 1999). Tais valores 
foram obtidos tanto para cada localidade amostrada, como para os grupos identificados pelos métodos descritos abaixo (rede de haplótipos, BAPS e AMOVA). Para a detecção de indícios de gargalo genético, é essencial que as populações não nativas sejam comparadas com aquelas das quais elas derivam (Dlugosch \& Parker, 2008).

\subsubsection{Redes de haplótipos}

As redes de haplótipos foram construídas pelo método de parcimônia estatística (com 95\% de nível de confiança) no programa TCS v.1.21 (Clement et al., 2000). Como resultado é gerada uma rede, na qual os haplótipos são conectados por um ao outro por um passo mutacional, representado por um traço, e os haplótipos não amostrados são representados por pequenas circunferências pretas (Posada \& Crandall, 2001). Os haplótipos são representados por circunferências, cujos tamanhos são proporcionais à sua frequência e a forma retangular representa o haplótipo ancestral ou central (Clement et al., 2000). As conexões ambíguas entre os haplótipos, ou seja, haplótipos conectados com pelo menos outros dois haplótipos, foram consideradas da seguinte forma: (1) a conexão entre dois haplótipos raros (frequência inferior a 5\%) é menos provável que um haplótipo raro e outro com frequência superior a 5\%; (2) conexões entre haplótipos da mesma região geográfica são mais prováveis que entre haplótipos de regiões diferentes (Excoffier \& Langaney, 1989).

\subsubsection{Análise de estrutura populacional: Bayesian Analysis of Population Structure (BAPS)}

A análise Bayesiana para a diferenciação genética entre populações foi conduzida por meio do software BAPS 6.0 (Corander et al., 2003; 2004; 2007). Inicialmente, esta trata o número de populações como parâmetro desconhecido e 
estima os grupos genéticos (clusters) com base na distribuição das frequências alélicas (Corander et al., 2003). Esse método permite, dessa forma, que ao invés de atribuir indivíduos não nativos a potenciais populações de origem, os indivíduos sejam agrupados sem uma definição a priori das populações. Consequentemente, quando indivíduos nativos e não nativos ocorrem no mesmo cluster, isso pode ser interpretado como um indício de sua população de origem (Geller et al., 2010).

\subsubsection{Análise de estrutura populacional: Análise de Variância Molecular (AMOVA)}

O grau de estruturação populacional genética também foi estimado por meio da Análise de Variância Molecular (AMOVA) (Excoffier et al., 1992), considerando a variação em cada sítio nucleotídico separadamente entre os haplótipos e utilizando o programa Arlequin v.3.5 (Excoffier et al., 2005). Diferentemente da análise anterior, esta realiza estimativas de componentes de variância dentro e entre os grupos previamente estabelecidos e fornece valores de $\phi$ que refletem a correlação da diversidade haplotípica em diferentes níveis hierárquicos: variação entre as localidades, entre localidades dentro de um grupo ou entre grupos (Excoffier et al., 1992). O фst se refere à covariância entre indivíduos dentro das localidades; o $\phi s c$, à covariância entre localidades dentro de um grupo e фct, à covariância entre grupos.

Com o objetivo de obter um refinamento maior do nível de estruturação genética, o Fst foi calculado comparando pares de localidades (com amostragem superior a um indivíduo) dentro de cada agrupamento identificado nas demais análises (AMOVA, BAPS, rede de haplótipos e análise filogenética) nas áreas nativas e do mar Mediterrâneo. Isso foi feito apenas para as sequências do gene mitocondrial COI, por este ser mais variável.

A aplicação da AMOVA, assim como as inferências a partir dos índices $\phi$ em estudos de espécies invasoras, devem ser feitas com cautela. Em populações em 
equilíbrio, baixos valores de $\phi s t$ sugerem um alto grau de conectividade entre as populações, através de fluxo gênico. Contudo, como em populações recentemente introduzidas o princípio de equilíbrio é violado e, quando o vetor de introdução deixa de existir, não há conexão entre as populações nativas e exóticas, o фst não pode ser utilizado para inferir conectividade e, sim apenas como uma medida alternativa de distância genética (Holland, 2000; Geller et al., 2010). Por essa razão, essas análises foram feitas apenas a fim de averiguar a conectividade entre as populações nativas e sua estruturação genética sem e com níveis hierárquicos.

Embora não nativos, os animais do mar Mediterrâneo foram analisados em conjunto com as populações nativas por dois motivos. Primeiro, são apontados como a principal fonte das populações americanas (Campos \& Türkay, 1989; Gómez \& Martínez-Iglesias, 1990; Lemaitre, 1995; Tavares \& Mendonça Jr., 1996). Segundo, outros estudos têm mostrado conectividade de populações de animais entre esta localidade e aquelas do oeste do oceano Índico, mais precisaente do mar Vermelho (Bucciarelli et al., 2002; Hassan et al., 2003).

\subsubsection{Testes de neutralidade}

Desvios da neutralidade foram verificados por meio dos testes de neutralidade D de Tajima e Fs de Fu conduzidos no programa Arlequin v.3.5 (Excoffier et al., 2005). O primeiro teste leva em consideração a diferença entre as estimativas do parâmetro $\theta$ ( $\theta=4 N e \mu$, onde $N e$ é o tamanho populacional efetivo e $\mu$ é a taxa de mutação de uma sequência), que pode ser utilizado para medir a quantidade de variação acumulada em uma sequência (Tajima, 1989; Clark \& Hartl, 2010). O parâmetro $\theta$ pode ser calculado com base no número de sítios segregantes em uma amostra (os sítios nucleotídicos na amostra que são ocupados por dois ou mais nucleotídeos, representado por S) ou no número de diferenças de nucleotídeos (os sítios nucleotídicos na amostra que diferem entre pares de sequências individuais, representado por T) (Tajima, 1989; 
Clark \& Hartl, 2010). Tajima (1989) propôs que a diferença entre essas duas estimativas de $\theta$ poderia ser utilizada para detecção de desvios da neutralidade. Este teste se baseia na premissa de alelos neutros de uma população de tamanho constante e modelo de sítios infinitos sem recombinação (Tajima, 1989; Hartl \& Clark, 2010).

Assim, quando D não é significativo ou é igual a zero, ou seja as diferença entre as estimativas de $\theta$ com base em $\Pi$ e em $S$ for igual a zero, a hipótese de evolução neutra é utilizada para explicar os polimorfismos encontrados. Nesse caso, todas as mutações seriam seletivamente neutras e o tamanho da população seria constante ao longo do tempo. Caso contrário, com eventos seletivos ou mudanças do tamanho efetivo da população ao longo do tempo, os valores de $D$ podem ser diferentes de zero. Assim, se negativos e significativos $(p<0,05)$ sugerem excesso de haplótipos com baixas frequências, o que pode estar relacionado à expansão populacional, eventos fundadores, efeito carona ou seleção purificadora (Templeton, 2006; Hamilton, 2009). Por outro lado, se positivos e significativos indicam um excesso de haplótipos com frequências intermediárias, o que pode estar relacionado à seleção direcional forte ou contração populacional (Hamilton, 2009).

O teste Fs de Fu (Fu, 1997) se baseia na distribuição de haplótipos e também no modelo de sítios infinitos sem recombinação (Ramos-Onsins \& Rozas, 2002). Este teste verifica a probabilidade de existirem $k$ alelos em uma amostra de $n$ sequências dado o valor de $\theta$. O valor de Fs é obtido pela equação Fs = In ( $\left.S^{\prime} / 1-S^{\prime}\right)$, em que $S^{\prime}$ (S' $=\operatorname{Pr}(\mathrm{K}>\mathrm{Kob} / \theta=\theta \pi)$ é a probabilidade de existir um número de alelos menor ou igual em uma amostra aleatória, dado que $\theta=\pi$ (diversidade nucleotídica). Desse modo, em uma amostra com excesso de mutações recentes, o valor de $\theta$ (baseado no valor de т) tende a ser menor do que aquele baseado no número de alelos. Assim, S' consiste em um indicador da quantidade de mutações recentes na amostra, influenciando o valor de Fs (Fu, 1997). Neste caso também, valores negativos e significativos ( $p<$ 
0,02 nesse caso) indicam um excessivo número de alelos, o que pode sugerir expansão populacional (Fu, 1997). Essa estatística tem uma sensibilidade maior para a detecção de novas mutações que o índice de Tajima e, assim, tem poder maior para a rejeição da neutralidade (Gopurenko, 2002).

\subsubsection{Migrate-n}

Uma estimativa do número de migrantes e do sentido na migração entre os grupos detectados nas áreas nativas (incluindo mar Mediterrâneo, que não é nativo) foi conduzida por meio do software Migrate-n v.3.6.11 que se baseia na teoria da coalescência (Beerli, 2004; 2006; 2009; Beerli \& Palczewski, 2010) utilizando apenas as sequências do marcador mais variável e com maior amostragem (COI). A estratégia selecionada foi a inferência Bayesiana para determinar o sentido da migração. Esta é normalmente utilizada para análises de um único locus (Beerli, 2006). Os parâmetros estabelecidos foram: o número de genealogias registradas por cadeia $=50.000$; quatro cadeias de aquecimento (temperaturas iguais a $1 ; 1,5 ; 3,0 ; 10000,0$ ). Além disso, considerando dois grupos (A e B), foram checadas a probabilidade de quatro configurações: (1) a ocorrência de migração de A para B; (2) migração de B para A; (3) migração tanto de A para B, quanto de B para A (hipótese panmítica) e (4) ausência de migração entre os grupos.

\subsection{Análises morfológicas}

Os estudos moleculares permitem o reconhecimento de invasões crípticas tanto ao nível de espécie como de populações e, dessa forma, fornecem indícios para estudos taxonômicos integrativos (Geller et al., 2010). Espécies crípticas podem ser inicialmente detectadas por meio de ferramentas moleculares, mas o uso de outras ferramentas, como as análises morfológicas, podem ser incorporados a fim de testar 
se a variação encontrada consiste em um indício de espécies crípticas ou variações intraespecíficas.

As análises morfológicas foram feitas de duas formas. Foi utilizada tanto uma abordagem comparativa de caracteres clássicos em estudos taxonômicos do grupo, incluindo análise de microscopia eletrônica de varredura do gonópodo 1, bem como uma abordagem morfométrica linear tradicional.

\subsubsection{Obtenção dos dados e análises morfológicas comparativas}

Com base nas informações contidas em trabalhos referentes à taxonomia do gênero Charybdis (Stephenson et al., 1957; Wee \& Ng, 1995; Padate et al., 2010), bem como nas diagnoses e descrições de C. hellerii (Stephenson et al., 1957; Stephenson, 1976; Lemaitre, 1995; Tavares \& Mendonça Jr., 1996; Coelho \& Santos, 2003), foram selecionados os caracteres mais variáveis para utilização nas análises morfológicas comparativas (Tabela 4). Um total de 247 animais provenientes de diversas áreas de sua distribuição foram analisados e comparados. 
Tabela 4. Lista de caracteres selecionados para a análise morfológica dos exemplares de Charybdis hellerii (A. Milne-Edwards, 1867).

\section{Tabela de caracteres}

Carapaca: presença e profundidade relativa dos sulcos inter-regionais; número, formato e tamanho relativo dos dentes frontais e anterolaterais (incluindo o dente orbital externo e o lateral) e dos entalhes separando-os; pilosidade; presença ou ausência de cristas dorsais.

Antena e antênula: tamanho; presença de cerdas, tubérculos e/ou espinhos.

Quelípodo (maior): presença, número e posicionamento de espinhos nos artículos; presença e posicionamento de franjas de cerdas em cada artículo.

Segundo, terceiro e quarto pereiópodos (pernas ambulatórias): presença, número e posicionamento de espinhos nos artículos; presença e posicionamento de franjas de cerdas em cada artículo.

quinto pereiópodo (perna natatória): presença, número e posicionamento de espinhos nos artículos; presença e posicionamento de franjas de cerdas em cada artículo.

Abdômen: formato e tamanho dos somitos abdominais; presença e posicionamento de franjas de cerdas nos segmentos.

Material examinado (M, machos e F, fêmeas): Lectótipo: 1M (Ic. 85 mm), MNHN B. 761 S, Nova Caledônia. Espécime seco examinado e que foi designado como lectótipo por Apel \& Spridonov (1998). Segundo esses autores, uma vez que nenhum espécime-tipo foi designado por A. Milne-Edwards (1867), todo o material citado por ele deveria ser considerado sintipo. Assim, como a descrição foi baseada em material da Nova Caledônia, bem como também foi mencionado material registrado por Heller (1865) sob o nome de Goniossoma orientalis das Ilhas Nicobar, todo esse material deveria ser considerado síntipo. No entanto, mais tarde, o material analisado por Heller (1865) foi demonstrado ser na realidade exemplares da espécie Portunus annulatus Fabricius (De Man, 1887-1888) (atualmente sinônimo de C. annulata) e não C. hellerii. Com base nisso, Apel \& Spridonov (1998) acharam conveniente designar um lectótipo a partir de indivíduos depositados na coleção seca do $\mathrm{MHNH}$, que são os exemplares possivelmente estudados por A. Milne-Edwards. Dos dois exemplares depositados na coleção, Apel \& Spiridonov (1998), então, designaram o de maior tamanho como o lectótipo, pois suas medidas são condizentes com as apresentadas pelo descritor $(85 \times 60 \mathrm{~mm})$. 
Estados Unidos da América, Carolina do Sul - 1F (Ic. 30,35 mm), USNM 251489: Georgetown, coordenadas não informadas, 07/vi/2000, col. R. Lehnert; Flórida - 1M (Ic. 58,06 mm), USNM 270248: Indian River, coordenadas, data de coleta e coletor não informados; $1 \mathrm{~F}$ (Ic. 58,65 mm), UF 26362: Monroe, Florida Keys, Long Keys, $24^{\circ} 50^{\prime} 35^{\prime \prime} \mathrm{N}, 80^{\circ} 51^{\prime} 47^{\prime \prime} \mathrm{O}, 2 / \mathrm{v} / 2010$, cols. F. Michonneau, G. Paulay, S. McPherson, H. Lin, J. Moore \& N. Evans; $1 \mathrm{M}$ (Ic. 65,60 mm), UF 26363: Monroe, Florida Keys, Long Keys, 2450'35”N, 8051'43”O, 2/v/2010, cols. F. Michonneau, G. Paulay, S. McPherson, H. Lin, J. Moore \& N. Evans; 1M (lc. 66,10 mm), USNM 275907: Indian River, Fort Pierce, coordenadas não informadas, 20/iv/1995, cols. R. Lemaitre \& W. Lee; 1M (Ic. 43,57 mm), UF 34905: Indian River Lagoon, 2946’35”N, 81¹4'50"O, 20/v/2004, cols. M. Turtora et al.; 1M (Ic. 36,09 mm), UF 34764: Indian River Lagoon, $29^{\circ} 57^{\prime} 31^{\prime \prime} \mathrm{N}, 81^{\circ} 19^{\prime} 01^{\prime \prime} \mathrm{O}, 28 / \mathrm{xi} / 2001$, cols. M. Turtora et al.; $1 \mathrm{M}$ (lc. 52,04 mm), UF 34774: Indian River Lagoon, $29^{\circ} 55^{\prime} 35^{\prime \prime} \mathrm{N}, 81^{\circ} 18^{\prime} 17^{\prime \prime} \mathrm{O}, 19 / \mathrm{vi} / 2004$, cols. M. Turtora et al.; 1M (Ic. 39,45 mm), UF 34775: Indian River Lagoon, 3000'28”N, 81'20'41"O, 21/vii/2004, cols. M. Turtora et al.; 1F (Ic. 39,33 mm), UF 34904: Indian River Lagoon, 2944'32”N, 81¹4'41"O, 19/vii/2002, cols. M. Turtora et al.; 2M (Ic. 73,42 mm; 54,73 $\mathrm{mm})$, UF 35646: Palm Beach, Ponte Blue Heron para Ilha Singer, 2646'59”N, 8002'39”O, 3/ii/2013, cols. G. Paulay, P. Norby, T. O'Hara \& C. Marshall;

Cuba - 2M (Ic. 67,54 mm; 56,61 mm), USNM 275916: Gibara Bay, Holguin, coordenadas não informadas, 05/ii/1987, col. O. Gomez;

Saint Martin, Antilhas Francesas - 1M (Ic. 48,35 mm), UF 32327: 1804'01'N, $63^{\circ} 00^{\prime} 43^{\prime \prime}$, 17/iv/2012, cols. G. Paulay, J. Slapcinsky \& A. Anker;

Panamá, Bocas Del Toro - 1M (Ic. 54,00 mm) e 1F (lc. 34,00 mm), CCDB 3551: Marine Harbor, $09^{\circ} 20^{\prime} 14^{\prime \prime} \mathrm{N}, 82^{\circ} 14^{\prime} 79^{\prime \prime} \mathrm{O}, 10 /$ viii/2011, cols. D. Felder \& F.L. Mantelatto;

Trinidad \& Tobago, llha Tobago - 1M (lc. 57,44 mm), UF 11258: Baia Canoe, coordenadas não informadas, 3/ii/2005; col. H.C. Liu;

Colômbia - 1M (Ic. 73,91 mm), SMF 18043: Departamento de la Guajira, Bahia de Portete, coordenadas não informadas, xii/1987, col. N. Campos;

Venezuela, Nueva Esparta - 2M (lc. 60,99 mm; 57,65 mm), CCDB 4601: Isla Cubagua, 11'99'19"N, 3748'04"O, 22/iii/2012, col. M. Velásquez; 2M (Ic. 56,32 mm; 44,70 mm), USNM 291182: Morro de Playa Valdez, Isla Margarita, coordenadas não informadas, 18/v/1989, cols. J. Bolaños e J.E. Hernandez; $1 \mathrm{M}$ (Ic. 73,73 mm), CCDB 3859: Isla Margarita, coordenadas não informadas, 31/viii/2011, coletores não informados; 
Guiana Francesa - 1M (Ic. 24,50 mm), MZUSP 10271: Plage de Rémiré, 0453'50"N, 52¹5’57”O, 10/xii/2001, cols. J.M. Amouroux \& M. Tavares;

Brasil, Pará - 1M (lc. 38,28 mm), CCDB 3858: Estuário do Taperaçu, Bragança, coordenadas não informadas, 15/vi/2011, col. A.B. Bentus; Ceará - 1M (Ic. 28,15 mm), CCDB 4561: Praia do Farol do Trapiá, Camocim, coordenadas não informadas, 08/iv/2012, col. C.B. Mendes; 1F (Ic. 37,96 mm), CCDB 4563; 1M (Ic. 32,19 mm), MOUFPE 150867: Pontal do Maceió, Fortim, coordenadas não informadas, 27/ix/2004, cols. L. Bezerra \& A. Almeida; 1M (Ic. 66,34 mm), Labomar - B 399: Praia do Pacheco, Caucaia, coordenadas não informadas, 20/viii/2011, col. Y.T.T.P. Torres; Rio Grande do Norte - 1M (Ic. 70,00 mm), MZUSP 24146: Foz do Rio das Conchas, arredores de porto do Mangue, coordenadas não informadas, 24/xi/2009, coletores não informados; 4M (Ic. 56,40 mm; 49,90 mm; 48,60 mm; 32,50 mm) e 1F (Ic. 44,90 mm), MZUSP 22463: Praia do Zumbi, Município de Rio do Fogo, 5²0'44”N, 35²1'28”'O, 28/xi/2009, cols. M. Tavares et al.; Pernambuco - 1M (Ic. 39,92 mm), MOUFPE 14961: Rio Paripe, coordenadas não informadas, iv/2009, coletores não informados; Alagoas - 1F (lc. 28,90 mm), NHM 1998. 2678: Morro de Camaragibe Beach, coordenadas não informadas, xi/1990, col. T.C.S. Calado; $1 \mathrm{M}$ (Ic. 26,30 mm), MZUSP 24839: Estuário do Rio Camaragibe, Barra do Camaragibe, 09²1'46"S, 35²4'21"O, 28/x/2011, cols. M. Tavares \& J.B. Mendonça; 1M (lc. 32,1 mm), MZUSP 22351: Passo do Camaragibe, Barra do Camaragibe, 09¹8'47"S, 35²4'57"O, 01/iv/2010, cols. W. Santana \& R. Bueno; $1 \mathrm{M}$ (Ic. 25,66 mm), CCDB 4562: Ponta Verde, coordenadas não informadas, 09/viii//2012, coletores não informados; Bahia - 2M (Ic. 72,80 mm; 40,38 mm) e 1F (Ic. 29,32 mm), MZUESC 961; 3M (Ic. 65,79 mm; 50,60 mm; 46,06 mm), MZUESC 964: Caravelas, coordenadas não informadas, 28/viii/2007, coletores não informados; 1M (lc. 47,06 mm) e 1F (Ic. 57,78 mm), MZUESC 687: Baía de Camamu, coordenadas não informadas, 25/iii/2005 coletores não informados; Espirito Santo $5 \mathrm{M}$ (Ic. 64,12 mm; 54,73 mm; 49,75 mm; 38,75 mm; 37,32 mm), CCDB 4040: Ilha do Frade, Vitória, $20^{\circ} 18^{\prime} 08^{\prime \prime S}, 40^{\circ} 17^{\prime} 08^{\prime \prime} \mathrm{O}, 21 / \mathrm{vi} / 2012$, cols. F.L. Carvalho, R. Robles \& D. Peiró; Rio de Janeiro - 1M (Ic. 33,54 mm) e 1F (Ic. 53,95 mm), MNRJ 19261: Praia dos Anjos, Arraial do Cabo, 22 $58^{\prime} 19^{\prime \prime S}, 42^{\circ} 01^{\prime} 12^{\prime \prime O}$, 31/viii/2003, col. C. Ferreira; 1M (Ic. 38,43 mm), MNRJ 19467: Lagoa de Itaipu, Niterói, 2257'51"S, 4203'42"O, 06/v/2005, coletores não informados; 2M (Ic. 60,36 mm; 70,77 mm), MNRJ 1586 e 2F (Ic. 60,07

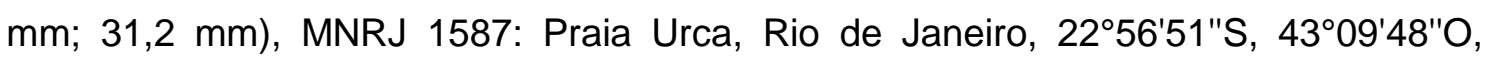
09/xi/1995, col. J.B. Mendonça-Junior; 2F (Ic. 34,07 mm; 34,07 mm), MNRJ 18373: Bacia de Campos, Rio de Janeiro, 14/vii/2002, Valentin Shanin Navy; 3M (Ic. 76,25 mm; 74,25 mm; 73,55 mm) e 1F (Ic. 54,16 mm), CCDB 473: Praia do Tangué, Angra 
dos Reis, $23^{\circ} 00^{\prime} 20,6$ "S, 44²1'39,0"O, 02/iv/2011, cols. T. da Silva, C. Souza \& T. do Valle; São Paulo - 5M (Ic. 68,79 mm; 68,12 mm; 55,10 mm; 45,55 mm; 42,46 mm), CCDB 2920: Enseada de Ubatuba, 2326'S, 4509'O, 26/v/1998, col. F.L. Mantelatto; $1 \mathrm{M}$ (Ic. 66,36 mm), CCDB 1942: Praia do Lamberto, Ubatuba, $23^{\circ} 30^{\prime} 02^{\prime \prime S}, 45^{\circ} 07^{\prime} 07^{\prime \prime O}$, 03/v/2007, col. F.L. Mantelatto; 3M (Ic. 47,33 mm; 46,14 mm; 41,72), CCDB 3660: Araçá, São Sebastião, 2348'78'S, 45²4'46”'O, 25/x/2011, cols. F. Carvalho, N. Rossi, I. Leone \& A. Costa; $2 F(58,92 \mathrm{~mm} ; 45,51 \mathrm{~mm})$, CCDB 1613: Praia do Guaiúba, Guarujá, 2400'51,4"S, 46¹7'42,5"O, 10/viii/2011, A. Castilho \& F.J. Zara; 2M (Ic. $73,77 \mathrm{~mm} ; 31,63 \mathrm{~mm}$ ) e 1F (Ic. 52,31 mm), CCDB 3882: Estuário Santos/São Vicente, 2358'33"S, 46²2'33"O, 14/ii/2011, col. R.C. Costa; 1M (Ic. 71,52 mm), CCDB 1459: Praia dos Milionários, São Vicente, 2358'33"S, 46²2'19"O, 23/x/2011, cols. F.J. Zara et al.; 1F (Ic. 17,30 mm), CCDB 1407: Ilha Anchieta, Ubatuba, 2333'26"S, 4503'00"O; 01/i/2001, cols. F.L. Mantelatto et al.; $1 \mathrm{M}$ (Ic. 54,45 mm), CCDB 3884: Saco da Ribeira, Ubatuba, 23³0'07"S, 4507'23"O, 02/ii/2001, col. F.L. Mantelatto; $1 \mathrm{M}$ (Ic. 29,65 mm) e 2F (Ic. 15,84 mm; 13,20 mm), CCDB 4059: Praia do Lamberto, Ubatuba, 23³0'02"S, 4507'07"O, 22/iv/2012, F.L. Mantelatto \& M. Negri; Paraná - 2M (Ic. 46,60 mm; 28,10 mm), MZUSP 20190: Cabaraquara, Guaratuba, 2551'14"S, 48³2'17”O, 29/ix/2007, col. S.F. Frigotto; $2 \mathrm{M}$ (Ic. $52,37 \mathrm{~mm} ; 37,18 \mathrm{~mm}$ ) e 1F (Ic. 45,22 mm), CCDB 887: Cananéia, $25^{\circ} 04^{\prime} 05^{\prime \prime S}, 47^{\circ} 55^{\prime} 36^{\prime \prime O}$, 29/viii/2011, cols. R.C. Costa et al.; Santa Catarina - 4M (Ic. 71,02 mm; 64,64 mm; 64,57 mm; 63,91 mm), CCDB 2909: Caieira da Barra, Florianópolis, 27³5'48"S, 48³2'58"O, 01/iv/1998, col. L.L. Dias; 1F (Ic. 30,02 mm), CCDB 1888: Praia do Sambaqui, Ponta Norte, Florianópolis, 27²9'12"S, 48³2'20"O, 16/iv/2007, cols. F.L. Mantelatto et al.; $1 \mathrm{M}$ (Ic. 34,09 mm) e 1F (Ic. 35,32 mm), SMF 40170: Florianópolis, Ribeirão da Ilha, 2744'03"S, 48³4'50"O, 15/vii/2010, col. E. Thomsen;

China, Hong Kong - 1M (Ic. 51,67 mm), NHM 1986.851: To Lo Harbour, coordenadas não informadas, 23/ix/1986, col. R. Seed; 1 F (lc. 44,83 mm), NHM 1939.8.12.2: Chunchou, 04/iv/1938, coordenadas e coletores não informados; 1M (Ic. 60,98 mm), NHM 1930.12.2.101: coordenadas e data de coleta não informadas, col. Barney; 3F (Ic. $52,89 \mathrm{~mm}, 56,11 \mathrm{~mm}, 78,81 \mathrm{~mm}$ ) e $1 \mathrm{M}$ (Ic. $44,64 \mathrm{~mm}$ ), material cedido por C.D. Schubart: coordenadas não informadas, 15/iv/2009, coletores não informados;

Austrália, Queensland - 1F (lc. 53,14 mm), SMF 38899: Yule Point, coordenadas não informadas, 08/vi/1999, col. M. Türkay; $1 \mathrm{M}$ (Ic. 54,83 mm), SMF 43966: CID Island, coordenadas não informadas, 11/viii/1975, col. Z. Stevcic; 1F (lc. 46,29 mm), SMF 40382: CID Island, coordenadas não informadas, 17/viii/1975, col. Z. Stevcic; 1M (Ic. $46,40 \mathrm{~mm}$ ) e $1 \mathrm{~F}$ (Ic. $37,54 \mathrm{~mm}$ ), NHM 1932.11.30.183-184: coordenadas, data de 
coleta e coletores não informados; 2M (Ic. 43,32 mm; 44,03 mm), AM P1658: Rowes Bay, Townsville, 19¹6'S, 146²0'L, 27/iii/1964, M.P. Hines; 2M (Ic. 67,50 mm; 56,13

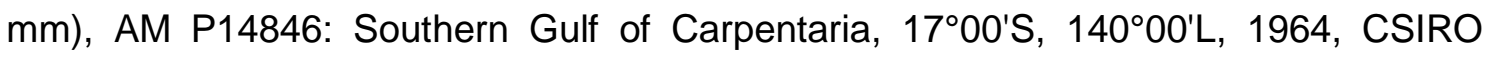
prawn survey; New South Wales - 1F (lc. 51,16 mm), AM P60473: Newcastle, $32^{\circ} 51^{\prime} \mathrm{S}, 151^{\circ} 52^{\prime} \mathrm{L}, 06 / \mathrm{iv} / 1995, \mathrm{FRV}$ “Kapala”; $2 \mathrm{M}$ (Ic. 42,76 mm; 38,77 mm), AM

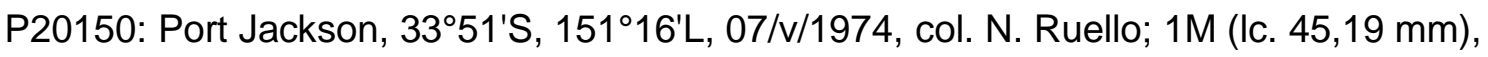
AM P88350: Saibai Island, Torres Strait, 09²3'S, 14240'L, 07/vii/1976, col. D. Brown; $1 \mathrm{M}$ (Ic. 49,10 mm), AM P80548: Lake Pambula, 3658'S, 14952'L, 29/v/2009, col. J. Dawson; Northern Territory - 2M (Ic. 27,10 mm; 19,51 mm), UF 35870: Darwin, Fannie Beach, $12^{\circ} 25^{\prime} 54^{\prime \prime S}, 130^{\circ} 50^{\prime} 03^{\prime \prime L}$, 05/vii/2012, coletores não informados; Western Australia - 1M (Ic. 30,35 mm), WAM C42913: Line 5, Kimberley, 17²7'12"S, $122^{\circ} 06^{\prime} 01^{\prime \prime L}, 22 / v i / 2008$, col. J. Keesing; 1M (Ic. 46,50 mm), WAM C55532: South West Creek, Port Hedland, $20^{\circ} 38^{\prime}$ S, $116^{\circ} 43^{\prime} \mathrm{L}, 07 / \mathrm{vi} / 2013$, coletores não informados; 1F (Ic. 41,40 mm), WAM C42912: Quandong - Coulomb Points, Kimberley, 1552'S, $124^{\circ} 37^{\prime}$ L, 16/vi/2008, col. J. Keesing;

Guam - 1M (lc. 25,59 mm), UF 2489: Apra Harbor, Baia de Sasa, Ilhas Mariana, coordenadas não informadas, 04/viii/1998, col. G. Paulay; 1M (lc. 55,35 mm), UF 217: Apra Harbor, Ilhas Mariana, coordenadas não informadas, 20/i/2000, col. G. Paulay;

Emirados Árabes Unidos - 4M (Ic. 36,00 mm; 37,03 mm; 37,35 mm; 49,30 mm) e 1F (Ic. 39,85 mm), SMF 24352: Porto de Fujairah, 25¹0'00"N, 056²8'00"L, 02/vii/1995, col. M. Apel;

Filipinas - 11M (Ic. 60,93 mm; 60,28 mm; 55,23 mm; 50,37 mm; 46,11 mm; 44,61 mm; 41,61 mm; 40,61 mm; 38,39 mm; 34,18 mm; 32,47 mm), USNM 73141: Iloilo, Ilha Canay, coordenadas não informadas, 6/iv/1929, col. H.C. Kellers; Bohol - 2M (Ic. $70.77 \mathrm{~mm}$; 54,10 mm), UF 11430: Iloilo, Rio Lcastleoboc, 9॰35'58"N, 12400'36"L, 2/v/2005, col. H.C. Liu; $1 \mathrm{M}$ (lc. $39,40 \mathrm{~mm}$ ) e $2 \mathrm{~F}$ (lc. 40,00 mm; 59,80 mm), MNHNB7351; 1F (Ic. 34,45 mm), MNHN-B31560; 1F (Ic. 36,00 mm), MNHN-B31559; 1M (Ic. $42,00 \mathrm{~mm}$ ), MNHN-B31561; 1M (Ic. 65,90 mm) e 1F (Ic. 55,00 mm), MNHN-B7298; $1 \mathrm{M}$ (lc. 58,07 mm), MNHN-B7338: adquirido no mercado de Saint Manila, 17/iii/1976; Campagne MUSORSTOM 1; 2F (Ic. 46,05 mm; 50,63 mm), MNHN-B7357: Manila, coordenadas não informadas,18/iii/1976; Campagne MUSORSTOM 1; 1M (Ic. 62,37 mm) e 1F (Ic. 49,96 mm), SMF 18043: Cebu, Cidade de Cebu, Carbon Market, 03/iv/1983, coletores não informados;

Guadalupe - 1M (Ic. 66,01 mm), MNHN-IU-2013-6823; 1F (Ic. 43,05 mm), MNHN-IU2013-6824; $1 \mathrm{~F}$ (Ic. 35,03 mm), MNHN-IU-2014-10223: 16²13'24"N, 61'31'49"O, 
02/v/2012, Campagne Karubenthos 2012; $1 \mathrm{~F}$ (Ic. 46,20 mm), MNHN-IU-2013-4917: $16^{\circ} 14^{\prime} 37^{\prime \prime} \mathrm{N}, 61^{\circ} 19^{\prime} 23^{\prime \prime} \mathrm{O}, 28 / \mathrm{v} / 2012$, Campagne Karubenthos 2012;

Irã, Qeshm - 4M (Ic. 40,67 mm; 49, 55 mm; 48,80 mm; 71,85 mm) e 1F (Ic. 44,98

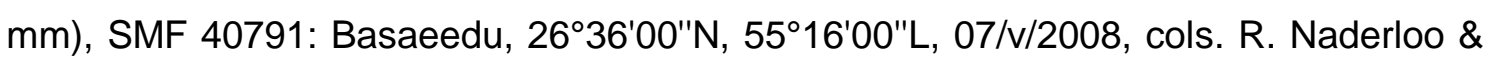
A. Kazemi; $2 \mathrm{~F}$ (Ic. $34,77 \mathrm{~mm}$; $44,92 \mathrm{~mm}$ ), SMF 40797: S-Kuste, 26² $43^{\prime} 00 \mathrm{~N}$, 5549'00"L, 10/i/2008, cols. R. Naderloo \& M. Türkay; 1M (Ic. 47,77 mm), SMF 40795: Dustku, 26³1'00"N, 55²1'00"L, 07/v/2008, cols. R. Naderloo \& M. Türkay; Hormozgan - 1 juvenil (Ic. 12,46 mm) e 1M (lc. 35,02 mm), SMF 40796: BandarAbbas, 2708'00"N, 56²0'00"L, 06/i/2008, cols. R. Naderloo \& M. Türkay; 1F (Ic. 45,97 mm), NHM 1985.54: Bandar-Abbas, coordenadas não informadas, 22/ii/1976, col. H. Fabour;

Israel, Haifa - 1M (lc. 56,10 mm), RMNH. CRUST. D. 17717: próximo à Tantura, coordenadas não informadas, 03/v/1962, coletores não informados;

Indonésia, Província de Molucas - 3M (lc. 51,30 mm; 61,50 mm; 70,50 mm) e 1F (muito danificado), RMNH. CRUST. D. 42963: Ambon, Baia de Baguala, coordenadas não informadas, 05/xii/1990, coletores não informados; Sumatra - 3M (lc. 56,85 mm; 44,00 mm; 40,62 mm), USNM 93095; $1 \mathrm{M}$ (Ic. 40,12 mm), USNM 1188767; 1M (lc. 34,67 mm), USNM 1188766; $1 \mathrm{M}$ (Ic. 77,31 mm), USNM 1188774: Bengkulu, coordenadas não informadas, xi/1925, col. H.C. Kellers; 4M (Ic. 66,45 mm; 69,08 mm; 60,11 mm; 55,11 mm), USNM 75892: Bengkulu, coordenadas não informadas, 25/xi/1925, col. H.C. Kellers;

Kuwait - 1F (Ic. 40,05), SMF 24358:entre as coordenadas $29^{\circ} 21^{\prime} 52^{\prime \prime} \mathrm{N}, 48^{\circ} 06^{\prime} 10^{\prime \prime L} \mathrm{e}$ 29²3'16"N, 4805'46"L, 23/iv/1995, expedição "Mutahida 5"; 2M (lc. 47,98 mm; 57,80 mm), NHM 1998. 2593-2594: Ras Al Jlay'ah, coordenadas não informadas, 12/x/1979, col. D. Clayton;

Líbano - 6M (Ic. 33,90 mm; 34,20 mm; 35,75 mm; 42,15 mm; 48,40 mm; 57,75 mm) e 1F (Ic. 40,00 mm), RMNH CRUST 29162, Saint George Bay; Beirute, coordenadas não informadas, 17/iii/1965, coletores não informados;

Malásia - 1M (lc. 44,65 mm), RMNH CRUST 5261: Port Dickison, coordenadas não informadas, iii/1946, coletores não informados;

Martinica - $2 \mathrm{~F}$ (lc. $59,89 \mathrm{~mm}$; 49,95 mm), SMF não catalogado: 14²3'57"N, $60^{\circ} 52$ '32"O, 09/i/2004, coletores não informados; $2 F$ (lc. 32,68 mm, 54,29 mm), NHM 1880.6.2: coordenadas, data de coleta e coletores não informados; 
Moçambique - 1M (lc. 52,94 mm), NHM 1955.3.5.129: Mongué Ferry, Estuário Morrumbene, Port of East Africa, coordenadas não informadas, 14/i/1954, Ecological Survey MOR. 8. Y.;

Nova Caledônia - 1M (Ic. 52,00 mm), MNHN-B31557; 1F (lc. 37,50 mm), MNHNB31558; 1F (Ic. 35,61 mm), MNHN-B31553: Lagon Nord-Ouest, 20²1'54"S, 16406'42"L, 29/iv/1988, col. B. Richer de Forges; 1F (Ic. 41,60 mm), MNHN-IU-201410224; 1F (Ic. 41,00 mm), MNHN-IU-2014-10225: Lagon Nord-Ouest, 2044'48"S, 164²2'36"'L, 27/iv/1988, col. B. Richer de Forges; 5M (Ic. 23,00 mm; 24,40 mm; 36,60 $\mathrm{mm} ; 45,75 \mathrm{~mm} ; 48,20 \mathrm{~mm}$ ) e $3 F$ (Ic. $22,50 \mathrm{~mm} ; 28,50 \mathrm{~mm} ; 46,00 \mathrm{~mm}$ ), MNHN-IU2014-10226: Lagon Nord-Ouest, 20²1'36"S, 16406'42"L, 29/iv/1988, col. B. Richer de Forges; $1 \mathrm{M}$ (Ic. 22,40 mm) e 2F (Ic. 10,60 mm e 35,00 mm), MNHN-IU-2014-10227: Baia de Saint Vincent, coordenadas não informadas, 22/iv/1986, coletores não informados; 1M (Ic. 6,20 mm); 3F (Ic. 40,01 mm; 41,00 mm; 58,40 mm), MNHN-IU2014-10228: Baia de Saint Vincent, coordenadas não informadas, 20/viii/1985, col. M. Kulbicki; $1 \mathrm{M}$ (Ic. 59,80 mm), MNHN-IU-2014-10273: Baia de Saint Vincent, coordenadas não informadas, 22/vi/2005, coletores não informados;

Paquistão, Província de Sindh - 1F (lc. 41,04 mm), NHM 1998. 2595: Ilha Manora, Karachi, coordenadas não informadas, 22/vii/1966, col. S.S. Hashmi; 1F (Ic. 47,95 $\mathrm{mm})$, NHM 1897.9.12.4: Karachi, coordenadas, data de coleta e coletores não informados; $1 \mathrm{M}$ (cw. $59.89 \mathrm{~mm}$ ), NHM 1889.6.17.16-18: coordenadas, data de coleta e coletores não informados;

Papua Nova Guiné - 1M (Ic. 71,77 mm), USNM 112064: Ilha Bougainville, coordenadas não informadas, 10/i/1945, col. W.M. Bartos;

Vietnã/Camboja - 5M (lc. 34,27 mm; 29,77 mm; 27,77 mm 27,62 mm; 26,91 mm): Golfo de Siam, coordenadas não informadas, 20/iv/1934, col. H.M. Smith;

Japão, Okinawa - 1M (Ic. 53,19 mm), UF 7113: Yonashiro Marine Road, calçada para Henza, 26¹9'54"N, 12755'33"L, 25/vii/2004, col. G. Paulay;

Singapura - 5F (lc. $62,52 \mathrm{~mm} ; 60,05 \mathrm{~mm} ; 57,79 \mathrm{~mm} ; 57,47 \mathrm{~mm} ; 33,66 \mathrm{~mm}$ ), CCDB 4882: coordenadas, data de coleta e coletores não informados, doação UF;

Tailândia, Província de Chomburi - 2M (Ic. 51,20 mm; 58,40 mm) e 1F (Ic. 52,10 mm), RMNH CRUST 36011: entre Naklua e Pataya, próximo à Bangkok, coordenadas não informadas, 30/xii/1903, coletores não informados;

Turquia, Província de Hatay - 2M (Ic. 37,65 mm; 47,30 mm), RMNH. CRUST. D. 38576: Praia de Iskederun, coordenadas não informadas, 27/xii/1990, col. H. 
Menckhors; $1 \mathrm{M}$ (Ic. 53,18 mm) e 1F (lc. 46,17 mm), CCDB 5460: localidade e coordenadas não informadas, 15/vii/2014, coletores não informados.

\subsubsection{Microscopia eletrônica de varredura do gonópodo 1}

A fim de investigar possíveis variações, o primeiro pleópodo (gonópodos 1) de machos geneticamente distintos e provenientes de diferentes localidades das regiões sudeste e sul do Brasil foi analisado por microscopia eletrônica de varredura. Para a preparação das amostras, estas foram inicialmente desidratadas em banhos de álcool de $30,50,70,80$, 90 e 100\%, por 30 min cada, sendo que o banho em álcool $100 \%$ foi feito em três repetições. Em seguida, as amostras foram submetidas à secagem em ponto crítico com $\mathrm{CO}_{2}$ líquido no EMS 850 ("Electron Microscopy Science ${ }^{\circledR ”), ~}$ devidamente montadas em vista ventral sobre stubs e recobertas com uma fina camada de ouro $24 \mathrm{~K}$ em um metalizador Denton Vacuum Desk II. As fotografias foram tomadas em um microscópio eletrônico de varredura (MEV) JSM 5410 (JOEL ${ }^{\circledR}$ ) no laboratório de Microscopia Eletrônica da Faculdade de Ciências Agrárias e Veterinária, UNESP, Jaboticabal. A digitalização e edição das micrografias eletrônicas obtidas foram desenvolvidas no editor de imagens Adobe Photoshop CS3 (Adobe System ${ }^{\circledR}$ ). A nomenclatura dessa estrutura seguiu Stephenson et al. (1957) e Wee \& Ng (1995).

Os espécimes machos que tiveram seus gonópodos 1 esquerdos extraídos e analisados foram os seguintes: Brasil, Rio de Janeiro - 1M (Ic. 76,25 mm), CCDB 473: Praia do Tangua, Angra dos Reis, $23^{\circ} 00^{\prime} 20^{\prime \prime S}, 44^{\circ} 21^{\prime} 39 " \mathrm{O}, 02 / \mathrm{iv} / 2011$, cols. T.C. Silva, C.A.S. Souza \& T. Thacyane; São Paulo - 1M (Ic. 29,65 mm), CCDB 4059: Praia do Lamberto, Ubatuba, $23^{\circ} 30^{\prime} 02^{\prime \prime S}, 45^{\circ} 07^{\prime} 07^{\prime \prime} \mathrm{O}, 03 / \mathrm{iv} / 2012$, cols. F.L. Mantelatto \& M. Negri; $1 \mathrm{M}$ (Ic. 54,45 mm), CCDB 40: Saco da Ribeira, Ubatuba, 23³0'05"S, 4507'23"O, 02/ii/2001, col. F.L. Mantelatto; 1M (Ic. 74,18 mm), CCDB 3882: Estuário Santos/São Vicente, 2358'33"S, 46²2'33"O, 14/ii/2011, col. R.C. Costa; 1 M (Ic. 37,18 mm), CCDB 887: Cananéia, 2504'05"S, 4955'36"O, 29/viii/2011, col. R.C. Costa; 
Santa Catarina - 1M (Ic. 79,09 mm), CCDB 2909: Caieira da Barra, Florianópolis, 27³5'48"S, 48³2'58"O, 01/iv/1998, col. L.L. Dias.

\subsubsection{Análise morfológica comparativa do espécime utilizado para o registro de Charybdis variegata na América}

O exemplar identificado como Charybdis variegata coletado em Ponta da Praia, Santos, São Paulo, Brasil (MZUSP 24446) e utilizado para o registro da introdução da espécie no continente americano feito por Sant'Anna et al. (2012b) também foi analisado. Os caracteres utilizados para a identificação do espécime e apontados por Sant'Anna et al. (2012b) e Padate et al. (2010) como distintos entre C. variegata e C. hellerii foram reexaminados, bem como foi feita uma comparação com outros espécimes de $C$. variegata depositados nas coleções científicas visitadas a fim de checar sua identificação. Os principais caracteres analisados foram os seguintes: ausência/ presença de espinho na margem posterior distal do carpo do quinto pereiópodo; ausência/presença de cristas transversais na região mesobranquial da carapaça e formato dos dentes frontais e antero-laterais da carapaça.

Os espécimes de C. variegata analisados foram os seguintes: $1 \mathrm{~F}$ (Ic. 41,52 mm), USNM 1188781: San Nicolas, Manila Bay, Filipinas, vi/1959, col. J.E. Morton; 1M (Ic. 42,48 mm), USNM 73158: Iloilo, Panay Island, Filipinas, iii-v/1929, coletores não informados; $1 \mathrm{M}$ (Ic. 38,10 mm) e 1F (Ic. 39,25 mm), RMNH. CRUST. D. 47335: Karachi Fish Harbour, Paquistão, 30/vi/1992, coletores não informados; 1F (lc. 16,45 mm), MNHN IU 2014-10272: Port d'Ehoala, Madagascar, 16/v/2010, expedição ATIMO VATAE; 1F (Ic. 15,00 mm), MNHN IU 2014-10272: Port d'Ehoala, Madagascar, 05/vi/2010, expedição ATIMO VATAE; $1 \mathrm{M}$ (Ic. 20,00 mm); MNHN IU 2010-7972: Port d'Ehoala, Madagascar, 25/v/2010, expedição ATIMO VATAE; 1M (17,47 mm); SMF 34448: Anan, Tokushima, Japão, 18/iv/1983, col. K. Sakai. 


\subsubsection{Obtenção e análises dos dados morfométricos}

Um total de 25 medidas foram obtidas a partir de 100 espécimes de $C$. hellerii provenientes de diversas localidades ao longo de sua distribuição (Tabela 1) a fim de verificar a existência ou não de diferenças intraespecíficas significativas. As medidas obtidas foram as seguintes (Figura 3): comprimento da carapaça (CC), largura da carapaça (LC), comprimento do dátilo, própodo, carpo e mero do primeiro ao quinto pereiópodo (CD1, CP1, CC1, CM1, CD2, CP2, CC2, CM2, CD3, CP3, CC3, CM3, CD4, CP4, CC4, CM4, CD5, CP5, CC5, CM5, respectivamente), largura do própodo do primeiro pereiópodo (LP1), altura do própodo do primeiro pereiópodo (AP1) e largura do dátilo do quinto pereiópodo (LD5). Estas foram obtidas utilizando-se paquímetro digital $(0,01 \mathrm{~mm})$ a partir de indivíduos que foram agrupados segundo os resultados moleculares. 


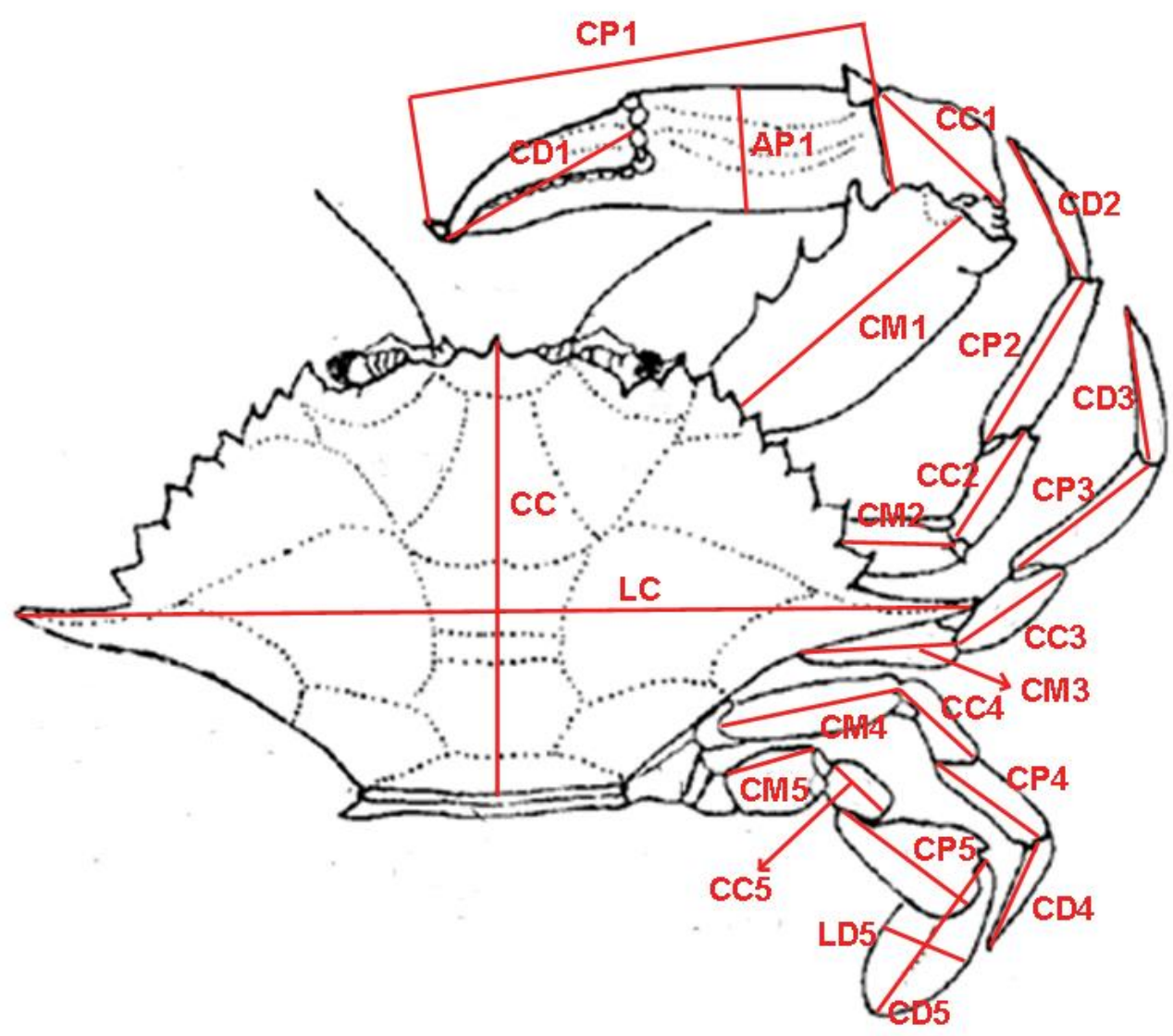

Figura 3. Esquema generalizado de um portunídeo indicando as medidas obtidas para as análises morfométricas. LC, largura da carapaça; CC, comprimento da carapaça; CD1, CP1, CC1 e CM1, comprimento do dátilo, do própodo, do carpo e do mero do primeiro pereiópodo; AP1, altura do própodo do primeiro pereiópodo; $C D 2, C P 2, C C 2$ e CM2, comprimento do dátilo, do própodo, do carpo e do mero do segundo pereiópodo; CD3, CP3, CC3 e CM3, comprimento do dátilo, do própodo, do carpo e do mero terceiro pereiópodo; CD4, CP4, CC4 e CM4, comprimento do dátilo, do própodo, do carpo e do mero do quarto pereiópodo; CD5, CP5, CC5 e CM5, comprimento do dátilo, do própodo, do carpo e do mero do quinto pereiópodo; LD5, largura do dátilo do quinto pereiópodo. A largura do própodo do primeiro pereiópodo (LP1) não está representada no esquema. Modificado de Rodríguez, 1982.

As análises foram feitas considerando machos e fêmeas separadamente, em virtude da possibilidade de dimorfismos sexuais já reportados para certas populações da espécie (Mantelatto \& Garcia, 2001; Sant'Anna et al., 2012). A distinção dos sexos foi feita com base no formato do primeiro pleópodo, o qual é rígido e modificado em gonópodos nos machos, o que não ocorre nas fêmeas, e na largura e formato do abdômen, que é mais largo nas fêmeas que nos machos (Bolaños et al., 2012). 
Os valores das medidas foram, inicialmente, logaritmizados utilizando o logaritmo natural "In", cuja base é o número irracional de Euler. Foi feita uma separação com base nos resultados moleculares do gene COI (mais variável), assim como no sexo. Para cada agrupamento, foram construídos gráficos de dispersão entre as variáveis dependentes e a variável independente (LC), a partir dos quais linhas de tendência e equações da reta foram obtidas. O ângulo de inclinação da reta calculado separadamente para cada grupo foi utilizado na equação alométrica $\left(\mathrm{Yi}^{*}=\mathrm{Yi}[\mathrm{X} / \mathrm{Xi}]^{\mathrm{b}}\right)$ com o intuito de remover os efeitos do tamanho dos espécimes (LC - variável independente) em relação a todas as demais 24 medidas (variáveis dependentes). Nesta, $\mathrm{Yi}^{*}$ representa o valor padronizado pela equação alométrica a ser obtido; Yi, a medida logaritmizada da característica a ser padronizada; $\mathrm{X}$, é a média das medidas logaritmizadas da largura da carapaça do grupo analisado; Xi, a medida logaritmizada da largura da carapaça de cada indivíduo analisado; e b, a constante que acompanhava a variável $\mathrm{x}$ nos gráficos construídos para cada variável dependente, relacionado ao ângulo de inclinação da reta (Tzeng, 2004).

Posteriormente foi realizada uma Análise Discriminante (AD) por meio do programa Statistica 8, a fim de buscar evidências da existência de diferenças morfométricas entre os indivíduos dos agrupamentos moleculares e determinar quais medidas foram mais relevantes na sua separação, caso existente. O poder de discriminação de cada variável foi observado pelo índice de Wilks'lambda associados aos valores estatísticos de $\mathrm{F}$ e P. Esse índice pode variar de 0 a 1 , no qual 0 representa total poder de discriminação e 1, ausência de discriminação. Em seguida, foi realizada uma análise de discriminantes canônicos para verificar graficamente a separação dos grupos. O teste de Chi-quadrado foi aplicado para avaliar a significância das variáveis canônicas (“Roots”) (Tzeng, 2004). 


\section{Resultados}




\subsection{Distância genética intra e interespecífica}

Para o marcador COI, a divergência genética intraespecífica de C. hellerii variou entre 0 e 4,2\% e a distância interespecífica, entre 6,2 a 21,5\% (Figura 5), exceto para as espécies do complexo Charybdis miles. Este marcador evidenciou a existência de um gap genético interespecífico entre as distâncias intraespecíficas de C. hellerii e a interespecíficas (Figuras 5). Foram notadas divergências genéticas intraespecíficas superiores entre alguns indivíduos provenientes de localidades da América (todos incluídos em G3, Figura 11) e os demais (círculo A, Figura 4) em relação à distância entre os demais espécimes excluindo os de G3, evidenciando um gap intraespecífico dentro de C. hellerii.

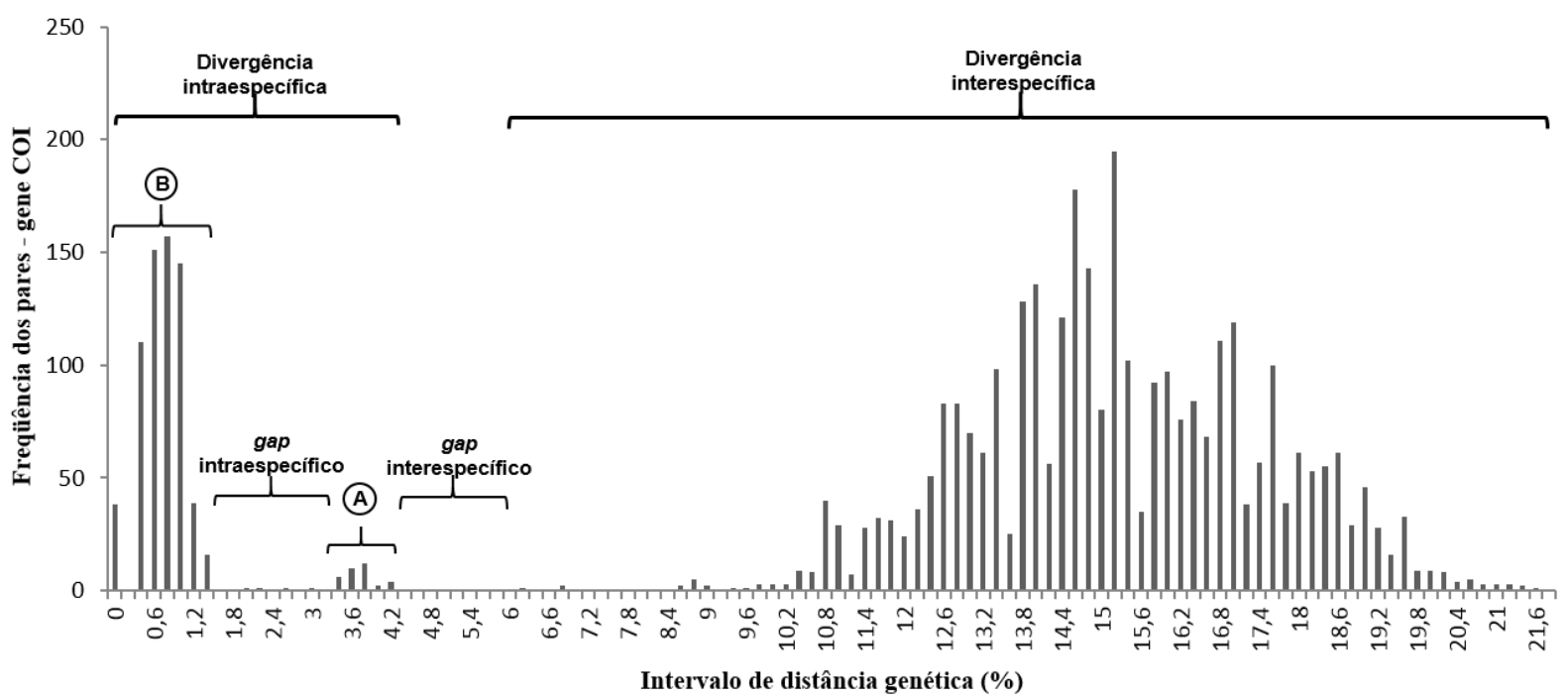

Figura 4. Histograma com as frequências de distâncias genéticas intraespecíficas obtidas a partir da comparação de indivíduos de Charybdis hellerii de diversas localidades, e interespecíficas obtidas a partir da comparação de diversas espécies do gênero Charybdis. $O$ círculo A indica a divergência genética entre G3 (grupo geneticamente distinto identificado nas localidades americanas) e os demais indivíduos de $C$. hellerii e o círculo B indica a divergência dentro de G3, entre os demais indivíduos, excluindo G3 e entre as espécies do complexo $C$. miles. 
Para o outro marcador mitocondrial, 16S rDNA, a divergência genética intraespecífica de $C$. hellerii variou entre 0 e $0,9 \%$, enquanto que a distância interespecífica variou de 3,9 a 15,2\% (Figura 5), também com exceção das espécies do complexo C. miles. Assim como o gene COI, este marcador também evidenciou a existência de um gap interespecífico (Figura 5). No entanto, o gap intraespecífico não foi evidente, pois a divergência genética entre G3 e os demais indivíduos não se mostrou sempre superior em relação a distância entre os demais indivíduos de $C$. hellerii, excluindo G3. Divergência genética nula foi encontrada entre as sequências do marcador nuclear $\mathrm{H} 3$ obtidas a partir de espécimes de $C$. hellerii provenientes de diferentes localidades.

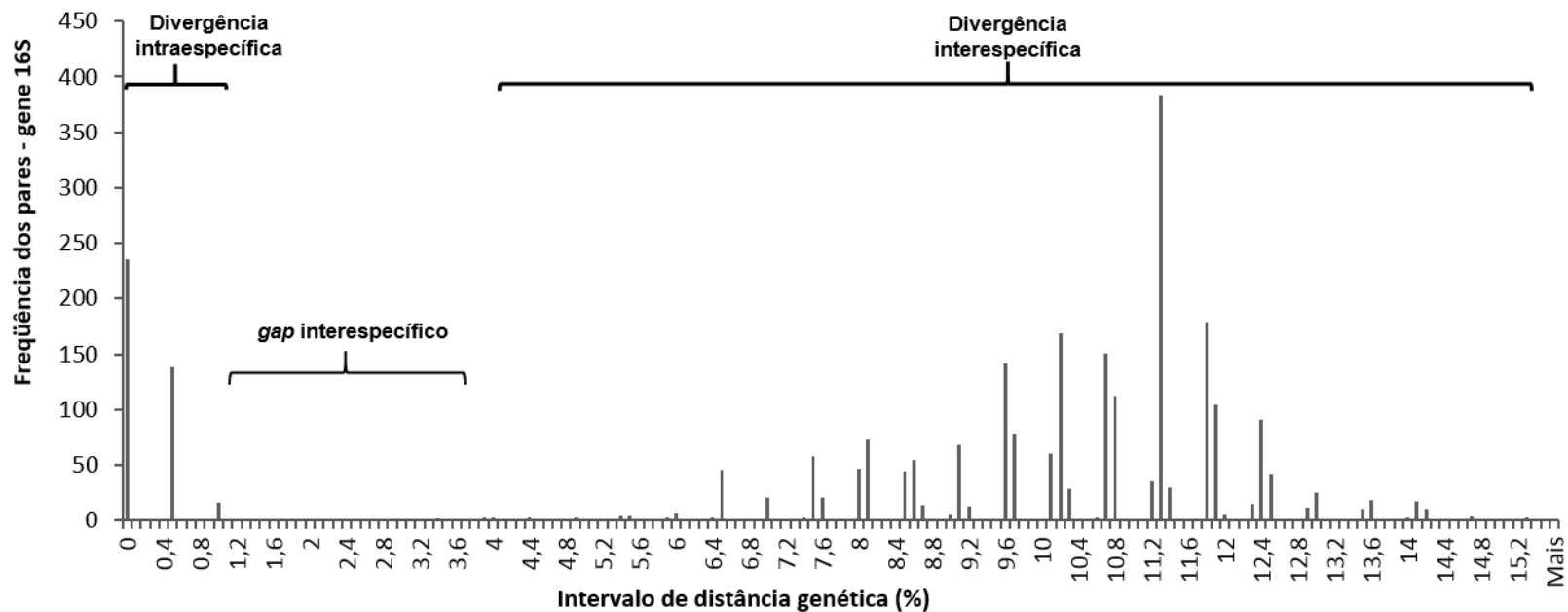

Figura 5. Histograma com as frequências de distâncias genéticas intraespecíficas obtidas a partir da comparação de indivíduos de Charybdis hellerii de diversas localidades, e interespecíficas obtidas a partir da comparação de diversas espécies do gênero Charybdis.

\subsection{Análise filogenética}

A análise conduzida pela inferência Bayesiana, bem como todas as abordagens conduzidas pelo critério de Máxima Verossimilhança, incluindo as diversas espécies do gênero Charybdis (individualmente para cada gene, COI e 16S 
rDNA; com as sequências concatenadas em uma, duas ou quatro partições; com a exclusão de áreas muito variáveis), geraram filogramas similares, com pequenas variações nos valores de suporte e na resolução de alguns ramos terminais. Todas elas indicaram a monofilia da espécie Charybdis hellerii, suportada por altos valores de bootstrap e probabilidade posterior (Figura 6). Tais topologias também possibilitaram uma noção das relações filogenéticas entre as espécies do gênero Charybdis e sugeriram a monofilia deste gênero e de Thalamita, outro gênero filogeneticamente próximo e pertencente à subfamília Thalamitinae (Figura 6).

As análises filogenéticas (Máxima Verossimilhança) intraespecíficas, considerando apenas indivíduos de localidades nativas e do mar Mediterrâneo foram condizentes com os resultados pela Bayesian Analysis of Population Structure (BAPS) e, por isso, os filogramas foram apresentados na seção de análises populacionais, junto com o resultado do BAPS (Figuras $8, \mathrm{~A}$ e 10, A). O filograma do COI incluindo os espécimes do Indo-Pacífico e mar Mediterrâneo indicou a separação em dois grupos. Um deles monofilético com indivíduos do mar Mediterrâneo e do oeste do oceano Índico e o outro parafilético com indivíduos do leste do oceano Índico e todos os espécimes do oceano Pacífico (Figura 8, A). Essa mesma separação foi observada para o gene 16S rDNA, porém, nesse caso, dois agrupamentos foram detectados dentre as localidades do Índico leste e do Pacífico (Figura 10, A). Os agrupamentos, no entanto, não foram suportados por altos valores de bootstrap no filograma gerado pelas sequências de COI e não apresentaram boa resolução nos ramos terminais no filograma de $16 S$ rDNA, em decorrência da elevada semelhança genética entre os espécimes. 


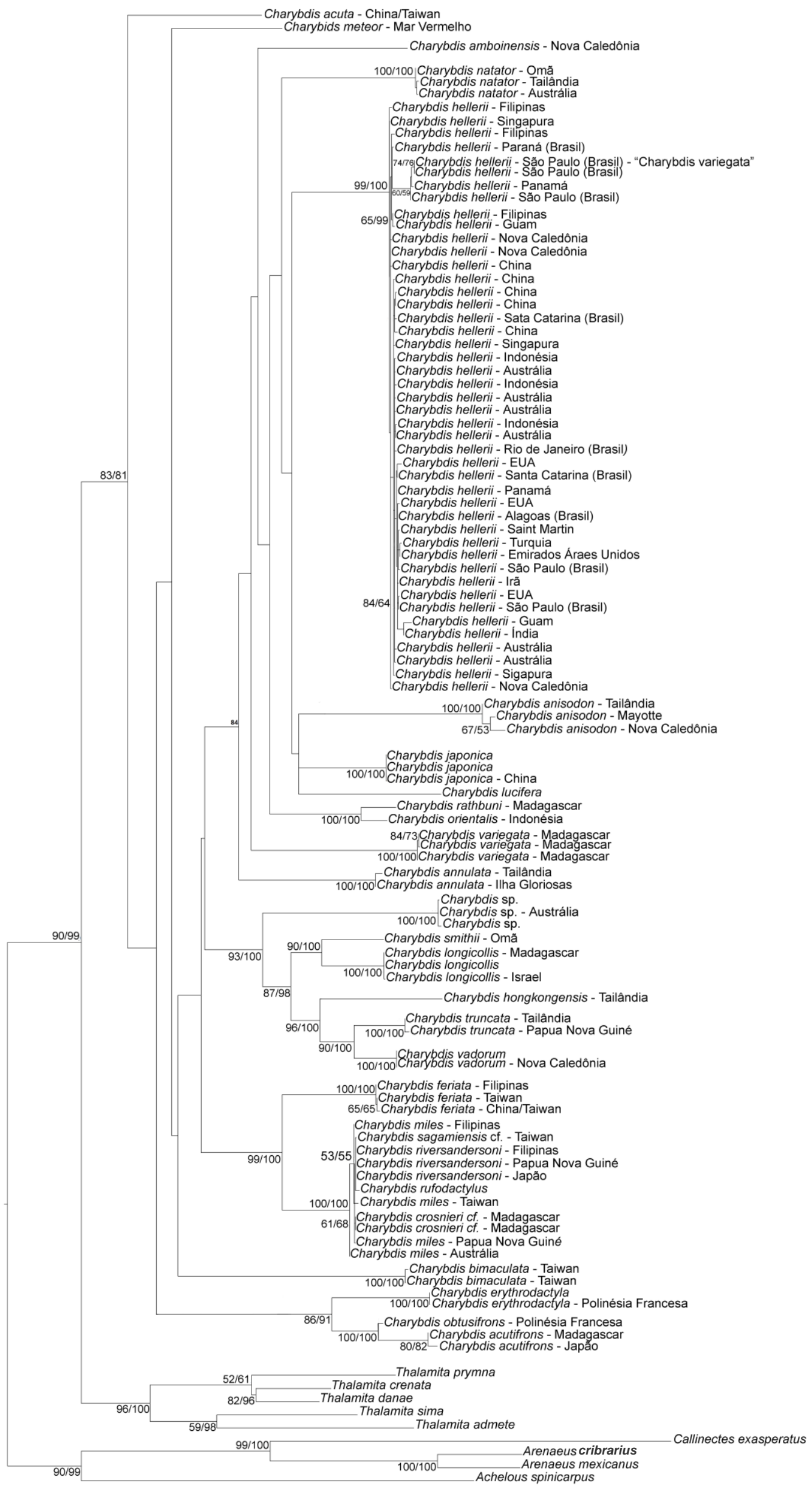


Figura 6. Árvore consenso dos filogramas de Inferência Bayesiana e Máxima Verossimilhança de espécies da subfamília Thalamitinae construídos com base nas sequências de dois marcadores mitocondriais, 16S rDNA e COI, de 28 espécies do gênero Charybdis e cinco do gênero Thalamita. Os símbolos próximos aos nós indicam o valor de bootstrap obtido na análise de Máxima Verossimilhança e a probabilidade a posteriori pela inferência Bayesiana (bootstrap/probabilidade a posteriori). As localidades indicadas na frente do nome dos táxons indicam o local de coleta, informação esta não obtida para todos os espécimes. Outras informações para cada espécime estão na Tabela 3. 


\subsection{Análises populacionais - localidades nativas e do mar Mediterrâneo (COI)}

\subsubsection{Estatística descritiva}

A partir do alinhamento de 556 pares de base de sequências parciais do gene COI obtidas de 53 indivíduos provenientes de 14 localidades das áreas nativas e do mar Mediterrâneo, foram encontrados 28 haplótipos (h), resultado de 33 sítios polimórficos (S), com diversidade haplotípica $(\mathrm{Hd})$ de 0,9238 , diversidade nucleotídica

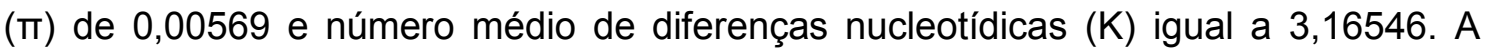
proporção de bases encontradas nas sequências obtidas foi: $A=0,2660 ; C=0,1900$; $\mathrm{G}=0,1710$ e $\mathrm{T}=0,3730$.

A estatística descritiva obtida por meio das sequências parciais do gene COI para as localidades amostradas, bem como para os agrupamentos identificados nas análises apresentadas em seguida, está apresentada nas Tabelas 5 e 6 , respectivamente. Como uma subestruturação foi identificada dentro do grupo Índico leste + Pacífico, evidenciando a distinção da Nova Caledônia (Tabela 8), os índices descritivos foram recalculados excluindo essa localidade. Assim, $S=23 ; \mathrm{h}=20 ; \mathrm{Hd}=$ 0,862; $\pi=0,00429$ e $K=2,38655$. O mesmo foi feito para o Índico oeste + mar Mediterrâneo excluindo a Índia: $S=4 ; \mathrm{h}=5 ; \mathrm{Hd}=0,709 ; \pi=0,00235$ e K = 1,30909. Isso foi feito, pois esta localidade apresentou diferença genética com as demais, embora as variações encontradas nas sequências retiradas do GenBank se concentraram nas suas extremidades, região normalmente muito variável. 
Tabela 5. Resultados obtidos da estatística descritiva para cada localidade nativa e do mar Mediterrâneo de Charybdis hellerii amostrada a partir de sequências parciais do gene mitocondrial COI. Símbolos: N, indivíduos amostrados; S, sítios polimórficos; $\mathrm{H}$, haplótipos; Hd, diversidade haplotípica; $\pi$, diversidade nucleotídica; $\mathrm{K}$, número médio de diferenças nucleotídicas.

\begin{tabular}{l|c|c|c|c|c|c}
\hline Localidade & $\mathbf{N}$ & $\mathbf{S}$ & $\mathbf{H}$ & $\mathbf{H d}$ & $\mathbf{\pi}$ & $\mathbf{K}$ \\
\hline Austrália & 13 & 6 & 6 & 0,641 & 0,00166 & 0,92308 \\
Filipinas & 4 & 9 & 4 & 1,000 & 0,00839 & 4,66667 \\
Guam & 1 & - & - & - & - & - \\
Japão & 1 & - & - & - & - & - \\
Singapura & 4 & 5 & 4 & 1,000 & 0,00450 & 2,50000 \\
China & 7 & 9 & 6 & 0,952 & 0,00514 & 2,85714 \\
Indonésia & 5 & 4 & 4 & 0,900 & 0,00288 & 1,60000 \\
Nova & 5 & 1 & 2 & 0,400 & 0,00072 & 0,40000 \\
Caledônia & 4 & 3 & 2 & 0,500 & 0,00270 & 1,50000 \\
Turquia & 4 & 3 & 4 & 1,000 & 0,00300 & 1,66667 \\
Irã & 1 & - & - & - & - & - \\
Emirados & 1 & - & - & - & - & - \\
Árabes Unidos & 1 & - & - & - & - & - \\
Israel & 2 & 0 & 1 & 0,000 & 0,00000 & 0,00000 \\
Egito & Índia &
\end{tabular}

Tabela 6. Resultados obtidos da estatística descritiva para os agrupamentos identificados nas áreas de ocorrência nativa e do mar Mediterrâneo de Charybdis hellerii amostradas a partir de sequências parciais do gene mitocondrial COI. Símbolos: N, indivíduos amostrados; S, sítios polimórficos; $\mathrm{H}$, haplótipos; $\mathrm{Hd}$, diversidade haplotípica; $\pi$, diversidade nucleotídica; $\mathrm{K}$, número médio de diferenças nucleotídicas.

\begin{tabular}{l|c|c|c|c|c|c}
\hline Agrupamentos & N & S & H & Hd & T & K \\
\hline $\begin{array}{l}\text { Pacífico + Índico } \\
\text { Leste }\end{array}$ & 40 & 24 & 22 & 0,887 & 0,00441 & 2,45385 \\
$\begin{array}{l}\text { Índico Oeste + mar } \\
\text { Mediterrâneo }\end{array}$ & 13 & 9 & 6 & 0,782 & 0,00461 & 2,56410 \\
\hline
\end{tabular}




\subsubsection{Rede de haplótipos}

Com base no alinhamento de 556 pares de base das sequências de COI obtidas a partir de 53 exemplares de $C$. hellerii proveniente das potenciais populações de origem das populações americanas, foram detectados 28 haplótipos em 14 localidades. Destes, 21 (75\%) consistiram em haplótipos individuais (singletons), ou seja, encontrados em um único indivíduo.

A rede de haplótipos evidenciou a separação de dois agrupamentos. Um contendo os indivíduos do mar Mediterrâneo e do oceano Índico oeste (representado em tons de verde na Figura 7) e o outro contendo os espécimes do oceano Índico leste e do Pacífico (representado em tons de azul na Figura 7), sendo que o primeiro grupo conteve 13 exemplares e o segundo, 40 . Um total de $50 \%$ (3 dentre 6 ) dos haplótipos do primeiro grupo consistiram em singletons, enquanto que estes representaram $81,8 \%$ (18 dentre 22) dos haplótipos do segundo. Este alto número de singletons, mais especificamente para o grupo Índico leste + Pacífico, reflete-se na conformação de estrela (star shape) apresentada por ele na rede de haplótipos, no qual se nota poucos haplótipos com frequência elevada e vários haplótipos diferindo por uma ou poucas mutações (Figura 7).

Dentre os haplótipos compartilhados por mais de um indivíduo, o haplótipo 1 foi o mais frequente, sendo compartilhado por 13 indivíduos provenientes de diversas localidades no oceano Índico leste e Pacífico. Os indivíduos do mar Mediterrâneo e do oceano Índico oeste formaram um clado monofilético na análise filogenética conduzida por Máxima Verossimilhança com essas sequências (Figura 7, A). 


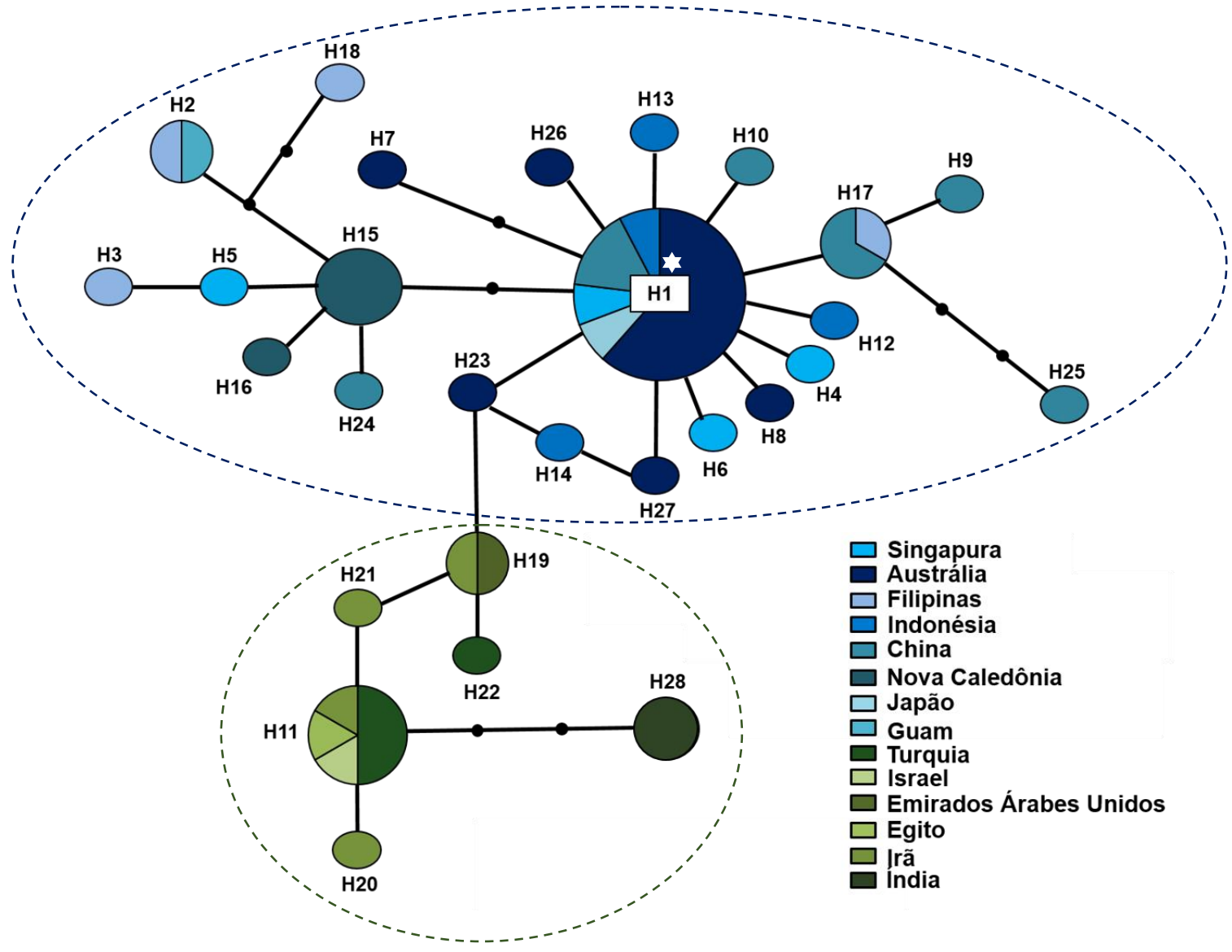

Figura 7. Rede de haplótipos gerada por parcimônia estatística no programa TCS a partir de sequências do gene COI de exemplares de $C$. hellerii provenientes do mar Mediterrâneo e de suas populações nativas nos oceanos Índico e Pacífico. O asterisco branco representa 0 haplótipo ancestral e o tamanho dos círculos é proporcional ao número de indivíduos portando os haplótipos. Cada linha da rede representa um passo mutacional e os pequenos círculos pretos representam haplótipos hipotéticos não amostrados. O tracejado azul delimita o agrupamento Índico leste + Pacífico. O tracejado verde delimita o agrupamento: Índico oeste + mar Mediterrâneo.

\subsubsection{Bayesian Analysis of Population Structure (BAPS)}

A Bayesian Analysis of Population Structure agrupou os indivíduos em dois clusters com base nas sequências de COI dos indivíduos das áreas nativas e do mar Mediterrâneo (Figura 8, B) suportados por um valor de probabilidade posterior igual a 0,92802. Estes grupos foram os mesmos identificados na rede de haplótipos (Figura 7), um contendo os espécimes do mar Mediterrâneo e do oceano Índico oeste e o outro, os indivíduos do Índico leste e do Pacífico, distintos por uma divergência 
genética de $0,7 \%$ a 1,4\% neste marcador. Esta análise, porém, não detectou mistura entre os indivíduos dos dois clusters.

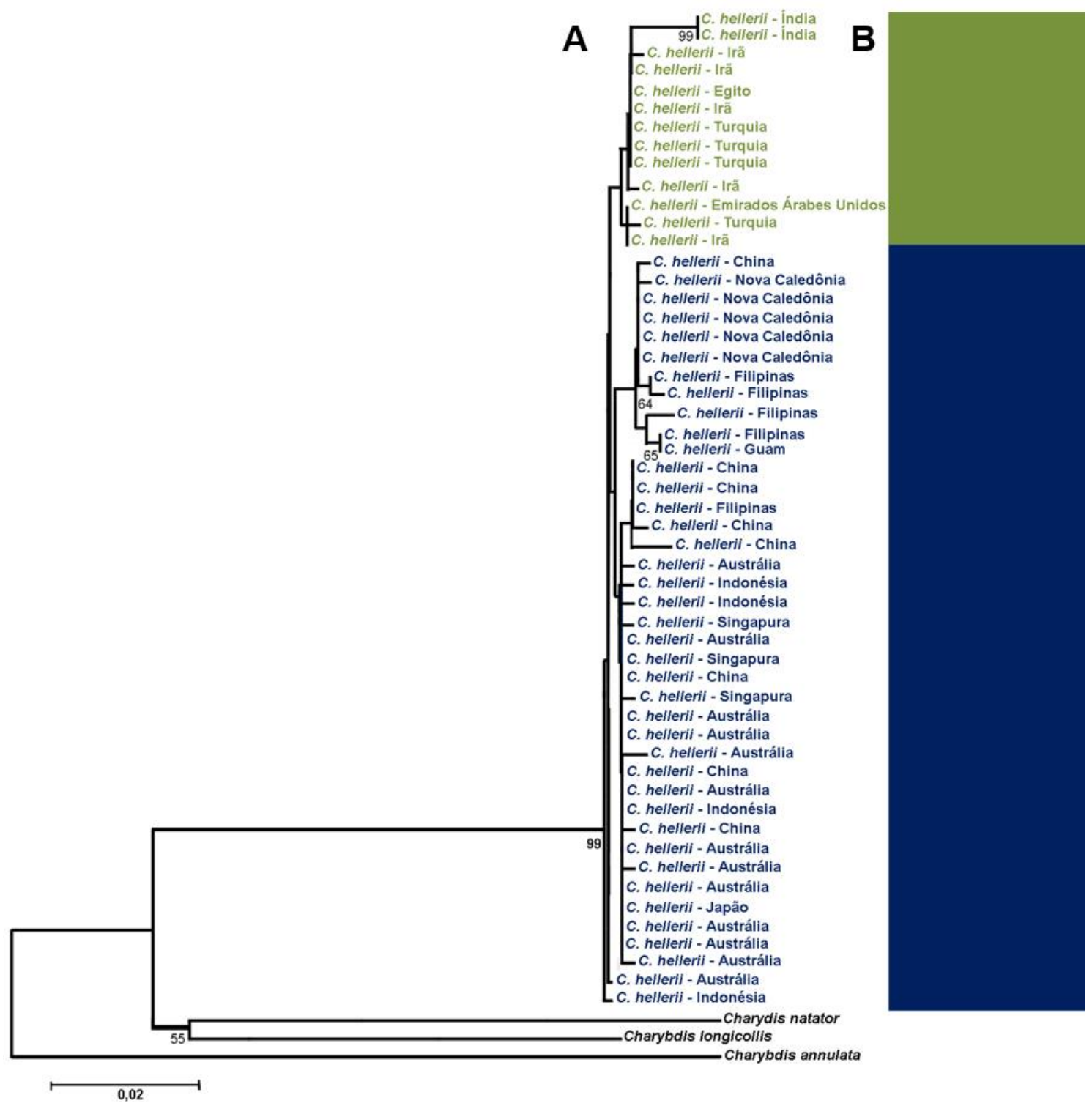

Figura 8. A, Filograma obtido pelo critério de Máxima Verossimilhança a partir sequências parciais do gene COI de espécimes de Charybdis hellerii provenientes do mar Mediterrâneo e de suas populações nativas nos oceanos Índico e Pacífico. Os números próximos aos nós correspondem aos valores de bootstrap para 408 réplicas e apenas são mostrados valores de bootstrap > 50\%. B, Gráfico em barras gerado pela Análise Bayesiana de Estruturação Populacional (BAPS) a partir de sequências parciais do gene COI de espécimes de Charybdis hellerii provenientes do mar Mediterrâneo e de suas populações nativas nos oceanos Índico e Pacífico. A probabilidade posterior para a separação dos dois clusters observados foi de 0,92802. Os indivíduos representados em azul ou verde no filograma (A) encontram-se no cluster de mesma cor no gráfico de barras (B). 


\subsubsection{Análise de Variância Molecular (AMOVA)}

Na Análise de Variância Molecular, quando nenhuma estruturação foi definida, a maior parte da variação foi encontrada dentro das localidades (52,013\%), embora alta e significativa porcentagem de variação também tenha sido encontrada entre elas (47,986\%). Definindo-se os dois grupos detectados nas análises anteriores (Mar Mediterrâneo + oceano Índico oeste e oceano Índico leste + Pacífico), uma porcentagem significativa de variação foi encontrada entre eles (38,739\%), confirmando sua diferenciação. Contudo, a maior parte da variação foi significativamente detectada dentro das localidades $(40,375 \%)$ e um variação significativa também foi encontrada entre as localidades dentro dos grupos $(20,884 \%)$ (Tabela 7). Os índices $\phi s t, \phi c t$ e $\phi s c$ foram todos significativos, indicando a existência de estruturação entre as localidades amostradas e grupos considerados (Tabela 7).

Tabela 7. Resultados da análise de variância molecular (AMOVA) realizadas com as sequências de $\mathrm{COI}$ de espécimes de Charybdis hellerii provenientes de diversas localidades do Indo-Pacífico e do mar Mediterrâneo. *Valores significativos, $p<0,05$. A estrutura testada foi estabelecida a priori.

\begin{tabular}{|c|c|c|c|}
\hline Estruturação & $\begin{array}{l}\text { Fonte de } \\
\text { variação }\end{array}$ & $\begin{array}{l}\text { Porcentagem } \\
\text { de variação }\end{array}$ & Fixation index \\
\hline Ausente & $\begin{array}{l}\text { Entre } \\
\text { localidades } \\
\text { Dentro das } \\
\text { localidades }\end{array}$ & $\begin{array}{l}47,986 \% \\
52,013 \%\end{array}$ & $\begin{array}{c}\phi s t=0,47^{*} \\
(p=0,00)\end{array}$ \\
\hline \multirow[t]{2}{*}{$\begin{array}{l}\text { AMOVA hierárquica } \\
\text { (2 grupos: Pacífico + } \\
\text { Índico Leste X } \\
\text { Índico Oeste e Mar } \\
\text { Mediterrâneo) }\end{array}$} & $\begin{array}{l}\text { Entre grupos } \\
\text { Entre } \\
\text { localidades } \\
\text { dentro dos } \\
\text { grupos }\end{array}$ & $38,739 \%$ & $\begin{aligned} \phi c t & =0,38^{*} \\
(p & =0,00)\end{aligned}$ \\
\hline & $\begin{array}{l}\text { Dentro das } \\
\text { localidades }\end{array}$ & $40,375 \%$ & $\begin{array}{c}\phi s t=0,59^{*} \\
(p=0,00)\end{array}$ \\
\hline
\end{tabular}

Os valores de Fst calculados par a par entre as localidades amostradas do agrupamento Índico leste + Pacífico estão apresentados na Tabela 8. Os indivíduos da 
Nova Caledônia se mostram geneticamente distintos dentre as demais localidades, apresentando menor estruturação apenas em relação a Singapura. Um indício de estruturação também foi detectado entre o Nordeste da Austrália e algumas localidades, Filipinas, China e Nova Caledônia (Tabela 8). Na comparação das localidades amostradas no oeste do oceano Índico e no mar Mediterrâneo o valor de Fst entre o Irã e a Turquia $(0,07692)$ não foi significativo, assim como o valor encontrado entre a Índia e o Irã (0,31429). O valor de Fst encontrado entre a Índia e a Turquia $(0,64179)$ foi significativo $(p<0,05)$.

Tabela 8. Valores de Fst calculados entre pares de localidades da distribuição nativa de Charybdis hellerii para sequências parciais do gene COI. * Valores significativos, $p<0,05$; ${ }^{* *}$ Valores significativos, $p<0,10$.

\begin{tabular}{|c|c|c|c|c|c|c|c|}
\hline Localidades & 1 & 2 & 3 & 4 & 5 & 6 & 7 \\
\hline $\begin{array}{l}\text { 1. Austrália (Nordeste - n } \\
=7 \text { ) }\end{array}$ & - & & & & & & \\
\hline 2. Austrália (Oeste $-n=5$ ) & 0,13592 & - & & & & & \\
\hline 3. Filipinas $(n=4)$ & $0,43278^{*}$ & 0,05308 & - & & & & \\
\hline 4. Singapura $(n=4)$ & 0,26139 & $-0,05263$ & 0 & - & & & \\
\hline 5. China $(n=7)$ & $0,29457^{*}$ & 0,01587 & $-0,04850$ & $-0,00946$ & - & & \\
\hline 6. Indonésia $(n=5)$ & 0,13592 & $-0,07143$ & 0,05308 & $-0,05263$ & 0,01587 & - & \\
\hline 7. Nova Caledônia $(n=5)$ & $0,66595^{*}$ & $0,35000^{*}$ & $0,32551^{*}$ & $0,32551^{\star *}$ & $0,29527^{*}$ & $0,35000^{*}$ & - \\
\hline
\end{tabular}

\subsubsection{Testes de neutralidade}

O teste de neutralidade $D$ de Tajima, realizado separadamente para cada agrupamento identificado, apresentou valor negativo e significativo para o grupo contendo animais do Pacífico e do Índico leste, regiões de ocorrência nativa da espécie, indicando desvio da neutralidade. Embora negativo, esse valor não foi significativo para o outro agrupamento (Tabela 9). O mesmo padrão foi encontrado para o Fs de Fu (Tabela 9). 
Tabela 9. Testes de neutralidade a partir de sequências parciais do gene $\mathrm{COI}$ de indivíduos de Charybdis hellerii provenientes das áreas amostradas em sua distribuição nativa e no mar Mediterrâneo, calculados de acordo com os agrupamentos identificados na análise filogenética, rede de haplótipos, BAPS e AMOVA.

\begin{tabular}{l|c|c}
\hline Agrupamento populacional & D de Tajima & Fs de Fu \\
\hline Pacífico + Índico Leste & $-1,906^{*}(p<0,05)$ & $-22,232^{*}(p<0,02)$ \\
Índico Oeste + mar Mediterrâneo & $-0,456(p>0,10)$ & $-0,491(p>0,10)$ \\
\hline
\end{tabular}

\subsubsection{Estimativas do sentido de movimento da migração - Migrate-n}

O sentido de migração entre os dois agrupamentos detectados, bem como a quantidade de migrantes, foi estimado no software Migrate-n. Dentre as quatro configurações testadas, a migração apenas no sentido do grupo do Pacífico + Índico leste para o grupos do Índico oeste + mar Mediterrâneo foi a que apresentou maior probabilidade $(0,838)$ (Tabela 10$)$. Tomando em conta essa configuração mais provável, o número efetivo de migrantes por geração estimado foi igual a 172763,35. Nessa configuração haveria, portanto, uma restrição para a dispersão no sentido oposto, ou seja, do Índico oeste + mar Mediterrâneo para o Pacífico + Índico leste.

Tabela 10. Probabilidades da ocorrência de migração ou ausência desta entre os dois grupos identificados nas localidades nativas e mar Mediterrâneo em quatro cenários diferentes estimadas com base nas sequências parciais do gene mitocondrial COI por meio do programa Migrate-n.

\begin{tabular}{l|c}
\hline Configurações de migração & Probabilidades \\
\hline Pacífico + Índico leste $\rightarrow$ Índico oeste + mar Mediterrâneo & 0,838 \\
Índico oeste + mar Mediterrâneo $\rightarrow$ Índico oeste + mar & 0,003 \\
Mediterrâneo & 0,000 \\
Ausente & 0,159 \\
Panmítica & \\
\hline
\end{tabular}




\subsection{Análises populacionais - localidades nativas e do mar Mediterrâneo (16S rDNA)}

\subsubsection{Estatística descritiva}

A partir do alinhamento de 497 pares de base de sequências parciais do gene 16S rDNA obtidas de 55 indivíduos provenientes de 13 localidades das áreas nativas e do mar Mediterrâneo, foram encontrados 8 haplótipos (h), resultado de 7 sítios polimórficos $(\mathrm{S})$, com diversidade haplotípica $(\mathrm{Hd})$ de 0,716 , diversidade nucleotídica ( $\pi)$ de 0,00192 e número médio de diferenças nucleotídicas $(K)$ igual a 0,95354. A proporção de bases encontradas nas sequências obtidas foi: $A=0,3400 ; C=0,1088$; $\mathrm{G}=0,1851$ e $\mathrm{T}=0,3661$.

A estatística descritiva obtida por meio das sequências parciais do gene $16 \mathrm{~S}$ rDNA para as localidades amostradas, bem como para os agrupamentos identificados nas análises apresentadas a diante e por regiões geográficas, está apresentada nas Tabelas 11, 12 e 13, respectivamente. Como uma subestruturação foi identificada dentro do grupo Índico leste + Pacífico, evidenciando a distinção da Nova Caledônia (Tabela 8; Figura 9), os índices descritivos foram recalculados excluindo essa localidade. Assim, $\mathrm{S}=7 ; \mathrm{h}=8 ; \mathrm{Hd}=0,576 ; \pi=0,00140$ e $\mathrm{K}=0,70588$. 
Tabela 11. Resultados obtidos da estatística descritiva para cada localidade nativa e do mar Mediterrâneo de Charybdis hellerii amostrada a partir de sequências parciais do gene mitocondrial 16S rDNA. Símbolos: N, indivíduos amostrados; S, sítios polimórficos; H, haplótipos; $\mathrm{Hd}$, diversidade haplotípica; $\pi$, diversidade nucleotídica; $\mathrm{K}$, número médio de diferenças nucleotídicas.

\begin{tabular}{l|c|c|c|c|c|c}
\hline Localidade & $\mathbf{N}$ & $\mathbf{S}$ & $\mathbf{H}$ & $\mathbf{H d}$ & $\mathbf{\pi}$ & $\mathbf{K}$ \\
\hline Austrália & 12 & 3 & 4 & 0,455 & 0,00101 & 0,50000 \\
Filipinas & 6 & 2 & 3 & 0,600 & 0,00134 & 0,66667 \\
Guam & 2 & 1 & 2 & 1,000 & 0,00201 & 1,00000 \\
Japão & 1 & - & - & - & - & - \\
Singapura & 4 & 1 & 2 & 0,500 & 0,00101 & 0,50000 \\
China & 7 & 2 & 3 & 0,524 & 0,00115 & 0,57143 \\
Indonésia & 4 & 1 & 2 & 0,500 & 0,00101 & 0,50000 \\
Nova & 7 & 0 & 1 & 0,000 & 0,00000 & 0,00000 \\
Caledônia & 4 & 0 & 1 & 0,000 & 0,00000 & 0,00000 \\
Turquia & 4 & 0 & 1 & 0,000 & 0,00000 & 0,00000 \\
Irã & 1 & - & - & - & - & - \\
Emirados & 1 & - & - & - & - & - \\
Árabes Unidos & 2 & 0 & 1 & 0,000 & 0,00000 & 0,00000 \\
Kuwait & Índia &
\end{tabular}

Tabela 12. Resultados obtidos da estatística descritiva para os agrupamentos identificados nas áreas de ocorrência nativa e do mar Mediterrâneo de Charybdis hellerii amostradas a partir de sequências parciais do gene mitocondrial 16S rDNA. Símbolos: N, indivíduos amostrados; S, sítios polimórficos; $\mathrm{H}$, haplótipos; $\mathrm{Hd}$, diversidade haplotípica; $\pi$, diversidade nucleotídica; $\mathrm{K}$, número médio de diferenças nucleotídicas.

\begin{tabular}{l|c|c|c|c|c|c}
\hline $\begin{array}{l}\text { Agrupamentos } \\
\text { genéticos }\end{array}$ & $\mathbf{N}$ & $\mathbf{S}$ & $\mathbf{H}$ & $\mathbf{H d}$ & $\mathbf{T}$ & $\mathbf{K}$ \\
\hline $\begin{array}{l}\text { Pacífico + Índico } \\
\text { Leste - 1 }\end{array}$ & 27 & 4 & 5 & 0,279 & 0,00060 & 0,29630 \\
$\begin{array}{l}\text { Pacífico + Índico } \\
\text { Leste - 2 }\end{array}$ & 15 & 1 & 2 & 0,133 & 0,00027 & 0,13333 \\
$\begin{array}{l}\text { Índico Oeste + } \\
\text { mar } \\
\begin{array}{l}\text { Mediterrâneo + } \\
\text { Austrália }\end{array}\end{array}$ & 13 & 0 & 1 & 0,000 & 0,00000 & 0,00000 \\
\hline
\end{tabular}


Tabela 13. Resultados obtidos da estatística descritiva para os agrupamentos geográficos identificados nas áreas de ocorrência nativa e do mar Mediterrâneo de Charybdis hellerii para o marcador mitocondrial 16S rDNA. Símbolos: N, indivíduos amostrados; S, sítios polimórficos; H, haplótipos; $\mathrm{Hd}$, diversidade haplotípica; $\pi$, diversidade nucleotídica; $\mathrm{K}$, número médio de diferenças nucleotídicas.

\begin{tabular}{l|c|c|c|c|c|c}
\hline $\begin{array}{l}\text { Agrupamentos } \\
\text { geográficos }\end{array}$ & $\mathbf{N}$ & $\mathbf{S}$ & $\mathbf{H}$ & $\mathbf{H d}$ & $\mathbf{T}$ & $\mathbf{K}$ \\
\hline $\begin{array}{l}\text { Pacífico + Índico } \\
\text { Leste }\end{array}$ & 43 & 7 & 8 & 0,619 & 0,00150 & 0,74419 \\
$\begin{array}{l}\text { Índico Oeste + } \\
\text { mar } \\
\text { Mediterrâneo }\end{array}$ & 12 & 0 & 1 & 0,000 & 0,00000 & 0,00000 \\
\hline
\end{tabular}

\subsubsection{Rede de haplótipos}

Com base no alinhamento de 497 pares de base das sequências de 16S rDNA obtidas a partir de 55 exemplares de $C$. hellerii proveniente das potenciais populações de origem das populações americanas, foram detectados 8 haplótipos em 13 localidades. Destes, 5 (62,5\%) consistiram em haplótipos individuais (singletons). Os 3 haplótipos restantes possuem frequências mais elevadas, sendo o haplótipo 2, o de maior frequência, compartilhado por 23 indivíduos. Os indivíduos do mar Mediterrâneo e do oeste do oceano Índico apresentaram sequências idênticas, sendo que o haplótipo compartilhado por eles também foi encontrado em um indivíduo proveniente da Austrália. Todos os outros 7 haplótipos foram encontrados em indivíduos provenientes do Índico leste e do Pacífico (Figura 9). Nessa rede de haplótipos também é possível individualizar os agrupamentos identificados nas demais análises (filogenética apresentada acima; BAPS e AMOVA mostradas a seguir), nas quais foi possível não apenas distinguir os agrupamentos Pacífico + Índico Leste (representados em tons de azul na Figura 10) e Índico Oeste + mar Mediterrâneo + Austrália (representados em tons de verde na Figura 10 e nesse caso também contendo um indivíduo proveniente da Austrália), mas também dois agrupamentos dentro do primeiro, denominados de 1 e 2 (delimitados por linhas tracejadas na Figura 
9). Estes dois agrupamentos não apresentam um padrão geográfico muito nítido, mas

é possível notar que o Pacífico + Índico Leste - 2, além de indivíduos de outras localidades, inclui todos os indivíduos provenientes de Nova Caledônia.

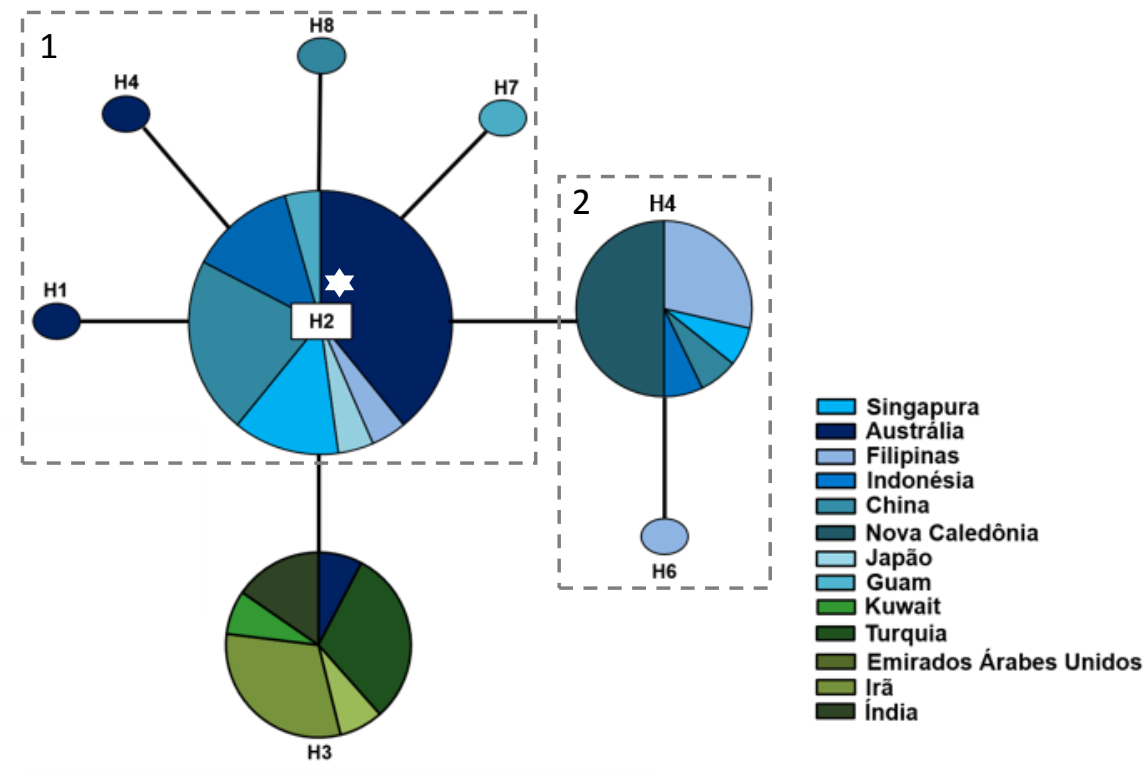

Figura 9. Rede de haplótipos gerada por parcimônia estatística no programa TCS a partir de sequências do gene 16S rDNA de exemplares de C. hellerii provenientes do mar Mediterrâneo e de suas populações nativas nos oceanos Índico e Pacífico. O asterisco branco representa 0 haplótipo ancestral e o tamanho dos círculos é proporcional ao número de indivíduos portando os haplótipos. Cada linha da rede representa um passo mutacional e as linhas tracejadas delimitam os grupos identificados dentro do Índico leste e Pacífico 1 e 2.

\subsubsection{Bayesian Analysis of Population Structure (BAPS)}

A Bayesian Analysis of Population Structure agrupou os indivíduos em três clusters com base nas sequências de 16S rDNA dos indivíduos das áreas nativas e do mar Mediterrâneo (Figura 10, B) suportados por um valor de probabilidade posterior igual a 0,55503 . Estes grupos foram os mesmos identificados na rede de haplótipos (Figura 9) e no filograma (Figura 10, A), um contendo os espécimes do mar Mediterrâneo, do oceano Índico oeste e um indivíduo da Austrália e os dois outros, indivíduos do Índico leste e do Pacífico, com uma divergência genética de 0 a 0,47\%. 
Esta análise, porém, não detectou mistura entre os indivíduos dos três clusters. Apenas o grupo contendo os indivíduos indivíduos do mar Mediterrâneo e do oceano Índico oeste mostrou-se monofilético (Figura 10, A).

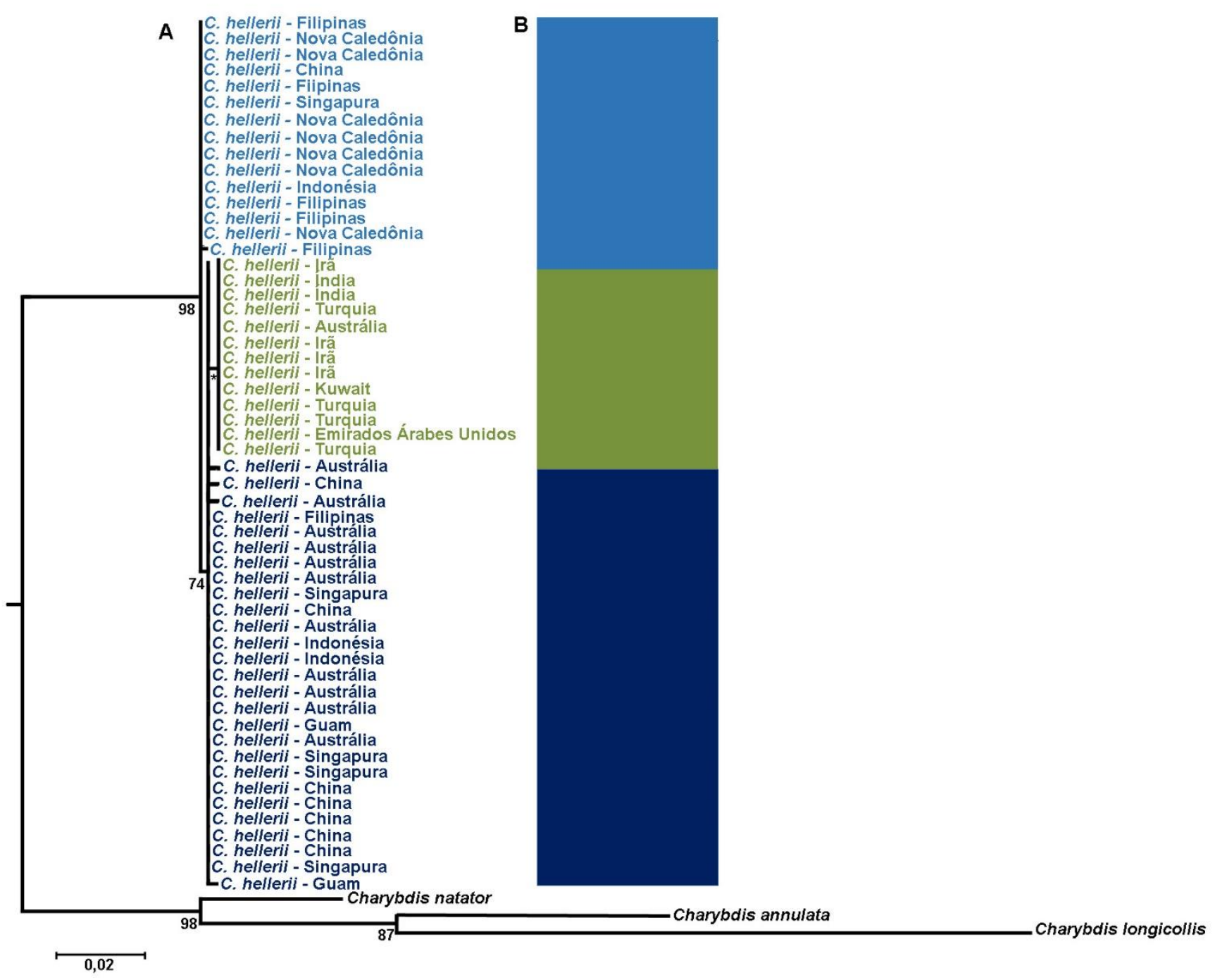

Figura 10. A, Filograma obtido pelo critério de Máxima Verossimilhança a partir sequências parciais do gene 16S rDNA de espécimes de Charybdis hellerii provenientes do mar Mediterrâneo e de suas populações nativas nos oceanos Índico e Pacífico. Os números próximos aos nós correspondem aos valores de bootstrap para 1008 réplicas e apenas são mostrados valores de bootstrap $>50 \%$. B, Gráfico em barras gerado pela Análise Bayesiana de Estruturação Populacional (BAPS) a partir de sequências parciais do gene COI de espécimes de Charybdis hellerii provenientes do mar Mediterrâneo e de suas populações nativas nos oceanos Índico e Pacífico. A probabilidade posterior para a separação dos três clusters observados foi de 0,79373 . Os indivíduos representados em azul claro, azul escuro ou verde no filograma (A) foram incluídos no cluster de mesma cor no gráfico de barras (B). 


\subsubsection{Análise de Variância Molecular (AMOVA)}

Na Análise de Variância Molecular, quando nenhuma estruturação foi definida, a maior parte da variação foi encontrada entre as localidades $(61,917 \%)$, embora alta e significativa porcentagem de variação também foi encontrada dentro delas (38,082\%). Definindo-se os três grupos detectados nas análises anteriores (Mar Mediterrâneo + oceano Índico oeste + Austrália X oceano Índico leste + Pacífico -1 X oceano Índico leste + Pacífico - 2), a maior porcentagem de variação foi encontrada entre eles (86,717\%), confirmando sua diferenciação. Contudo, $13,282 \%$ da variação foi encontrada dentro deles. Estruturando-se os grupos genéticos em dois grupos geográficos, um deles agrupando o oceano Índico leste + Pacífico e o outro contendo os indivíduos do Mar Mediterrâneo + oceano Índico oeste, 22,830\% da variação foi detectada entre os grupos geográficos, porém esta não foi significativa $(p=0,43)$. Uma porcentagem significativa de $11,991 \%$ foi encontrada dentro dos grupos geográficos (Tabela 14). 
Tabela 14. Resultados da análise de variância molecular (AMOVA) realizadas com as sequências de 16S rDNA de espécimes de Charybdis hellerii provenientes de diversas localidades do Indo-Pacífico e do mar Mediterrâneo. *Valores significativos, $p<0,05$. A estrutura testada foi estabelecida a priori.

\begin{tabular}{|c|c|c|c|}
\hline & Fonte de variação & $\begin{array}{c}\text { Porcentagem de } \\
\text { variação }\end{array}$ & Fixation index \\
\hline Sem estruturação & $\begin{array}{l}\text { Entre localidades } \\
\text { Dentro das } \\
\text { localidades }\end{array}$ & $\begin{array}{l}61,917 \% \\
38,082 \%\end{array}$ & $\begin{array}{c}\phi s t=0,62^{*} \\
(p=0,00)\end{array}$ \\
\hline $\begin{array}{l}\text { grupos genéticos: } \\
\text { Pacífico Oeste + Índico } \\
\text { Leste } 1 \text { X Pacífico Oeste } \\
+ \text { Índico Leste } 2 \text { X } \\
\text { Índico Oeste + } \\
\text { Mediterrâneo + } \\
\text { Austrália } \\
\end{array}$ & $\begin{array}{l}\text { Entre grupos } \\
\text { Dentro dos grupos }\end{array}$ & $\begin{array}{l}86,717 \% \\
13,282 \%\end{array}$ & $\begin{aligned} \phi s t & =0,867^{*} \\
(p & =0,00)\end{aligned}$ \\
\hline $\begin{array}{l}2 \text { grupos geográficos: } \\
\text { Pacífico Oeste + Índico } \\
\text { Leste X Índico Oeste + } \\
\text { Mediterrâneo }\end{array}$ & $\begin{array}{l}\text { Entre grupos } \\
\text { Entre os grupos } \\
\text { genéticos dentro } \\
\text { dos grupos } \\
\text { geográficos } \\
\text { Dentro dos grupos } \\
\text { genéticos }\end{array}$ & $\begin{array}{l}65,178 \% \\
11,991 \%\end{array}$ & $\begin{array}{c}\phi c t=0,228 \\
(p=0,43) \\
\phi s c=0,844^{*} \\
(p=0,00) \\
\phi s t=0.880^{*} \\
(p=0,00)\end{array}$ \\
\hline
\end{tabular}

\subsubsection{Testes de neutralidade}

O teste de neutralidade $D$ de Tajima, realizado separadamente para cada agrupamento genético identificado, apresentou valor negativo e significativo apenas para o grupo Pacífico Oeste + Índico Leste 1 (Tabela 15). O mesmo padrão foi encontrado para o Fs de Fu. Como as sequências dos indivíduos do grupo índico Oeste + Mar Mediterrâneo + Austrália se mostraram idênticas, o cálculo desses índices não foi possível para este grupo. Os valores de D de Tajima e Fs de Fu para o agrupamento dos dois grupos genéticos do Pacífico e Índico leste em um único grupo geográfico, foram negativos e significativos $(-1,472$ e $-4,578$, respectivamente; $p<0,05$ para ambos). Os valores negativos evidenciam desvio da neutralidade. 
Tabela 15. Testes de neutralidade a partir de sequências parciais do gene $16 \mathrm{~S}$ rDNA de indivíduos de Charybdis hellerii provenientes das áreas nativas amostradas no Índico leste e Pacífico, calculados de acordo com os agrupamentos identificados na análise filogenética, rede de hapótipos, BAPS e AMOVA. *Valores significativos, $p<0,05$.

\begin{tabular}{l|c|c}
\hline Agrupamento genético & D de Tajima & Fs de Fu \\
\hline Pacífico + Índico Leste 1 & $-1,888^{*}(p<0,05)$ & $-4,198^{*}(p<0,02)$ \\
Pacífico + Índico Leste 2 & $-1,159(p>0,10)$ & $-0,648(p>0,10)$ \\
\hline
\end{tabular}

\subsection{Análises populacionais - localidades nativas, do mar Mediterrâneo e da América (COI)}

\subsubsection{Estatística descritiva}

A partir do alinhamento de 556 pares de base de 140 indivíduos provenientes de 33 localidades ao longo da distribuição mundial de $C$. hellerii, a estatística descritiva mostrou que há 33 haplótipos (h), resultado de 50 sítios polimórficos (S), com diversidade haplotípica $(\mathrm{Hd})$ de 0,8851, diversidade nucleotídica ( $\pi$ ) de 0,01020 e número médio de diferenças nucleotídicas $(K)$ igual a 5,67102. A estatística descritiva para as localidades da América, bem como por agrupamentos genéticos e total para este continente, por meio das sequências do gene COI está apresentada nas Tabelas 16 e 17. 
Tabela 16. Resultados obtidos da estatística descritiva a partir de sequências parciais do gene mitocondrial $\mathrm{COI}$ de Charybdis hellerii provenientes de cada localidade amostrada na América. Símbolos: N, indivíduos amostrados; S, sítios polimórficos; $\mathrm{H}$, haplótipos; $\mathrm{Hd}$, diversidade haplotípica; $\pi$, diversidade nucleotídica; $\mathrm{K}$, número médio de diferenças nucleotídicas.

\begin{tabular}{l|c|c|c|c|c|c}
\hline Localidade & N & S & h & Hd & $\mathbf{\pi}$ & K \\
\hline EUA & 9 & 4 & 3 & 0,556 & 0,00189 & 1,05556 \\
Belize & 3 & 1 & 2 & 0,667 & 0,00120 & 0,66667 \\
Saint Martin & 1 & - & - & - & - & - \\
Guadalupe & 3 & 20 & 3 & 1,000 & 0,02398 & 13,33334 \\
Martinica & 3 & 20 & 3 & 1,000 & 0,02398 & 13,33334 \\
Trinidad \& Tobago & 1 & - & - & - & - & - \\
Panamá & 3 & 19 & 2 & 0,667 & 0,02278 & 12,66676 \\
Venezuela & 2 & 20 & 2 & 1,000 & 0,03597 & 20,00000 \\
Pará - Brasil & 1 & - & - & - & - & - \\
Ceará - Brasil & 4 & 1 & 2 & 0,667 & 0,00119 & 0,66667 \\
Rio Grande do Norte - Brasil & 4 & 20 & 3 & 0,834 & 0,01798 & 10,0000 \\
Pernambuco - Brasil & 1 & - & - & - & - & - \\
Alagoas - Brasil & 4 & 20 & 3 & 0,834 & 0,01798 & 10,0000 \\
Bahia - Brasil & 6 & 2 & 3 & 0,734 & 0,00204 & 1,13333 \\
Espirito Santo - Brasil & 6 & 20 & 4 & 0,867 & 0,01882 & 10,46667 \\
Rio de Janeiro - Brasil & 7 & 20 & 5 & 0,857 & 0,01148 & 6,38095 \\
São Paulo - Brasil & 22 & 22 & 8 & 0,844 & 0,01414 & 7,86147 \\
Paraná - Brasil & 2 & 5 & 2 & 1,000 & 0,00899 & 5,00000 \\
Santa Catarina - Brasil & 5 & 5 & 3 & 0,700 & 0,00360 & 2,00000 \\
\hline
\end{tabular}


Tabela 17. Resultados obtidos da estatística descritiva para os indivíduos de Charybdis hellerii da América agrupados de acordo com a estruturação identificada nas análises incluindo indivíduos provenientes de toda sua distribuição. Estes resultados foram obtidos a partir de sequências parciais do gene mitocondrial COI. Símbolos: $\mathrm{N}$, indivíduos amostrados; $\mathrm{S}$, sítios polimórficos; $\mathrm{H}$, haplótipos; $\mathrm{Hd}$, diversidade haplotípica; $\pi$, diversidade nucleotídica; K, número médio de diferenças nucleotídicas.

\begin{tabular}{l|c|c|c|c|c|c}
\hline Grupos & N & S & H & Hd & $\boldsymbol{\pi}$ & K \\
\hline $\begin{array}{l}\text { América - G1 } \\
\text { (relacionado ao mar } \\
\text { Mediterrâneo e Índico } \\
\text { oeste) }\end{array}$ & 65 & 6 & 5 & 0,675 & 0,00163 & 0,90673 \\
$\begin{array}{l}\text { América - G2 } \\
\text { (relacionado ao Índico } \\
\text { leste e Pacífico) }\end{array}$ & 7 & 5 & 5 & 0,905 & 0,00394 & 2,19048 \\
G3 & 15 & 0 & 1 & 0,000 & 0,00000 & 0,00000 \\
\hline América total & 87 & 26 & 11 & 0,790 & 0,01156 & 6,42609 \\
\hline
\end{tabular}

\subsubsection{Rede de haplótipos}

Com base no alinhamento de 556 pares de base das sequências de COI obtidas a partir de 140 exemplares de C. hellerii provenientes de sua distribuição mundial, foram detectados 33 haplótipos em 34 localidades. Destes, 20 (60,6\%) consistiram em haplótipos individuais (singletons). A rede conectando estes 33 haplótipos evidenciou a separação de três agrupamentos. Um contendo os indivíduos do mar Mediterrâneo, do oceano Índico oeste (representado em tons de verde na Figura 11) e a maioria dos indivíduos das localidades americanas. Este foi chamado de G1 e apresentou 78 indivíduos. O outro contendo os espécimes do oceano Índico leste, do Pacífico (representado em tons de azul na Figura 11) e alguns indivíduos provenientes das localidades americanas. Este foi chamado de G2 e apresentou 47 indivíduos. Por fim, um terceiro grupo (G3) contendo 15 indivíduos provenientes apenas de localidades americanas e apresentando sequências idênticas, ou seja, um único haplótipo.

Um total de $37,5 \%$, ou seja, 3 dentre 8 dos haplótipos de G1 consistiram em singletons, enquanto que estes representaram $75 \%$ de G2, ou seja, 18 dentre 24 
haplótipos. Como resultado desse elevado número de singletons e poucos haplótipos com frequência elevada, todos diferindo por uma ou poucas mutações, este último grupo (G2) apresentou uma conformação de estrela (star shape) (Figura 11). Dentre os haplótipos compartilhados por mais de um indivíduo, o haplótipo 3 foi o mais frequente, sendo compartilhado por 36 indivíduos provenientes de diversas localidades na América, do mar Mediterrâneo e do Índico oeste. Os haplótipos identificados foram distribuídos um mapa de acordo com as localidades amostradas (Figura 12). 


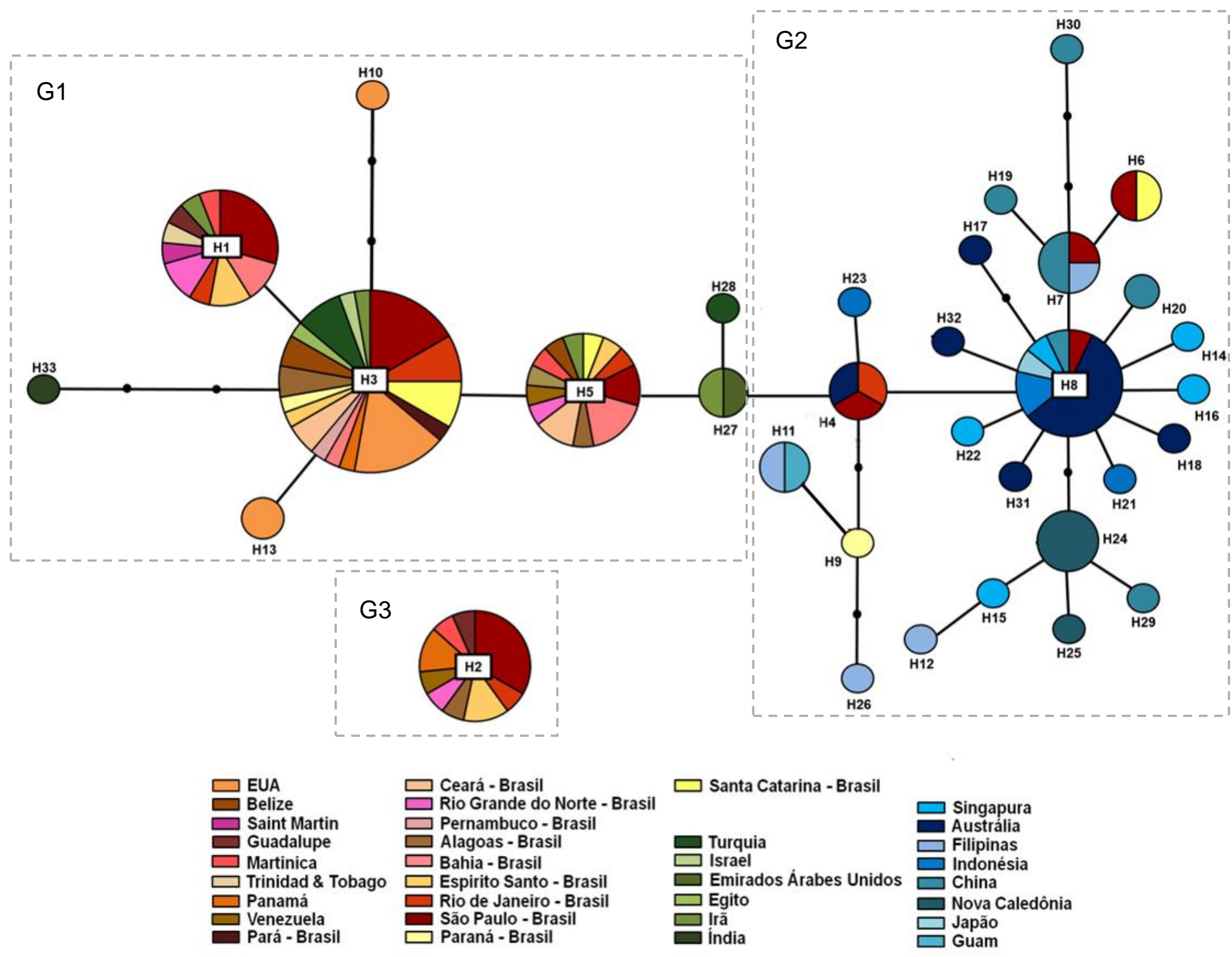

Figura 11. Rede de haplótipos gerada por parcimônia estatística no programa TCS a partir de sequências parcias do gene mitocondrial $\mathrm{COI}$ de exemplares de $C$. hellerii provenientes de sua distribuição mundial. O tamanho dos círculos é proporcional ao número de indivíduos portando os haplótipos. Cada linha da rede representa um passo mutacional e as linhas tracejadas delimitam os grupos identificados G1, G2 e G3. 


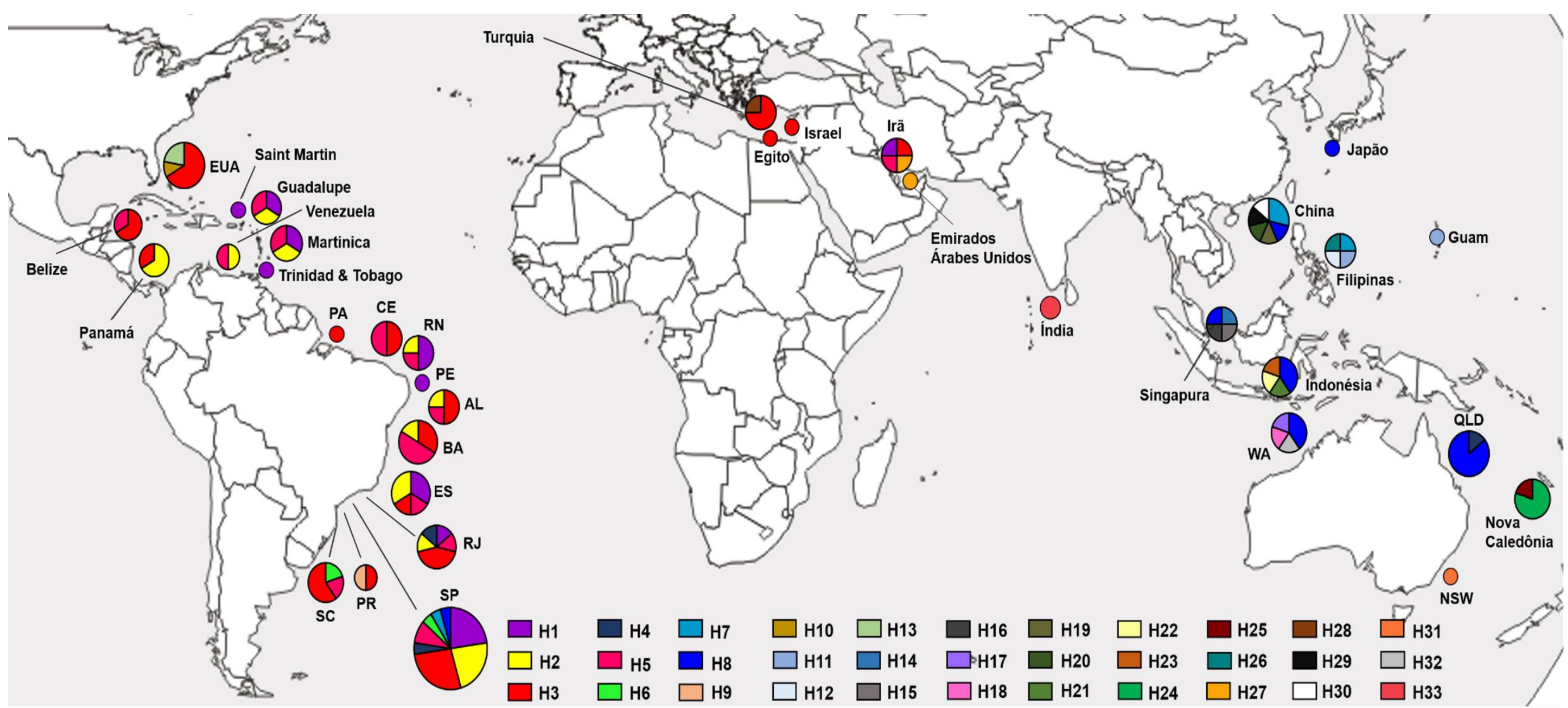

Figura 12. Distribuição dos haplótipos $(\mathrm{H})$ de Charybdis hellerii detectados a partir de sequências parciais do gene mitocondrial COI ao longo das localidades amostradas. 


\subsubsection{Bayesian Analysis of Population Structure (BAPS)}

A Bayesian Analysis of Population Structure agrupou todos os indivíduos em três clusters com base nas sequências de COI (Figura 13, B) suportados por um valor de probabilidade posterior igual a 1,00000. Estes grupos foram os mesmos identificados na rede de haplótipos, G1, G2 e G3 (Figura 11, B). Assim, a maioria dos indivíduos da América foi agrupada com os indivíduos do mar Mediterrâneo e do Índico oeste em G1; apenas sete indivíduos do litoral sul do Brasil foram agrupados com os indivíduos do Índico leste e do Pacífico em G2, bem como foi detectado um agrupamento com 15 indivíduos provenientes de diversas localidades da América (Figura 13, B). Além disso, foi detectado um pequeno grau de mistura entre os clusters G1 e G2 (Figura 13, B). Os espécimes agrupados pela BAPS estão identificados com a mesma cor no filograma construído pelo critério de Máxima Verossimilhança (Figura 13, A). Neste, G1 e G3 formaram grupos monofiléticos, mas não suportados por alto valores de bootstrap. 


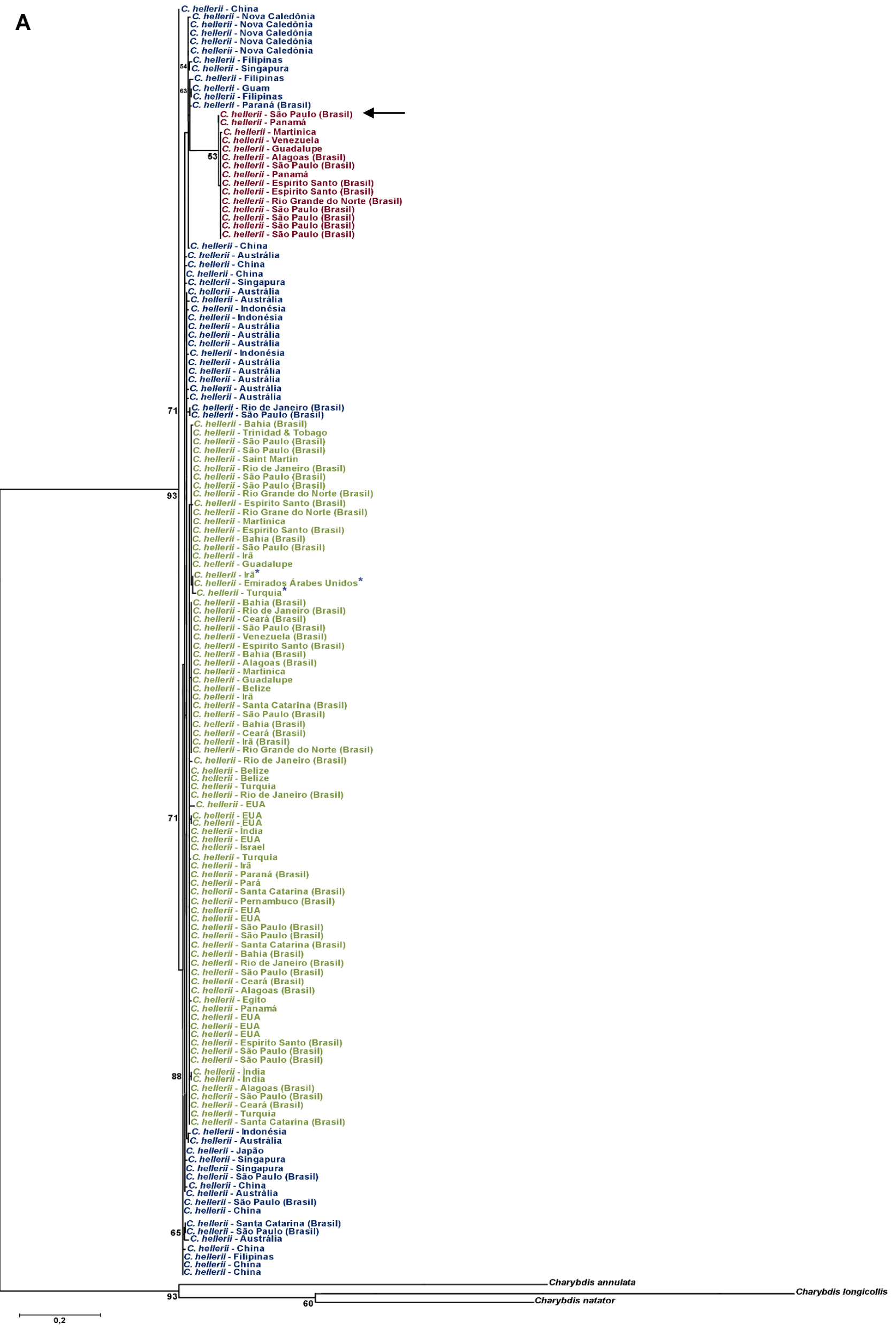


B

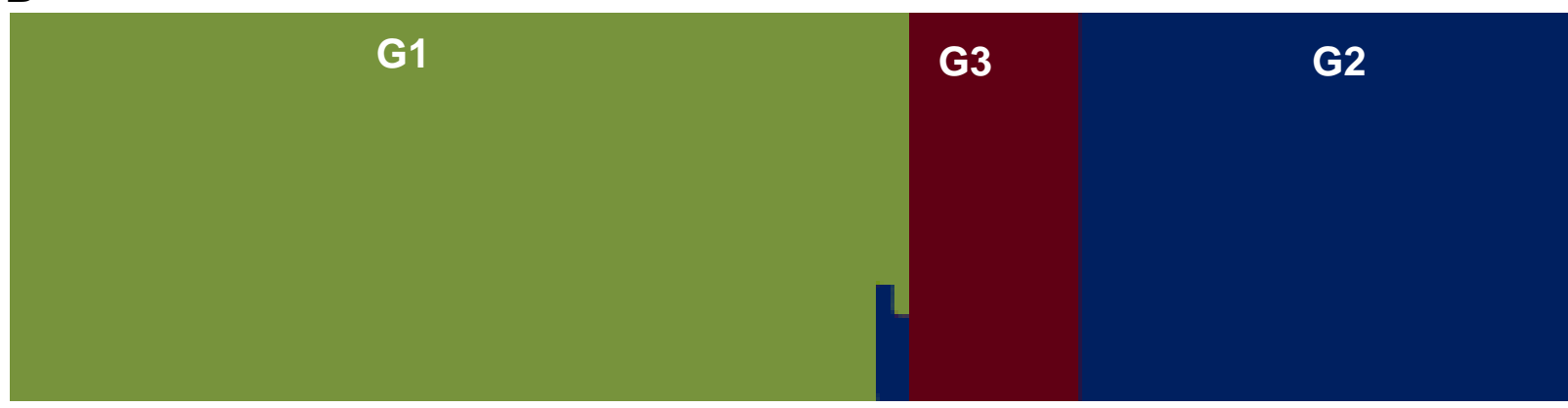

Figura 13. A, Filograma obtido pelo critério de Máxima Verossimilhança a partir sequências parciais do gene $\mathrm{COI}$ de espécimes de Charybdis hellerii provenientes de toda sua distribuição. Os números próximos aos nós correspondem aos valores de bootstrap para 600 réplicas e apenas são mostrados valores de bootstrap $>50 \%$. Os espécimes marcados com um asterisco são aqueles nos quais a mistura com G2 foi detectada no BAPS. B, Gráfico em barras gerado pela Análise Bayesiana de Estruturação Populacional (BAPS) a partir de sequências parciais do gene $\mathrm{COI}$ de espécimes de Charybdis hellerii provenientes de toda sua distribuição. A probabilidade posterior para a separação dos três clusters observados foi de 1,00000. G1, cluster que contém os indivíduos representados na mesma cor na árvore filogenética (A), ou seja, maioria dos espécimes da América, todos do mar Mediterrâneo e do Índico oeste; G2, cluster que contém os indivíduos representados na mesma cor na árvore filogenética (A), ou seja, sete espécimes da América, todos do Índico leste e Pacífico; G3, cluster que contém os indivíduos representados na mesma cor na árvore filogenética $(A)$ contendo quinze indivíduos de diversas localidades americanas. A seta indica o espécime utilizado para o registro de Charybdis variegata na costa americana por Sant'Anna et al. (2012). 


\subsection{Análises populacionais - localidades nativas, do mar Mediterrâneo e da América (16S rDNA)}

\subsubsection{Estatística descritiva}

A partir do alinhamento de 497 pares de base de 121 indivíduos provenientes de 33 localidades ao longo da distribuição mundial de $C$. hellerii, a estatística descritiva mostrou que há 23 haplótipos (h), resultado de 15 sítios polimórficos (S), com diversidade haplotípica $(\mathrm{Hd})$ de 0,8282, diversidade nucleotídica ( $\pi$ ) de 0,00306 e número médio de diferenças nucleotídicas $(\mathrm{K})$ igual a 1,55069. A estatística descritiva para as localidades da América, bem como para os agrupamentos genéticos e total para este continente, por meio das sequências do gene 16S rDNA está apresentada nas Tabelas 18 e 19. Como o agrupamento C3 (ver análise de estruturação populacional a diante) não apresentou animais da América, este não foi utilizado para os cálculos de estatística descritiva dos agrupamentos da América. 
Tabela 18. Resultados obtidos da estatística descritiva a partir de sequências parciais do gene mitocondrial 16S rDNA de Charybdis hellerii provenientes de cada localidade amostrada na América. Símbolos: N, indivíduos amostrados; S, sítios polimórficos; $\mathrm{H}$, haplótipos; $\mathrm{Hd}$, diversidade haplotípica; $\pi$, diversidade nucleotídica; K, número médio de diferenças nucleotídicas.

\begin{tabular}{l|c|c|c|c|c|c}
\hline Localidade & N & S & H & Hd & $\mathbf{\pi}$ & K \\
\hline EUA & 5 & 3 & 3 & 0,800 & 0,00316 & 1,60000 \\
Belize & 3 & 1 & 2 & 0,667 & 0,00132 & 0,66667 \\
Saint Martin & 1 & - & - & - & - & - \\
Guadalupe & 4 & 3 & 2 & 0,500 & 0,00296 & 1,50000 \\
Martinica & 3 & 3 & 2 & 0,667 & 0,00395 & 2,00000 \\
Trinidad \& Tobago & 1 & - & - & - & - & - \\
Panamá & 3 & 3 & 3 & 1,000 & 0,00395 & 2,00000 \\
Venezuela & 4 & 3 & 2 & 0,500 & 0,00296 & 1,50000 \\
Guiana Francesa & 1 & - & - & - & - & - \\
Pará - Brasil & 1 & - & - & - & - & - \\
Ceará - Brasil & 2 & 1 & 2 & 1,000 & 0,00198 & 1,00000 \\
Rio Grande do Norte - & 3 & 2 & 2 & 0,667 & 0,00264 & 1,33333 \\
Brasil & 1 & - & - & - & - & - \\
Pernambuco - Brasil & 4 & 4 & 3 & 0,833 & 0,00395 & 2,00000 \\
Alagoas - Brasil & 2 & 0 & 1 & 0,000 & 0,00000 & 0,00000 \\
Bahia - Brasil & 3 & 3 & 2 & 0,667 & 0,00395 & 2,00000 \\
Espirito Santo - Brasil & 3 & 4 & 3 & 1,000 & 0,00527 & 2,66667 \\
Rio de Janeiro - Brasil & 16 & 7 & 7 & 0,742 & 0,00359 & 1,81667 \\
São Paulo - Brasil & 1 & - & - & - & - & - \\
Paraná - Brasil & 5 & 2 & 2 & 0,400 & 0,00158 & 0,80000 \\
Santa Catarina - Brasil & \multicolumn{5}{|}{}
\end{tabular}


Tabela 19. Resultados obtidos da estatística descritiva para os indivíduos de Charybdis hellerii da América agrupados de acordo com a estruturação identificada nas análises incluindo indivíduos provenientes de toda sua distribuição. Estes resultados foram obtidos a partir de sequências parciais do gene mitocondrial 16S rDNA. Símbolos: N, indivíduos amostrados; S, sítios polimórficos; $\mathrm{H}$, haplótipos; Hd, diversidade haplotípica; $\pi$, diversidade nucleotídica; K, número médio de diferenças nucleotídicas.

\begin{tabular}{l|c|c|c|c|c|c}
\hline Grupos genéticos & $\mathbf{N}$ & $\mathbf{S}$ & $\mathbf{H}$ & $\mathbf{H d}$ & $\mathbf{T}$ & $\mathbf{K}$ \\
\hline $\begin{array}{l}\text { América - C1 } \\
\text { (relacionados ao mar } \\
\text { Mediterrâneo e Índico } \\
\text { oeste) }\end{array}$ & 38 & 5 & 6 & 0,334 & 0,00071 & 0,35989 \\
$\begin{array}{l}\text { América - C2 } \\
\text { (relacionados ao Índico } \\
\text { leste e Pacífico) }\end{array}$ & 2 & 0 & 0 & 0,000 & 0,00000 & 0,00000 \\
C4 & 16 & 4 & 4 & 0,442 & 0,00120 & 0,60833 \\
C5 & 10 & 2 & 3 & 0,378 & 0,00079 & 0,40000 \\
\hline América total & 66 & 10 & 13 & 0,736 & 0,00326 & 1,64942 \\
\hline
\end{tabular}

\subsubsection{Rede de haplótipos}

Com base no alinhamento de 497 pares de base das sequências de 16S rDNA obtidas a partir de 121 exemplares de C. hellerii provenientes de sua distribuição mundial, foram detectados 23 haplótipos em 34 localidades. Destes, 14 (60,8\%) consistiram em haplótipos individuais (singletons). A rede conectando estes 23 haplótipos evidenciou a separação dos cinco agrupamentos (Figura 14), encontrados também na análise BAPS apresentada a seguir (Figura 15, B). Os haplótipos diferiram por uma ou poucas mutações. Dentre os haplótipos compartilhados por mais de um indivíduo, o haplótipo 1 foi o mais frequente, sendo compartilhado por 40 indivíduos provenientes de diversas localidades na América, do mar Mediterrâneo e do Índico oeste. 


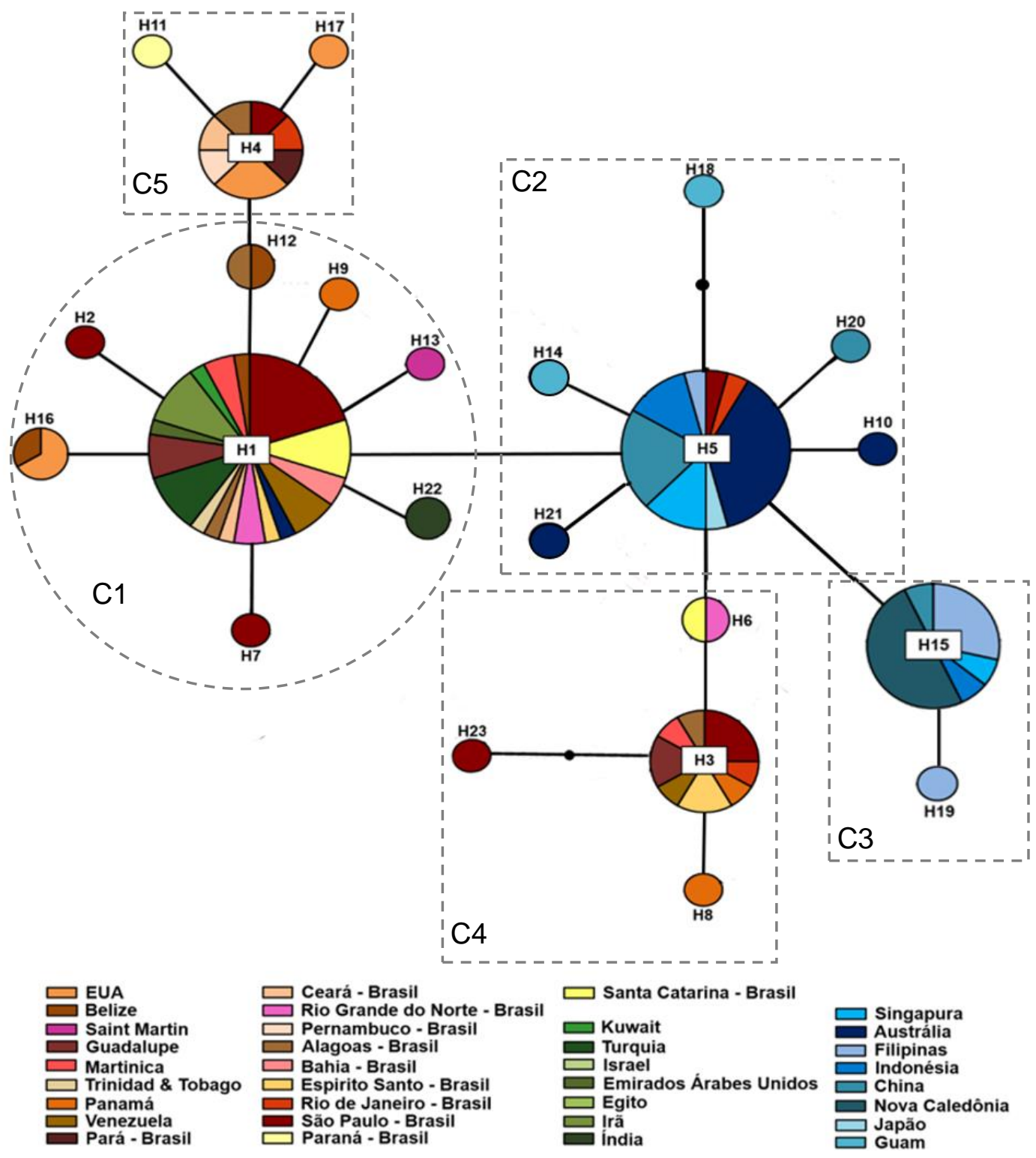

Figura 14. Rede de haplótipos gerada por parcimônia estatística no programa TCS a partir de sequências parciais do gene mitocondrial 16S rDNA de exemplares de $C$. hellerii provenientes de sua distribuição mundial. O tamanho dos círculos é proporcional ao número de indivíduos portando os haplótipos. Cada linha da rede representa um passo mutacional e os pequenos círculos pretos representam haplótipos hipotéticos não amostrados. As linhas tracejadas delimitam os agrupamentos genéticos identificados pelo BAPS.

\subsubsection{Bayesian Analysis of Population Structure (BAPS)}

A Bayesian Analysis of Population Structure agrupou todos os indivíduos em cinco clusters com base nas sequências de $16 \mathrm{~S}$ rDNA (Figura 15, B) suportados por um valor de probabilidade posterior igual a 0,99324. Estes grupos foram os mesmos 
identificados na rede de haplótipos como C1, C2, C3, C4 e C5 (Figura 15, B). Destes cinco clusters, dois contiveram apenas indivíduos de localidades americanas (C4 e C5) sem qualquer padrão geográfico. O cluster de maior frequência conteve indivíduos de localidades americanas, do mar Mediterrâneo e do Índico oeste (C1) e quanto aos dois demais (C2 e C3) um conteve tanto indivíduos da América como do Índico leste e do Pacífico e o outro, apenas indivíduos do Pacífico e Índico leste, incluindo todos os sete exemplares provenientes da Nova Caledônia (Figura 15, B). Os espécimes agrupados pela BAPS estão identificados com a mesma cor no filograma construído pelo critério de Máxima Verossimilhança (Figura 15, A), somente C4 monofilético e nenhum suportado por alto valor de bootstrap. 


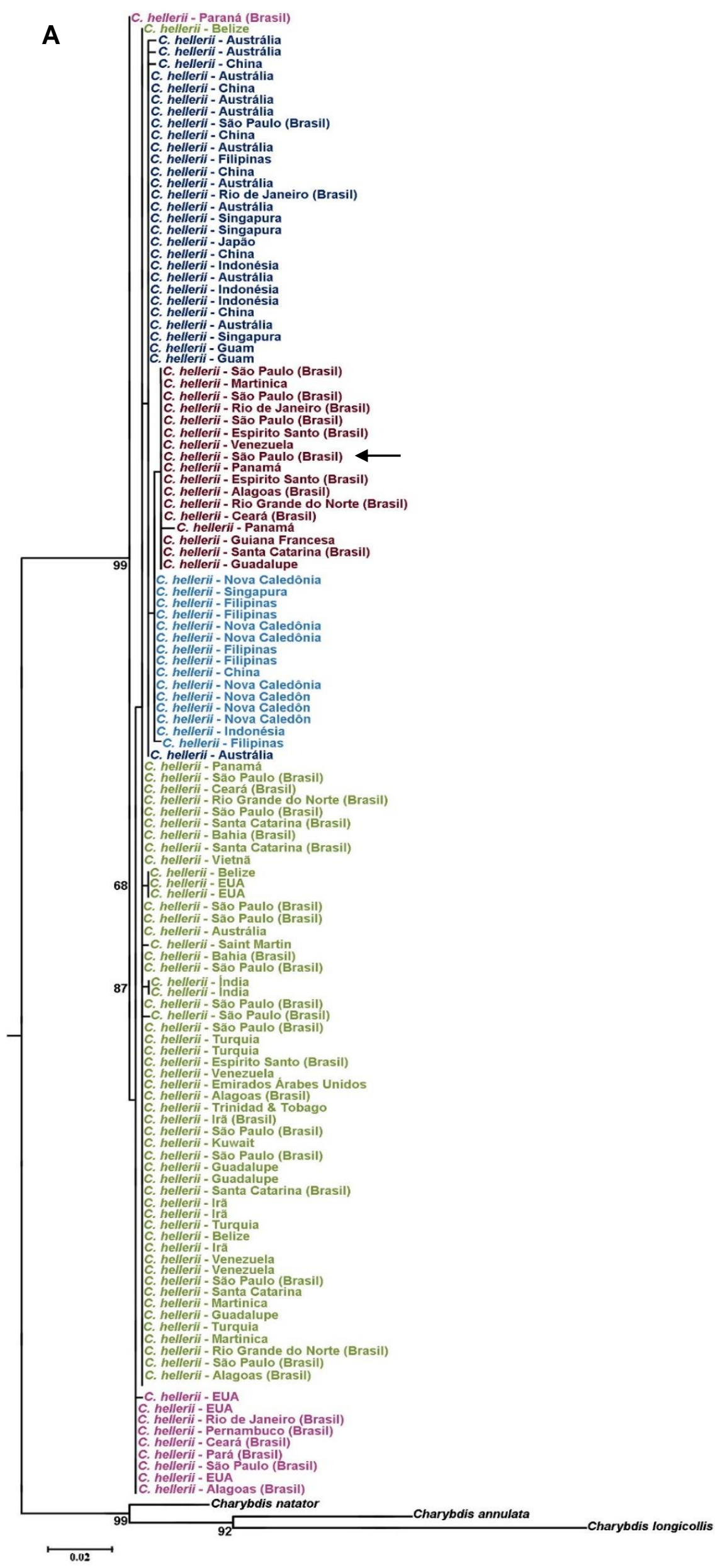


B

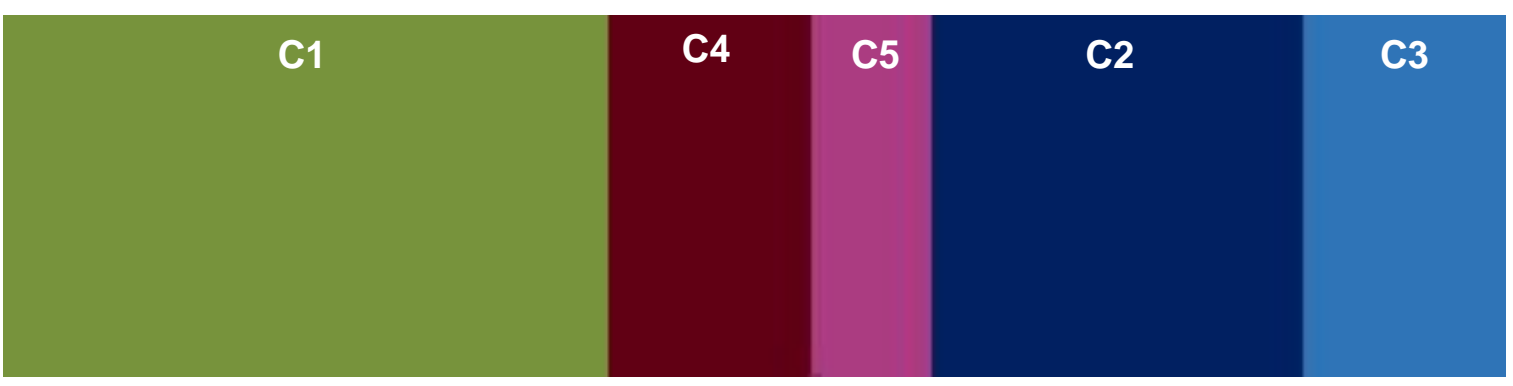

Figura 15. A, Filograma obtido pelo critério de Máxima Verossimilhança a partir sequências parciais do gene 16S rDNA de espécimes de Charybdis hellerii provenientes de toda sua distribuição. Os números próximos aos nós correspondem aos valores de bootstrap para 456 réplicas e apenas são mostrados valores de bootstrap $>50 \%$. B, Gráfico em barras gerado pela Análise Bayesiana de Estruturação Populacional (BAPS) a partir de sequências parciais do gene $16 S$ rDNA de espécimes de Charybdis hellerii provenientes de toda sua distribuição. A probabilidade posterior para a separação dos cinco clusters observados foi de 0,99324 . Os clusters ( 1 1, C2, C3, C4 e C5) contém os indivíduos representados na mesma cor no filograma (A), ou seja, C1 contém a maioria dos espécimes da América, todos do mar Mediterrâneo e do Índico oeste; C2 e C3, três espécimes da América, todos do Índico leste e Pacífico; C4 e C5, indivíduos de diversas localidades americanas. A seta indica o exemplar previamente identificado como Charybdis variegata e utilizado para o registro dessa espécies na costa americana por Sant'Anna et al. (2012).

\subsection{Bayesian Analysis of Population Structure (BAPS) - COI e 16S rDNA concatenados}

A Análise Bayesiana de Estrutura Populacional (BAPS) também foi feita com os dois marcadores analisados de forma concatenada. Como foram incluídos apenas indivíduos com ambos os marcadores sequenciados, 101 exemplares foram analisados. Esta resultou em quatro agrupamentos (A1, A2, A3 e A4). A1 conteve 48 indivíduos, incluindo todos os indivíduos do mar Mediterrâneo e Índico oeste e a maioria dos exemplares americanos. A2 conteve 27 indivíduos, incluindo tanto exemplares do Pacífico e Índico leste como quatro de populações americanas. A3 com doze indivíduos, sendo que um exemplar da América e os demais do Pacífico e Índico leste, inclusive todos os da Nova Caledônia. A4 com apenas exemplares da América, sem aparente padrão geográfico (Figura 16). 
A análise concatenada foi conduzida, pois algumas diferenças foram notadas entre as análises dos dois marcadores. Primeiramente, dois exemplares da América que, pela análise de $\mathrm{COI}$, haviam se mostrado mais próximos do grupo do Pacífico e Índico leste, posicionaram-se no cluster junto com animais do mar Mediterrâneo e do Índico oeste pela análise de 16S rDNA. No entanto, a análise concatenada confirmou sua proximidade com o Pacífico e Índico leste. Um exemplar proveniente da Austrália também compartilhou haplótipos com indivíduos do mar Mediterrâneo e do Índico oeste pela análise de 16S rDNA (Figuras 9 e 14), embora tenha sido incluído no agrupamento Ìndico leste + Pacífico pela análise de COI. Além disso, dois exemplares proximamente relacionados ao mar Mediterrâneo e Índico oeste pela análise de COI, foram incluídos em C4 (grupos geneticamente distinto da América sem aparente padrão geográfico) pela análise de 16S rDNA. Pela análise concatenada, estes se mostraram mais próximos aos do mar Mediterrâneo e Índico oeste. A análise concatenada confirmou a existência de dois grupos no Pacífico e Índico leste (A2, A3), um deles composto majoritariamente por indivíduos da Nova Caledônia (Figura 16), padrão este já observado na análise de 16S rDNA (Figuras 10 e 15) e mostrou a existência de apenas um grupo contendo apenas indivíduos da América (A4) (Figura 16), padrão já observado na análise de COI (Figuras 7 e 8). 


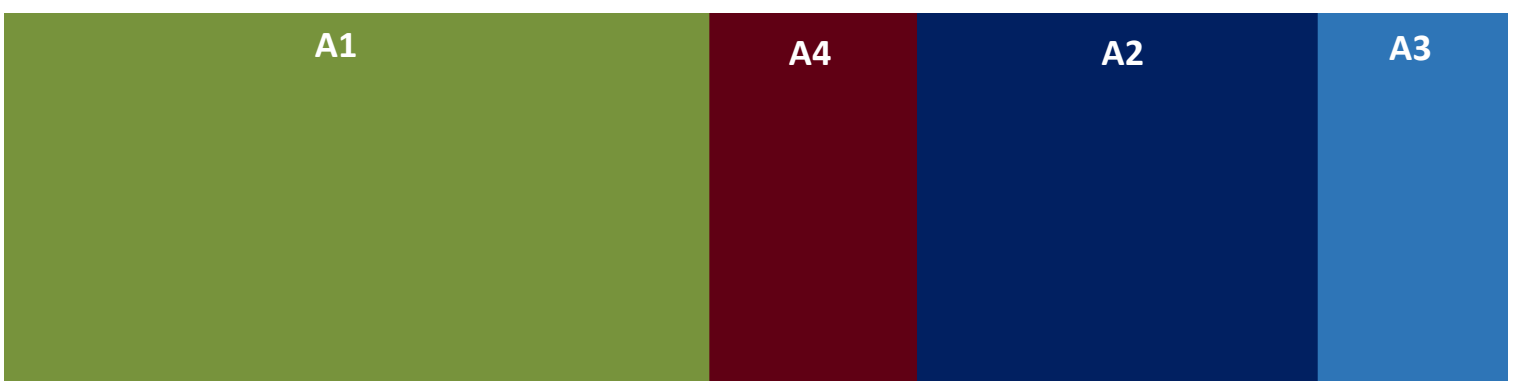

Figura 16. Gráfico em barras gerado pela Análise Bayesiana de Estruturação Populacional (BAPS) a partir de sequências concatenadas dos genes mitocondriais COI e 16S rDNA de espécimes de Charybdis hellerii provenientes de toda sua distribuição. A probabilidade posterior para a separação dos quatro clusters observados foi de 1,00000. O cluster A1 contém a maioria dos espécimes da América, todos do mar Mediterrâneo e do Índico oeste; A2 e A3, todos do Índico leste e Pacífico e cinco de populações americanas; A4, indivíduos de diversas localidades americanas.

Assim, considerando os resultados desta análise concatenada, a estatística descritiva de maneira a possibilitar a comparação entre população não nativa e sua população de origem permaneceria a mesma para o marcador $\mathrm{COI}$, com os dois agrupamentos identificados no Pacífico + Índico leste como um único agrupamento geográfico de origem, pois há sobreposição na distribuição dos haplótipos. A origem dos indivíduos de A4 é desconhecida, por isso, não se pode agrupá-los ou compará-los com outro grupo. A estatística descritiva para o marcador 16S rDNA de acordo com as regiões de origem para os indivíduos da América foi recalculada de acordo com a Tabela 20.

Tabela 20. Resultados obtidos da estatística descritiva para os indivíduos de Charybdis hellerii da América agrupados de acordo com a estruturação identificada na análise concatenada incluindo indivíduos provenientes de toda sua distribuição. Símbolos: $\mathrm{N}$, indivíduos amostrados; S, sítios polimórficos; H, haplótipos; Hd, diversidade haplotípica; $\pi$, diversidade nucleotídica; $\mathrm{K}$, número médio de diferenças nucleotídicas.

\begin{tabular}{l|c|c|c|c|c|c}
\hline Grupos & $\mathbf{N}$ & $\mathbf{S}$ & $\mathbf{h}$ & $\mathbf{H d}$ & $\mathbf{\Pi}$ & $\mathbf{K}$ \\
\hline América (A2 + A3) & 5 & 3 & 3 & 0,800 & 0,00277 & 1,40000 \\
América (A1) & 46 & 7 & 8 & 0,577 & 0,00155 & 0,78647 \\
América (A4) & 15 & 4 & 4 & 0,371 & 0,00128 & 0,64762 \\
\hline
\end{tabular}




\subsection{Análise morfológica comparativa de Charybdis hellerii}

Nos 247 animais analisados, as variações mais significativas foram encontradas em alguns caracteres. Dentre eles, a pilosidade da superfície dorsal da carapaça, a presença/ausência de cristas mesobranquiais, o formato dos dentes frontais, formato das quelas e o número de espinhos no mero do quelípodo e na margem posterior do própodo na pata natatória. A superfície dorsal da carapaça variou de completamente lisa a totalmente pilosa (Figura 17). O formato dos dentes da margem frontal variou de afilado a arredondado na extremidade. As cristas dorsais na região mesobranquial também variaram desde completamente ausentes até dois pares de cristas extremamente reduzidas, quando comparadas a cristas bem desenvolvidas de espécies como C. variegata (Figura 21). Os quelípodos variaram substancialmente quanto à forma, desde mais robustos a mais finos e alongados (Figura 17). A margem dorsal do mero do quelípodo geralmente apresentou três espinhos proximais maiores e um distal menor, mas às vezes somente três espinhos ou cinco espinhos (três proximais e dois distais). O número de espinhos na margem posterior do própodo do quinto periópodo mostrou-se assimétrico entre os lados esquerdo e direito e variou de 5 a 18 (Figura 18).

Nenhuma variação, contudo, foi encontrada de modo a diferir os grupos evidenciados nas análises moleculares. Em outras palavras, as análises moleculares revelaram ausência de distinção genética a partir dos marcadores utilizados entre exemplares com diferentes características e indivíduos com diferentes características foram encontrados dentro de uma mesma localidade, tanto em áreas nativas quanto em não nativas. Isto indica que tais variações morfológicas possivelmente constituem variações intraespecíficas. Além disso, nenhuma variação foi encontrada na morfologia do gonópodo 1 dos exemplares analisados, bem como nos demais caracteres analisados (Tabela 4). O gonópodo 1 foi caracterizado como longo, delgado, com abertura mésio-distal e três fileiras de cerdas, uma na superfície interna, caracterizada por cerdas curtas, terminando na base do gonópodo como pequenos espínulos; uma 
externa com cerdas mais longas, tornando-se menores e mais próximas na porção distal e uma fileira mésio-ventral com 4-7 cerdas diminutas (Figura 19).

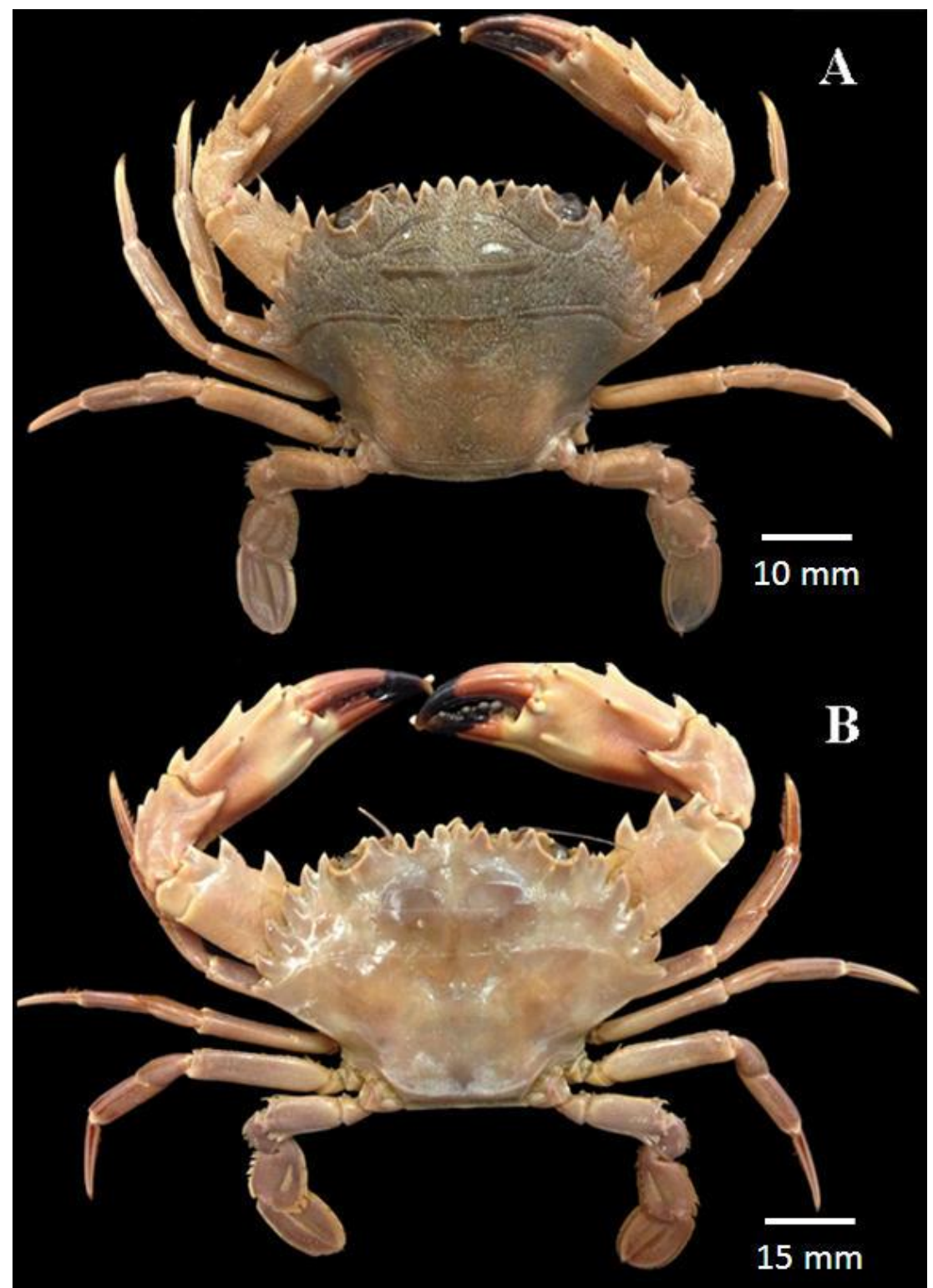

Figura 17. Exemplares de Charybdis hellerii (A. Milne-Edwards, 1867) provenientes de Martinica e depositados no Senckenberg Museum Frankfurt (SMF) demonstrando as variações morfológicas que são encontradas na espécie dentro de uma mesma população. A. Fêmea; lc. 45,95 mm - com pilosidade na carapaça e quelípodo mais alongado e fino; B. Macho; Ic. 64, 82 $\mathrm{mm}$ - sem pilosidade e com quelípodo mais robusto. 

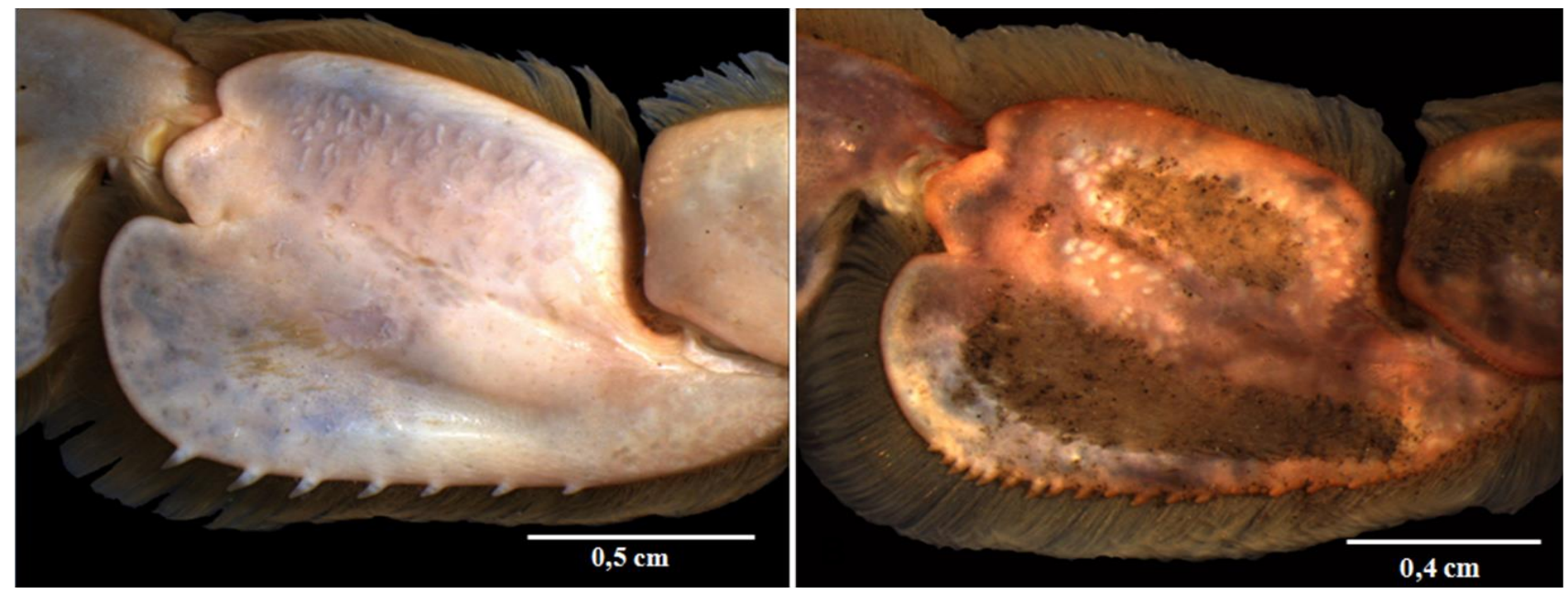

Figura 18. A, Vista dorsal do própodo do quinto pereiópodo de espécime macho de Charybdis hellerii (CCDB 2920 , Ic. $68,12 \mathrm{~mm}$ ) com sete grandes espinhos em sua margem posterior. B, Vista dorsal do própodo de exemplar fêmea de Charybdis hellerii (CCDB 3882, Ic. $52,31 \mathrm{~mm}$ ) com 16 pequenos espinhos em sua margem posterior.

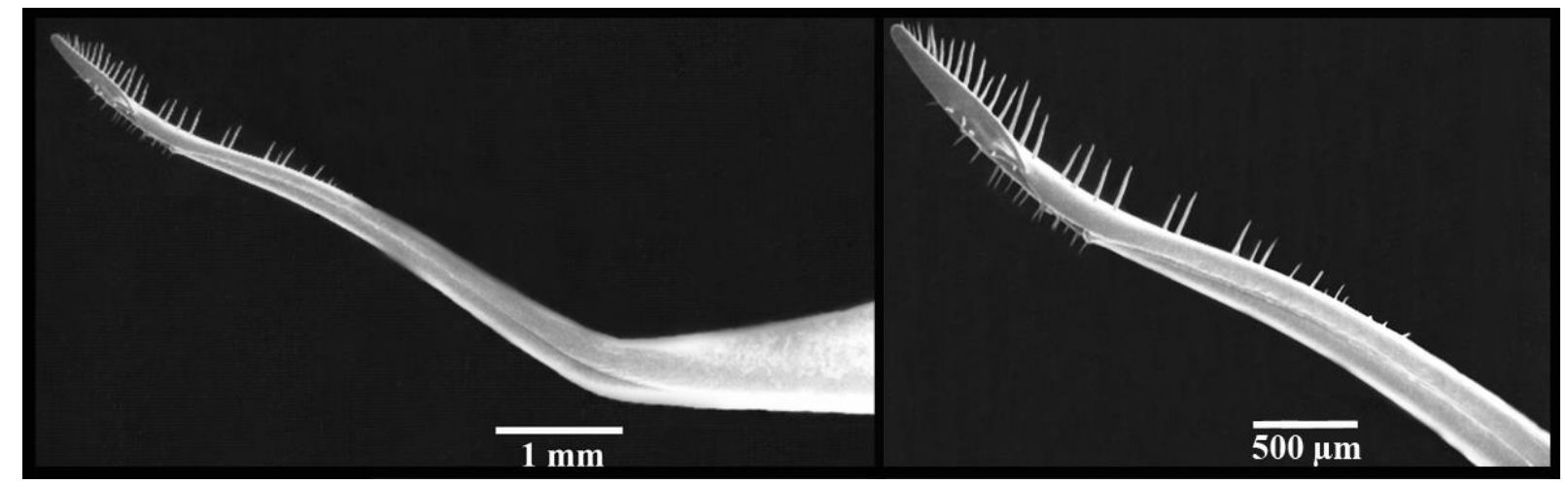

Figura 19. Microscopia Eletrônica de Varredura (MEV) em vista mésio-ventral do gonópodo 1 esquerdo de Charybdis hellerii proveniente do estuário de Santos/São Vicente, São Paulo, Brasil (CCDB 3882, lc. $74,18 \mathrm{~mm}$ ).

\subsection{Análise morfológica comparativa do indivíduo utilizado para o registro de}

\section{Charybdis variegata na América}

A análise comparativa do exemplar de " $C$. variegata" coletado no litoral de São Paulo (MZUSP 24446) com outros animais identificados como $C$. variegata provenientes do Indo-Pacífico depositados em diversas coleções científicas, bem como com espécimes de $C$. hellerii, possibilitou a confirmação de que o exemplar fora identificado 
de forma incorreta, sendo que todas as evidências demostram que ele se trata de mais um representante de $C$. hellerii.

As evidências que possibilitaram a constatação acima descrita foram as seguintes:

1) A presença no exemplar de "C. variegata" de um espinho na margem posterior distal do carpo do quinto pereiópodo, característica esta diagnóstica de $C$. hellerii e que é ausente em C. variegata (Figura 20, A e B).

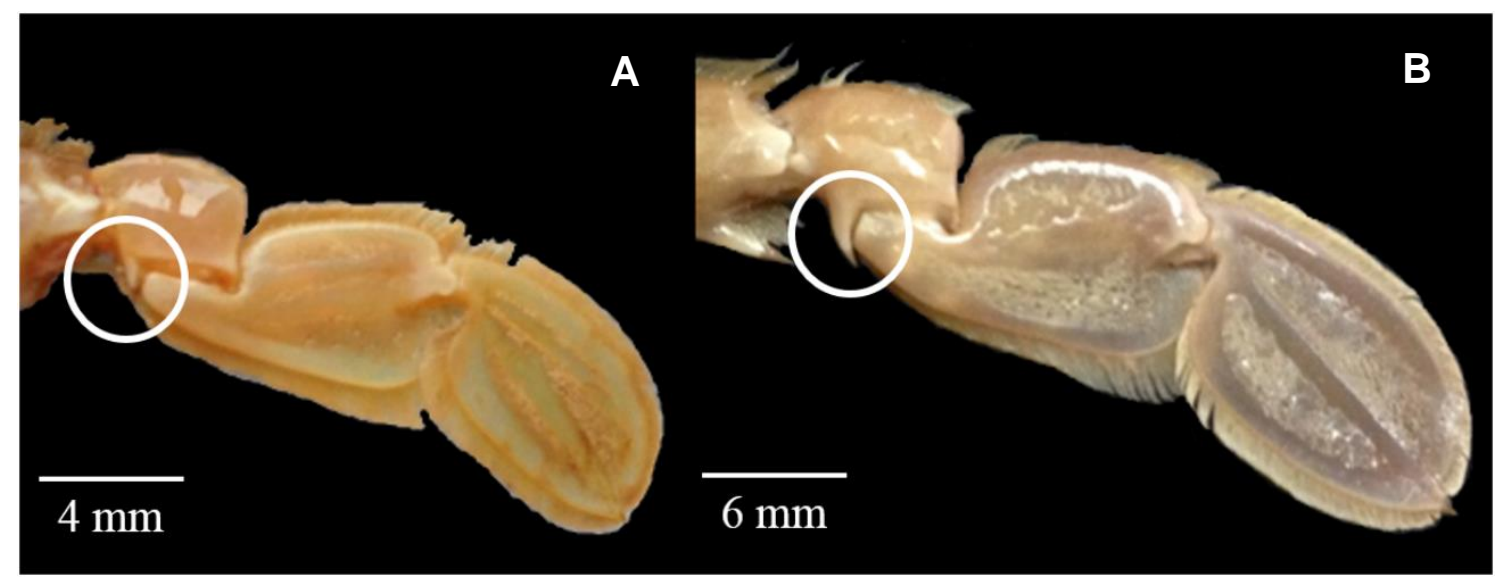

Figura 20. A. Vista ventral do quinto pereiópodo de exemplar de Charybdis variegata (RMNH. CRUST. D. 47335, fêmea; Ic. 39,25 mm); B. Vista ventral do quinto pereiópodo de exemplar de Charybdis hellerii previamente identificado como C. variegata por Sant'Anna et al. (2012b) (MZUSP 24446, fêmea; Ic. 49,95 mm). Círculos brancos destacam a extremidade posterior do carpo, evidenciando a ausência de espinho em $C$. variegata $(A)$ e a presença em $C$. hellerii (B).

2) Ausência de dois pares de cristas transversais na carapaça posteriores ao sexto dente anterolateral, mais precisamente na região mesobranquial. As cristas existentes nos exemplares de $C$. variegata analisados para comparação são muito diferentes (mais desenvolvidas) em relação às constatadas no exemplar de São Paulo (Figuras 21, A e B). Além disso, cristas reduzidas como deste exemplar foram observadas em outros exemplares de C. hellerii. 


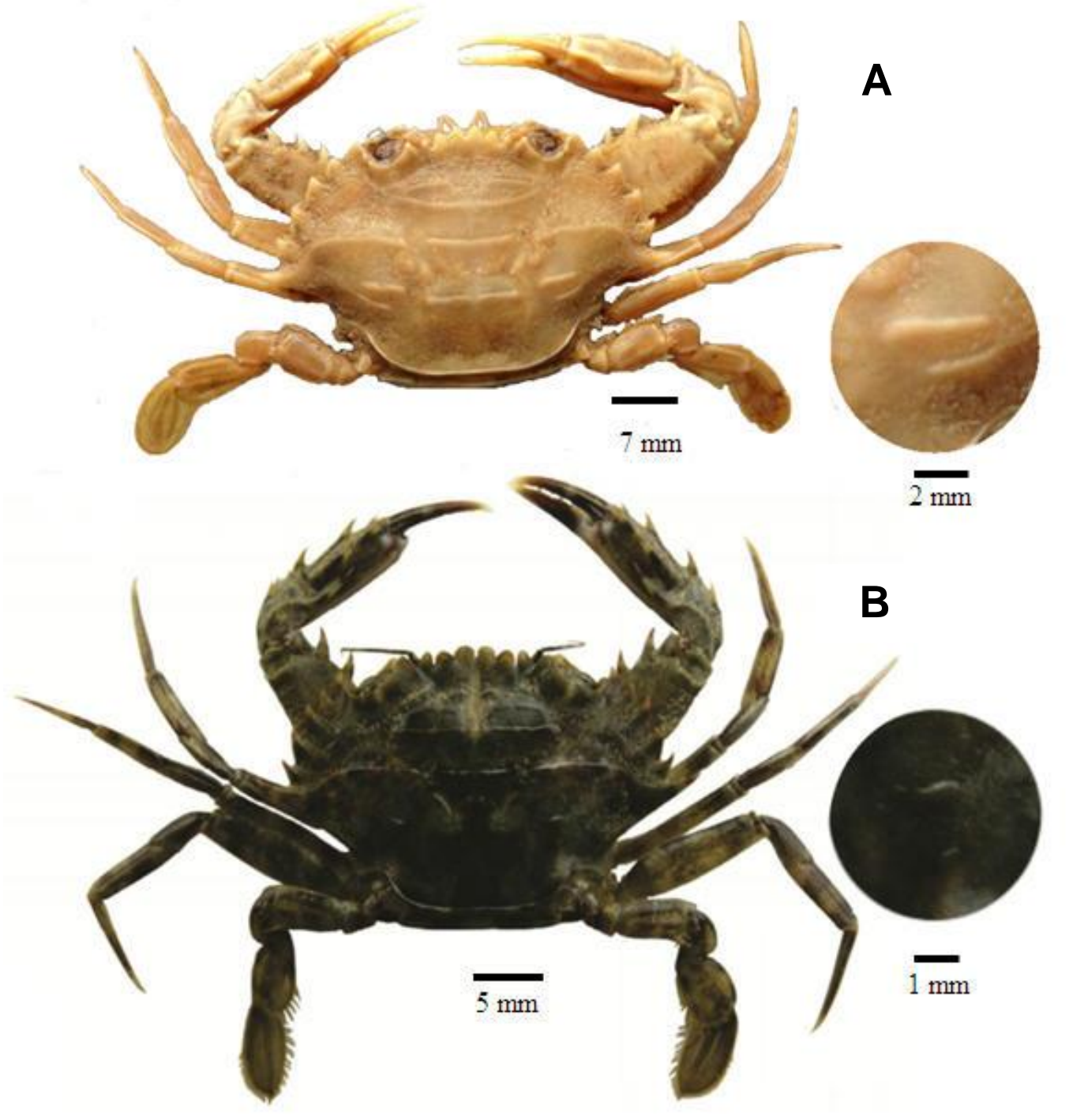

Figura 21. A, Vista dorsal de um exemplar de Charybdis variegata (RMNH. CRUST. D. 47335fêmea; Ic. 39,25 mm); B, Vista dorsal do exemplar coletado na Baía de Santos, São Paulo e utilizado para o registro de C. variegata na costa de São Paulo (MZUSP 24446, fêmea juvenil, Ic. 24,00 mm). B, modificado de Sant'Anna et al. (2012b). Dentro dos círculos detalhes das cristas mesobranquiais apresentadas por cada indivíduo.

3) O sexto dente anterolateral do exemplar identificado como "C. variegata" não é largo, espiniforme e projetado lateralmente como dos verdadeiros representantes de C. variegata.

4) Não possui todos os dentes frontais acuminados na extremidade, característica de $C$. variegata (Figura 21, B). 


\subsection{Análise morfológica morfométrica de Charybdis hellerii}

Estas foram conduzidas considerando os três grupos identificados pelas análises moleculares com o gene COI (G1, contendo a maioria dos espécimes da América, todos do mar Mediterrâneo e do Índico oeste; G2, contendo alguns espécimes da América, todos do Índico leste e Pacífico; G3, contendo indivíduos de diversas localidades americanas). Embora as análises de 16S rDNA e a BAPS concatenada tenham sugerido a existência de mais grupos, foram considerados os grupos identificados por COI de modo a possibilitar um maior número amostral $(\mathrm{n})$ dentro dos grupos (Tabela 21). A largura da carapaça (variável independente) variou de $2,58 \mathrm{~cm}$ a $4,43 \mathrm{~cm}$.

Tabela 21. Constituição de cada grupo para as análises morfométricas de Charybdis hellerii, em relação ao sexo e à localidade (associada ao grupo genético), e os respectivos números amostrais por grupo $(\mathrm{N})$.

\begin{tabular}{c|c|c|c}
\hline Grupo & Sexo & Localidade & N \\
\hline G1 & Fêmea & América + mar Mediterrâneo + Índico oeste (G1) & 17 \\
G1 & Macho & América + mar Mediterrâneo + Índico oeste (G1) & 47 \\
G2 & Fêmea & América + Índico leste + Pacífico (G2) & 10 \\
G2 & Macho & América + Índico leste + Pacífico (G2) & 15 \\
G3 & Fêmea & América (G3) & 7 \\
G3 & Macho & América (G3) & 4 \\
\hline
\end{tabular}

As relações morfométricas dos 6 subgrupos analisados pelo método Wilks' Lambda apresentaram diferenças estatísticas significativas nas seguintes variáveis dependentes: comprimento da carapaça (CC), comprimento, largura e altura do própodo do quelípodo (CP1, LP1 e AP1, respectivamente), comprimento do mero do quelípodo (CM1), comprimento do própodo do segundo pereiópodo (CP2), comprimento do dátilo e do própodo do terceiro pereiópodo (CP3 e CM3, respectivamente), largura do dátilo do quinto pereiópodo (LD5) comprimento do própodo do quinto pereiópodo (CP5) (Tabela 22). 
Tabela 22. Poder discriminante de cada variável morfométrica e seu respectivo valor de significância ( $p$-value) para Charybdis hellerii. Os valores em negrito indicam a aceitação da hipótese alternativa de que há diferença estatisticamente significativa entre os indivíduos analisados para aquela variável. CC, comprimento da carapaça; LC, largura da carapaça; CD1, CP1, CC1, CM1, CD2, CP2, CC2, CM2, CD3, CP3, CC3, CM3, CD4, CP4, CC4, CM4, CD5, CP5, CC5, CM5, comprimento do dátilo, própodo, carpo e mero do primeiro ao quinto pereiópodo, respectivamente; LP1, largura do própodo do primeiro pereiópodo; AP1, altura do própodo do primeiro pereiópodo; LD5, largura do dátilo do quinto pereiópodo.

\begin{tabular}{c|ccc}
\hline $\begin{array}{c}\text { Variáveis } \\
\text { dependentes }\end{array}$ & $\begin{array}{c}\text { Wilks' } \\
\text { Lambda }\end{array}$ & $\mathbf{F}$ & $\boldsymbol{p}$-value \\
\hline CC & $\mathbf{0 , 0 0 2 3 9 8}$ & $\mathbf{3 , 5 9 3 3 9}$ & $\mathbf{0 , 0 0 5 9 2 3 ^ { \star }}$ \\
CD1 & 0,002110 & 1,45467 & 0,215607 \\
CP1 & $\mathbf{0 , 0 0 2 7 2 2}$ & $\mathbf{5 , 9 9 9 9 5}$ & $\mathbf{0 , 0 0 0 1 1 0 ^ { \star }}$ \\
LP1 & $\mathbf{0 , 0 0 2 2 8 8}$ & $\mathbf{2 , 7 7 4 9 3}$ & $\mathbf{0 , 0 2 3 9 9 8 ^ { \star }}$ \\
AP1 & $\mathbf{0 , 0 0 2 2 9 1}$ & $\mathbf{2 , 7 9 5 2 7}$ & $\mathbf{0 , 0 2 3 1 7 8 ^ { \star }}$ \\
CC1 & 0,002155 & 1,78846 & 0,126254 \\
CM1 & $\mathbf{0 , 0 0 2 2 3 0}$ & $\mathbf{2 , 3 4 7 9 3}$ & $\mathbf{0 , 0 4 9 6 4 2 ^ { \star }}$ \\
CD2 & 0,001978 & 0,47845 & 0,791178 \\
CP2 & $\mathbf{0 , 0 0 2 4 6 7}$ & $\mathbf{4 , 1 0 7 7 3}$ & $\mathbf{0 , 0 0 2 4 7 4}$ \\
CC2 & 0,002049 & 1,00240 & 0,422766 \\
CM2 & 0,002064 & 1,11232 & 0,361685 \\
CD3 & $\mathbf{0 , 0 0 2 3 1 2}$ & $\mathbf{2 , 9 5 6 3 1}$ & $\mathbf{0 , 0 1 7 5 9 8 ^ { \star }}$ \\
CP3 & $\mathbf{0 , 0 0 8 6 2 7}$ & $\mathbf{4 9 , 8 0 9 9 7}$ & $\mathbf{0 , 0 0 0 0 0 0}$ \\
CC3 & 0,002015 & 0,74774 & 0,590446 \\
CM3 & 0,002031 & 0,86938 & 0,506116 \\
CD4 & 0,002072 & 1,17242 & 0,331321 \\
CP4 & 0,001960 & 0,33972 & 0,887169 \\
CC4 & 0,001986 & 0,53531 & 0,748840 \\
CM4 & 0,002044 & 0,96656 & 0,444226 \\
CD5 & 0,002067 & 1,13374 & 0,350621 \\
LD5 & $\mathbf{0 , 0 0 2 2 3 9}$ & $\mathbf{2 , 4 1 0 7 2}$ & $\mathbf{0 , 0 4 4 6 3 1 ^ { \star }}$ \\
CP5 & $\mathbf{0 , 0 0 2 3 3 5}$ & $\mathbf{3 , 1 2 2 0 3}$ & $\mathbf{0 , 0 1 3 2 5 3 ^ { \star }}$ \\
CC5 & 0,001996 & 0,61218 & 0,690835 \\
CM5 & 0,002097 & 1,35614 & 0,251230 \\
\hline
\end{tabular}

A análise de discriminante mostrou diferenças significativas entre quase todos os grupos, com exceção entre fêmeas de G1 e fêmeas de G3 e entre machos de G2 e machos G3 (Tabela 23). A análise de discriminantes canônicos apresentou duas variáveis (roots) como significativas $(p<0,05)$ (Tabela 24). Os escores das variáveis canônicas (roots 1 e 2) estão ilustrados na Figura 22, onde verifica-se uma tendência de 
estruturação morfométrica entre machos e fêmeas, bem como a distinção morfométrica das fêmeas de G2 (Pacífico + Índico leste + América) em relação aos demais grupos.

Tabela 23. Valores de significância da análise discriminante entre 6 subgrupos de Charybdis hellerii definidos com base em sequência parciais do gene COI. Os valores marcados com asterisco indicam a aceitação da hipótese alternativa de que há diferença estatisticamente significativa entre os indivíduos analisados para aquela variável. G1, contem a maioria dos espécimes da América, todos do mar Mediterrâneo e do Índico oeste; G2, contem alguns espécimes da América, todos do Índico leste e Pacífico; G3, contem indivíduos de diversas localidades americanas.

\begin{tabular}{c|c|c|c|c|c|c}
\hline \multirow{2}{*}{ Subgrupos } & \multicolumn{6}{|c}{$p$-values } \\
\cline { 2 - 7 } & G1 F & G1 M & G3 F & G3 M & G2 F & G2 M \\
\hline G1 F & - & $0,000000^{*}$ & 0,684459 & $0,000000^{*}$ & $0,000000^{*}$ & $0,000000^{*}$ \\
G1 M & $0,000000^{*}$ & - & $0,000002^{*}$ & $0,000998^{*}$ & $0,000000^{*}$ & $0,000001^{*}$ \\
G3 F & 0,684459 & $0,000002^{*}$ & - & $0,000000^{*}$ & $0,000000^{*}$ & $0,000000^{*}$ \\
G3 M & $0,000000^{*}$ & $0,000998^{*}$ & $0,000000^{*}$ & - & $0,000000^{*}$ & 0,496692 \\
G2 F & $0,000000^{*}$ & $0,000000^{*}$ & $0,000000^{*}$ & $0,000000^{*}$ & - & $0,000000^{*}$ \\
G2 M & $0,000000^{*}$ & $0,000001^{*}$ & $0,000000^{*}$ & 0,496692 & $0,000000^{*}$ & - \\
\hline
\end{tabular}

Tabela 24. Teste do Chi-quadrado com raízes sucessivamente removidas. Os valores destacados em negrito indicam a aceitação da hipótese alternativa de que há diferença estatisticamente significativa entre os indivíduos analisados para aquela variável.

\begin{tabular}{c|c|c|c|c|c}
\hline $\begin{array}{c}\text { Raízes } \\
\text { removidas }\end{array}$ & $\begin{array}{c}\text { Valor de } \\
\text { Eigen }\end{array}$ & R Canônico & $\begin{array}{c}\text { Wilks' } \\
\text { Lambda }\end{array}$ & $\begin{array}{c}\text { Chi- } \\
\text { quadrado }\end{array}$ & p-value \\
\hline 0 & $\mathbf{2 7 , 2 7 3 3 8}$ & $\mathbf{0 , 9 8 2 1 5 6}$ & $\mathbf{0 , 0 0 1 9 1 4}$ & $\mathbf{5 2 5 , 7 2 6 2}$ & $\mathbf{0 , 0 0 0 0 0 0 ^ { * }}$ \\
1 & $\mathbf{6 , 4 0 9 2 8}$ & $\mathbf{0 , 9 3 0 0 7 2}$ & $\mathbf{0 , 0 5 4 1 1 1}$ & $\mathbf{2 4 5 , 0 0 4 9}$ & $\mathbf{0 , 0 0 0 0 0 0 ^ { * }}$ \\
2 & 0,62987 & 0,621653 & 0,400921 & 76,7752 & 0,171434 \\
3 & 0,33492 & 0,500891 & 0,653448 & 35,7414 & 0,740963 \\
4 & 0,14639 & 0,357351 & 0,872300 & 11,4762 & 0,932926 \\
\hline
\end{tabular}




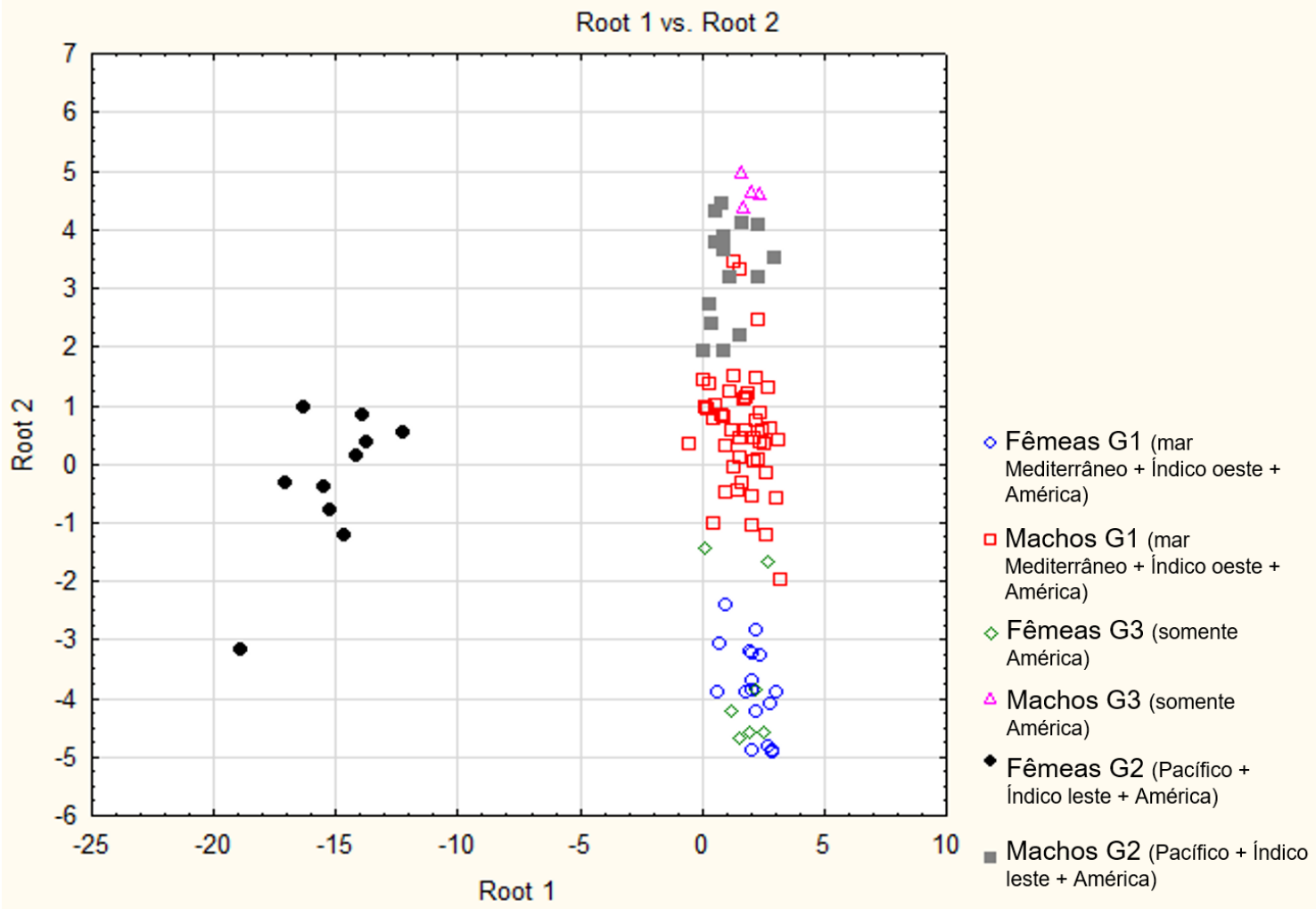

Figura 22. Análise canônica dos 6 subgrupos de Charybdis hellerii - fêmeas G1, G2, G3 e machos G1, G2, G3. Destaque para a estruturação morfométrica entre os fêmeas de G2 em relação aos demais grupos. 


\section{DISCUSSÃO}




\subsection{Status taxonômico de Charybdis hellerii (A. Milne-Edwards, 1867) e comparações interespecíficas}

A identificação e delimitação acurada de uma espécie invasora são fatores cruciais para a compreensão das bioinvasões (como identificação das rotas e origens das introduções) e desenvolvimento de planos de manejo eficientes (Holland, 2000; Geller et al., 2010). No caso de C. hellerii, embora variações morfológicas e moleculares tenham sido identificadas entre populações e indivíduos, estas não subsidiaram a separação da espécie em diferentes entidades taxonômicas e, assim, representam variações intraespecíficas. Isto forneceu suporte para uma investigação mais confiável do histórico de introdução desta espécie.

Investigações têm mostrado que espécies invasoras aparentemente bem conhecidas taxonomicamente se dissolvem em complexos de espécies quando analisadas em detalhes, representando, dessa forma, invasões crípticas ao nível de espécie (Geller et al., 2010). Não há um meio operacional simples para se distinguir entre variação intra e interespecífica. Normalmente, os pesquisadores se baseiam em dois fatores: primariamente no padrão filogenético, especificamente pela detecção de monofilia recíproca como um identificador de espécies distintas; e também no grau de diferenciação genética entre os indivíduos, de modo a compará-la com o grau de divergência interespecífica esperada para o locus analisado (Geller et al., 2010). Além disso, muitas vezes recorrem à integração de dados de outra natureza, como morfológicos ou ecológicos, para apoiarem seus achados (Geller et al., 2010).

A monofilia da espécie estudada foi sugerida no filograma construído com diversas espécies do gênero Charybdis e outros exemplares da subfamília Thalamitinae e suportada por altos valores de bootstrap e probabilidade a posteriori (Figura 6), o que suporta a identidade taxonômica de $C$. hellerii. Ainda, nenhum padrão de monofilia recíproca foi detectado dentro do clado $C$. hellerii nos filogramas gerados 
(Figuras 8, 10, 13 e 16). Este resultado não fornece indícios da existência de espécies crípticas designadas como C. hellerii.

A inexistência de variação no marcador nuclear $\mathrm{H}$, bem como variações intraespecíficas (COI - 0 a 4,2\% e 16S rDNA - 0 a 0,9\%), inferiores às interespecíficas (COI - 6,2 a $21,5 \%$ e $16 \mathrm{~S}$ rDNA - 3,9 a 15,2\%) formando um gap interespecífico nos outros dois marcadores mitocondriais (Figuras 4 e 5), também suportam a validade da espécie como táxon único. É exatamente na existência deste gap interespecífico mencionado que se baseia a técnica de DNA Barcoding (Hebert et al., 2003). De acordo com ela e utilizando um marcador molecular padrão (designado como sendo a mesma região do gene $\mathrm{COI}$ empregada neste estudo), seria possível designar com precisão um espécime à sua espécie, uma vez que as variações intraespecíficas seriam inferiores às interespecíficas (Hebert et al., 2003).

Vale notar, porém, que muitas são as críticas à essa técnica. O fragmento padrão de COI pode não permitir a discriminação ao nível de espécie para alguns grupos, por apresentar evolução muito lenta (Chase \& Fay, 2010) ou sobreposição das divergências inter e intraespecíficas (Meyer \& Paulay, 2005). A sua aplicação também pode ser prejudicada e levar a interpretações erradas pela amplificação de pseudogenes ou ocorrência de introgressão (Funk \& Omland, 2003; Rubinoff et al., 2006; Song et al., 2008; Pires \& Marinoni, 2010).

Contudo, de modo geral, é inegável que a incorporação dessa ferramenta em estudos de taxonomia tradicional, filogenéticos e populacionais tem trazido contribuições significativas (Hajibabaei et al., 2007), inclusive para investigações acerca de espécies invasoras (Geller et al., 2010). Os aspectos populacionais e do histórico de invasão de $C$. hellerii serão discutidos em detalhes nas seções seguintes. Os perfis taxonômicos e filogenéticos foram atestados pela comprovação da validade taxonômica da espécie e algumas inferências a partir do filograma gerado a partir de sequências de espécies da subfamília Thalamitinae (Figura 6). 
Com base neste filograma e levando em conta as limitações recorrentes do fato de não ter sido feita a inclusão de todas as espécies dos gêneros Thalamita e Charybdis, ambos se mostram monofiléticos e, presumidamente, válidos. A relação próxima entre eles foi anteriormente corroborada (Spiridonov et al., 2014) e não pôde ser testada no presente estudo por serem os dois únicos gêneros incluídos no ingroup. Contudo, este mesmo trabalho diferentemente indicou a polifilia desses gêneros (Spiridonov et al., 2014), com análises sugerindo uma proximidade maior da espécie Thalamita sima com o gênero Charybdis e não com outras espécies do gênero Thalamita (Spiridonov et al., 2014 - Figuras 4 e 5), bem como o posicionamento da espécie Xiphonectes tenuipes (De Haan, 1833) dentro do clado de Charybdis (Spiridonov et al., 2014 - Figura 6). Análises moleculares abrangendo outras espécies desses gêneros, de outros táxons da subfamília, como do gênero Thalamitoides A. Milne-Edwards, 1869 e de outros portunideos poderão fornecer informações mais precisas sobre suas relações e história evolutiva.

A maioria das espécies com sequências de mais de um exemplar incluídas mostraram-se monofiléticas, subsidiando suas validades taxonômicas (Figura 6). A única e expressiva exceção foi observada para as espécies do complexo Charybdis miles, as quais são caracterizadas por extrema semelhança morfológica e habitam ambientes de grande profundidade (Spiridonov \& Türkay, 2001). As diferenças genéticas entre suas espécies foram similares ao valores de variação intraespecífica calculados para $C$. hellerii e, justamente por representarem um complexo de espécies, foram desconsiderados para a detecção do gap entre as variações intraespecíficas de C. hellerii e interespecíficas esperadas para o gênero Charybdis.

Este complexo é constituído por seis espécies, C. crosnieri Spiridonov \& Türkay, 2001; C. meteor Spiridonov \& Türkay, 2001; C. miles (De Haan, 1835); C. riversandersoni Alcock, 1899; C. rufodactylus Stephenson \& Türkay, 1968 e C. sagamiensis Parisi, 1916 (Stephenson \& Rees, 1968; Spiridonov \& Türkay, 2001). 
Embora diversos caracteres diagnósticos tenham sido apontados para a identificação de cada uma delas por Spiridonov \& Türkay (2001), estas espécies mostraram elevada semelhança molecular dos marcadores estudados, não possibilitando sua distinção com base nestes dados genéticos. Ainda, C. meteor posicionou-se fora do grupo monofilético constituído pelas demais espécies do complexo (Figura 6). Estes fatores sugerem a necessidade de novas análises para a compreensão da relação entre elas, bem como suas validades taxonômicas. Em uma escala mais ampla, estudos dessa natureza contribuem consideravelmente para o conhecimento da biodiversidade marinha ainda muito negligenciada.

Mais especificamente sobre as comparações morfológicas não morfométricas, embora variações morfológicas expressivas tenham sido detectadas entre os exemplares de C. hellerii (Figura 17), exemplares com características distintas apresentaram sequências idênticas para os marcadores empregados, suportando sua natureza intraespecífica. Além disso, a ocorrência de indivíduos com características morfológicas distintas (Figura 17) observada dentro de uma mesma localidade nas áreas nativas indica que estas variações não estão correlacionadas com os agrupamentos genéticos encontrados nesta região (Figura 7). As variações também não foram associadas ao grupo genético detectado somente na América (G3 - Figura 11).

Variações na coloração, característica não abordada no presente estudo, suscitou a possibilidade de um complexo de espécie designado como $C$. hellerii (P.K.L. Ng, comunicação pessoal). Variações foram observadas tanto entre indivíduos de ocorrência simpátrica em áreas nativas, como Singapura, quanto entre estes e espécimes da América. Contudo, além dos presentes resultados indicarem o contrário, estas variações poderiam estar relacionadas a mudanças ontogenéticas. Análises da coloração realizadas em espécimes não nativos de São Vicente (SP) mostraram que esta variou significantemente com o tamanho (Watanabe et al., 2015). Indivíduos 
pequenos e imaturos foram mais escuros que os maiores e maduros. O abdômen das fêmeas também mudou de cor com a maturidade sexual (Watanabe et al., 2015).

Diferenças na coloração conforme o tamanho já haviam sido apontadas por Wee \& Ng (1995). Segundo eles, espécimes maiores têm carapaça em tons alaranjados e creme e pernas arroxeadas. Já os menores têm tonalidades mais avermelhadas na superfície dorsal da carapaça, quelípodos e pernas com manchas e faixas, dedos basalmente vermelhos, distalmente marrons e com a extremidade branca.

A coloração observada em imagens de indivíduos provenientes de Singapura cedidas por N.T. Son, bem como encontradas em Yokes \& Galil (2006) de indivíduos provenientes da Turquia, foram condizentes com a descrição de Wee \& Ng (1995) e também indicam a existência de indivíduos esverdeados. Indivíduos amostrados na América apresentaram coloração em tonalidades avermelhadas, marrom e esverdeadas (Watanabe et al., 2015). Assim, aparentemente, não há um padrão de coloração correlacionado com os agrupamentos genéticos encontrados. Uma análise sistemática dessa característica não pode ser feita, pois grande parte dos indivíduos analisados estavam fixados em álcool e não exibiam mais sua coloração original. $\mathrm{A}$ observação de espécimes frescos poderia fornecer maior respaldo para inferências sobre esta característica.

Adicionalmente, quanto à morfologia do gonópodo 1, além de variações não terem sido evidenciadas entre os exemplares analisados, a caracterização aqui apresentada é condizente com a descrição apresentada por Stephenson et al. (1957) para exemplares da costa da Austrália e por Wee \& Ng (1995) para exemplares de Singapura e da Península da Malásia. Isto consiste em mais um indício para a identidade dos espécimes de diferentes localidades, considerando que o primeiro pleópodo em Charybdis é bastante uniforme e as diferenças podem servir para indicar espécies distintas (Stephenson et al., 1957). 


\subsection{Diversidade e estruturação genética de Charybdis hellerii em suas localidades nativas e mar Mediterrâneo}

Os resultados moleculares e morfológicos não são suficientes para corroborar a hipótese de um complexo de espécies designado como $C$. hellerii, mas eles demonstram claramente a ocorrência de estruturação genética nas áreas nativas. Dois grupos geneticamente distintos foram identificados, um composto por espécimes de populações provenientes do oeste do oceano Índico (e mar Mediterrâneo, localidade não nativa) e o outro por espécimes provenientes do leste do oceano Índico e do Pacífico. A separação desses dois grupos foi bastante evidente nas redes de haplótipos (Figuras 7 e 9) e na Análise Bayesiana de Estrutura Populacional - BAPS (Figuras 8 e 10). A significância da diferença genética entre eles foi confirmada pela AMOVA (Tabelas 7 e 14).

A maior abrangência possível das áreas nativas, bem como a descoberta de variação genética entre estas áreas, é fundamental para o rastreamento das potenciais origens de introduções e detecção de invasões múltiplas, ou seja, invasões crípticas ao nível intraespecífico (Darling et al, 2008; Geller et al., 2010; Cristescu, 2015). A estruturação filogeográfica substancial nas localidades nativas possibilita a detecção de introduções independentes. Estas podem resultar na introdução de indivíduos com características fisiológicas diferentes, o que torna muito relevante sua investigação para o desenvolvimento de ações de manejo (Geller et al., 2010).

Se, por um lado, acreditava-se que o alto grau de dispersão das formas larvais planctônicas de espécies marinhas seriam suficientes para uma grande conectividade entre suas populações ao longo de toda sua distribuição (Palumbi, 1994; Duda e Palumbi, 1999, Barber et al., 2000), por outro lado, há um acúmulo cada vez maior de evidências de que descontinuidades genéticas separando populações em grupos relativamente homogêneos não são exceções e seriam mantidas por barreiras geográficas e/ou ecológicas à dispersão (Knowlton \& Jackson, 1993). Estas 
descontinuidades podem delimitar limites de ruptura genética (genetic breakpoint) que facilitam a identificação regional de fontes das introduções como sendo de um lado ou de outro dessa ruptura (Geller et al., 2010).

Evidências de estruturação genética entre os oceanos Índico e Pacífico têm sido acumuladas em diversos estudos com muitas espécies marinhas que ocorrem no Indo-Oeste Pacífico (e.g. Williams et al., 2002; Ragionieri et al., 2010, 2012). O padrão encontrado no presente estudo não é similar apenas ao verificado em outras espécies de crustáceos (Birgus latro - Lavery et al., 1996; Penaeus monodon - Duda \& Palumbi, 1999; Brooker et al., 2000; Scylla serrata - Gopurenko et al., 1999; Haptosquilla pulchella, Haptosquilla glyptocercus e Gonodactylellus viridis - Barber et al., 2002; 2006; Neosarmatium meinerti - Ragionieri et al., 2010, 2012), como também espécies de estrela-do-mar (Williams \& Benzie, 1998; Williams et al., 2002; Benzie, 1999a) e peixes (Lacson \& Clark, 1995; McMillan \& Palumbi, 1995; Nelson et al., 2000; Kochzius et al., 2003; Lourie et al., 2005; Froukh \& Kochzius, 2008). Benzie (1999a) correlacionou essa ruptura genética com eventos recentes, em virtude da baixa divergência genética encontrada entre os agrupamentos encontrados em seu estudos, o que é condizente com o caso de C. hellerii, com divergência de 0,70\% - 1,4\% para COI e $0,00-0,47 \%$ para $16 S$ rDNA.

Este padrão de estruturação é recorrentemente associado com repetidos períodos de baixas dos níveis oceânicos em decorrência das glaciações durante o Pleistoceno (2,6 milhões a 10 mil anos atrás), restringindo ou até impedindo a dispersão por longo períodos entre as duas áreas (Potts, 1983; Palumbi, 1997; Benzie, 1999b; Williams et al., 2002). A principal conexão entre esses dois oceanos é via corrente da Indonésia (Indonesian Throughflow - ITF) (Gordon \& Fine, 1996) e sugerese que os níveis oceânicos dessa conexão tenham baixado consideravelmente repetidas vezes nos últimos três milhões de anos, até $120 \mathrm{~m}$ dos níveis atuais (Haq et al., 1987; Krantz, 1991; Rohling et al., 1998; Siddall et al., 2003). Durante este período, 
o mar de Java, entre as ilhas de Java e Bornéu, estaria totalmente seco (McManus, 1985; Voris, 2000). Além disso, a ressurgência de água fria na base do arco insular indonésio teria restringido algumas vias de dispersão entre as ilhas do leste indonésio e, assim, agido como uma barreira para a dispersão de larvas entre esses dois oceanos (Fleminger, 1985).

Estas alterações teriam ocorrido em paralelo à separação dos dois oceanos por movimentações tectônicas no arquipélago Indo-Malaio. Há cerca de 30 milhões de anos, a maioria das ilhas deste arquipélago não existiam ou não estavam em sua posição atual. Os oceanos Índico e Pacífico eram livremente conectados pelo chamado Indonesian seaway que permitia a entrada da corrente sul equatorial do Pacífico (SEC) no oceano Índico (Figura 23, A). No entanto, cerca de 5 milhões de anos mais tarde, este padrão começou a mudar com o movimento da Austrália, Nova Guiné e da Península da Cabeça de Pássaro em direção ao norte e pelo desenvolvimento da ilha Celebes (Sulawesi) (Hall, 1998). Consequentemente, cerca de 3 a 4 milhões de anos atrás, a interconexão Indonesia seaway foi fechada (Cane \& Molnar, 2001) (Figura 23, B) e a SEC desviada, finalmente levando à presente conformação em que o fluxo de água do Pacífico para o oceano Índico ocorre via mares da Indonésia, isto é, pela Indonesian Throughflow (Gordon \& Fine, 1996; Gordon, 2005). O sentido da movimentação das águas do Pacífico para o Índico é condizente com o resultado encontrado pela análise realizada no software Migrate-n, segundo o qual a migração no sentido do grupo do Pacífico + Índico leste para o grupos do Índico oeste + mar Mediterrâneo foi a que apresentou maior probabilidade (Tabela 10), havendo restrição para migração no sentido oposto. 

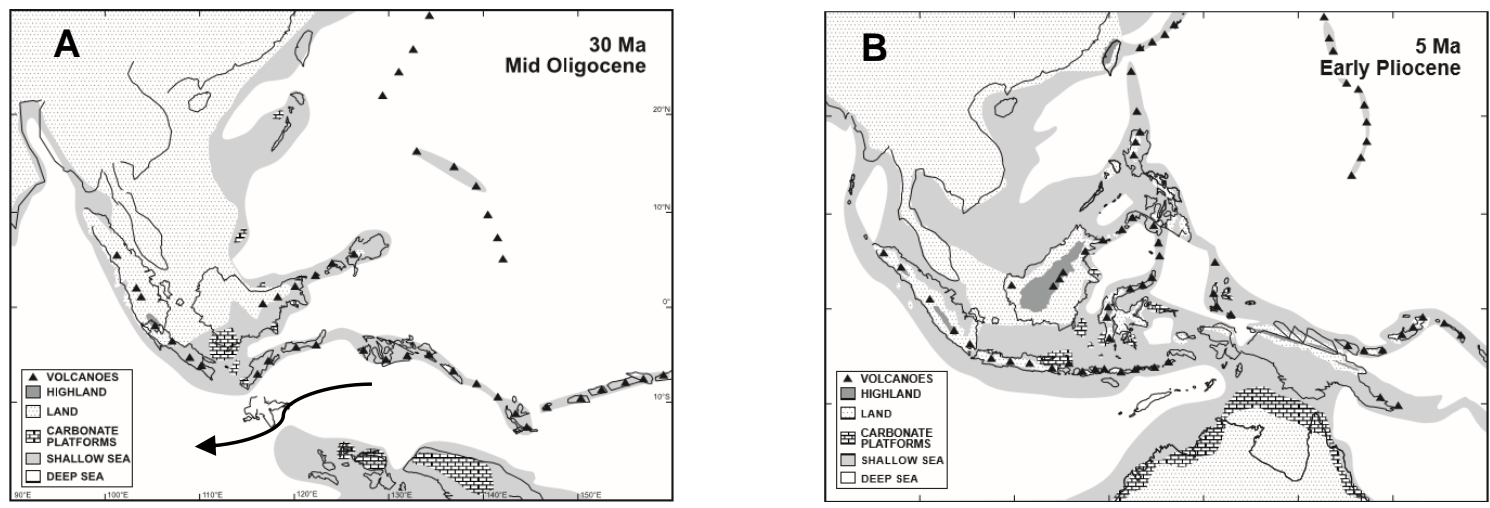

Figura 23. A, distribuição de terra e mar no sudeste asiático há $30 \mathrm{Ma}$. A flecha representa a interconexão entre os oceanos Índico e Pacífico (Indonesia seaway). B, distribuição de terra e mar no sudeste asiático há 5 Ma. Figuras removidas e modificadas de Hall (1998).

Os indivíduos amostrados no leste do oceano Índico se mostraram geneticamente mais próximos aos do Pacífico, apesar de estarem localizados no Índico. Este mesmo padrão foi observado por Williams et al. (2002) e Benzie (1999a) para as espécies de estrela-do-mar Linckia laevigata (Linnaeus, 1758) e Acanthaster planci (Linnaeus, 1758), respectivamente, sendo provavelmente mantido pelas correntes da ITF. Diversos trabalhos sustentam a estruturação genética entre populações da Austrália leste e oeste (Gopurenko \& Hughes, 2002). Diferenciação esta, porém, não observada para $C$. hellerii pelo valor não significativo de Fst calculado entre estas duas localidades (Tabela 8).

Comparativamente e considerando que a amostragem no Índico oeste foi inferior em relação ao Pacífico, sem amostragem em localidades do sudoeste do Índico, como Madagascar, a diversidade genética encontrada no agrupamento Índico oeste + mar Mediterrâneo foi inferior à relativa ao Índico leste + Pacífico (Tabelas 6 e 13). Este mesmo padrão foi observado para o camarão-tigre-gigante Penaeus monodon Fabricius, 1798 (Duda \& Palumbi, 1999; Benzie et al., 2002; You et al., 2008). Nos resultados encontrados para o marcador 16 S rDNA, apenas um haplótipo foi encontrado no agrupamento menos diverso em contraste com sete haplótipos encontrados no outro (Tabela 13). Segundo Benzie et al. (2002), este achado sugere 
que as populações do Índico oeste tenham sofrido redução no tamanho populacional por efeito gargalo.

Diferenciação condizente com a estruturação genética encontrada nas áreas nativas foi encontrada nas análises morfométricas, principalmente no que se refere às fêmeas dessas duas regiões identificadas, mas também encontrada para os machos (Tabela 23; Figura 22). Análises preliminares conduzidas para o camarão $P$. monodon também mostraram diferenciação morfométrica entre essas duas regiões (You et al., 2008). Características morfológicas são afetadas tanto por fatores genéticos como ambientais (Tzeng, 2004). Assim, tais diferenças morfométricas podem tanto refletir diferenças genéticas entre esses dois grupos, bem como diferenças ambientais entre as duas regiões (Tzeng, 2004). Embora as diferenças genéticas tenham sido constatadas nos marcadores moleculares, não se pode assumir necessariamente que as diferenças nos caracteres morfométricos possuem base totalmente genética.

Os resultados de estruturação genética obtidos pelo marcador 16S rDNA (Figuras 9 e 10), bem como pelos valores de $\phi s t$ pela comparação par a par entre as localidades do Pacífico para o gene COI (Tabela 8) e a distribuição geográfica dos haplótipos (Figura 12), evidenciaram a subestruturação genética dos indivíduos da Nova Caledônia. Esta diferenciação genética indica a presença de barreiras que impediram ou ainda impedem a migração entre a Nova Caledônia e demais localidades do Pacífico oeste. No entanto, pela análise de 16S rDNA, indivíduos da Nova Caledônia compartilharam haplótipos com outras localidades, como Filipinas, Indonésia, Singapura e China (Figura 9), e haplótipos de COI detectados nestas mesmas localidades estiveram mais próximos daqueles da Nova Caledônia do que de demais localidades do Pacífico oeste (Figura 7). Isto sugere que a migração e fluxo gênico podem ser possíveis ou ocorreram em algum momento do passado evolutivo, porém não sendo suficiente para possibilitar a homogeneização da Nova Caledônia com as demais localidades (Taillebois et al., 2013). 
Foi encontrado padrão semelhante para a espécie de peixe anfídroma, com elevado potencial dispersivo, Sicyopus zosterophorum (Bleeker, 1857), para a qual dois grupos geográficos foram detectados, um englobando Fiji, Vanuatu e Nova Caledônia e o outro, Okinawa (Japão), Palau, Filipinas e Papua Nova Guiné (Taillebois et al., 2013). Estes autores também associaram essa disruptura com as repetidas baixas do nível do mar durante o Pleistoceno, de modo que estas teriam impossibilitado a dispersão larval na Barreira do Estreito de Torres entre o extremo Norte da Austrália e a Papua Nova Guiné. Contudo, outros fatores, como traços da história de vida, barreiras oceânicas e disponibilidade de habitats não podem ser descartados (Taillebois et al., 2013).

Embora as análises com o marcador $\mathrm{COI}$ tenham revelado um valor elevado e significativo de $\phi s t(0,59)$, evidenciando estruturação entre as localidades amostradas, para que investigações quanto à fragmentação das populações de $C$. hellerii no Índico leste e Pacífico oeste possam ser conduzidas de forma mais detalhada, uma amostragem mais abrangente, principalmente em número amostral, deve ser realizada. Esse alto valor de 0,59 é provavelmente resultado dos singletons existentes em cada localidade (2 nas Filipinas - H12 e H26; 3 em Singapura - H14, H15 e H16; 4 na Austrália - H17, H18, H31 e H32; 4 China - H19, H20, H29 e H30; 3 na Indonésia - H21, H22 e H23 e 1 na Nova Caledônia - H25) (Figura 12).

A existência de um número elevado de singletons nessa região se associa a outro fator observado que consiste nos valores negativos e significativos encontrados para T de Tajima e F de Fu (Tabelas 9 e 15), assim o agrupamento do Índico leste + Pacífico apresentou a hipótese de evolução neutra rejeitada por ambos os testes. 0 excesso de haplótipos com frequência baixa e distintos por uma ou poucas mutações (alta diversidade haplotípica, mas baixa diversidade nucleotídica), constatado na própria rede de haplótipos com formato star-like, poderia indicar, dentre outros fatores, a expansão populacional consequente às condições glaciais experienciadas na região durante as atividades glaciais do Pleistoceno. As mudanças no tamanho populacional 
poderiam ser explicadas pelo fechamento das rotas de dispersão e redução dos habitats durante as baixas do nível do mar, que teriam resultado em reduções populacionais (bottlenecks), seguidos pela recolonização de novos habitats após a elevação dos níveis novamente com o término da última glaciação, permitindo o crescimento das populações reduzidas (Gopurenko, 2002).

Estudos genéticos comparativos conduzidos com espécies de peixes de água doce (Bernatchez \& Wilson, 1998) e de recifes de corais (Fauvelot et al., 2003), entre regiões afetadas pelas glaciações e outras não atingidas revelaram diferenças genéticas substanciais. Enquanto as primeiras são ocupadas por espécies que apresentam evidências de expansão demográfica recente e geralmente baixa diversidade genética (baixa diversidade nucleotídica, mas alta diversidade haplotípica), as segundas são ocupadas por populações com alto nível de divergência genética (alta diversidade nucleotídica) (Bernatchez \& Wilson, 1998; Fauvelot, et al., 2003; Cristescu, 2015).

Em suma, com base nos marcadores estudados e nos dados morfométricos, as áreas nativas (+ mar Mediterrâneo) da ocorrência de $C$. hellerii estão estruturadas em dois agrupamentos, Índico leste + Pacífico e Índico oeste + Mediterrâneo. O primeiro estaria enfrentando um processo de expansão, enquanto que no segundo, no qual os valores do teste de neutralidade não foram significativos, os polimorfismos seriam explicados pela evolução neutra. Subgrupos foram detectados dentro destes agrupamentos, principalmente pela distinção da Nova Caledônia no primeiro e na Índia no segundo (Figura 12). As sequências de animais da Índia, porém, foram retiradas do GenBank e apresentaram variações nas extremidades, região em que as variações podem ser decorrentes de erros no processo de sequenciamento ou amplificação. 


\subsection{Aspectos genéticos e histórico da introdução de Charybdis hellerii na costa} americana

A estruturação filogeográfica detectada nas áreas nativas de C. hellerii foi suficiente para suportar a hipótese de que o mar Mediterrâneo corresponde à principal origem das populações introduzidas na América. A maior parte dos haplótipos encontrados ao longo da costa americana coincide com os detectados no agrupamento Índico oeste + mar Mediterrâneo. Contudo, o compartilhamento de haplótipos entre espécimes da costa americana com o agrupamento Índico leste + Pacífico também sugere a ocorrência de introduções provenientes dessa região (Figura 12). Os resultados, assim, apontam a ocorrência de múltiplas introduções no Atlântico ocidental.

A ideia de que as populações americanas de $C$. hellerii são provenientes do mar Mediterrâneo é prevalente na literatura e é baseada no fato de que as introduções coincidem com um aumento no tráfego de navios entre o Mediterrâneo e áreas distantes na época próxima aos primeiros registros dessa espécie na América (Campos \& Türkay, 1989; Gómez \& Martínez-Iglesias, 1990; Lemaitre, 1995). Por outro lado, introduções provenientes do Pacífico também encontram suporte no incremento entre as relações econômicas e políticas e, consequentemente, do tráfego de navios entre a Ásia e países americanos, como o Brasil, em meados da década de 90 (Oliveira, 2004). Em ambos os casos o vetor teria sido a água de lastro de navios contendo larvas e as introduções provenientes do Índico leste + Pacífico muito provavelmente teriam ocorrido via rota Cabo da Boa Esperança. A rota via Canal do Panamá é muito pouco provável, pois haplótipos relacionados ao Índico leste + Pacífico teriam sido encontrados em outras áreas da costa americana.

A detecção de introduções provenientes do Índico leste + Pacífico permitiram a constatação de introduções crípticas ao nível intraespecífico de C. hellerii na costa americana. Os erros decorrentes de se tratar invasões múltiplas como um evento 
único vão além da subestimativa da frequência com que eventos de introdução ocorreram, mas também levam à negligência de outras possíveis rotas e vetores, que podem ocasionar ou ter ocasionado o trânsito de outras espécies, bem como suposições erradas sobre as características ecológicas e genéticas da espécie invasora (Geller et al., 2010). Por meio desta rota ocorreu a introdução de espécimes de $C$. hellerii e pode ser a rota para outras espécies exóticas.

A constatação de introduções múltiplas foi possível graças à estruturação genética nas áreas nativas e do mar Mediterrâneo, corroborando o preceito de que a presença em população não nativas de haplótipos com distribuição não sobreposta nas áreas de origem pode sugerir a ocorrência de múltiplas introduções provenientes de áreas geneticamente distintas (Geller et al., 2010). É suportado, dessa forma, que múltiplas introduções independentes de $C$. hellerii tenham ocorrido e foram provavelmente seguidas por dispersão. Como os eventos de introdução são relativamente recentes, com o registro mais antigo datando para 1986 ou 1987 (Gómez \& Martínez-Iglesias, 1990; McMillen-Jackson, 2008), não haveria tempo suficiente para a perda dessa diferença genética existente nas populações de origem.

Com base nos dados gerados, porém, não é possível detectar ao certo quantas introduções ocorreram provenientes de cada região e nem onde exatamente estas águas de lastro foram liberadas. Sustenta-se, porém, que introduções provenientes do mar Mediterrâneo possam ter ocorrido uma ou mais vezes em diferentes lugares ao longo da costa americana e a dispersão das formas larvais tenha se dado para outras regiões. Considerando apenas o padrão de movimentação das correntes superficiais atuando no Atlântico ocidental, bem como as datas de registro, um cenário teórico seria a ocorrência de introduções independentes no Atlântico Norte, incluindo o mar do Caribe, e no litoral brasileiro. No primeiro, a dispersão se daria em direção ao Norte pela corrente Norte Equatorial e no segundo, em direção ao sul pela corrente Brasileira. Contudo, nota-se que os mecanismos de dispersão tanto naturais quanto 
antropogênicos podem contribuir com as invasões (Lejeusne et al., 2014). Dentre os antropogênicos, a movimentação de navios, tanto comerciais quanto privados, ao longo da costa americana pode contribuir. Os cargueiros comerciais, por exemplo, não liberam água de lastro apenas nos portos. Para ajustar a sua estabilidade, água de lastro pode ser liberada no mar enquanto um navio viaja ao longo do litoral e, consequentemente, o plâncton pode ser liberado em áreas que não possuem tráfego transoceânico ou de grande cargueiros (Lejeusne et al., 2014). Além disso, barcos de pesca e recreacionais também podem ter água de lastro e contribuir com a dispersão (Lejeusne et al., 2014).

Por outro lado, a ocorrência restrita de haplótipos provenientes do Índico leste + Pacífico no sul do Brasil (litoral de Santa Catarina, São Paulo e Rio de Janeiro, Figura 12) indica introduções provenientes dessas regiões apenas nessas áreas. Nesse caso, a dispersão para o Norte não teria ocorrido ou ocorreu em pequena escala, possivelmente pela restrição imposta pela movimentação da corrente Brasileira em sentido sul e sem dispersão por longas distâncias via navegação costeira.

Como estruturação genética não foi encontrada entre o mar Mediterrâneo e o Índico oeste (sem Fst significativo entre o Irã e a Turquia), exceto Índia, suporta-se a conectividade entre essas duas áreas, assim como proposto em estudos com peixes (Bucciarelli et al., 2002; Hassan et al., 2003). Embora haplótipos encontrados no Irã, não tenham sido detectados no mar Mediterrâneo, é possível que isto tenha ocorrido em decorrência de uma amostragem insuficiente para detectar tal variação no Mediterrâneo. Assim, assumindo esta localidade como a principal origem da população americana, é razoável propor que, como os mesmos haplótipos encontrados no Irã também foram encontrados na América, estes não tenham sido amostrados no mar Mediterrâneo. A amostragem de mais indivíduos do Mediterrâneo possivelmente possibilitaria a detecção destes haplótipos encontrados no Irã. 
Para algumas espécies estudadas, este crivo genético durante a invasão do mar Mediterrâneo via Canal de Suez parece não ter ocorrido (Bucciarelli et al., 2002; Hassan et al., 2003; Hassan \& Bonhomme, 2005; Azzurro et al., 2006). Hassan et al. (2003) sustentaram um cenário em que introduções de duas espécies de peixes no mar Mediterrâneo não teriam passado por um crivo genético e demográfico, mas, em contraste, são o produto de constantes e repetidos influxos de animais no mar Mediterrâneo provenientes do mar Vermelho, mantendo sua diversidade mitocondrial original durante a colonização. Isso possivelmente se estende para outros grupos, como os crustáceos. Muito provavelmente também o próprio tráfego de navios do Índico oeste para outras regiões via Canal de Suez contribui para o influxo de animais e, consequentemente, de diversidade genética para o Mediterrâneo, o que torna 0 crivo genético ainda mais improvável para C. hellerii.

A existência de um grupo geneticamente distinto na costa americana (G3, Figuras 11 e 13; C4, Figuras 14 e 15; A4, Figura 16), sem qualquer padrão geográfico, pode estar associada com introduções provenientes de populações não amostradas nas regiões nativas. $O$ curto período de tempo de ocorrência de $C$. hellerii na costa americana enfraquece qualquer tentativa de se hipotetizar seu surgimento nessa região pós eventos de introdução. Considerando a taxa de evolução dos genes estudados, é realmente pouco provável que mudanças consideráveis na composição das sequências tenham ocorrido desde a introdução dessa espécie na América (Murakami-Sugihara et al., 2012). Além disso, as análises filogenéticas (Figuras 13 e 15), bem como a rede de haplótipos de 16S rDNA (Figura 15), apontam a proximidade deste grupo com o agrupamento Índico leste + Pacífico, o que sustenta ainda mais a não amostragem de sua região de origem em áreas provavelmente do Pacífico e que provavelmente apresenta elevada estruturação genética.

Os grupos genéticos detectados na área nativa coincidem com dois domínios biogeográficos propostos por Spalding et al. (2007), o Western Indo-Pacific e o Central 
Indo-Pacific. Simplificadamente, segundo estes autores, estes domínios consistem em grandes regiões oceânicas incluindo áreas costeiras, bentônicas e pelágicas, cujos biotas são internamente coerentes aos níveis taxonômicos superiores, como resultado de uma história evolutiva compartilhada. Apresentam altas taxas de endemismo e os fatores relacionados a isso incluem fatores abióticos, como temperatura da água, isolamento histórico (Spalding et al., 2007). As ecoregiões foram delineadas, assim, com base na configuração taxonômica, influenciadas por história evolutiva, padrões de dispersão e isolamento (Spalding et al., 2007) e foram corroboradas pela espécie em estudo. Tendo isso em mente e considerando que nem todos os domínios da ocorrência nativa de C. hellerii foram amostrados, como o Eastern Indo-Pacific, onde está o Havaí, ou foram pouco amostrados, como o Temperate Northern Pacific, onde está o Japão, e a Temperate Australasia, a inclusão da primeira e a abrangência maior das demais poderiam fornecer um quadro mais amplo sobre o histórico de introdução de C. hellerii e talvez até a detecção de haplótipos detectados na América, mas não observados nas áreas nativas analisadas.

A amostragem insuficiente das potenciais regiões de origem das introduções é apontada como um fator crucial que pode ocasionar falhas em estudos genéticos de espécies invasoras (Geller et al., 2010). Uma amostragem adequada permite que se tenha certeza da não sobreposição na distribuição de certos haplótipos nas áreas de origem para apontar com segurança a origem de populações introduzidas e o surgimento de haplótipos novos em áreas invadidas. A intensidade de amostragem para a inferência de populações de origem é dependente do grau de estruturação filogeográfica nessas áreas (Taylor \& Keller, 2007). As dificuldades nesse fator são fortemente associadas a populações de origem extremamente fragmentadas ou àquelas com baixa resolução filogeográfica (Darling et al., 2008).

Um exemplo de problemas envolvendo a não amostragem adequada nas áreas de origem é representado pelo caso da espécie de gastrópode Littorina littorea 
(Linnaeus, 1758) (Blakeslee \& Byers, 2008; Blakeslee et al., 2008). Esta espécie é comum na Europa e se tornou abundante ao redor de Halifax (Nova Escócia, Canadá) em meados do século XIX, dispersando-se para o sul por volta de 1880 (Carlton, 1982). Entretanto, uma diversidade genética maior que a esperada detectada nas populações da América do Norte, bem como a presença de diversos singletons nessa área, levou alguns autores a concluir, também com base em análises de coalescência realizadas, que as populações de $L$. littorea na América do Norte, na verdade, eram nativas (Wares et al., 2002). Análises realizadas mais tarde, porém, propuseram que, na verdade, a diversidade genética na Europa fora anteriormente subamostrada (Chapman et al., 2007), de modo que uma amostragem mais abrangente nas áreas nativas e não nativas, em associação com análises mais precisas e corroboradas por dados genéticos obtidos de um parasita trematódeo específico de L. littorea, permitiram a constatação de que não havia subclados americanos e de que as populações americanas seriam, sim, exóticas (Blakeslee \& Byers, 2008; Blakeslee et al., 2008).

A comparação das diversidades haplotípica e nucleotídica de localidades nativas e não nativas para ambos os marcadores utilizados evidencia para o primeiro índice (Tabelas 5, 11, 16 e 18) uma certa variação e falta de padrão, uma vez que ele é dependente no número de indivíduos amostrados (Clark \& Hartl, 2010). Comparando-se as localidades com maior " $n$ " amostral, observa-se que as diversidades haplotípicas de localidades exóticas são similares às de localidades nativas e do mar Mediterrâneo. Estudos comparando a diversidade genética de populações exóticas e nativas tem, de forma geral, reportado valores comparáveis de variação entre essas áreas (Cristescu, 2015).

As diversidades nucleotídicas para as localidades americanas foram majoritariamente superiores àquelas calculadas para as localidades do Indo-Pacífico e do mar Mediterrâneo, o que evidencia que os haplótipos das primeiras apresentaram 
maiores diferenças entre si. A diversidade nucleotídica calculada para toda a América $(\pi=0,01156-\mathrm{COI} ; \pi=0,00326-16 \mathrm{~S}$ rDNA) foi superior em relação às demais regiões de origem (Pacífico + Índico Leste: $\pi=0,00441-\mathrm{COI} ; \pi=0,00150-16 S$ rDNA e Índico Oeste + mar Mediterrâneo: $\pi=0,00461-$ COI; $\pi=0,00000-16 S$ rDNA). Estes resultados para ambos os índices, diversidade haplotípica e nucleotídica, estão possivelmente relacionados à ocorrência de introduções independentes de localidades geneticamente diferentes na América. Ainda, a grande diversidade nucleotídica encontrada na América para COI se deve principalmente aos indivíduos de G3 (Figura 11), cuja origem não foi rastreada e cujo haplótipo se difere dos demais em muitas posições nucleotídicas.

A comparação destes parâmetros entre a América e as possíveis regiões de origem permite a constatação de que após invasões provenientes de ambas as regiões detectadas nas análises das populações nativas e mar Mediterrâneo, bem como de uma terceira localidade não rastreada, a diversidade haplotípica da América para $\mathrm{COI}(\mathrm{Hd}=0,790)$ foi pouco inferior à do Pacífico + Índico Leste $(\mathrm{Hd}=0,887) \mathrm{e}$ semelhante à Índico Oeste + mar Mediterrâneo $(\mathrm{Hd}=0,782)$. Para o marcador $16 \mathrm{~S}$ rDNA, a diversidade haplotípica total da América $(\mathrm{Hd}=0,736)$ foi um pouco superior a do Pacífico + Índico leste $(\mathrm{Hd}=0,619)$ e muito superior à do Índico oeste + mar Mediterrâneo, onde todos os haplótipos desse gene foram idênticos. De qualquer modo, a diversidade haplotípica detectada na América foi elevada e também estaria correlacionada com a ocorrência de introduções múltiplas.

As diferenças notadas entre ambos os marcadores estariam relacionadas com suas particularidades. Por exemplo, a existência de indivíduos que pela análise de COI estiveram mais próximos do Índico leste + Pacífico, mas com o contrário sendo obtido pela análise de 16S rDNA, provavelmente é devido à retenção de polimorfismos ancestrais neste gene mais conservado. Isto se torna mais evidente, pois, na análise desse gene somente das áreas nativas, observou-se um indivíduo proveniente da 
Austrália agrupado com Índico Oeste + Pacífico (Haplótipo 3, Figura 9). Este resultado expressa a importância de uma seleção adequada dos loci analisados, bem como da utilização de combinada de diferentes marcadores (Geller et a., 2010). O uso isolado do 16S rDNA poderia incorrer em erros de interpretação.

Em geral, tem-se demonstrado que dispersões mediadas por atividade humana podem resultar em um elevado nível de diversidade genética dentro das populações introduzidas em relação às de origem (e.g. Voisin et al., 2005; Lejeusne et al., 2014; Lallias et al., 2015) e as perdas na diversidade são geralmente mínimas (Wares et al., 2005). A diversidade genética de populações não nativas depende de vários fatores, tanto referentes às populações de origem como à demografia das invasões, dentre eles: o número de indivíduos introduzidos, diversidade e estruturação das populações de origem, gargalos genéticos associados aos eventos de introdução e eventuais processos seletivos determinando a proporção de diversidade genética que é retida nessas populações (Holland, 2000). A ocorrência de introduções múltiplas é constantemente apontada como fator facilitador de diversidade genética alta nas populações introduzidas (Roman \& Darling, 2007; Dlugosch \& Parker, 2008).

Se por um lado, acredita-se que introduções múltiplas tendem a elevar a pressão de propágulo e compensar os crivos genéticos da introdução pelo influxo de diversidade adicional, sendo muitas vezes crucial para o sucesso das introduções (Lockwood et al., 2005; Dlugosch \& Parker, 2008, Roman \& Darling, 2007; Lejeusne et al., 2014). Não se sabe até que ponto, porém, a elevada diversidade constatada em marcadores neutros reflete a diversidade em traços adaptativos (Butlin \& Tregenza, 1998; Reed \& Frankham, 2001). Estes marcadores são extremamente acurados para a análise de histórias demográficas, porém não são interessantes em termos de respostas evolutivas das espécies introduzidas (Wares et al., 2005). Além disso, sugere-se que introduções independentes provenientes de origens geneticamente distintas podem permanecer por um tempo como "mosaicos de más adaptações" até 
que realmente venham a se misturar (Dlugosch \& Parker, 2008). Apesar desta proposição, estes autores não invalidam a importância de introduções múltiplas, mas acreditam que estas sejam cruciais para o sucesso à longo prazo, de modo a proporcionar o surgimento de novas combinações gênicas que resultem em uma diversificação fenotípica e altere o potencial adaptativo de populações invasoras (e.g. Kolbe et al., 2007).

A identificação de gargalo demográfico é normalmente muito complicada. Não basta apenas comparar os índices de diversidade alélica entre a população exótica e a sua nativa identificada. É importante também conhecer os alelos de um locus (Nei et al., 1975). No entanto, a ocorrência de novas mutações pode interferir nessa comparação (Nei et al., 1975), bem como o número de indivíduos amostrados, no qual se baseia o cálculo dos índices de diversidade (Clark \& Hartl, 2010). Normalmente, negligencia-se todas as mutações ocorrentes após a introdução e estas tendem a influenciar mais evidentemente o número de alelos (entende-se haplótipos) do que a diversidade nucleotídica, pois tendem a ter baixa frequência (Nei et al., 1975). No caso de introduções recentes, como o caso de $C$. hellerii, a interferência de mutações recentes no cálculo de diversidade se torna ainda menos expressiva e os alelos detectados nas áreas não nativas provavelmente não foram amostrados nas regiões nativas.

Considerando as introduções independentemente e que tenha ocorrido um número mínimo de introduções, indício de gargalo genético expressivo não foi detectado para a introdução proveniente do mar Mediterrâneo. Para COI, dos cinco haplótipos detectados nos 11 indivíduos do agrupamento Índico oeste + mar Mediterrâneo (excluindo a Índia, que apresentou diferenciação genética e não é apontada como fonte das populações americanas), apenas dois não foram encontrados nas populações americanas. Além disso, dois haplótipos detectados somente nos EUA ( $\mathrm{H} 10$ e H13) possivelmente não foram amostrados as regiões de 
origem. Em contraste, dos 20 haplótipos encontrados nos 36 espécimes do agrupamento Índico leste + Pacífico (excluindo a Nova Caledônia, que apresentou diferenciação genética e não é apontada como fonte das populações americanas), três foram encontrados em quatro dos 87 indivíduos amostrados na América, o que sugere a ocorrência de uma gargalo genético associado ao efeito do fundador neste evento de introdução. Dois outros haplótipos (H6 e H9) encontrados no sul do Brasil, mostraram-se mais próximos do agrupamento Índico leste + Pacífico, porém não foram detectados nas áreas de origem.

Comparando as diversidades haplotípicas dos grupos genéticos identificados nas áreas nativas e de suas potenciais regiões geográficas de origem, observa-se uma diferença mínima entre os valores encontrados para COI entre o Índico Oeste + mar Mediterrâneo (excluindo a Índia, $\mathrm{Hd}=0,709$ ) e o grupos da América geneticamente próximo a este $(\mathrm{Hd}=0,675)$. Para $16 \mathrm{~S}$ rDNA, porém, o valor do grupo da América é maior ( $\mathrm{Hd}=0,577$, pela análise de BAPS concatenada), pois não houve diferença entre as sequências do Índico Oeste + mar Mediterrâneo para esse marcador. Embora a comparação do número de haplótipos tenha evidenciado perda de alguns haplótipos durante a introdução, os indivíduos da América relacionados ao Índico leste + Pacífico apresentaram uma diversidade haplotípica $(\mathrm{Hd}=0,905)$ um pouco superior à do Índico leste + Pacífico (excluindo a Nova Caledônia, $\mathrm{Hd}=0,862$ ) para COI e para 16S rDNA (América $\mathrm{Hd}=0,800$, análise concatenada, e Ìndico leste + Pacífico, excluindo a Nova Caledônia $\mathrm{Hd}=0,576)$. Essa elevada diversidade haplotípica encontrada na América para as introduções provenientes do Índico leste + Pacífico estão relacionados ao baixo número de animais encontrados na América, os quais apresentam diferentes haplótipos. De qualquer modo, os resultados sugerem que não houve a introdução de muitos haplótipos existentes nessa região de origem, onde a população foram encontradas assinaturas de expansão em um contexto histórico. 


\subsection{Registro de Charybdis variegata (Fabricius, 1798) na costa americana}

A baixa (ou até mesmo nula) divergência genética entre o indivíduo identificado como "C. variegata" para o litoral de São Paulo e espécimes de $C$. hellerii, bem como a grande dissimilaridade morfológica em relação a outros indivíduos identificados como C. variegata do Indo-Pacífico consistem em fortes indícios de ocorrência de erro de identificação. Os resultados indicam que esse exemplar consiste em mais um espécime de C. hellerii.

Os registros de espécies marinhas exóticas têm sido fortemente incrementados nos últimos anos como consequência do crescimento do número de pesquisadores não taxonomistas trabalhando na descrição da biodiversidade ou que estão restritos ao uso de ferramentas tradicionais que não detectam outras diferenças em nível específico. Na realidade este representa mais um caso complexo que necessita de uma investigação acurada não apenas voltada ao espécime coletado, mas também de outras espécies simpátricas ou alopátricas para melhor contextualizar o problema, o que em alguns casos não é tomado em conta. Como consequências, erros, tais como este, podem conduzir a sérios problemas e impactos sobre os esforços crescentes de descrição da diversidade e sua preservação, bem como na elaboração de estratégias de manejo (Soledade et al., 2013). 
6. Conclusão 
Os resultados moleculares e morfológicos sustentaram $C$. hellerii como uma única entidade taxonômica, porém evidenciaram estruturação genética e morfométrica nas áreas nativas (Indo-Pacífico). Nesta, dois grupos foram identificados, um composto pelos indivíduos do mar Mediterrâneo + Índico oeste e o outro, Índico leste + Pacífico. Esta estruturação forneceu ainda mais indícios do mar Mediterrâneo como a principal fonte de origem das populações americanas, mas também revelou a região do Índico leste + Pacífico como outra potencial origem, indicando a ocorrência de introduções múltiplas. As introduções provenientes do Índico leste + Pacifico teriam se restringido ao sul do Brasil e teriam ocorrido, provavelmente, via rota Cabo da Boa Esperança. Um terceiro grupo genético detectado na costa americana e geneticamente mais próximo do Índico leste + Pacífico sugere introdução proveniente de uma localidade não amostrada nas áreas de origem. Os valores de diversidade haplotípica nas áreas exóticas foram comparáveis aos das de origem. Já os valores de diversidade nucleotídica foram predominantemente superiores nas primeiras em relação às segundas, o que reflete alto grau de diferenciação entre os haplótipos dentro de uma mesma localidade na América. Esses resultados referentes aos índices de diversidade estão possivelmente relacionados à ocorrência de introduções múltiplas provenientes de áreas geneticamente distintas. Pela comparação do número de haplótipos, indícios de gargalo genético expressivo não foram encontrados nas introduções provenientes do mar Mediterrâneo. Nas introduções provenientes do Índico oeste + Pacífico, gargalo genético significativo possivelmente ocorreu. Ainda, uma segunda espécie, Charybdis variegata, recentemente registrada para a costa americana, consiste em mais um exemplar de C. hellerii. 
7. Referências 
Ahmed, M. \& G. Abbas. 1999. Summer abundance of juvenile finfish and shellfish in Korangi Creek, Karachi (Pakistan: northern Arabian Sea). Pakistan Journal of Zoology, 31: 365-378.

Allendorf, F.W. \& L.L. Lundquist. 2003. Introduction: Population biology, evolution, and control of invasive species. Conservation Biology, 17(1): 24-30.

Almeida, A.O.; Coelho, P.A. \& J.T.A. Santos. 2003. New records of decapod crustaceans (Dendrobranchiata and Brachyura) for the state of Bahia, Brazil. Nauplius, $11(2):$ 129-133.

Apel, M. \& V.A. Spiridonov. 1998. Taxonomy and zoogeography of the portunid crabs (Crustacea: Decapoda: Brachyura: Portunidae) of the Arabian Gulf and adjacent waters. Fauna of Arabia, 17: 159-331.

Astanei, I.; Gosling, E.; Wilson, J. \& E. Powell. 2005. Genetic variability and phylogeography of the invasive zebra mussel, Dreissena polymorpha (Pallas). Molecular Ecology, 14(6): 1655-1666.

Audzijonyte, A.; Wittmann, K.J. \& R. Väinölä. 2008. Tracing recent invasions of the Ponto-Caspian mysid shrimp Hemimysis anomala across Europe and to North America with mitochondrial DNA. Diversity and Distribution, 14(2): 179-186.

Avise, J.C. 2009. Phylogeography: retrospect and prospect. Journal of Biogeography, 36(1): 3-15.

Azzurro, E.; Golani, D.; Bucciarelli, G. \& G. Bernardi. 2006. Genetics of the early stages of invasion of the Lessepsian rabbitfish Siganus luridus. Journal of Experimental Marine Biology and Ecology, 333(2): 190-201.

Barber, P.H.; Erdmann, M.V. \& S.R. Palumbi. 2006. Comparative phylogeography of three codistributed stomatopods: origins and timing of regional lineage diversification in the coral triangle. Evolution, $\underline{60}(9)$ : 1825-1839.

Barber, P.H.; Palumbi, S.R.; Erdmann, M.V. \& M.K. Moosa. 2000. A marine Wallace's line? Nature, 406: 692-693.

Barber, P.H.; Palumbi, S.R.; Erdmann, M.V. \& M.K. Moosa. 2002. Sharp genetic breaks among populations of a benthic marine crustacean indicate limited oceanic larval transport: patterns, causes, and consequences. Molecular Ecology, 11: 659-674.

Barrett, S.C.H. \& J.R. Kohn. 1991. Genetic and evolutionary consequences of small population size in plants: implications for conservation. pp. 3-30. In: Falk, D.A. \& 
K.E. Holsinger (Eds.). Genetics and conservation of rare plants. Oxford University Press, New York, EUA.

Beerli, P. 2004. Effect of unsampled populations on the estimation of population sizes and migration rates between sampled populations. Molecular Ecology, 13: 827836.

Beerli, P. 2006. Comparison of Bayesian and maximum likelihood inference of population genetic parameters. Bioinformatics, 22(3): 341-345.

Beerli, P. 2009. How to use migrate or why are markov chain monte carlo programs difficult to use? In: Bertorelle, G.; Bruford, M.W.; Hauffe, H.C.; Rizzoli, A. \& C. Vernesi (Eds.). Population Genetics for Animal Conservation. Volume 17. Conservation Biology. Cambridge University Press, Cambridge, Reino Unido.

Beerli, P. \& M. Palczewski. 2010. Unified framework to evaluate panmixia and migration direction among multiple sampling locations. Genetics, 185(1): 313326.

Bentes, A.B.; Lima, W.G.; Fernandes, S.; Paula, J.D.; Silva, K.; Abrunhosa, F. \& B. Bentes. 2013. Occurrence of Charybdis hellerii (Milne Edwards, 1867) (Crustacea, Decapoda, Portunidae) in an Amazonian Estuary. Biota Amazônia, $\underline{3}(3): 181-184$.

Benzie, J.A.H. 1999a. Major genetic differences between crown-of-thorns starfish (Acanthaster planci) populations in the Indian and Pacific Oceans. Evolution, $\underline{53}$ : 1782-1795.

Benzie, J.A.H. 1999b. Genetic structure of coral reef organisms - ghosts of dispersal past. American Zoologist, 39: 131-135.

Benzie, J.A.H.; Ballment, E.; Forbes, A.T.; Demetriades, N.T. \& K. Sugama. 2002. Mitochondrial DNA variation in Indo-Pacific populations of the giant tiger prawn, Penaeus monodon. Molecular Ecology, 11: 2553-2569.

Bernatchez, L. \& C.C. Wilson. 1998. Comparative phylogeography of Nearctic and Palearctic fishes. Molecular Ecology, 17: 2563-2565.

Bezerra, L.E.A. \& A.O. Almeida. 2005. Primeiro registro da espécie indo-pacífica Charybdis hellerii (A. Milne-Edwards, 1867) (Crustacea: Decapoda: Portunidae) para o litoral do estado do Ceará, Brasil. Tropical Oceanography, 33(1): 33-38.

Blackburn, T.M.; Lockwood, J.L. \& P. Cassey. 2015. The influence of numbers on invasion success. Molecular Ecology, 24(9): 1942-1953. 
Blakeslee, A.M.H. \& J.E. Byers. 2008. Using parasites to inform ecological history: comparisons among three congeneric marine snails. Ecology, 89: 1068-1078.

Blakeslee, A.M.H.; Byers, J.E. \& M.P. Lesser. 2008. Solving cryptogenic histories using host and parasite molecular genetics: the resolution of Littorina littorea's North American origin. Molecular Ecology, 17: 3684-3696.

Bolaños, J.A.; Baeza, J.A.; Hernandez, J.E.; Lira, C. \& R. López. 2012. Population dynamics and reproductive output of the non-indigenous crab Charybdis hellerii in the south-eastern Caribbean Sea. Journal of the Marine Biological Association of the United Kingdom, 93(3): 469-474.

Briggs, W.H. \& I.L. Goldman. 2006. Genetic variation and selection response in model breeding populations of Brassica rapa following a diversity bottleneck. Genetics, 172: 457-465.

Brockerhoff, A. \& C. McLay. 2011. Human-mediated spread of alien crabs. pp. 27-106. In: Galil, B., Clark, P.F. \& J.T. Carlton. (Eds.). In the Wrong Place - Alien Marine Crustaceans: Distribution, Biology and Impacts. Invading Nature. Springer Series in Invasion Ecology. Volume 6. London. 723p.

Brooker, A.L.; Benzie, J.A.H.; Blair, D. \& J.J. Versini. 2000. Population structure of the giant tiger prawn Penaeus monodon in Australian waters, determined using microsatellite markers. Marine Biology, 136: 149-157.

Brown, W.M.; George, M., Jr \& A.C. Wilson. 1979. Rapid evolution of animal mitochondrial DNA. Proceedings of the National Academy of Sciences of the USA, $\underline{76}(4):$ 1967-1971.

Bucciarelli, G.; Golani, D. \& G. Bernardi. 2002. Genetic cryptic species as biological invaders: the case of a Lessepsian fish migrant, the hardyhead silverside Atherinomorus lacunosus. Journal of Experimental Marine Biology and Ecology, 273:143-149.

Butlin, R.K. \& T. Tregenza. 1998. Levels of genetic polymorphism: marker loci versus quantitative traits. Philosophical Transactions of the Royal Society of London. Series B, Biological Sciences, 353: 187-198.

Calado, T.C.S. 1996. Registro de Charybdis hellerii (Milne Edwards, 1867) em águas do litoral brasileiro (Decapoda: Portunidae). Boletim de Estudos de Ciências do Mar, $\underline{9}$ : 175-180.

Campos, N.H. \& M. Türkay. 1989. On a record of Charybdis hellerii from the Caribbean coast of Colombia. Senckenbergiana Maritima, 20(3/4): 119-123. 
Cane, M.A. \& P. Molnar. 2001. Closing of the Indonesian seaway as a precursor to east African aridification around 3-4 million years ago. Nature, 411:157-162.

Carlton, J.T. 1982. The historical biogeography of Littorina littorea on the Atlantic coast of North America, and implications for the interpretation of the structure of New England intertidal communities. Malacology Review, 15:146.

Carlton, J.T. 1989. Man's role in changing the face of the ocean: biological invasions and implications for conservation of nearshore environments. Conservation Biology, $\underline{3}(3)$ : 265-273.

Carlton, J.T. 2009. Deep invasion ecology and the assembly of communities in historical time. pp. 13-56. In: Rilov, G. \& J.A. Crooks (Eds.). Biological Invasions in Marine Ecosystems: Ecological, Management, and Geographic Perspectives. Ecological Studies, Volume 204. Springer-Verlag, Berlim, Alemanha. 641p.

Carlton J.T \& G.M. Ruiz. 2005a. The magnitude and consequences of bioinvasions in marine ecosystems: implications for conservation biology. In: Norse, E.A. \& L.B. Crowder (Eds.). Marine Conservation Biology: The Science of Maintaining the Sea's Biodiversity. Island Press, Washington D.C., EUA. 496p.

Carlton, J.T. \& G.M. Ruiz. 2005b. Vector science and integrated vector management in bioinvasion ecology: conceptual frameworks. pp. 36-58. In: Mooney, H.A.; Mack, R.N.; McNeeley, J.A.; Neville, L.E.; Johan Schei, P. \& J.K. Waage (Eds.). Invasive Alien Species: A New Synthesis. Island Press, Covelo, California, EUA.

Carlton, J.T. \& J.B. Geller. 1993. Ecological roulette: the global transport of nonindigenous marine organisms. Science, 261: 78-82.

Carqueija, C.R.G. \& E.P. Gouvêa. 1996. A ocorrência, na costa brasileira, de um Portunidae (Crustacea, Decapoda), originário do Indo-Pacífico e Mediterrâneo. Nauplius, $\underline{4}(1)$ : 105-112.

Castresana, J. 2000. Selection of conserved blocks from multiple alignments for their use in phylogenetic analysis. Molecular Biology and Evolution, 17: 540-552.

Chakraborty, A.; Otta, S.K.; Joseph, B.; Kumar, S.; Md, S.H.; Karunasagar, I.; Venugopal, M.N. \& I. Karunasagar. 2002. Prevalence of white spot syndrome virus in wild crustaceans along the coast of India. Current Science, $\underline{82(11):}$ 1392-1397.

Chang, Y.S.; Peng, S.E.; Wang, H.C.; Hsu, H.C.; Ho, C.H., Wang, C.H.; Wang, S.Y.; Lo, C.F. \& G.H. Kou. 2001. Sequencing and amplified restricted fragment length 
polymorphism analysis of ribonucleotide reductase large subunit gene of the white spot syndrome virus in blue crab (Callinectes sapidus) from American coastal waters. Marine Biotechnology, $\underline{3}(2)$ : 163-171.

Chapman, J.W.; Carlton, J.T.; Bellinger, M.R. \& A.M. Blakeslee. 2007. Premature refutation of a human-mediated marine species introduction: the case history of the marines nail Littorina littorea in the northwest Atlantic. Biological Invasions, 9: 737-750.

Chase, M.W. \& M.F. Fay. 2009. Barcoding of plants and fungi. Science, 325: 682-683.

Chu, K.H.; Tsang, L.M.; Ma, K.Y; Chan, T.Y. \& P.K.L. Ng. 2009. Decapod phylogeny: what can protein-coding genes tell us? pp. 89-99. In: Martin, J.W.; Crandall, K.A. \& D.L. Felder. (Eds.). Decapod Crustacean Phylogenetics. Crustacean Issues 18. CRC Press, Taylor \& Francis Group, Boca Raton, London, New York.

Clark, A.G. \& D.L. Hartl. 2010. Princípios de Genética de Populações. 4ª Edição. Artmed, Porto Alegre, Brasil. 660p.

Clement, M.; Posada, D. \& K.A. Crandall. 2000. TCS: a computer program to estimate gene genealogies. Molecular Ecology, $\underline{9}(10):$ 1657-1660.

Coelho, P.A. \& M.C.F. Santos. 2003. Ocorrência de Charybdis hellerii (Milne Edwards, 1867) (Crustacea, decapoda, Portunidae) no litoral de Pernambuco. Boletim Técnico Científico CENEPE, 11(1): 167-173.

Colautti, R.I. \& H.J. Maclsaac. 2004. A neutral terminology to define 'invasive' species. Diversity and Distributions, $\underline{10}(2):$ 135-141.

Colgan, D.J.; McLauchlan, A.; Wilson, G.D.F.; Livingston, S.P.; Edgecombe, G.D.; Cassis, G. \& M.R. Gray. 1998. Histone H3 and U2 snRNA DNA sequences and arthropod molecular evolution. Australian Journal of Zoology, 46(5): 419-443.

Corander, J.; Gyllenberg, M. \& T. Koski. 2007. Random Partition models and Exchangeability for Bayesian Identification of Population Structure. Bulletin of Mathematical Biology, 69: 797-815.

Corander, J.; Waldmann, P. \& M.J. Sillanpää. 2003. Bayesian analysis of genetic differentiation between populations. Genetics, 163: 367-374.

Corander, J.; Waldmann, P.; Marttinen, P. \& M.J. Sillanpää. 2004. BAPS 2: enhanced possibilities for the analysis of genetic population structure. Bioinformatics, $\underline{20}$ : 2363-2369.

Cristescu, M.E. 2015. Genetic reconstructions of invasion history. Molecular Ecology, 24(9): 2212-2225. 
Darling, J.A.; Bagley, M.J.; Roman, J.; Tepolt, C.K. \& J.B. Geller. 2008. Genetic patterns across multiple introductions of the globally invasive crab genus Carcinus. Molecular Ecology, 17(23): 4992-5007.

Darriba, D.; Taboada, G.L.; Doallo, R. \& D. Posada. 2012. jModelTest 2: more models, new heuristics and parallel computing. Nature Methods, $\underline{9}(8): 772$.

Davis, M.A. \& K. Thompson. 2000. Eight ways to be a colonizer; two ways to be an invader: a proposed nomenclature scheme for invasion ecology. Bulletin of the Ecological Society of America, 81: 226-230.

Dineen, J.F.; Clark, P.F.; Hines, A.H.; Reed, S.A. \& H.P. Walton. 2001. Life history, larval description, and natural history of Charybdis hellerii (Decapoda, Brachyura, Portunidae), an invasive crab in the western Atlantic. Journal of Crustacean Biology, 21(3): 774-805.

Dlugosch, K.M. \& I.M. Parker. 2008. Founding events in species invasions: genetic variation, adaptative evolution, and the role of multiple introductions. Molecular Ecology, 17(1): 431-449.

Dlugosch, K.M.; Anderson, S.R.; Braasch, J.; Cang, F.A. \& H.D. Gillette. 2015. The devil is in the details: genetic variation in introduced populations and its contributions to invasion. Molecular Ecology, 24(9): 2095-2111.

Duda, T.F. \& S.R. Palumbi. 1999. Population structure of the black tiger prawn, Penaeus monodon, among western Indian Ocean and western Pacific populations. Marine Biology, 134: 705-710.

Dupont, L.; Viard, F. \& J.D.D. Bishop. 2007. Combined effects of bottlenecks and selfing in populations of Corella eumyota, a recently introduced sea squirt in the English Channel. Diversity and Distributions, $\underline{13}(6)$ : 808-817.

Edgar, R.C. 2004a. MUSCLE: multiple sequence alignment with high accuracy and high throughput. Nucleic Acids Research, 32(5): 1792-1797.

Edgar, R.C. 2004b. MUSCLE: a multiple sequence alignment method with reduced time and space complexity. BMC Bioinformatics, $\underline{5}: 113$.

Elton, C.S. 1958. The ecology of invasion by plants and animals. Methuen and Co. Ltd., London, Reino Unido. 181p.

Excoffier, L. \& A. Langaney. 1989. Origin and differentiation of human mitochondrial DNA. American Journal of Human Genetics, 44: 73-85. 
Excoffier, L.; Laval, G. \& S. Schneider. 2005. Arlequin (version 3.0): an integrated software package for population genetics data analysis. Evolutionary Bioinformatics Online, 1 : 47-50.

Excoffier, L.; Smouse, P.E. \& J.M. Quattro. 1992. Analysis of molecular variance inferred from metric distances among DNA haplotypes: application to human mitochondrial DNA restriction data. Genetics, 131: 479-491.

Fauvelot, C.; Bernardi, G. \& S. Planes. 2003. Reductions in the mitochondrial DNA diversity of coral reef fish provide evidence of population bottlenecks resulting from Holocene sea-level change. Evolution, $\underline{57}(7)$ : 1571-1583.

Felder, D.L.; Dworschak, P.C.; Robles, R.; Bracken, H.D.; Windsor, A.M.; Felder, J.M. \& R. Lemaitre. 2009. Obvious invaders and overlooked infauna: unexpected constituents of the decapod crustacean fauna at Twin Cays, Belize. Smithsonian Contributions to the Marine Sciences, 38: 181-188.

Felsenstein, J. 1973. Maximum Likelihood and minimum-steps methods for estimating evolutionary trees from data on discrete characters. Systematic Biology, 22(3): 240-249.

Felsenstein, J. 1981. Evolutionary trees from DNA sequences: a Maximum Likelihood approach. Journal of Molecular Evolution, 17: 368-376.

Felsenstein, J. 1985. Confidence limits on phylogenies: an approach using the bootstrap. Evolution, 39 (4): 783-791.

Feres, S.J.C.; Lopes, A.T.L. \& L.A. Santos. 2007. Primeiro registro de Charybdis hellerii (Milne Edwards, 1867) para o litoral maranhense-Brasil (Crustacea, Decapoda, Portunidae). Boletim do Laboratório de Hidrobiologia, 20(1): 7782.

Ferreira, A.C.; Sankarankuty, C.; Cunha, I.M.C. \& F.T. Duarte. 2001. Yet another record of Charybdis hellerii (A. Milne-Edwards) (Crustacea, Decapoda) from the Northeast of Brazil. Revista Brasileira de Zoologia, 18 (suppl. 1): 357-358.

Fleminger, A. 1985. The Pleistocene equatorial barrier between the Indian and Pacific Oceans and a likely cause for Wallace's line. UNESCO Technical Papers in Marine Science, 49: 84-97.

Folmer, O.; Black, M.; Hoeh, W.; Lutz, R. \& R. Vrijenhoek. 1994. DNA primers for amplification of mitochondrial cytochrome c oxidase subunit I from diverse metazoan invertebrates. Molecular Marine Biology and Biotechnology, $\underline{3}(5)$ : 294-299. 
Francisco, A.K. \& P.M. Galetti Junior. 2005. Genetic distance between broodstocks of the marine shrimp Litopenaeus vannamei (Decapoda, Penaeidae) by mtDNA analyses. Genetics and Molecular Biology, 28 (2): 258-261.

Frankham, R. 2005. Invasion biology: resolving the genetic paradox in invasive species. Heredity, 94: 385-385.

Fratini, S.; Ragionieri, L. \& S. Cannicci. 2010. Stock structure and demographic history of the Indo-West Pacific mud crab Scylla serrata. Estuarine, Coastal and Shelf Science, $\underline{86}(1): 51-61$.

Frigotto, S.F. \& M. Serafim-Junior. 2007. Primeiro registro de Charybdis hellerii (Milne Edwards, 1867) (Crustacea) no litoral do estado do Paraná. Estudos de Biologia, 29(67): 227-230.

Froukh, T. \& M. Kochzius. 2008. Species boundaries and evolutionary lineages in the blue green damselfishes Chromis viridis and Chromis atripectoralis (Pomacentridae). Journal of Fish Biology, 72: 451-457.

Fu, Y.-X. 1997. Statistical tests of neutrality of mutations against population growth, hitchhiking and background selection. Genetics, 147(2): 915-925.

Funk, D.J. \& K.E. Omland. 2003. Species-level paraphyly and polyphyly: frequency, causes, and consequences, with insights from animal mitochondrial DNA. Annual Review of Ecology and Systematics, 34: 397-423.

Galil, B.S. 2000. A sea under siege - alien species in the Mediterranean. Biological Invasions, 2: 177-186.

Galil, B.S.; Froglia, C. \& P. Noël. 2002. CIESM Atlas of Exotic Species in the Mediterranean, Vol. 2: Crustaceans: Decapods and Stomatopods (Briand, F. Eds.). CIESM Publishers, Monaco. 192p.

Geller, J.B.; Darling, J.A. \& J.T. Carlton. 2010. Genetic Perspectives on Marine Biological Invasions. Annual Review of Marine Science, 2: 367-393.

Gómez, O. \& J.C. Martínez-Iglesias. 1990. Reciente hallazgo de la espécie indopacifica Charybdis hellerii (A. Milne-Edwards, 1867) (Crustacea: Decapoda: Portunidae) en aguas cubanas. Caribbean Journal of Science, 26 (1/2): 70-72.

Gopurenko, D. 2002. Genetic structure within the distribution of the Indo-West Pacific mud crab Scylla serrata (Forskål, 1775). Tese de Doutorado apresentada à Faculty of Environmental Science, Australian School of Environmental Studies, Griffith University, Queensland, Austrália. 
Gopurenko, D. \& J.M. Hughes. 2002. Regional patterns of genetic structure among Australian populations of the mud crab, Scylla serrata (Crustacea: Decapoda): evidence from mitochondrial DNA. Marine and Freshwater Research, 무: 849857.

Gopurenko, D.; Hughes, J.M. \& C.P. Keenan. 1999. Mitochondrial DNA evidence for rapid colonization of the Indo-West Pacific by the mud crab Scylla serrata. Marine Biology, 134: 227-233.

Gordon, A.L. 2005. Oceanography of the Indonesian Seas and their throughflow. Oceanography, 18(4): 15-27.

Gordon, A.L. \& R.A. Fine. 1996. Pathways of water between the Pacific and Indian oceans in the Indonesian seas. Nature, $\underline{379}$ : 146-149.

Goujon, M.; McWilliam, H.; Li, W.; Valentin, F.; Squizzato, S.; Paern, J. \& R. Lopez. 2010. A new bioinformatics analysis tools framework at EMBL-EBI. Nucleic Acids Research, 38(suppl. 2): W695-W699.

Grapputo, A.; Boman, S.; Lindström, L.; Lytinen, A. \& J. Mappes. 2005. The voyage of an invasive species across continents: genetic diversity of North American and European Colorado potato beetle populations. Molecular Ecology, 14(14): 42074219.

Grosholz, E. 2002. Ecological and evolutionary consequences of coastal invasions. Trends in Ecology \& Evolution, 17(1): 22-27.

Hajibabaei, M.; Singer, G.A.C.; Hebert, P.D.N. \& D.A. Hickey. 2007. DNA barcoding: how it complements taxonomy, molecular phylogenetics and population genetics. Trends in Genetics, 23(4): 167-172.

Hall, B.G. 2008. Phylogenetic trees made easy: A how-to manual. 3rd Edition. Sinauer Associates, Inc. Sunderland, Massachusetts, EUA. 233p.

Hall, R. 1998. The plate tectonics of Cenozoic SE Asia and the distribution of land and sea pp. 99-131. In: Hall, R. \& J.D. Holloway. (Eds.). Biogeography and Geological Evolution of SE Asia. Backhuys Publishers, Leiden, Holanda.

Hall, T.A. 2005. BioEdit v.7.0.5. Biological sequences alignment editor for Windows. Ibis Therapeutics a division of Isis pharmaceutical. Disponível em: http://www.mbio.ncsu.edu/BioEdit/bioedit.html.

Hamilton, M.B. 2009. Population Genetics. Wiley-Blackwell, Hoboken, EUA. 422p. 
Handley, L.J.L.; Estoup, A.; Evans, D.M.; Thomas, C.E.; Lombaert, E.; Facon, B; Aebi, A. \& H.E. Roy. 2011. Ecological genetics of invasive alien species. Biological Control, 56: 409-428.

Haq, B.U.; Hardenbol, J. \& P.R. Vail. 1987. Chronology of fluctuating sea levels since the Triassic. Science, 235: 1156-1167.

Harrison, J.S. 2004. Evolution, biogeography, and the utility of mitochondrial $16 \mathrm{~S}$ and $\mathrm{COI}$ genes in phylogenetic analysis of the crab genus Austinixa (Decapoda: Pinnotheridae). Molecular Phylogenetics and Evolution, $\underline{30}(3)$ : 743-754.

Hassan, M.; Harmelin-Vivien, M. \& F. Bonhomme. 2003. Lessepsian invasion without bottleneck: example of two rabbitfish species (Siganus rivalus and Siganus luridus). Journal of experimental Marine Biology and Ecology, 291: 219-232.

Hassan, M. \& F. Bonhomme. 2005. No reduction in neutral variability of mitochondrial and nuclear genes for a Lessepsian migrant, Upeneus moluccensis. Journal of Fish Biology, $\underline{66}(3)$ : 865-870.

Hebert, P.D.N.; Cywinska, A.; Ball, S.L. \& J.R. DeWaard. 2003. Biological identifications through DNA barcodes. Proceedings of the Royal Society of London B Biological Science, 270: 313-321.

Heller, C. 1865. Crustaceen. In: Reise der österreichischen Fregatte "Novara" um die Erde in den Jahren 1857, 1858, 1859 unter den Befehlen des Commodore B. von Wüllerstorf-Urbair. Zoologischer. Theil 2. Abteilung 3. 280p.

Hendry, A.P. \& T.P. Quinn. 1997. Variation in adult life history and morphology among Lake Washington sockeye salmon (Oncorhynchus nerka) populations in relation to habitat features and ancestral affinities. Canadian Journal of Fisheries and Aquatic Sciences, 54: 75-84.

Hernandez, G. \& J.A. Bolaños. 1995. Additions to the anomuran and brachyuran fauna of northeastern Venezuela. The Crustacean Society Summer Meeting, May 1995: 25-27. [Abstract].

Hewitt, C.L.; Everett, R.A.; Parker, N. \& M.L. Campbell. 2009. Marine bioinvasion management: structural framework. pp. 327-334. In: Rilov, G. \& J.A. Crooks (Eds.). Biological Invasions in Marine Ecosystems: Ecological, Management, and Geographic Perspectives. Ecological Studies, Volume 204. Springer-Verlag, Berlim, Alemanha.

Hickerson, M.J.; Carstens, B.C.; Cavender-Bares, J.; Crandall, K.A.; Graham, C.H.; Johnson, J.B.; Rissler, L.; Victoriano, P.F. \& A.D. Yoder. 2010. Pylogeography's 
past, present, and future: 10 years after Avise, 2000. Molecular Phylogenetics and Evolution, 54(1): 291-301.

Holland, B.S. 2000. Genetics of marine bioinvasions. Hydrobiologia, $\underline{420}(1)$ : $63-71$.

Huelsenbeck, J.P. \& F. Ronquist. 2001. MrBayes: Bayesian inference of phylogeny. Bioinformatics, 17: 754-755.

Hufbauer, R.A. 2008. Biological invasions: paradox lost and paradise gained. Current Biology, 18: 246-247.

IUCN (World Conservation Union). 2000. IUCN guidelines for the prevention of biodiversity loss due to biological invasion. IUCN, Gland, Switzerland.

Kajita, Y.; O’Neill, E.M.; Zheng, Y.; Obrycki, J.J. \& D.W. Weisrock. 2012. A population genetic signature of human releases in an invasive ladybeetle. Molecular Ecology, 21(22): 5473-5483.

Kim, W. \& L.G. Abele. 1990. Molecular phylogeny of selected decapod crustaceans based on 18S rRNA nucleotide sequences. Journal of Crustacean Biology, 10: $1-13$.

Kochzius, M.; Söller, R.; Khalaf, M.A. \& D. Blohm. 2003. Molecular phylogeny of the lionfish genera Dendrochirus and Pterois (Scorpaenidae, Pteroidae) based on mitochondrial DNA sequences. Molecular Phylogenetics and Evolution, 28: 396-403.

Kolar, C.S. \& D.M. Lodge. 2001. Progress in invasion biology: predicting invaders. Trends in Ecology and Evolution, 16(4): 199-204.

Kolbe, J.J.; Glor, R.E.; Schettino, L.R.G; Lara, A.C.; Larson, A. \& J.B. Losos. 2004. Genetic variation increases during biological invasion by a Cuban lizard. Nature, 431: 177-181.

Kolbe, J.J.; Larson, A. \& J.B. Losos. 2007. Differential admixture shapes morphological variation among invasive populations of the lizard Anolis sagrei. Molecular Ecology, 16:1579-1591.

Koskinen, M.T.; Haugen, T.O. \& C.R. Primmer. 2002. Contemporary fisherian lifehistory evolution in small salmonid populations. Nature, 419: 826-830.

Knowlton, N. \& J.B.C. Jackson. 1993. Inbreeding and outbreeding in marine invertebrates. pp. 200-249. In: Thornhill, N.W. (Ed.). The Natural History of Inbreeding and Outbreeding. University of Chicago Press, Chicago, EUA.

Krantz, D.E. 1991. A chronology of Pliocene sea-level fluctuations: the US middle Atlantic costal plain record. Quaternary Science Reviews, 10: 163-174. 
Lacson, J.M. \& S. Clark. 1995. Genetic divergence of Maldivian and Micronesian demes of the damsel fishes Stegastes nigricans, Chrysiptera biocellata, $C$. glauca and C. leucopoma (Pomacentridae). Marine Biology, 121: 585-590.

Lallias, D.; Boudry, P.; Batista, F.M.; Beaumont, A.; King, J.W.; Turner, J.R. \& S. Lapègue. 2015. Invasion genetics of the Pacific oyster Crassostrea gigas in the British Isles inferred from microsatellite and mitochondrial markers. Biological Invasions, 17(10): 2581-2595.

Lavery, S.; Moritz, C. \& D.R. Fielder. 1996. Indo-Pacific population structure and evolutionary history of the coconut crab Birgus latro. Molecular Ecology, $\underline{5}(4)$ : 557-570.

Lee, C.E. 2002. Evolutionary genetics of invasive species. Trends in Ecology \& Evolution, 17(8): 386-391.

Leinonen, T.; O’Hara, R.B.; Cano, J.M. \& J. Merilä. 2008. Comparative studies of quantitative trait and neutral marker divergence: a meta-analysis. Journal of Evolutionary Biology, 21: 1-17.

Lejeusne, C.; Saunier, A.; Petit, N.; Béguer, M.; Otani, M.; Carlton, J.T.; Rico, C. \& A.J. Green. 2014. High genetic diversity and absence of founder effects in a worldwide aquatic invader. Scientific Report, 4: 5808.

Lemaitre, R. 1995. Charybdis hellerii (Milne Edwards, 1867), a nonindigenous portunid crab (Crustacea: Decapoda: Brachyura) discovered in the Indian River lagoon System of Florida. Proceedings of the Biological Society of Washington, 108(4): 643-648.

Li, W.; Cowley, A.; Uludag, M.; Gur, T.; McWilliam, H.; Squizzato, S.; Park, Y.M.; Buso, N. \& R. Lopez. 2015. The EMBL-EBI bioinformatics web and programmatic tools framework. Nucleic Acids Research, 43(Web Server Issue): W580-W584.

Lima-Júnior, T.B.; Aragão, M.I.C.; Silva, J.P.; Melo, G.A.S. \& J.R.S.A. Leite. 2008. Occurrence of two Indo-Pacific species of Brachyura on the coast of Piauí, Brazil. Boletim do Laboratório de Hidrobiologia, 21(1): 35-40.

Liu, M.Y.; Cai, Y.X. \& C.S. Tzeng. 2007. Molecular systematics of the freshwater prawn genus Macrobrachium Bate, 1868 (Crustacea: Decapoda: Palaemonidae) inferred from mtDNA sequences, with emphasis on East Asian species. Zoological Studies, $\underline{46}(3):$ 272-289.

Lockwood, J.; Cassey, P. \& T. Blackburn. 2005. The role of propagule pressure in explaining species invasions. Trends in Ecology and Evolution, 20: 223-228. 
Loebmann, D.; Mai, A.C.G. \& J.T. Lee. 2010. The invasion of five alien species in the Delta do Parnaíba Environmental Protection Area, Northeastern Brazil. Revista de Biologia Tropical, $\underline{58}(3)$ : 909-923.

Lourie, S.A.; Green, D.M. \& C.J. Vincent. 2005. Dispersal, habitat differences, and comparative phylogeography of Southeast Asian seahorses (Syngnathidae: Hippocampus). Molecular Ecology, 14:1073-1094.

Mack, R.N.; Simberloff, D.; Lonsdale, W.M.; Evans, H.; Clout, M. \& F.A. Bazzaz. 2000. Biotic invasions: causes, epidemiology, global consequences and control. Ecological Applications, $\underline{10}(3)$ : 689-710.

Mantelatto, F.L. \& E.K. Corrêa. 1996. Composition and seasonal variations of the brachyuran crabs (Crustacea, Decapoda) living on Sargassum cymosum in Ubatuba Region, São Paulo, Brazil. Bioikos, $\underline{9}(1)$ : 22-31.

Mantelatto, F.L. \& L.L. Dias. 1999. Extension of the known distribution of Charybdis hellerii (A. Milne-Edwards, 1867) (Decapoda, Portunidae) along the western tropical South Atlantic. Crustaceana, $\underline{72(6): 617-620 .}$

Mantelatto, F.L. \& M.M. Souza-Carey. 1998. Brachyura (Crustacea, Decapoda) associated to Schizoporella unicornis (Bryozoa, Gymnolaemata) in Ubatuba Bay (SP), Brazil. Brazilian Archives of Biology and Technology, 41(2): 212-217.

Mantelatto, F.L. \& R.B. Garcia. 2001. Biological aspects of the nonindigenous portunid crab Charybdis hellerii in the western tropical South Atlantic. Bulletin of Marine Science, $\underline{68}(3):$ 469-477.

Mantelatto, F.L.; Pardo, L.M.; Pileggi, L.G. \& D.L. Felder. 2009. Taxonomic reexamination of the hermit crab species Pagurus forceps and Pagurus comptus (Decapoda: Paguridae) by molecular analysis. Zootaxa, 2133: 20-32.

Mantelatto, F.L.; Robles, R.; Biagi, R. \& D.L. Felder. 2006. Taxonomic and distributional status based on molecular data for hermit crab genera Loxopagurus Forest, 1964, and Isocheles Stimpson, 1858 (Decapoda, Anomura, Diogenidae). Zoosystema, 28(2): 495-506.

Mantelatto, F.L.; Robles, R. \& D.L. Felder. 2007. Molecular phylogeny of the western Atlantic species of the genus Portunus (Crustacea: Brachyura, Portunidae). Zoological Journal of the Linnean Society, 150(1): 211-220.

May, G.E.; Gelembiuk, G.W.; Panov, V.E.; Orlava, M.I. \& C.E. Lee. 2006. Molecular ecology of sebra mussel invasions. Molecular Ecology, 15: 1021-1031. 
Mayr, E. 1965. The nature of colonizations in birds. pp. 29-43. In: Baker, H.G. \& G.L. Stebbins. (Eds.). The Genetics of Colonizing Species. Academic Press, London, Reino Unido.

Mclvor, L.; Maggs, C.A.; Provan, J. \& M.J. Stanhope. 2001. rbcL sequences reveal multiple cryptic introductions of the Japanese red alga Polysiphonia harveyi. Molecular Ecology, 10(4): 911-919.

McKay, J.K. \& R.G. Latta. 2002. Adaptive population divergence: markers, QTL and traits. Trends in Ecology \& Evolution, 17: 285-291.

McManus, J.W. 1985. Marine speciation, tectonics and sea-level changes in Southeast Asia. Proceedings of the Fifth International Coral Reef Congress, Tahiti, $\underline{4}$ : 133-138.

McMillan, W.O. \& S.R. Palumbi. 1995. Concordant evolutionary patterns among IndoWest Pacific butterflyfishes. Proceedings of the Royal Society of London B Biological Science, 260: 229-236.

McMillen-Jackson, A.L. 2008. First record of the Indo-Pacific swimming brab, Charybdis hellerii (A. Milne-Edwards, 1867) in the Gulf of Mexico. Crustaceana, 81(7): 889-894.

McWilliam, H.; Li, W.; Uludag, M.; Squizzato, S.; Park, Y.M.; Buso, N.; Cowley, A.P. \& R. Lopez. 2013. Analysis tool web services from the EMBL-EBI. Nucleic Acids Research, 41(Web Server Issue): W597-W600.

Melo, G.A.S. 1996. Manual de Identificação dos Brachyura (Caranguejos e Siris) do litoral brasileiro. Editora Plêiade, São Paulo, Brasil. 603 p.

Meusnier, I.; Valero, M.; Destombe, C.; Gode, C.; Desmarais, E.; Bonhomme, F.; Stam, W.T. \& J.L. Olsen. 2002. Polymerase chain reaction-single strand conformation polymorphism analyses of nuclear and chloroplast DNA provide evidence for recombination, multiple introductions and nascent speciation in the Caulerpa taxifolia complex. Molecular Ecology, 11(11): 2317-2325.

Meyer, C.P. \& G. Paulay. 2005. DNA barcoding: Error rates based on comprehensive sampling. PLoS Biology, $\underline{3}(12)$ : e422.

Miller, M.A.; Pfeiffer, W. \& T. Schwartz. 2010. Creating the CIPRES Science Gateway for inference of large phylogenetic trees. In: Proceedings of the Gateway Computing Environments Workshop (GCE), New Orleans, Louisiana. 
Milne-Edwards, A. 1867. Descriptions de quelques espéces nouvelles de Crustacés Brachyures. Annales de la Société entomologique de France, $4 \mathrm{e}$ série, $\underline{7}$ : 263-288.

Moosa, M.K. 1981. Crustacés décapodes: Portunidae. Résultats des Campagnes Musorstom I. Philippines (18-28 Mars 1796). Collection Mémoires ORSTOM, 91: 141-150.

Murakami-Sugihara, N.; Furota, T. \& K. Okamoto. 2012. Genetic structure of the exotic clam Mercenaria mercenaria in Tokyo Bay, determined using mitochondrial DNA. Fisheries Science, 78: 569-575.

Musiello-Fernandes, J.; Vilar, C.C. \& D.M. Rosa. 2011. Ocorrência da espécie exótica Charybdis hellerii Milne Edwards, 1867 (Crustacea, Portunidae) no litoral do Espírito Santo. Natureza on-line, $\underline{9}(1): 35-37$.

Naylor, R.L.; Williams, S.L. \& D.R. Strong. 2001. Aquaculture: a gateway for exotic species. Science, 294: 1655-1656.

Negreiros-Fransozo, M.L. 1996. The zoea I of Charybdis hellerii (A. Milne-Eswards, 1867) (Decapoda, portunidae) obtained in laboratory. Nauplius, $\underline{4}(1):$ 165-168.

Negri, M.; Pileggi, L.G. \& F.L. Mantelatto. 2012. Molecular barcode and morphological analyses reveal the taxonomic and biogeographical status of the striped-legged hermit crab species Clibanarius sclopetarius (Herbst, 1796) and Clibanarius vittatus (Bosc, 1802) (Decapoda : Diogenidae). Invertebrate Systematics, 266(6): 561-571.

Nei, M.; Maruyama, T. \& R. Chakraborty. 1975. The bottleneck effect and genetic variability in populations. Evolution, 29: 1-10.

Neigel, J.E. 1997. A comparison of alternative strategies for estimating gene flow from genetic markers. Annual Review of Ecology and Systematics, 28: 105-128.

Nelson, D.L. \& M.M. Cox. 2006. Lehninger: princípios de bioquímica. 4ª Edição. Sarvier, São Paulo, Brasil. 1202 p.

Nelson, J.S.; Hoddell, R.J.; Chou, L.M.; Chan, W.K. \& V.P.E. Phang. 2000. Phylogeographic structure of false clownfish, Amphiprion ocellaris, explained by sea level changes on the Sunda shelf. Marine Biology, 137: 727-736.

Ng, P.K.L.; Guinot, D. \& P.J.F. Davie. 2008. Systema Brachyurorum: Part I. An annotated checklist of extant brachyuran crabs of the world. The Raffles Bulletin of Zoology, 17: 1-286. 
Norse, E. 1993. Global marine biological diversity: a strategy for building conservation into decision making. Island Press, Washington, D.C., EUA. $383 p$.

Oliveira, H.A. 2004. Brasil-China: Trinta anos de uma parceria estratégica. Revista Brasileira de Política Internacional, 47(1): 7-30.

Özcan, T.; Katağan, T. \& A. Kocataş. 2005. Brachyuran crabs from Iskenderun Bay (southeastern Turkey). Crustaceana, $\underline{78}(2):$ 237-243.

Padate, V.P.; Rivonker, C.U.; Anil, A.C.; Sawant, S.S. \& V. Krishnamurthy. 2010. A new species of portunid crab of the genus Charybdis (de Haan, 1833) (Crustacea: Decapoda: Brachyura) from Goa, India. Marine Biology Research, 6(6): $579-590$.

Palumbi, S.R. 1994. Genetic divergence, reproductive isolation, and marine speciation. Annual Review of Ecology and Systematics, 25: 547-572.

Palumbi, S.R. 1997 Molecular biogeography of the Pacific. Coral Reefs, 16: S47-S52.

Pileggi, L.G. \& F.L. Mantelatto. 2010. Molecular phylogeny of the freshwater prawn genus Macrobrachium (Decapoda, Palaemonidae), with emphasis on the relationships among selected American species. Invertebrate Systematics, 24: 194-208.

Pimental, D.; Lach, L.; Zuniga, R. \& D. Morrison. 2000. Environmental and economic costs of nonindigenous species in the United States. Bioscience, 50(1): 53-65.

Pires, A.C. \& L. Marinoni. 2010. DNA barcoding and traditional taxonomy unified through Integrative Taxonomy: a view that challenges the debate questioning both methodologies. Biota Neotropica, 10(2): http:// www.biotaneotropica.org.br/ v10n2/en/abstract?thematic-review+bn03110022010.

Por, F.D. 1978. Lessepsian migration: the influx of Red Sea biota into the Mediterranean by way of the Suez Canal. Ecological Studies. Volume 23. Springer-Verlag, Berlim, Alemanha. 230p.

Posada, D. \& K.A. Crandall. 2001. Evaluation of methods for detecting recombination from DNA sequences: computer simulations. Proceedings of the National Academy of Sciences of the USA, 98: 13757-13762.

Potts, D.C. 1983. Evolutionary disequilibrium among Indo-Pacific corals. Bulletin of Marine Science, $\underline{33}$ : 619-632.

Qian, G.; Zhoa, Q.; Wang, A.; Zhu, L.; Zhou, K. \& H. Sun. 2011. Two new decapod (Crustacea: Malacostraca) complete mitochondrial genomes: bearings on the 
phylogenetic relationships within the Decapoda. Zoological Journal of the Linnean Society, 162: 471-481.

Ragionieri, L.; Cannicci, S.; Schubart, C.D. \& S. Fratini. 2010. Gene flow and demographic history of the mangrove crab Neosarmatium meinerti: a case study from the western Indian Ocean. Estuarine, Coastal and Shelf Science, 86: 179188.

Ragionieri, L.; Fratini, S. \& C.D. Schubart. 2012. Revised taxonomy of the Neosarmatium meinerti complex (Decapoda: Brachyura, Ssesarmidae) with the description of three pseudocryptic Indo-west Pacific species. The Raffles Bulletin of Zoology, $\underline{60}(1):$ 71-87.

Rambaut, A. 2009. FigTree version 1.3.1 [computer program]. http://tree.bio.ed.ac.uk

Ramos-Onsins, S.E. \& J. Rozas. 2002. Statistical properties of new Neutrality tests against population growth. Molecular Biology and Evolution, 19(12): 20922100.

Reed, D.H. \& R. Frankham. 2001. How closely correlated are molecular and quantitative measures of genetic variation? A meta-analysis. Evolution, $\underline{55}$ : 1095-1103.

Reuschel, S. \& C.D. Schubart. 2006. Phylogeny and geographic differentiation of Atlanto-Mediterranean species of the genus Xantho (Crustacea: Brachyura: Xanthidae) based on genetic and morphometric analyses. Marine Biology, 148: 853-866.

Richardson, D.M.; Pyšek, P. \& J.T. Carlton. 2011. A compendium of essential concepts and terminology in invasion ecology. In: Richardson, D.M. (Ed.). Fifty Years of Invasion Ecology: The Legacy of Charles Elton. Edição 1. Blackwell Publishing Ltd, Chichester, Reino Unido. 432p.

Richardson, D.M.; Pyšek, P.; Rejmánek, M.; Barbour, M.G.; Panetta, F.D.; Barbour, M.G.; Panetta, F.D. \& C.J. West. 2000. Naturalization and invasion of alien plants: concepts and definitions. Diversity and Distributions, $\underline{6}(2): 93-107$.

Rius, M. \& J.A. Darling. 2014. How important is intraspecific genetic admixture to the success of colonising populations? Trends in Ecology \& Evolution, 29: 233242.

Rius, M.; Turon, X; Ordóñez, V. \& M. Pascual. 2012. Tracking invasion histories in the sea: facing complex scenarios using multilocus data. PLoS One, $\underline{7}(4)$ : e35815. 
Robles, R.; Tudge, C.; Dworschak, P.C.; Poore, G.C.B. \& D.L. Felder. 2009. Molecular phylogeny of the Thalassinidea based on nuclear and mitochondrial genes. In: Martin, J.W.; Crandall, K.A. \& D.L. Felder. (Eds.). Decapod Crustacean Phylogenetics. Crustacean Issues 18. CRC Press, Boca Raton, Flórida, EUA.

Roderick, G.K. \& M. Navajas. 2003. Genes in new environments: Genetics and evolution in biological control. Nature Reviews in Genetics, 4: 889-899.

Rodríguez, B.D. 1982. Los cangrejos de la familia portunidae (Decapoda: Brachyura) del Caribe colombiano. Anales del Instituto de Investigaciones Marinas de Punta Betín, 12: 137-184.

Rodríguez, G. \& H. Suárez. 2001. Anthropogenic dispersal of decapods crustaceans in aquatic environments. Interciencia, 26 (7): 282-288.

Rohling, E.J.; Fenton, M.; Jorissen, F.J.; Bertrand, P.; Ganssen, G. \& J.P. Caulet. 1998. Magnitudes of sea-level lowstands of the past 500,000 years. Nature, 394 : 162-165.

Roman, J. \& J.A. Darling. 2007. Paradox lost: genetic diversity and the success of aquatic invasions. Trends in Ecology and Evolution, 22: 454-464.

Ronquist, F.; Teslenko, M.; Van Der Mark, P.; Ayres, D.; Darling, A.; Höhna, S.; Larget, B.; Lui, L.; Suchard, M.A. \& J.P. Huelsenbeck. 2012. MrBayes 3.2: efficient Bayesian phylogenetic inference and model choice across a large model space. Systematic Biology, 61: 539-542.

Rosa, L.C. 2014. New records of portunid crabs (Decapoda: Brachyura: Portunidae) from Sergipe, NE Brazil. Check List, $\underline{10}(2):$ 445-447.

Rossi, N. \& F.L. Mantelatto. 2013. Molecular analysis of the freshwater prawn Macrobrachium olfersii (Decapoda, Palaemonidae) supports the existence of a single species throughout its distribution. PLoS One, $\underline{8}(1)$ : e54698.

Rozas, J. \& R. Rozas. 1999. DnaSP version 3.0: an integrated program for molecular population genetics and molecular evolution analysis. Bioinformatics, 15(2): 174-175.

Rubinoff, D.; Cameron, S. \& K. Will, K. 2006. A genomic perspective on the shortcomings of mitochondrial DNA for "Barcoding" identification. Journal of Heredity, $\underline{97}(6)$ : 581-594.

Sakai, A.K.; Allendorf, F.W; Holt, J.S.; Lodge, D.M.; Molofsky, J.; With, K.A.; Baughman, S.; Cabin, R.J.; Cohen, J.E.; Ellstrand, N.C.; McCauley, D.E.; O’Neil, P.; Parker, I.; Thompson, J.N. \& S.G. Weller. 2001. The population biology of 
invasive species. Annual Review of Ecology, Evolution, and Systematics, $\underline{32}$ : 305-332.

Sambrook, J.; Fritsch, E.F. \& T. Maniatis. 1989. In vitro amplification of DNA by the Polymerase Chain Reaction. In: Sambrook, J.; Fritsch, E.F. \& T. Maniatis (Eds.). Molecular cloning: a laboratory manual. $2^{\circ}$ Edition. Cold Spring Harbor Laboratory, Cold Spring Harbor Laboratory Press, Nova lorque, EUA. 1659p.

Sant'Anna, B.S.; Watanabe, T.T.; Turra, A. \& F.J. Zara. 2012a. Relative abundance and population biology of the non-indigenous crab Charybdis hellerii (Crustacea: Brachyura: Portunidae) in a southwestern Atlantic estuary-bay complex. Aquatic Invasions, $\underline{7}(3)$ : 347-356.

Sant'Anna, B.S.; Watanabe, T.T.; Turra, A. \& F.J. Zara. 2012b. First record of the nonindigenous portunid crab Charybdis variegata from the western Atlantic coast. Biolnvasions Records, 1(1): 11-16.

Schubart, C.D. 2009. Mitochondrial DNA and decapod phylogenies: the importance of pseudogenes and primer optimization. In: Martin, J.W.; Crandall, K.A. \& D.L. Felder (Eds.). Decapod Crustacean Phylogenetics. Crustacean Issues. Volume 18. Boca Raton, London, New York: CRC Press, Taylor \& Francis Group.

Schubart, C.D. \& M.G.J. Huber. 2006. Genetic comparisons of German populations of the stone crayfish, Austropotamobius torrentium (Crustacea: Astacidae). Bulletin Français de la Pêche et de la Pisciculture. 380-381: 1019-1028.

Schubart, C.D.; Cuesta, J.A. \& A. Rodrígues. 2001. Molecular phylogeny of the crab genus Brachynotus (Brachyura: Varunidae) based on the 16Sr RNA gene. Hydrobiologia, $\underline{449}(1-3):$ 41-46.

Schubart, C.D.; Neigel, J.E. \& D.L. Felder. 2000. Use of the mitochondrial 16S rRNA gene for phylogenetic and population studies of Crustacea. Crustacean Issues, 12: 817-830.

Selkoe, K.A.; Henzler, C.M. \& S.D. Gaines. 2008. Seascape genetics and the spatial ecology of marine populations. Fish and Fisheries, $\underline{9}$ : 363-377.

Siddall, M.; Rohling, E.J.; Almogi-Labin, A. Hemleben, C.; Meischner, D.; Schmelzer, I. \& D.A. Smeed. 2003. Sea-level fluctuations during the last glacial cycle. Nature, 423: 853-858.

Simon, C.; Frati, F.; Beckenbach, A.; Crespi, B.; Liu, H. \& P. Flook. 1994. Evolution, weighting, and phylogenetic utility of mitochondrial gene sequences and a 
compilation of conserved polymerase chain reaction primers. Annals of the Entomological Society of America, 87: 651-701.

Soledade, G.O.; Baeza, J.A.; Boehs, G.; Simões, S.M.; Santos, P.S.; Costa, R.C. \& A.O. Almeida. 2013. A precautionary tale when describing species in a world of invaders: morphology, coloration and genetics demonstrate that Lysmata rauli is not a new species endemic to Brazil but a junior synonym of the Indo-Pacific $L$. vittata. Journal of Crustacean Biology, $\underline{33}(1)$ : 66-77.

Song, H.; Buhay, J.E.; Whiting, M.F. \& K.A. Crandall. 2008. Many species in one: DNA barcoding overestimates the number of species when nuclear mitochondrial pseudogenes are coamplified. Proceedings of the National Academy of Sciences of the USA, $\underline{105(36): 13486-13491 .}$

Spalding, M.D.; Fox, H.E.; Allen, G.R.; Davidson, N.; Ferdaña, Z.A.; Finlayson, M.; Halpern, B.S.; Jorge, A.M.; Lombana, A.; Lourie, S.A.; Martin, K.D.; McManus, E.; Molnar, J.; Recchia, C.A. \& J. Robertson. 2007. Marine ecoregions of the world: a bioregionalization of coastal and shelf areas. BioScience, $\underline{57}(7)$ : 573583.

Spiridonov, V.A. \& M. Türkay. 2001. Deep sea swimming crabs of the Charybdis miles species group in the Western Indian Ocean (Crustacea: Decapoda: Portunidae). Journal of Natural History, $\underline{35}(3)$ : 439-469.

Spiridonov, V.A.; Neretina, T.V. \& D. Schepetov. 2014. Morphological characterizations and molecular phylogeny of Portunoidea Rafinesque, 1815 (Crustacea Brachyura): implications for understanding evolution of swimming capacity and revision of the family-level classification. Zoologischer Anzeiger, 253: 404-429.

Stamatakis, A. 2006. RAxML-VI-HPC: Maximum Likelihood-based phylogenetic analyses with thousands of taxa and mixed models. Bioinformatics, 22(21): 2688-2690.

Stamatakis, A.; Hoover, P. \& J. Rougemont. 2008. A rapid bootstrap algorithm for the RAxML web Servers. Systematic Biology, 57(5): 758-771.

Steinitz, W. 1929. Die wanderung indopazifischer arten ins mittelmeer seit beginn der Quartärperiode. Internationale Revue der gesamten Hydrobiologie und Hydrographie, 22(1): 1-90.

Stephenson, W. 1972. An annotated checklist and key to the Indo-West Pacific swimming crabs (Crustacea: Decapoda, Portunidae). Bulletin of the Royal Society of New Zealand, 10: 1-64. 
Stephenson, W. 1976. Notes on Indo-West-Pacific Portunids (Decapoda, Portunidae) in the Smithsonian Institution. Crustaceana, 31(1): 11-26.

Stephenson, W. \& M. Rees. 1968. A revision of the Charybdis miles 'group' of species (Crustacea: Portunidae), with description of a new species from Queensland waters. Memoirs of the Queensland Museum, 15(2), 91-108.

Stephenson, W.; Hudson, J.J. \& B. Campbell. 1957. The Australian portunids (Crustacea; Portunidae). II. The genus Charybdis. Australian Journal of Marine and Freshwater Research, $\underline{8}(4): 491-507$.

Stockwell, C.A.; Mulvey, M. \& G.L. Vinyard. 1996. Translocations and the preservation of allelic diversity. Conservation Biology, 10: 1133-1141.

Taillebois, L.; Castelin, M.; Ovenden, J.R.; Bonillo, C. \& P. Keith. 2013. Contrasting genetic structure among populations of two amphidromous fish species (Sicydiinae) in the Central West Pacific. PLoS One, $\underline{8}(10)$ : e75465.

Tajima, F. 1989. Statistical method for testing the neutral mutation hypothesis by DNA polymorphism. Genetics, $\underline{123(3): ~ 585-595 . ~}$

Talavera, G. \& J. Castresana. 2007. Improvement of phylogenies after removing divergent an ambiguously aligned blocks from protein sequence alignments. Systematic Biology, 56: 564-577.

Tavares, M. 2011. Alien Decapod Crustaceans in the Southwestern Atlantic Ocean. pp. 251-267. In: Galil, B., Clark, P.F. \& J.T. Carlton. (Eds.). In the Wrong Place Alien Marine Crustaceans: Distribution, Biology and Impacts. Invading Nature. Springer Series in Invasion Ecology. Volume 6. London. 723p.

Tavares, M. \& B. Mendonça Jr. 1996. Charybdis hellerii (A. Milne-Edwards, 1867) (Brachyura: Portunidae), eighth nonindigenous marine decapods recorded from Brazil. Crustacean Research, 25: 151-157.

Tavares, M. \& J.M. Amouroux. 2003. First record of the non-indigenous crab, Charybdis hellerii (A. Milne-Edwards, 1867) from French Guyana (Decapoda, Brachyura, Portunidae). Crustaceana, 76(5): 625-630.

Taylor, D.J. \& S.R. Keller. 2007. Historical range expansion determines the phylogenetic diversity introduced during contemporary species invasion. Evolution, 61:334-345.

Templeton, A.R. 2006. Population Genetics and Microevolutionary Theory. John Wiley \& Sons, Hobuken, EUA. 705p. 
Timm, L. \& H.D. Bracken-Grisson. 2015. The forest for the trees: molecular phylogenies with an emphasis on higher-level Decapoda. Journal of Crustacean Biology, 35(5): 577-592.

Tsutsui, N.D.; Suarez, A.V.; Holway, D.A. \& T.J. Case. 2000. Reduced genetic variation and the success of an invasive species. Proceedings of the National Academy of Sciences of the USA, 97: 5948-5953.

Tzeng, T.D. 2004. Stock identification of sword prawn Parapenaeopsis hardwickii in the East China Sea and Taiwan Strait inferred by morphometric variation. Fisheries Science, 70: 758-764.

Voisin, M.; Engel, C.R. \& F. Viard. 2005. Differential shuffling of native genetic diversity across introduced regions in a brown alga: aquaculture vs. maritime traffic effects. Proceedings of the National Academy of Sciences of the USA, 102(15): 5432-5437.

Voris, H.K. 2000. Maps of Pleistocene sea levels in Southeast Asia: shorelines, river systems and time durations. Journal of Biogeography, 27: 1153-1167.

Wares, J.P.; Goldwater, D.S.; Kong, B.Y. \& C.W. Cunningham. 2002. Refuting a controversial case of a human-mediated marine species introduction. Ecology Letters, $\underline{5}$ : 577-584.

Wares, J.P.; Hughes, A.R. \& R.K. Grosberg. 2005. Mechanisms that drive evolutionary change. Insights from species introductions and invasions. pp. 229-257. In: Sax, D.F.; Stachowicz, J.J. \& S.D. Gaines. (Eds.). Species Invasions: Insights into Ecology, Evolution, and Biogeography. Sinauer Associates, Sunderland, Massachusetts, EUA.

Watanabe, T.T.; Zara, F.J.; Hattori, G.Y.; Turra, A. \& B.S. Sant'Anna. 2015. Biological associations of color variation in the Indo-Pacific swimming crab Charybdis hellerii. Anais da Academia Brasileira de Ciências, 87(1): 219-232.

Wee, D.P.C. \& P.K.L. Ng. 1995. Swimming crabs of the genera Charybdis de Haan, 1833, and Thalamita Latreille, 1829 (Crustacea: Decapoda: Brachyura Portunidae) from Peninsular Malaysia and Singapore. The Raffles Bulletin of Zoology, 1 (Supplementary Issue): 1-128.

Williams S.T. \& J.A.H. Benzie. 1998. Evidence of a biogeographic break between populations of a high dispersal starfish: congruent regions within the Indo-West Pacific defined by color morphs, mtDNA and allozyme data. Evolution, 52: 8799. 
Williams, S.T.; Jara, J.; Gomez, E. \& N. Knowlton. 2002. The marine Indo-West Pacific break: contrasting the resolving power of mitochondrial and nuclear genes. Integrative and Comparative Biology, 42(5): 941-952.

Yokes, B. \& B.S. Galil. 2006. New records of alien decapods (Crustacea) from the Mediterranean coast of Turkey, with a description of a new palaemonid species. Zoosystema, 28: 747-755.

You, E.M.; Chiu, T.S.; Liu, K.F.; Tassanakajon, A.; Klinbunga, S.; Triwitayakorn, K.; de la Peña, L.D.; Li, Y. \& H.T. Yu. 2008. Microsatellite and mitochondrial haplotype diversity reveals population differentiation in the tiger shrimp (Penaeus monodon) in the Indo-Pacific region. Animal Genetics, 39: 267-277.

Xia, X.; Xie, Z.; Salemi, M.; Chen, L. \& Y. Wang. 2003. An index of substitution saturation and its application. Molecular Phylogenetics and Evolution, 26-1-7.

Zhang, D.X. \& G.M. Hewitt. 2003. Nuclear DNA analyses in genetic studies of populations: practice, problems and prospects. Molecular Ecology, 12(3): 563584.

Zink, R.M. \& G.F. Barrowclough. 2008. Mitochondrial DNA under siege in avian phylogeography. Molecular Ecology, 17(9): 2107-2121. 